


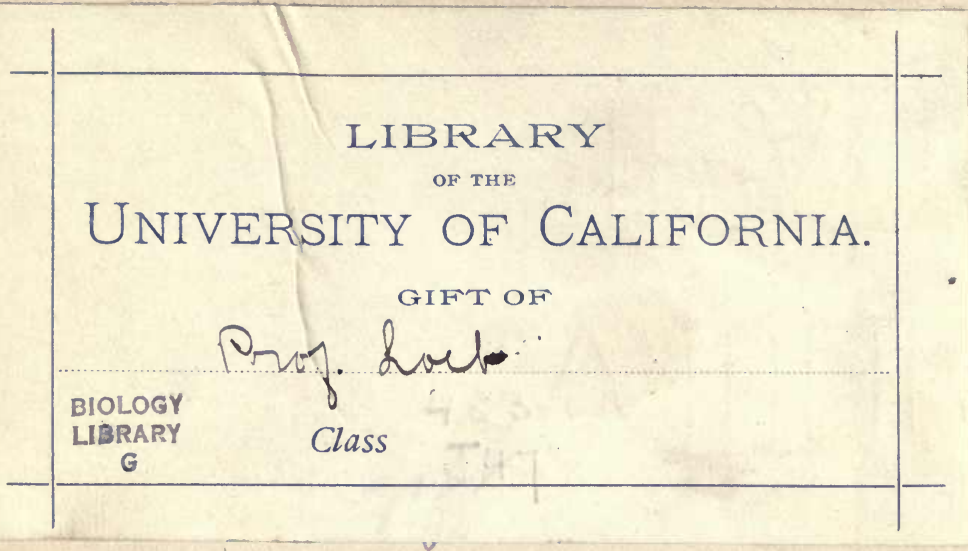




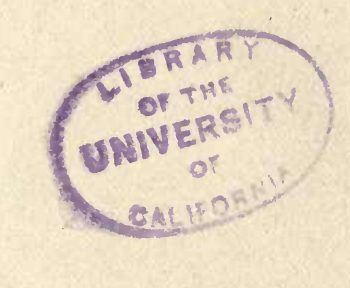





\section{HUMAN PHYSIOLOGY}

PERSONAL HYGIENE AND PUBLIC HEALTH 
Thes 
0 


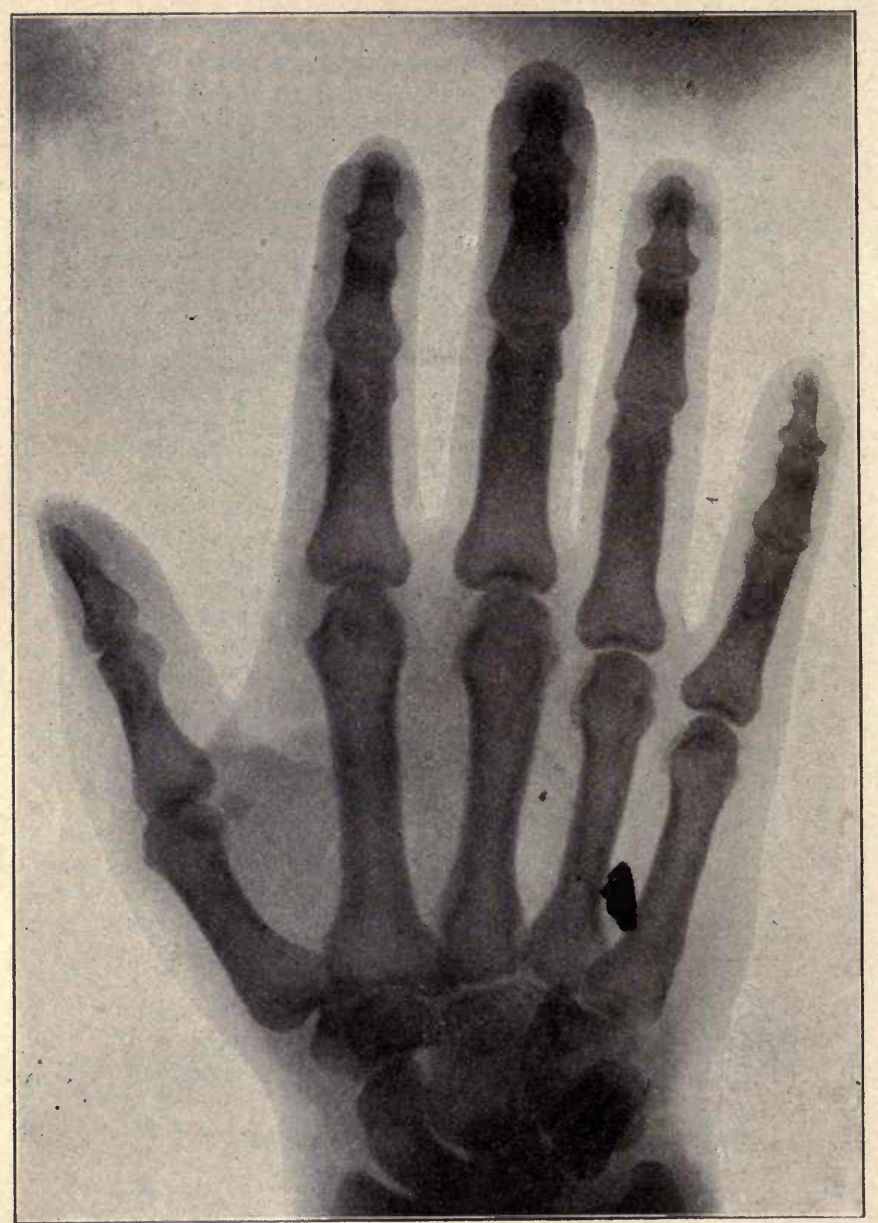

From an X-ray Photograph of the Hand, showing a Bullet imbedded in the Flesh. 


\section{PRACTICAL LESSONS}

IN

\section{HUMAN PHYSIOLOGY}

\section{PERSONAL HYGIENE AND PUBLIC HEALTH}

FOR SCHOOLS

BY

JOHN I. JEGI, M.S.

PROFESSOR OF PHYSIOLOGY AND PSYCHOLOGY, STATE NORMAL SCHOOL, MILWAUKEE

AUTHOR OF "SYLLABUS OF HUMAN PHYSIOLOGY"

FULLY ILLUSTRATED

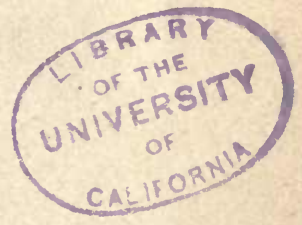

New 19ark

THE MACMILLAN COMPANY

LONDON: MACMILLAN \& CO., LTD.

1903

All rights reiserved 


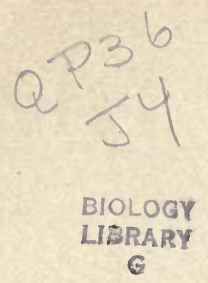

COPYRIGHT, I903,

BY THE MACMILLAN COMPANY.

Set up, electrotyped, and published August, 1903.

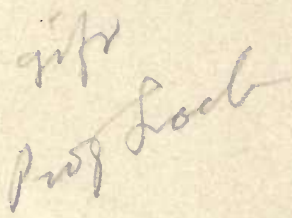

Norwood 扔ress

J. S. Cushing \& Co. - Berwick \& Smith Co.

Norwood, Mass., U.S.A. 


\section{PLAN OF THE BOOK}

There are so many good text-books published to-day on all school subjects that whenever a new one comes from the press all persons interested examine it eagerly to see what new features it may contain. The reasons why this text was written are given in brief in the following paragraphs.

Sequence of Topics. - In any science the order in which the various subjects are brought to the learner's mind is a matter of the utmost consequence. Unless the various topics are presented in a logical or natural order, the pupils fail to grasp the connection between them. In texts where each chapter is complete in itself, and need have little relation with what has preceded or with what follows, the pupils may learn much that is valuable and useful, but this knowledge must always remain scrappy, disconnected, and unorganized.

The logical arrangement of subject-matter has long been regarded as an essential feature of a good textbook. In this book an attempt is made to present the subject in such a way that the pupil shall see the relation which the various topics sustain to each other and to the entire body of knowledge. In other words, the 
"story plan" has been adopted so far as it is possible in the treatment of physiology.

The cell is taught as the unit of structure and function from the very first. The pupil learns something of the life history of the amoba in the first chapter. He studies the medium in which the amoba lives, and learns how the amœba gets its food, and how it eliminates its waste products. Then he learns that each cell of the human body is a living, acting unit that resembles the amœba in its life history. Then follows a study of the medium in which the cells of the human body live, and from which they obtain their food, and to which they give off their wastes. This naturally leads to a consideration of the whole subject of foodsolids, liquids, and gases.

After learning what the different foods are, where they come from, and the amount required, he must see how each gets into the blood and becomes part of the blood. In the chapter on Respiration he learns how oxygen the simplest food - gets into the blood. Then follows a chapter on Digestion and one on Absorption, to see how the solid and liquid foods are prepared for the blood and how they enter the blood. After the three kinds of food have been traced into the blood he studies Circulation, to learn how the foods are carried to the various cells in all parts of the body. Next he learns what becomes of the foods in the cells, what uses they serve, and what waste products they form. Then these waste materials are traced to the organs of excretion, and he learns how they are taken out of the blood and 
how they are eliminated from the body. This completes the story of the foods, which is told in the first twelve chapters.

Bones and muscles are next discussed, to learn how some of the energy of the foods is used in moving any part of the body and in locomotion. These two topics must be studied together so as to bring out the fact that the bones serve as levers for the muscles, and hence such activities as standing, walking, running, swimming, breathing, talking, etc., are made possible.

Next follows a study of the nervous system and the special senses, to see how all the processes and activities of the human body are controlled and unified. This furnishes an opportunity to review all the other systems and at the same time to study them in a new light. The last three chapters treat bacteria and diseases, general sanitation, and accidents and emergencies respectively.

Hygiene. - The central thought of the entire book is personal hygiene and public health. Such facts of structure are taught as are necessary to enable the pupil to understand the laws of health. Hygiene will be dogmatic and uninteresting if one does not know how an organ or a system works, and a knowledge of function demands a certain amount of anatomy. It is a mistake to attempt to teach hygiene without the necessary background of physiology and anatomy. For that reason the subject of hygiene is considered in connection with each topic discussed and generally in the same chapter, but there are several chapters devoted wholly to hygiene. 
The subject of bacteria and transmissible diseases is treated in a simple way so as to bring it within the comprehension of the pupils. While this subject is not generally discussed in elementary physiologies, it cannot be denied that it forms an important phase of personal hygiene and public health. The schools can do much to make people more intelligent on this important question if they will teach such simple facts as are presented in these two chapters.

The Alcohol Question. - The subject of alcohol is treated in the chapter on Drinks and Narcotics in the early part of the book. Then in connection with the discussion of each system throughout the book, there is a brief statement of the specific effect of alcohol upon that system. An attempt has been made to state the truth so far as it is known at the present time and without coloring the facts. No good can come from the extravagant statements so often made by well-meaning persons in discussing this subject in books and magazines for the young.

The treatment of stimulants and narcotics is ample enough to meet the requirements of the laws of those states which prescribe instruction on the effects of stimulants and narcotics on the human system, and, at the same time, it is scientific, being based on the latest researches.

Exercises and Experiments. - This text-book is not made on the laboratory plan, and yet a large number of simple exercises and experiments that can be performed with inexpensive apparatus are suggested in 
the body of the text. Instead of placing the exercises in a separate chapter at the end of the book, they occur in connection with the sections which they are intended to illustrate. In this way the exercises become part of the regular lessons, and the pupil learns to associate them with the proper facts.

While most of these exercises are so simple that they can be shown with such appliances as are found in the ordinary kitchen, they should be regarded as an essential part of the text. The experiments should be performed by the teacher before the class, and later they may be repeated by the pupils at home or at school.

Reviews and Summaries. - At the beginning of each chapter that introduces a new and related subject there is a paragraph reviewing briefly what has been taught in the preceding chapters, and showing the relation which this new chapter bears to the old and familiar. This facilitates still more the organization of the facts of this science and gives them their proper perspective. It emphasizes, by embodying in the plan of the text, that old and important pedagogical principle, "From the known to the related unknown." Each chapter closes with a brief summary of the main points to be remembered. Such reviews and summaries are absolutely essential to a mastery of the subject. A very common mistake in teaching this subject is to permit the related facts necessary to an intelligent understanding of the new lesson or new topic to fade out of the mind entirely. A systematic arrangement of 
topics, reviews, and summaries will do much to improve the character of the teaching in physiology.

Gradation of Subject-matter. - There is a steady, but well-graded, progress from the easy and simple to the more difficult and complex, both in the mode of treatment and in the arrangement of the topics. On the whole, the facts presented in this text-book may be a little more difficult than those found in most of the physiologies for corresponding grades, but the sentences are short, the language clear and simple, the treatment logical and connected, the illustrations numerous, and the reviews and summaries frequent, so that the book will not seem difficult to the pupils. 


\section{ACKNOWLEDGMENTS}

Most of the drawings for this book were made by students in my classes at the Normal School. Two of the plates were kindly furnished by the Educational Review, one by Ginn \& Company, and several by The Macmillan Company. Due credit is given under each figure.

A number of physicians, superintendents, principals, and teachers of physiology read parts or all of the manuscript, and I am greatly indebted to them for many helpful suggestions and criticisms.

I am also indebted to Professor W. S. Watson, of the State Normal School, Whitewater, Wisconsin, to Professor C. E. Patzer, of Milwaukee, and to Mr. Lewis C. Sleeper, of Milwaukee, for rendering valuable assistance in the proof reading; and to Miss Delia G. Ovitz, Librarian, State Normal School, Milwaukee, for preparing the index.

JOHN I. JEGI.

State Normal School, Milwaukee,

June, 1903. 



\section{CONTENTS}

CHAPTER I

PAGE

INTRODUCTION .

Why we should study the Human Body - The Human Body - Anatomy - Physiology - Hygiene - The Amœba - The Cell - Some Definitions - The Body compared to a City - Order of Topics - Summary of the Main Points.

\section{CHAPTER II}

The Blood and the Lymph.

Cell Medium - Uses of the Blood - What Blood looks like - Composition of Blood - Quantity - Clotting - Anæmia How to keep the Blood Pure and Wholesome - Summary of the Main Points.

CHAPTER III

Foods

Definition of Foods - Kinds of Foods - Proteids - Carbohydrates - Fats - Water - Salts - Oxygen - Substances taken with Foods - Animal Foods - Vegetable Foods - Hygiene Value of Cooking - Amount of Food-Summary of the Main Points.

\section{CHAPTER IV}

DRINKS AND NARCotics .

Pure Water - Impure Water - Tea and Coffee-Milk - Alcohol - Alcoholic Drinks - Alcohol as a Food - The Appetite for Alcohol - Tobacco - Cigarettes - Summary of the Main Points. 


\section{CHAPTER V}

RESPIRATION

Review - The Air Passages - The Nose - The Pharynx and

Larynx - The Trachea and Bronchial Tubes - The Lungs -

Covering of the Lungs - How Air gets into the Lungs - Capacity of the Lungs - How Air gets into the Blood - Changes in the Air - Rate of Breathing - Summary of the Main Points.

\section{CHAPTER VI}

Hygiene of RESPIRATION

Disease Germs in the Air - Diseases of the Air Passages Sources of Impure Air - The Air purified - Ventilation Method of Ventilation - Chest Freedom - Proper Breathing -Alcohol - Summary of the Main Points.

\section{CHAPTER VII}

\section{Digestion}

Review - The Alimentary Canal - Glands - The Mouth The Teeth - Structure of the Teeth - Mouth Digestion Swallowing - Stomach Digestion - Intestinal Digestion Places of Digestion - Peristalsis - Summary of the Main Points.

\section{CHAPTER VIII}

From the Alimentary Canal to the Heart

Review - Absorption - Absorption of Fats - The Other Foods - The Liver - Foods in the Right Heart - The Large Intestine - Summary of the Main Points.

\section{CHAPTER IX}

Hygiene of Digestion and Absorption

Pure Foods - Adulterated Foods - Cooking - Care of Teeth - The Appetite - Hygiene of Eating - Dress and Digestion - Diseases of the Alimentary Canal - Alcohol and Digestion The Large Intestine - Summary of the Main Points. 


\section{CHAPTER X}

Circulation of the Blood

Review - The Heart - Valves and Openings of the Heart -

Blood Vessels - Lymphatics - Course of the Blood - Rate of Blood Flow - What makes the Blood move - The Heart Beat - Sounds of the Heart - The Pulse - Alcohol and Tobacco Summary of the Main Points.

\section{CHAPTER XI}

Foods in THE TIssues

Review - The Lymph - The Cell - The Wastes - Changes in the Blood-Animal Heat-Loss of Heat-Regulation of Temperature - Summary of the Main Points.

\section{CHAPTER XII}

The Skin And The Kidneys

Review - The Skin - Glands of the Skin - Appendages of the Skin - Care of the Skin - Bathing - Clothing - The Kidneys - Diseases of the Kidneys - The Effect of Alcohol upon the Skin and Kidneys - Summary of the Main Points.

\section{CHAPTER XIII}

Bones AND JoInTs .

Uses of Bones - The Skeleton - Table of Bones - Composition of Bone - Structure of Bone - Cartilage - Joints Posture - The Curved Spine and Round Shoulders - Summary of the Main Points.

\section{CHAPTER XIV}

Muscles AND EXerCise .

Uses of Muscles - Description of Muscles - Structure of Muscles - How Muscles work - Large Muscles - Food of Muscles - Value of Exercise - Amount of Exercise - Physical Training in our Schools - Time of Exercise-Fatigue and Rest-Massage - Alcohol and Tobacco-Summary of the Main Points. 


\section{CHAPTER XV}

Special Uses of Muscles

Review - Bones as Levers - Standing - Walking and Running - Muscles of Expression - The Larynx and its Use - Voice Sounds - Care of the Voice - Summary of the Main Points.

\section{CHAPTER XVI}

The Nervous System

Plan of the Nervous System - Nerve Tissue - The Nerves The Spinal Cord - The Brain - The Bulb - The Cerebellum The Cerebrum - The Sympathetic Nervous System - Mind and Brain - Summary of the Main Points.

\section{CHAPTER XVII}

Care and Training of the Nervous System

Food and Air - Exercise - Education - Habit - Fatigue and Overwork - Rest and Sleep-Alcohol - Tobacco - Summary of the Main Points.

\section{CHAPTER XVIII}

The Special Senses and Sensations • • • • •

Sensations - General Senses - The Sense of Touch - The Sense of Taste - The Sense of Smell - The Sense of Hearing The External Ear - The Middle Ear - The Inner Ear - The Course of a Sound Wave - Care of the Ear - The Sense of Sight - The Eyeball-Muscles of the Eye-Appendages of the Eye - The Inside of the Eyeball - The Course of Light - Defective Vision - Care of the Eyes - Summary of the Main Points.

\section{CHAPTER XIX}

Bacteria and Diseases . • • • • • • 279

Bacteria - Bacteria as our Friends - Bacteria as Enemies How Disease Germs get into the Body - Disease Germs in the Body - Consumption - Pneumonia - Cholera - Typhoid Fever - Dysentery - Diphtheria - Scarlet Fever - Measles - Smallpox - Mumps - Whooping Cough - Malarial Fever - Yellow Fever - Grippe - Pink Eye - Summary of the Main Points. 


\section{CHAPTER XX}

Public Health and Personal Hygiene

The Problems - Public Intelligence - Foucis - Water Supply

- The Air - Garbage - Cleanliness - Diseases - Schools and Diseases - Disinfection - Personal Hygiene - Summary of the Main Points.

\section{CHAPTER XXI}

First Aid in Accidents and Emergencies .

Introduction - Burns and Scalds - Sunstroke - Fainting Suffocation - Choking - Apparent Drowning - Fits - Bruises - Frost Bite - Poisonous Stings - Poisons - Sprains - Dislocations - Broken Bones - Cuts in the Skin - External Bleeding - Nose Bleeding — Lung and Stomach Bleeding - Sore Throat.

GLossary .

INDEX 



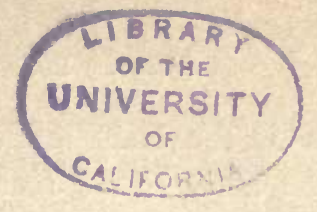

\section{PRACTICAL LESSONS}

IN

\section{HUMAN PHYSIOLOGY}

CHAPTER I

\section{INTRODUCTION}

1. Why we should study the Human Body. - We all wish to become strong, useful, and happy members of society. In order that this goal may be reached it is necessary to properly care for our bodies. We must learn early to habitually do those things which will make the body strong, robust, and healthy, and to avoid all those things which tend to hinder growth, enfeeble the body, and cause disease.

The human body is a wonderful machine that must be understood if it is to serve its purpose best. This book attempts to explain in a simple way these bodies of ours, and to teach us how to care for them properly in health, and how to prevent disease.

2. The Human Body. - We all know that the body consists of the head, arms, trunk, and legs; that it is covered with skin, and that it is made up of bones, muscles, nerves, blood, etc. We know that the dif- 
ferent parts of the body are under our control. We can move the head, hands, feet, and, in fact, the entire body at our pleasure. The bones are moved by the muscles which are controlled by the nerves that carry the messages sent out by the mind.

In some respects the body may be compared to a locomotive. The locomotive consists of a furnace, a boiler, a piston, wheels, levers, etc., while the body has bones, muscles, a heart, a stomach, a brain, etc., as its machinery. Coal and wood are put into the furnace, while meats, potatoes, bread, etc., are taken into the stomach, and serve as fuel. The heat from the coal changes the water in the boiler to steam, which is the motive power that turns the wheels and moves the train along the track. The foods taken into the stomach and changed to blood are burned in the cells of the body. The heat thus produced serves to keep us warm and to keep in operation the machinery of the human body. The body differs from the locomotive in that it is selfoiling, self-repairing, and self-increasing in size, - some of the foods serving these purposes. Beautiful and wonderful as is the most complicated machine ever invented by man, the body exceeds it in beauty of form, delicacy of adjustment, and complexity of organization.

The study of the human body is one of the most interesting and useful branches taught in our schools. We call this study human anatomy, physiology, and hygiene.

3. Anatomy. - The science which treats of the gross structure of the body, i.e. the shape, size, and location of 
the various parts, is called human anatomy. The body is made up of many different parts called organs, as the heart, liver, stomach, eyes, etc. The clock in the room has hands, a case, a dial, a mainspring, etc. These are all facts of anatomy. Can you mention others? Give something of the anatomy of a jackknife, of a school desk, of a shoe.

4. Physiology. - The science which deals with the uses or functions of the various parts of the body is called human physiology. The teeth are for the purpose of cutting and grinding foods; the stomach helps to prepare foods for the blood; and the skin serves to protect the body from foreign objects. The hands of the clock indicate the time of day; the key is for winding the clock; and the case contains the works and protects them against dust and other harmful substances. These are facts of physiology.

5. Hygiene. - The science which deals with the care of the various parts of the body or with the laws of health is called personal hygiene. The teeth should be properly cleaned daily; our meals should occur at regular intervals and at the same hour each day; the foods should be well cooked and thoroughly chewed; and the skin should be kept clean by frequent bathing. The clock should be wound at the same time daily; and should be kept in a dry, clean, safe place. These are statements of hygiene.

We shall learn in this book many of the important laws of health, so that we shall be able to do those things which will make us strong and keep us well. 
We shall learn something of public health or of the laws that relate to the well-being of people living in towns, villages, and cities. There are laws of public health as well as of personal hygiene.

6. The Amœba. - In water and moist earth there live animals so small that they can be seen only with the aid of a microscope. The amøba belongs to one of these classes. It looks when highly magnified like a bit of jelly. No one who does not watch it closely for a long time would believe that it is a live animal. It is so simple in structure that it is without mouth, head, legs, or stomach, and yet it has the power to move about in
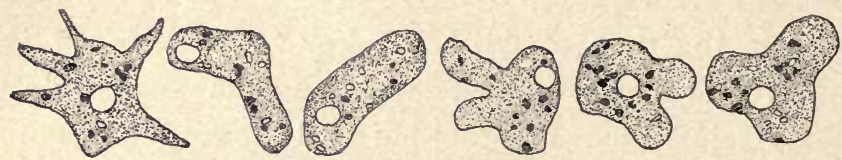

FIG. I. - Amœbas as seen under the microscope (Buchholz).

the water, to breathe, and to eat. When the amœba has grown to full size it divides and forms two tiny amœbas, each having all the power of the parent. The amoba is a tiny bit of living matter called protoplasm.

Place under the microscope a drop of water taken from a stagnant pond, or from a barrel of rain water that has become somewhat slimy. Examine it very carefully for amobas. Make a drawing of what you see.

7. The Cell. - Our bodies are very complex in structure, being made up of numerous parts or organs which do not look at all alike. Each of these parts is composed of many small bits of living matter called 
cells. The amoeba is a single cell, but our bodies consist of millions upon millions of cells, each of which is a living particle like the amœba. Every cell in the body takes in foodsand gives off wastes; it may be said then that it eats and breathes.

The cells of the human body vary in size, shape, and

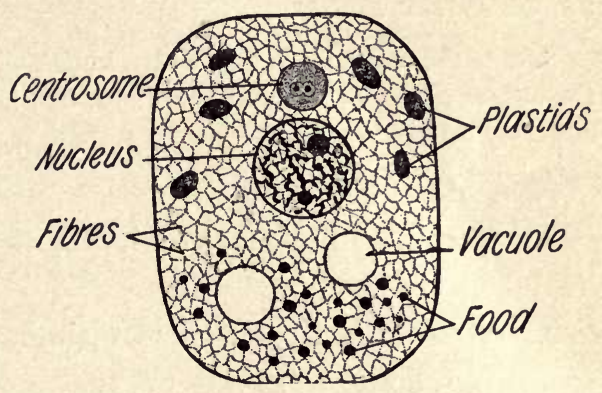
FIG. 2.-A typical cell. Modified from Wilson (Zinns). consistency. Some are small, globular masses, some are thin, flat, or scaly, and others are long, slender, and very irregular. Some are very soft and like jelly, while others are hard, firm, and like bone. Each cell has a

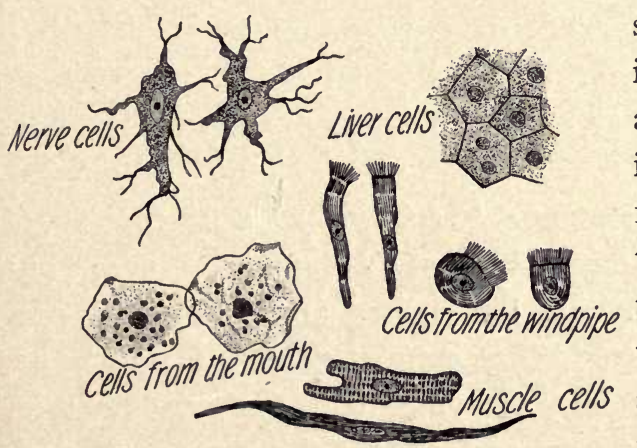

FIG. 3.- Various cells of the body (Zinns). special use, and its size and shape are such as to fit it to best perform its function. Although the cells differ widely from one another in appearance and use, they are all composed chiefly of water (about three fourths), a substance quite like the white of an egg, called proteid, 
some sugar and starch, fats, and salts. These little masses are held in place by fine threads or fibers known as connective tissue.

Scrape the moist lip lightly with a knife and place the mass under the microscope. Try to find very light, flat, irregular scales. These are scaly cells. Make a drawing.

\section{Some Definitions.}

I. A cell is any mass of living matter containing a nucleus.

2. A tissue is a collection of similar cells having the same functions, as bony tissue, nerve tissue, muscle tissue, and fat or adipose tissue.

3. An organ is a collection of several tissues arranged in some definite and compact way to perform some special function, as the heart, lungs, liver, and eye.

4. A system is a group of several organs that aid each other in doing the same kind of work, as the nervous, muscular, and digestive systems.

5. An organism is a collection of all the systems necessary to carry on the life processes, as man, dog, fish, and oyster.

9. The Body compared to a City. - A city consists of hundreds of human beings all dependent upon one another, each having his desires and wants and contributing his share to the common good. Trains, boats, and wagons are busy carrying food, fuel, and luxuries to supply the needs and satisfy the wants of each individual in the city. The city depends upon the surrounding country, upon other cities, and more or less upon the rest of the world. Water is piped into the 
city and carried into the various rooms of every house. Pipes from the houses convey the sewerage from the city into a lake or river, and wagons gather up the garbage and ashes from every house. Have you ever thought what a problem it is to feed a city and to remove its wastes? It is not the city as a whole but each individual person of the city that must be fed, clothed, sheltered, and cared for. Each person has needs that must be supplied and wants that must be satisfied.

The human body consists of millions of cells, each having its wants and doing its share for the common good. They all depend upon one another. The food which is taken into the mouth reaches the stomach, and, finally, the blood. It must, however, be carried to the individual cells all over the body. The blood conveys the foods to the cells and removes the waste products from them. It is not the body as a whole but each and every living cell that must receive food, be kept warm, and have its wastes removed, so that it may properly do its share of work.

The cells of the body correspond to the individuals of the city. Each cell is a living unit, having its needs and doing its work. That is the important thing to remember in studying physiology. As we learn more about the human body this comparison will be clearer.

10. Order of Topics.

I. We shall first study the blood which receives the food and conveys it to the cells, and which carries away from the cells their wastes and removes them from the 
body. Blood is the liquid upon which the life and wellbeing of each cell depend.

2. Then we shall see what the different foods are, where they come from, and how they are prepared for the blood.

3. Next we shall study water and other drinks taken with our meals. Tobacco and other narcotics will be treated in the same chapter.

4. We shall then learn how oxygen of the air gets into the blood. This will be studied under Respiration.

5. Under Digestion and Absorption we shall learn how the solid and liquid foods are dissolved and taken into the blood.

6. After we have learned how the foods and oxygen get into the blood we shall study Circulation to see how the blood is carried to the cells in all parts of the body.

7. In the chapter on Foods in the Tissues we shall learn how the various things we eat and drink are used by the cells, and how the cells grow, keep warm, and do their work.

8. We shall then study the skin and the kidneys to see how the heat of the body is regulated, and how the waste products are removed from the blood and eliminated from the body.

9. The bones and muscles will next be studied to learn what the framework of the body is and how the muscles act on the bones to produce motion and to do work. In this connection we shall also study voice and speech. 
IO. The nervous system, which controls all parts of the body and forms the organ of the human mind, will be treated next.

I I. In close relation to the nervous system stand the sense organs that enable us to see, hear, taste, smell, and feel.

I2. We shall then study some of the more common diseases to see how they are caused, how they spread, and how they may be warded off.

I3. This will be followed by a chapter on public health and personal hygiene, based on our knowledge of the human body as learned in studying this book.

This order of topics we shall find easy to follow, for it is a very natural way of studying the human body. It will make the whole subject easy to understand, and at the same time very interesting, because one thing grows right out of another.

\section{SUMMARY OF THE MAIN POINTS}

I. A study of the human body will enable us to understand its parts, how they work, and how to keep well.

2. The human body is a very complex organism, being composed of many parts, each having its own needs and doing its own work for the common good. It is a wonderful machine.

3. Anatomy is the science which deals with the gross or general structure of the human body.

4. Physiology is the science which deals with the uses of the different parts of the body.

5. Hygiene is the science and art of health. It tells how to get well, and how to keep the body in a healthy condition all the time. 
6. A cell is any small mass of living matter containing a nucleus. It is the unit of structure and function in both animal and plant life.

7. The human body consists of millions of cells, each of which must have food to keep it alive and in good working condition.

8. In some respects the life and activity of each cell may be compared to that of an individual person in a large city.

9. It is important to remember that each cell in the human body is a living unit, having its own needs and doing its own work.

Io. The human body is made up of several systems; each system is composed of organs; every organ is constructed out of tissues; and a tissue in turn is made up of cells. 


\section{CHAPTER II}

\section{THE BLOOD AND THE LYMPH}

11. Cell Medium. - We learn that the amœba moves about in water from which it obtains its food and to which it gives off its wastes. Each living working cell of our bodies lives in a liquid called lymph. The cells cannot move about in search of food, and so lymph containing all the foods necessary for the cells is brought to them by the blood as it circulates to all parts of the body. Lymph is a liquid that is found in all parts of the body: in fingers and toes, in heart and lungs, in stomach and liver, in muscles and bones. It is so generally distributed that every cell is surrounded by a small amount of lymph, just as the amœba is surrounded by water. If we put a sponge in water, it will take up the liquid until it is completely filled. Now if we place the sponge on the table, we cannot see the water within it, and yet we know that every tiny particle of sponge is moist, and is bathed in water. In a very similar way the lymph permeates the human body and comes in contact with each and every cell.

The cells get their nourishment directly from the lymph and give off their waste materials and worn-out parts to it. The blood supplies the lymph with food 
matcrials for the cells, and removes from it the waste products of the cells.

12. Uses of the Blood. - All the foods we eat are changed in the body so that they become part of the blood, and may be used to keep the cells in a good, healthy condition. The water we drink also gets into the blood and is carried to the cells, where it is of great use. Even the air we breathe finds its way into the blood, which then carries the oxygen to the cells throughout the body. Thus we see that the blood brings oxygen and foods together in the cells in all parts of the body. The chief function of the blood is to carry foods and wastes. The blood is necessary to keep us alive; to keep us well; to give us strength to work; and to make us grow.

13. What Blood looks like. - We have all seen blood and know that it is a bright red liquid. Through a microscope it is not red at all but yellow in color. The whole mass of water of a large lake looks blue, but a small amount does not. And it is just so with the blood; a drop looks red, but a very small amount as seen under the microscope looks pale yellow.

Prick yourself with a sharp, clean needle so as to draw a small drop of blood. Examine it with a microscope. Describe what you find. The small masses are red blood corpuscles floating about in the plasma. Do you see larger white masses? They are white corpuscles.

14. Composition of Blood. - Under the microscope we see thousands of tiny yellow bodies moving about in a colorless liquid. These solids, oddly enough, are 
called red corpuscles. They are about one thirty-two hundredth of an inch in diameter, and so numerous that a single small drop contains about five millions of them. We also find white corpuscles, a little larger than the red, but they are not nearly as numerous.

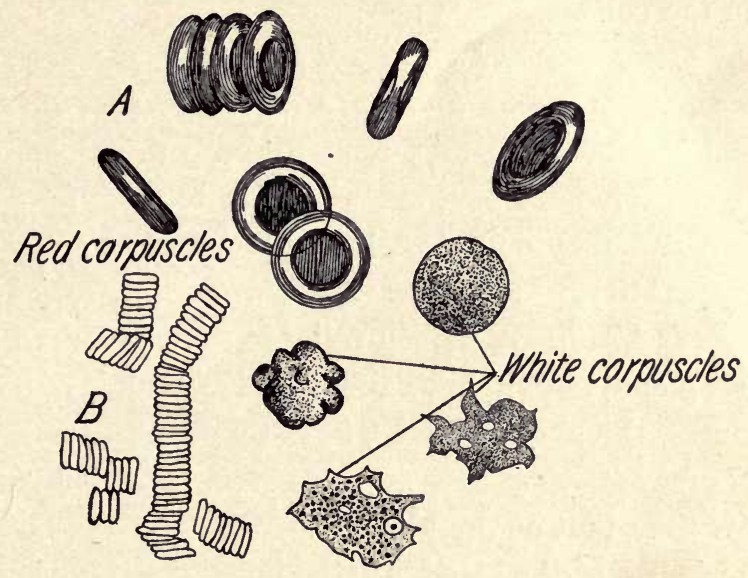

FIG. 4. - Human blood corpuscles (Zinns).

The colorless liquid in which the corpuscles float about is called plasma. Plasma is water containing in solution the foods that have been changed into blood and also the wastes of the cells.

What are the corpuscles for? The red corpuscles are very numerous and surely must be of great value. It is the red corpuscles that have the power to carry oxygen from the lungs to all the cells of the body. This is their only use, and an important office it is. They are busy day and night, doing all they can to keep the cells supplied with oxygen. We know that a fire in a stove or a fur. 
nace will not burn when the drafts are closed, cutting off the supply of air. Each cell in the body is a little furnace in which the foods we eat are slowly burned up or oxidized. If the blood contains too few red corpuscles, or if we do not breathe enough oxygen, the fire must be low in the cells.

The white corpuscles are said to have the power to destroy disease germs and to pick out poisons that get into the blood, and so they tend to keep the blood pure and wholesome. They are thought to aid in bloodclotting, and they doubtless have other functions.

15. Quantity. - About one thirteenth of the weight of the body is blood. A person weighing one hundred and fifty-six pounds would have about twelve pounds of blood. Of course, the amount varies in different persons. The exact amount of lymph is unknown, but it is much greater than that of the blood.

One fourth of the blood is in the lungs, heart, and large blood vessels; one fourth in the liver; one fourth in the small blood vessels of the muscles and skin; and one fourth in the various other organs of the body.

16. Clotting. - When the blood is exposed to the air, little threads called fibers form in the plasma, that entangle the corpuscles and form a solid mass called a clot. The fibers that form throughout the entire mass are made of a substance called fibrinogen, that is found in the plasma. By the contraction of these fibers, a yellowish watery fluid called serum is squeezed out of the solid mass in which the clot then floats. Blood minus the clot equals blood serum. 
Clotting is of great value as a means of preventing bleeding to death from wounds. The clot forms a plug that closes the opening of a blood vessel.

Get a tumbler half full of fresh blood and leave it exposed to the air for a short time. Watch it carefully and describe the formation of the blood clot. The yellowish liquid that is squeezed out is the serum.

17. Anæmia. - Blood may contain red corpuscles so poorly made or so few in number that they are unable to carry a sufficient amount of axygen to the cells of the body. Such a condition is known as anamia. A person who is anæmic is languid, pale in the face, lips, and under the finger nails. He complains that he is tired after the slightest exercise, and suffers much from headache and drowsiness.

\section{How to keep the Blood Pure and Wholesome.}

I. Eat an abundance of good, wholesome food daily.

2. Work and sleep in rooms thoroughly ventilated.

3. Take a sufficient amount of outdoor exercise in the sunshine each day.

4. Keep the clothing loose, so as not to interfere with the circulation of the blood or with the action of the lungs.

5. Keep the skin clean by frequent baths.

6. Neverdrink beverages that contain alcohol, whether in large or small quantities.

7. Get enough sleep every night so that the waste products may be removed from the blood daily.

8. Remember that health depends largely upon the condition and quantity of the blood. 


\section{SUMMARY OF THE MAIN POINTS}

I. Each living, working cell of the human body is surrounded by lymph which contains the food for the cells, and the wastes of the cells.

2. The blood receives solid foods, water, and oxygen and carries them to the lymph, and removes from the lymph the wastes of the cells.

3. The mass color of blood is bright red, but a small amount as seen under a microscope is pale yellow.

4. The blood is made up of red and white corpuscles and plasma.

5. The red corpuscles are oxygen carriers, and the white ones destroy disease germs that get into the blood, and aid in blood clotting.

6. The average person has from ten to twelve pounds of blood, and a much larger quantity of lymph.

7. One fourth of the blood is in the heart, lungs, and large blood vessels; one fourth in the liver; one fourth in the muscles; and one fourth in the other organs.

8. The blood clots when exposed to the air, and so tends to prevent great loss of blood from wounds.

9. Anæmia is due to a lack of coloring matter in the blood.

Io. The general health depends upon the condition and amount of blood. 


\section{CHAPTER III}

\section{FOODS}

19. Definition of Foods. - We have learned that all the cells of the body need food to keep them well and to enable them to do their work properly. We have learned that the blood and lymph are the great body liquids from which each cell gets its food and to which it gives off its wastes. How does the blood get its food supply? The supply in the blood would soon be used up if it were not constantly renewed from the outside. We eat, drink, and breathe to furnish the blood proper material to carry to the cells for their nourishment and use. Not all substances taken into the mouth can be used by the cells. Some are not only useless but harmful and even poisonous.

A food is any substance that enters the blood, and without doing any harm in the body helps to cause growth, to repair the cells, or to give heat and mechanical energy.

20. Kinds of Food. - The body, like other machines, wears out with use, but differs from them in that it is self-increasing, self-repairing, and self-oiling. For this purpose it needs tissue-building food stuffs known as proteids. The locomotive consumes coal to produce the heat which changes the water to steam, and the 
body needs foods to furnish the heat which keeps us warm and to yield the energy which enables us to work. The chief heat-producing and energy-yielding food stuffs are called carbohydrates (starches and sugars) and fats.

The proteids, carbohydrates, and fats would be of no value to the cells without oxygen. It is only when coal and oxygen are made to combine that heat is produced in a furnace, and likewise no burning or oxidation could take place in the cells without an abundant supply of oxygen.

The solid food stuffs could not get into the blood nor to the cells if they were not dissolved in water and carried along by water, which makes up a large part of the blood. Salt is another class of necessary food stuffs.

\section{TABLE OF FoOD STUFFs}

I. Proteids, the building foods.

2. Carbohydrates

3. Fats the force and heat producing foods.

4. Water

5. Salts

6. Oxygen important aids in both.

21. Proteids. - They form the only class of foods that contain all the elements necessary to cause growth and to repair cells. For this reason proteids are absolutely necessary to maintain life. Eggs, lean meats, cheese, beans, peas, lentils, and milk are among the common foods that belong to this class. Most of the cereals, as wheat, barley, oats, and corn, contain considerable proteid. This is the kind of food that makes muscle and other tissues. We would starve without proteids. 
Could we live on proteids alone? Yes. Yet the proteids do not form an ideal food, because they are not easily oxidized in the body, and so are not as valuable for producing heat and energy as the carbohydrates and fats. How much proteid, then, should we eat? The answer to this question is simple. We should eat just enough proteid to repair the cells properly and to afford sufficient material for growth.

Obtain five cents' worth of iodine from a drug store and dilute it with water until it shows a light brown color. Label and save for future use.

I. Take any food that contains proteid, as lean meat, and place it in a strong iodine solution for a short time. Notice how brown it becomes. What do you infer?

2. Try the white of an egg and other proteids in the same way,

22. Carbohydrates. - This is a very large class of food stuffs, including starches and sugars obtained from both the animal and the vegetable kingdoms. Most vegetables are rich in starches, as, for example, wheat, rye, barley,
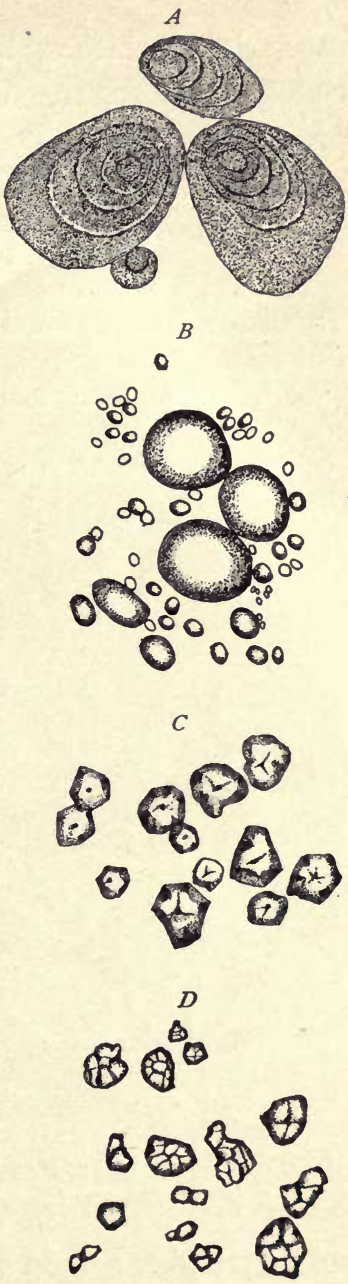

FIG. 5. - Starch as seen under the microscope (Buchholz): $A$, potato; $B$, wheat ; $C$, corn ; and $D$, oats. 
oats, rice, potatoes, tapioca, etc. Some fruits contain considerable sugar. Carbohydrates are heat and energy producing foods and should form the bulk of our daily meals. They are quite easily prepared for the blood and readily oxidized in the cells.

I. Take a little common starch and boil it for a few minutes. Then add a few drops of iodine solution. Notice the characteristic blue color.

2. Test other foods that contain starch in a similar way.

23. Fats. - All meats and nearly all vegetables contain more or less fat and oil, so it is really impossible

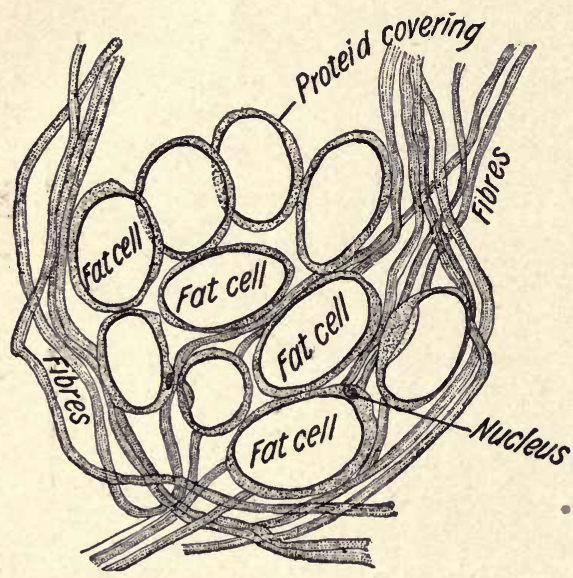

FIG. 6. - Fat meat as it appears under the microscope (Buchholz). to avoid fats. Pork, butter, lard, suet, olive oil, etc., are rich in fats and oils. Fats are very important heatproducing foods, but they are not as easily digested as proteids or starches, and hence - should not form a very large part of our meals. In the winter and in very

cold countries people eat considerable fats and oils.

24. Water. - When we remember that about three fourths of the human body is water, we can see how important it must be as a food. Nearly everything 
that we eat contains more or less water, and, besides, we drink water freely not only with our meals but at other times. All common beverages, as milk, coffee, tea, cocoa, and chocolate are almost entirely water.

Table showing the Percentage of Water in Some Foods

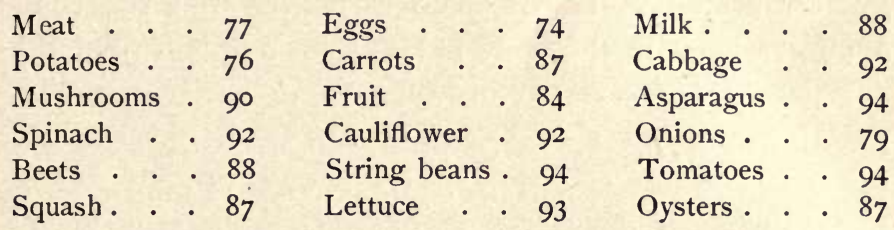

I. Carefully weigh a good-sized fresh potato. Then leave it in a warm place for a few days and watch it dry up slowly until there is little left. Weigh again. The loss of weight is due to the loss of water by evaporation.

2. Try other vegetables in a similar way. If the vegetables are sliced thin, the evaporation will go on faster.

Water has many uses in the body. It moistens and dissolves the solid foods so that they may be easily swallowed and taken into the blood. The blood itself is over eighty per cent water. It holds in solution all the solid foods and carries along the corpuscles of the blood. The lymph around the cells has a larger proportion of water. The cells of the body are nearly eighty per cent water. The wastes of the cells are dissolved in water and so removed from the body through the skin, lungs, and kidneys.

25. Salts. - The most essential food of this class is common table salt. Meats, vegetables, and fruits all contain salt, but not enough to supply our need. We add salt to nearly everything we eat. Salt may neither 
build tissue nor furnish heat, and yet we must eat considerable of it to keep our bodies in good health. Each cell must have in it a certain amount of common salt to do its work properly. Just what it does we do not know with certainty, but it seems to stimulate the cells to greater activity. It has been estimated that the total amount of salt in the body is less than one half pound.

26. Oxygen. - Did you ever think of the air we breathe as being a food? Many do not call it a food, but we shall consider it in connection with foods. We know that oxygen breathed into the lungs gets into the blood and is then carried to all the cells of the body by the red corpuscles. Does a fire burn well if you close the drafts that furnish it air? Well, the foods cannot be oxidized in the cells without an abundant supply of oxygen. When solid foods, water, and oxygen are carried to the cells, they undergo certain chemical changes there, i.e. they are slowly burned or oxidized. This oxidation produces heat that is used to keep up the body temperature, and energy that is used in doing work. Oxygen is also used to transform the foods we eat into tissues of the body. Oxygen is so important that we could live only a few minutes without it.

Put a lighted candle into an empty fruit jar. The candle.burns brightly for a few moments, but as soon as the oxygen in the jar is used up the flame dies. If the candle is taken out, lighted, and lowered into the jar again, it will be extinguished at once because there is no oxygen left in the jar.

2\%. Substances taken with Foods. - There are many things eaten simply because an appetite has been 
formed for them. They are then said to be palatable. Mustard, ginger, pepper, pickles, olives, vinegar, horseradish, and flavors of all kinds belong to this class. Some of these things have no value whatever as foods, but may be of use to stimulate the appetite and to aid digestion under certain conditions, if used moderately. When a person is well he seldom needs anything to stimulate his appetite, and the excessive use of all such substances is not only unnecessary but may be very harmful.

28. Animal Foods. - The foods that come from animals are among the most important articles of our daily meals. Only a few will be mentioned here.
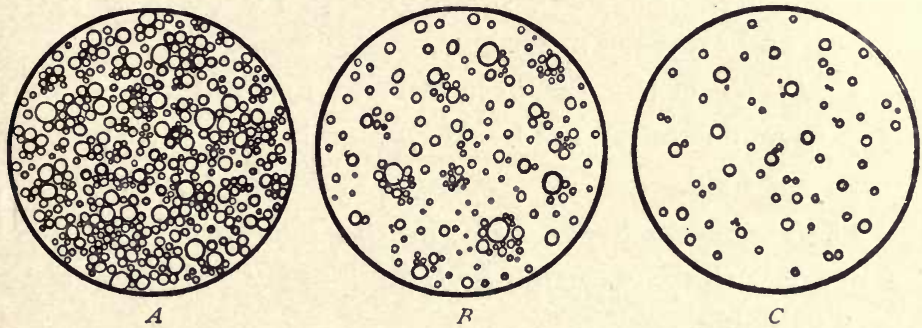

FIG. 7.-Showing fat globules (Gunnison): $A$, cream; $B$, milk ; and $C$, skim milk.

I. Milk is almost an ideal food. It contains all the food stuffs necessary for man and is about the only nourishment adapted to infants. For an adult the proportion of the different food stuffs in milk is not quite right. He would be obliged to drink a large quantity of milk in order to get the amount of proteids and carbohydrates necessary. And, furthermore, man needs a food that gives the stomach more to do. 
2. Cheese is a valuable food, but cannot be easily changed into blood. It should be eaten in small quantities only.

3. Meats form a most valuable article of diet. They are the most easily digested of all the proteids if eaten in small quantities, and are very nutritious. There is danger of eating more meat than is necessary to supply the blood with tissue-building foods. Beef, fish, mutton, lamb, veal, pork, poultry, and game are among the most common meats.

4. Eggs contain all the important food stuffs axcept carbohydrate, and may be eaten in place of meats occasionally. They are easily digested, if properly prepared, and are very nutritious.

5. Butter is the fat of milk, and forms a digestible and very palatable food. Bread and butter form an excellent food.

29. Vegetable Foods. - From the plant world we get a great variety of articles of diet, many of which are very valuable.

I. The cereals supply us with bread, rice, and the many breakfast foods so commonly used at present. Wheat bread is probably the most widely used as well as the most important of this class, as it contains all of the food stuffs except fat. Some one has called bread "the staff of life," and when butter is added they together form "the gold-headed cane." Rice, you know, is the food most used in China. With proteids and fats it would give nearly as much nourishment as bread and butter. Malt, barley, wheat, and other cereals, prepared 
in various ways as breakfast foods, are all easily digested and are very nutritious for most people.

2. The so-called vegetables are not very nutritious, but they are cheap and easily digested and therefore are used extensively. Under this head we have the Irish potatoes, sweet potatoes, beets, carrots, squash, cabbage, tomatoes, peas, beans, and lentils. The Irish potato is
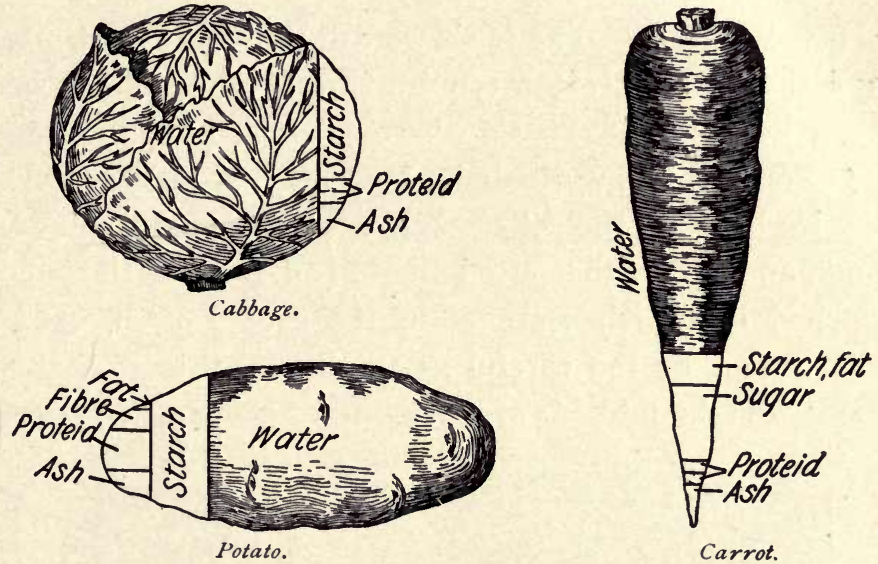

FIG. 8. - Showing composition of potato, carrot, and cabbage. Modified from Snyder's "Losses in boiling vegetables" (Zinns).

the king of vegetables. Some of these articles, as cabbage and beans, are not easily digested, and some contain but little nourishment. Green vegetables are taken with other foods because of their palatable qualities; they contain salts, acids, and aromatic substances.

3. Under this class of foods must be mentioned ripe fruits, as berries, apples, oranges, bananas, grapes, etc. Most of the fruits are valuable for their juices, which 
contain salts, acids, and sugar. They are not especially nourishing.

4. Nuts contain a large amount of proteid and fat, which makes them valuable as articles of diet. They must be well chewed and eaten in small quantities, for they are rather difficult to digest. The Germans say that nuts and cheese are "gold in the morning, silver at noon, and lead at night."

30. Hygiene. - The foods we eat, the water we drink, and the air we breathe require careful attention, as we shall learn later. Places where foods are kept should be clean and well ventilated. How often are the pantry, the ice box, and the cellar sadly neglected! Air, water, milk, and meats that are impure, and fruits artificially ripened or overripe, are often the causes of diseases. We cannot be too careful as to the conditions of the foods we take into our systems.
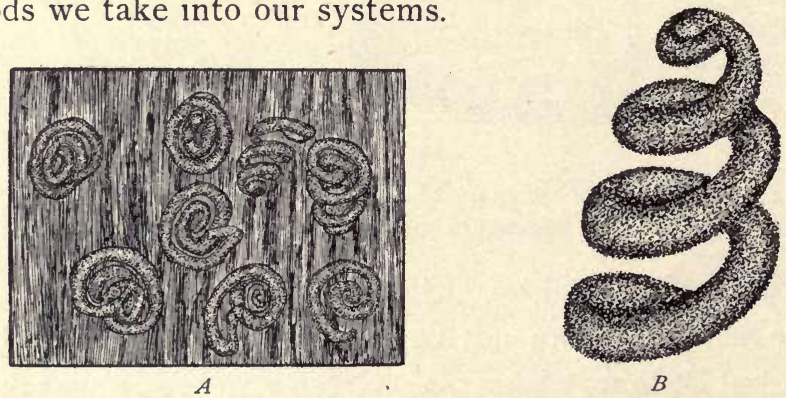

FIG. 9.- Trichinæ (Buchholz): $A$, trichinæ, as seen in a muscle of a young man who died of trichinosis; $B$, a single trichina magnified.

31. Value of Cooking. - Why do we cook foods? Some will say because they taste better and look more attractive when cooked. That is true; but there are other 
reasons more important. In beef and pork are sometimes found little parasites and germs that cause disease if taken into the body. Cooking, if well done, kills all injurious things of this kind. We should never eat raw meats. Many foods, especially vegetables and green fruits, are more easily digested when cooked.

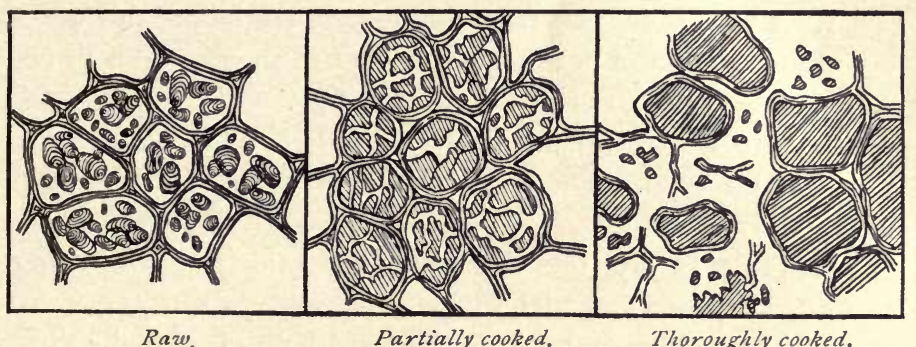

FiG. 10. - Showing how cooking changes the starch cells of potato. Drawn from Year-book of Department of Agriculture, 1900 (Zinns).

Cooking causes the cell walls of vegetables to burst, and so permits the starches and sugars to escape. In meats the connective tissue is loosened, and so the most important elements become exposed to the action of the juices in the stomach and intestines.

Apply the starch test to raw and to boiled starch. Do you notice any difference?

32. Amount of Food. - The amount one should eat depends upon age, health, occupation, and many other things. On an average an adult who works moderately needs each day about one fourth of a pound of proteid; a little less than one fourth of a pound of fat; a little more than three fourths of a pound of carbohy- 
drate; about one eighth of a pound of salt; and from three to five pounds of water. The foods we eat each day should be so selected as to yield this amount of each food stuff if we wish to be in good health.

\section{SUMMARY OF THE MAIN POINTS}

I. A food is any substance that enters the blood, and without doing any harm in the body helps to cause growth, to repair the cells, and to yield heat and energy.

2. The food stuffs are proteids, carbohydrates, fats, salts, water, and oxygen. These food stuffs are oxidized in the cells of the body.

3. Proteids are the tissue-building and tissue-repairing foods. They are essential to life.

4. The carbohydrates form the great bulk of our daily diet. They serve to yield heat and energy.

5. The fats are the greatest heat producers, but are not as valuable as the carbohydrates, because they are more difficult to digest.

6. Water is found in all of the foods we eat, but that does not meet the demand of the body. We must drink considerable water each day, for it has many uses in the body.

7. Water dissolves the solid foods, moistens the mouth and other organs to aid in swallowing, makes up a large part of the blood and lymph, and is an essential part of each cell.

8. The cells cannot do their work properly unless considerable salt is present.

9. Foods are of no use to the body without oxygen; but when foods and oxygen are brought together in the cells, heat is produced and tissues may be built up and repaired.

Io. Mustard, ginger, pepper, pickles, olives, vinegar, horseradish, and all flavors are not true foods, and when taken in excess prove harmful. 
I1. The most important animal foods are milk, cheese, meats, eggs, and butter.

12. Cereals, vegetables, fruits, and nuts are the important foods obtained from the plant world.

13. All foods and places where foods are stored must be clean and well ventilated, so that the foods may be kept pure and wholesome.

14. Cooking kills disease germs; makes foods attractive and palatable; and in most cases aids digestion.

15. An adult who does a moderate amount of work requires every day about one fourth of a pound of proteid; one fourth of a pound of fat ; three fourths of a pound of carbohydrate ; two ounces of salt; and from three to five pounds of water. 


\section{CHAPTER IV}

\section{DRINKS AND NARCOTICS}

33. Pure Water. - The clear and sparkling water of our springs, wells, and lakes, that tastes so good and forms really the only drink necessary for man and beast alike, is by no means pure to the chemist. Water that is chemically pure,-distilled water,-is not found in nature, neither is it pleasant to drink, for it is flat and tasteless. What is in the spring water that we thought was pure and is so agreeable to the taste? When it is carefully examined by a chemist, it is found to contain minerals of various kinds, and air. The most common minerals are lime, soda, potash, iron, magnesia, and sulphur.

The water that is most healthful is not absolutely pure but contains air and many mineral substances that are valuable to the body. It is only when these minerals are too abundant, and especially when water contains disease germs, that it becomes dangerous to drink.

I. Dissolve salt or sugar in water until you can easily taste it. Then heat the solution to the boiling point and collect the vapor that is given off. Do you detect any taste? What has become of the salt or sugar?

2. Evaporate the entire solution. Do you have any solid left? 
34. Impure Water. - Typhoid fever, dysentery, cholera, and many other dangerous diseases are generally due to germs that live in the water. Many of these diseases can be traced directly to some well located in a barnyard, or other filthy place, from which surface water is drained into it. People are often careless in choosing a location for a well for drinking purposes. It should not be dug in a low

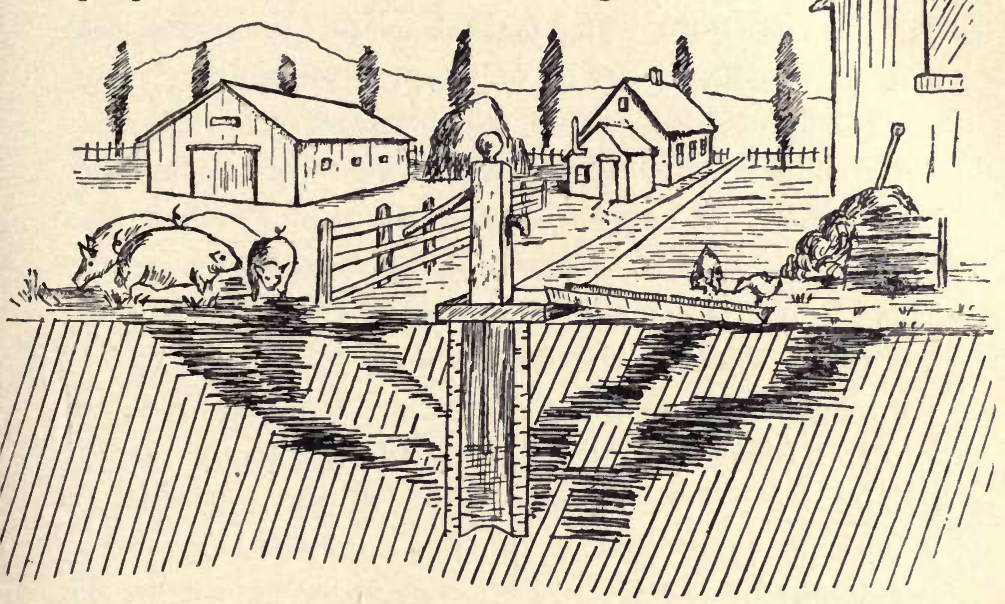

FIG. II. - Showing how surface drainage may contaminate the water of a badly located well (Zuppke).

place, where water from all directions may run into it, but on a spot on a level with the house and barn and sufficiently removed from all sources of contamination. The germs in drinking water are the direct cause of thousands of deaths yearly, both in the country and in our large cities.

Many people filter the drinking water. This is an 
excellent precaution to take when there is reason to suspect disease germs. How can it be purified? There is but one safe way to purify water containing disease germs, and that is to boil it. If the temperature of water is kept at the boiling point for about twenty minutes, all germs are destroyed, and when cooled it may be safely taken into the stomach. The common water filters are of value in removing the coarse substances, and so making the water look clear and pure; but they cannot be relied upon to remove the germs that cause disease unless they are properly cared for.

In connection with bad water we must discuss ice. Ice is just as impure as the water of which it was formed, because freezing does not kill the disease germs. Ice from lakes or rivers whose waters are unfit for drinking purposes should not be put into drinking water nor used in ice boxes in which foods are kept. Serious diseases are often traced to the use of impure ice. The excessive use of ice water is an American habit that cannot be defended from the standpoint of health. The temperature of substances taken into the stomach should not be below $44^{\circ} \mathrm{F}$. nor above $13 \mathrm{I}^{\circ} \mathrm{F}$.

35. Tea and Coffee. - These are not foods, but have become almost universal beverages with meals, in place of water. Both contain substances that have a stimulating effect upon the muscles and the nerves. Some people use tea or coffee when very tired because they make them feel better. This is because they restore muscular activity and stimulate the brain cells. 
Tea and coffee excite the nerves, so that one does not realize that he is tired.

Some adults who are well and strong may use these drinks without feeling any harm whatever, unless they are taken in too large quantities or are made too strong. Persons who are weak, however, may find that even a cup of tea or coffee taken daily causes serious nervous disturbances, including sleeplessness and restlessness, as well as disorder to digestion. Children should not use either tea or coffee, because they retard physical growth, make the complexion dark and muddy, stimulate the kidneys too much, delay digestion, and have a harmful effect upon their delicate and sensitive nervous systems. The use of tea frequently causes muscular tremor.

The extensive use of tea and coffee is simply a matter of habit. A person in good health does not need these stimulants, and their excessive use is the cause of much of the nervousness and poor digestion so common in this country. We should drink only those things that will keep us strong and well.

6. Milk. - We have learned that milk is almost an ideal food, and as a beverage it should rank next to water in importance. It does not agree with some, but most persons find it a very satisfactory substitute for tea and coffee. Great care must be taken to keep the milk free from disease germs, because it easily absorbs any impurities the air may contain. In the cellar or ice box no vegetables, cheese, or meats should be kept with milk if it is not in sealed bottles. If strong 
cheese, or a bunch of onions, and milk are placed side by side, the latter will soon be tainted with the odor of the former. Vessels containing milk should always be covered, or, still better, sealed.

Milk of diseased cows or that which has not been kept clean is dangerous to use. Typhoid fever and other serious diseases are often due to the use of impure milk. We should use fresh, wholesome milk more and more with our meals instead of tea and coffee and other less valuable beverages, for it is an excellent drink and at the same time a very nutritious food.

Place some milk in a shallow pan, in an ice box, side by side with onions, cheese, or vegetables, and notice that the milk becomes tainted in a short time.

37. Alcohol. - If sweet apple juice be allowed to stand for some time in a warm place, it slowly loses its sweetness and finally becomes strong and biting to the taste. What has happened? The sugar of the apple juice has been changed into a gas, called carbon dioxid,

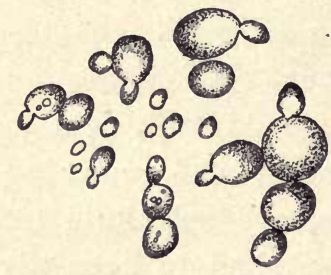

FIG. I2. - Yeast plants (Buchholz). that you can see bubbling up through the liquid and escaping into the air, and into alcohol which remains in the liquid and gives it its strong biting taste.

What makes the sugar break up into carbon dioxid and alcohol? There is a tiny yeast plant on all fruits and in the air. When the apples were crushed this plant was in the liquid and began to live on the sugar as its food. The yeast plant 
multiplies very rapidly. In a short time these myriads of plants, called ferments, change all the sugar into alcohol and carbon dioxid.

All alcohol is manufactured by yeast plants living and growing in the sugar of fruits and vegetables. We call this change, due to the yeast plant, fermentation, and the liquid formed, fermented liquor. Since many ways of obtaining alcohol have been devised there are numerous varieties of alcoholic beverages. But whatever its source it has the same effect upon plants, animals, and man.

Put one part of molasses to ten parts of water, and a few crumbs of yeast into a fruit jar or large bottle, and shake the mixture thoroughly. Cover it with a saucer and set it away in a warm place for a day. Do you notice bubbles rising in the liquid? These are carbon dioxid. Test the gas above the liquid with a burning match, and with lime water. The sugar has been decomposed into carbon dioxid and alcohol by the growing yeast plant. If it is left to continue for several days, the alcohol will be broken up into vinegar and water. What happens when preserves "work," or when cider becomes hard? Why is yeast used in making bread ? Why is bread sometimes sour? Why soggy?

38. Alcoholic Drinks. - The following are among the most common beverages which contain alcohol: wines, beers, and spirits.

I. Wines are made from the juice of the grape and various small fruits, as the currant, blackberry, elderberry, raspberry, cherry, gooseberry, etc. The percentage of alcohol in wine depends upon the amount of sugar in the fruit from which the wine was made. Wines contain from six to twenty per cent of alcohol.

2. Quite like the wines are apple, pear, and orange cider. 
3. Malt beverages, as beer, porter, and ale, are made from barley, wheat, corn, and rice. The beers contain less alcohol than the wines, the amount varying from two to eight per cent.

4. The home-made beers, as the root and birch, contain from one to three per cent of alcohol.

5. Spirits or distilled liquors are all produced by a process of distillation and contain a high percentage of alcohol. Whisky, which contains from thirty to sixty percent of alcohol, is made from rye, corn, potatoes, and other things rich in starch. Brandy contains from fifty to sixty per cent of alcohol and is made chiefly from wines of various kinds. Rum contains from sixty to seventy per cent of alcohol and is made from cane sugar and molasses. The alcohol formed by fermentation has essence of rum added to it. Gin is produced from wines and whiskies by double distillation and is flavored with juniper berries, coriander, almond cake, or various other aromatic substances.

39. Is Alcohol a Food? - Alcohol is not a food but a poison. We all know the poisonous effect alcohol produces upon the young, even when taken in small quantities ; and in large amounts it acts like a narcotic poison that paralyzes the nervous system and has been known to destroy life. You will remember that our definition of foods says, "and without doing any harm in the body," which at once bars out all alcoholic drinks. It is claimed that alcohol may be oxidized in the body, like carbohydrates and fats, and produce heat to keep us warm. While this may be true as is shown by many 
careful experiments, yet because of its harmful effects it cannot be classed with those things that go to make muscle and brain, to give us strength, to keep us warm, and to make us useful, happy, healthy individuals.

40. The Appetite for Alcohol. - If any of the beverages containing alcohol are used occasionally, even in small quantities, the body becomes accustomed to them and craves them when they are not regularly provided. More than that, they create an artificial appetite, a craving, which can be satisfied only by taking a constantly increasing amount. That is not true of food. Our appetite for potatoes, bread, or beefsteak can be as readily satisfied to-day as a year ago, and it will not take a larger quantity a year hence. Anything we eat or drink for which such an artificial appetite is acquired must be looked upon with great suspicion. Total abstinence is the only real safeguard against the unnatural craving for alcohol. We shall learn in later chapters of the effects of alcoholic drinks upon the various organs of the body.

41. Tobacco. - No one clains that tobacco is a food or a necessity for our well-being. All regard it as a luxury, and an expensive one at that. Tobacco contains nicotine, a violent narcotic poison, to which its harmful effects are due. Smoking and chewing are useless, expensive, and injurious habits.

While an adult may not be aware of the harmful effects due to the constant use of tobacco, a young person cannot conceal the injuries to both body and mind that result from its use. Physicians tell us that it 
dwarfs physical growth and development of the young, produces harmful effects upon many organs of the body, as the brain, heart, and stomach, and acts in a most injurious way upon the memory and all other mental powers.

42. Cigarettes. - Cigarettes contain the same narcotic poisons found in tobacco. The purest cigarette contains nicotine. It is said that waste tobacco and cigar stumps are frequently used in the manufacture of the cheaper grades of cigarettes. Of course the amount of poison in a cigarette must be very small, and yet the cigarette habit so common among boys and young men is more harmful to health and vigorous mental activity than the use of tobacco in any other form. This is true because the cigarette is so very mild that the smoker gets little satisfaction unless some of the smoke is inhaled. In this way the smoke affects not only the mouth, throat, and nose, but all the air passages and even the lungs. As the habit grows, more and more of the poison is taken into the lungs, where it comes in contact with the blood. It is then carried to all the organs and tissues of the body. It is the way in which the cigarettes are used that makes them so dangerous to the young. A young man who wishes to keep his body well and strong cannot afford to get into the habit of using narcotic poisons in any form.

\section{SUMMARY OF THE MAIN POINTS}

I. Absolutely pure water is tasteless, but when it contains only mineral salts or other things that are not injurious it is the most palatable and healthful drink we have. 
2. Impure water is very dangerous, for it may contain germs that cause the most dreaded diseases known to man, as cholera, typhoid fever, etc.

3. Boiling is the only safe way to purify water, because no other means can remove or destroy the disease germs. Filters have some value.

4. The ice that forms on stagnant ponds, lakes, and rivers, whose waters are unfit to drink, should not be used for drinking purposes, because it is just as impure as the water upon which it forms. Freezing does not kill disease germs.

5. Next to water, milk is the most wholesome drink, and it will be used more generally as we learn more of its value. Impure milk, however, is very dangerous.

6. Tea and coffee contain poisons that act as stimulants upon the nerves, and a young person in good health does not need to use either. We are better off if we let them alone.

7. The yeast plant feeds upon the sugar of vegetables and fruits and slowly breaks it up into carbon dioxid and alcohol. The carbon dioxid is a gas and escapes, but the alcohol remains in the liquid and gives it a strong biting taste. Yeast and other things that act in the same way are called ferments.

8. Wines, beers, and spirits are the common varieties of beverages that contain alcohol.

9. Alcohol produces harmful effects upon the body of a growing boy or girl and therefore cannot be classed among foods or wholesome drinks.

ro. The youth who takes alcohol in any form finds that he needs a constantly increasing quantity to satisfy his abnormal appetite.

I 1. Nicotine of tobacco has a harmful effect upon the brain, heart, stomach, and other organs of the body. Its effect is most marked upon the young. 


\section{CHAPTER V}

\section{RESPIRATION}

43. Review. - We have learned what the cells of the human body consist of, and what they need in order to do their work well and to keep us in good health. We have learned which foods are most nutritious and what substances are harmful. We have also learned what we should drink to keep in perfect health. The foods we eat and the liquids we drink can be used by the cells of the body only when there is a large amount of fresh air (oxygen) in the cells. The oxygen of the air combines with the foods, causing a very slow burning or oxidation to take place in the cells.

We must now learn how the air gets from the room in which we live into each and every cell of the body, where it is used. That whole process we call respiration.

44. The Air Passages. - We breathe through the skin as some of the lower animals do, but most of the air gets into the blood through a number of tubes that together are called the air passages. Air enters the body through the nose, which is the beginning of these air tubes. Then follow the pharynx, larynx, trachea (windpipe), two bronchi, many bronchial tubes, and, 
finally, thousands of little air pouches, or sacs of the lungs.

These tubes are made of a firm substance like gristle, called cartilage, which gives them their shape and holds them open so that we can breathe easily day and night. The cartilage is covered with muscles and connective tissue. The tubes are all lined with a moist, delicate, velvety lining called a mucous membrane. The different organs of the air passages are alike in their general structure, but they differ much in size and shape.

45. The Nose. - This diagram shows how large and irregular is the space in the nose through which air passes. That is for the purpose of spreading the air out over a large area, so that it may be changed to the temperature of the body

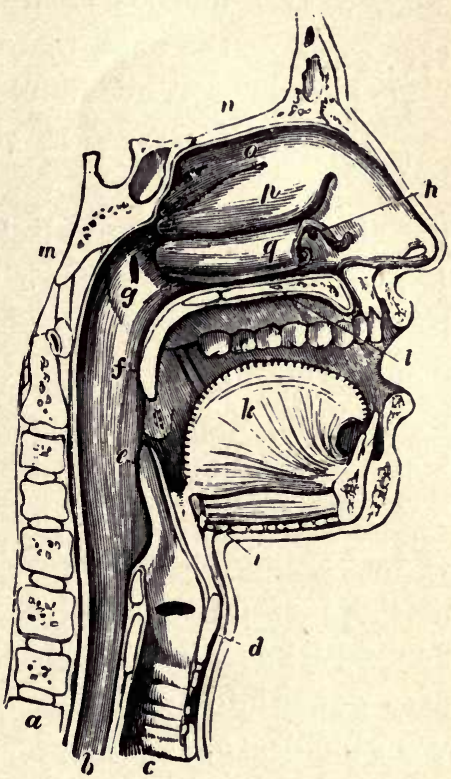

FIG. 13. - Showing the nose and mouth. (From Huxley's "Elementary Physiology"): $a$, spinal column; $b$, food passage or gullet; $c$, windpipe ; $d$, voice box; $e$, epiglottis; $f$, soft palate; $g$, Eustachian tube; $h$, opening of the tear duct; $i$, hyoid bone; $k$, tongue; $l$, hard palate; $m, n$, bones of the skull; $0, p, q$, turbinate bones of the nose. before going into the delicate little air sacs of the lungs. The moist mucous membrane of the nose picks out dust 


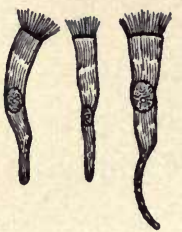

FIG. I4. - Ciliated cells from the nose (Zinns).

and foreign substances by means of its hairs and hairlike cilia. Besides doing all this, the nose is the organ of smell. Little nerve endings are found in the mucous membrane of the upper part of the nose, that enable us to smell.

Why should we breathe through the nose rather than through the mouth? The nose warms, moistens, and purifies the air and is the natural channel made for breathing. If persons breathe through the mouth, they cannot detect foul air by its odor; the mucous membrane of the mouth and throat become dry; cold, dry air reaches the delicate tissues of the lungs, where it is sure to cause discomfort and even disease; and all the fine particles of dust and dirt floating about in the air pass down into the lungs. We should always breathe through the nose.

46. The Pharynx and Larynx. - After passing through the two nostrils the air enters the pharynx. This is a rather large funnel-shaped organ that serves as a reception hall for both air and foods. At

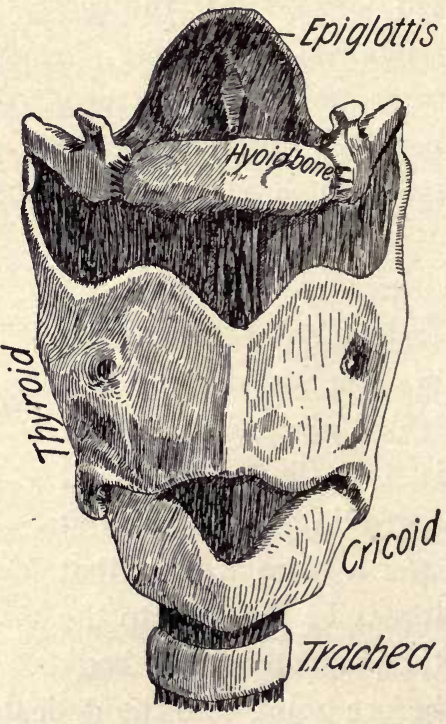

FIG. 15. - Larynx (Zuppke). 
the lower part of the pharynx the air leaves it and enters the larynx through an opening called the glottis. The top of the larynx is guarded by a trapdoor (cpiglottis) which closes the glottis in the act of swallowing, and so prevents food and drink from entering the air tubes leading to the lungs.

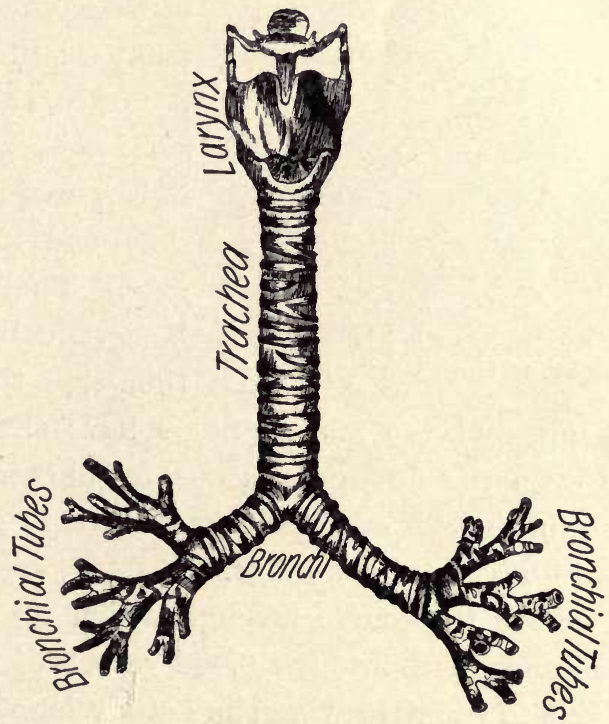

FIG. I6. - Larynx, trachea, and bronchi. From Heitzmann's "Anatomy" (Becker).

The larynx (voice box) is a very delicately constructed organ, serving both as a passage for air and as the organ for producing voice. It is a very useful organ and will be described more fully in a later chapter.

47. The Trachea and Bronchial Tubes. - The larynx ends below in the trachea, or windpipe, which is a tube 
about four and one half inches long and three fourths of an inch in diameter. The cartilages of the trachea are in the form of small C-shaped rings held in place by muscles and connective tissue. The trachea divides at its lower extremity into two smaller air passages, called the right and left bronchi, going to the two lungs. Each

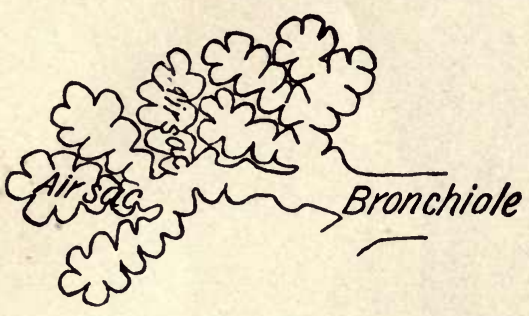

FIG. 17. - Showing how a bronchiole ends in air sacs. (After Schäfer.) of these gives rise to many still smaller passages, called bronchial tubes, which get lighter and finer until they end in the air sacs. The cartilage has gradually become thinner, the rings have disappeared, the muscle fibers have slowly faded out, and even the delicate mucous membrane has become so thin that air can easily pass through it into the small blood vessels of the lungs.

Thus we see the course through which the air is led from the atmosphere into the blood vessels of the lungs. How it gets to the tissues we shall study later.

Get a windpipe from the meat market.

I. Cut out one of the rings of cartilage and clean off all the muscle and connective tissue. Compare the cartilage with bone.

2. Cut off a portion of the lining, which can easily be seen when the windpipe is cut open. It consists of mucous membrane.

48. The Lungs. - The lungs are two large, pinkish, spongy masses that completely fill the chest (thorax), except that part which the heart occupies. The chest 
is bounded below by the diaphragm, a large domeshaped muscle that divides the body into two parts, called the chest and the abdomen, and above by the muscles of the neck.

The healthy lungs of a young person have a pale pinkish color, while the lungs of an old man who has lived many years in a city full of dust and smoke have a dark brown, almost black, color.

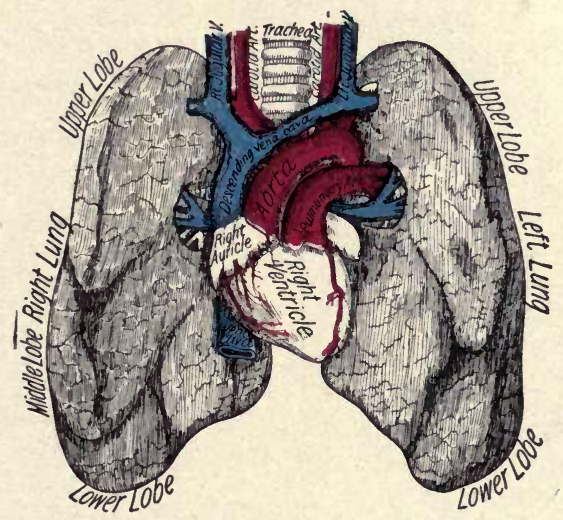

FIG. I8. - Front view of the lungs, heart, and large blood vessels (Zuppke).

The right lung is a trifle larger than the left, weighing about two ounces more. Each lung is composed of parts or divisions called lobes. The right has three lobes and the left two. The lobes in turn are made up of numerous small lobules. Did you ever notice the peculiar mottled appearance of a fresh lung? Each of the little areas is a lobule. If we look at a lobule under the microscope, we shall see that it consists of bunches of sacs filled with air and capillaries filled with 
- CHAP.

blood. It is in these small lobules that the air we breathe comes in contact with the blood.

I. Procure a sheep's lungs and notice the size, shape, color, and texture. Notice the air tubes leading to each lung. Will the lungs float in water?

2. Blow up the lungs by breathing into the windpipe.

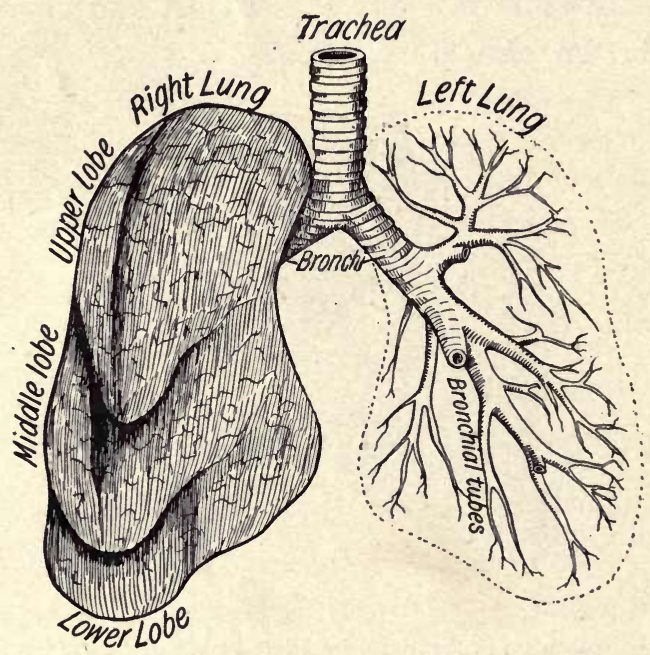

FIG. I9:- Showing the trachea, right lung, and the bronchial tubes of the left lung (Zuppke).

49. Covering of the Lungs. - Each lung is closely covered with a thin, delicate, saclike serous membrane called the pleura. The outer part of this sac lines the walls of the chest, while the inner part covers the lungs.

- There is a small amount of fluid in the sacs which serves to keep the membrane moist, and so prevents friction and disease which would result from the constant rub- 
bing of the surfaces due to the movement of the lungs and chest in breathing. The liquid serves as a natural oil to lubricate the membranes and hence to make breathing easy.

50. How the Air gets into the Lungs. - We have learned about the passages through which the air is conveyed to the lungs. But how do we breathe?

What makes the air go into these passages? We shall try to answer these

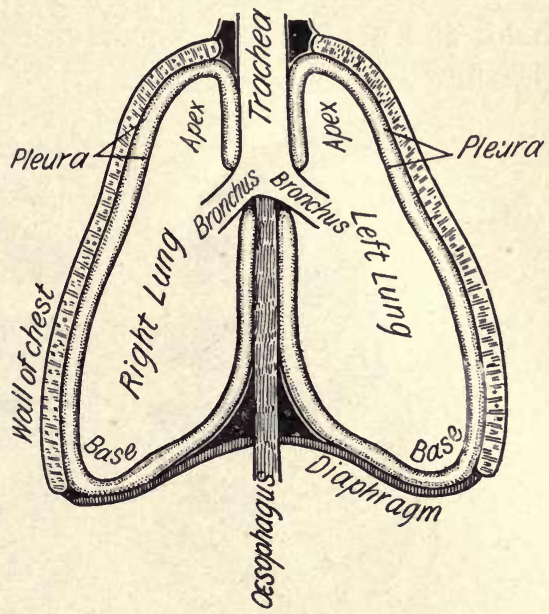
FIG. 20.- Showing how the pleuræ cover the lungs (Zuppke).

questions. We know that the chest rises and falls and the ribs move in and out in breathing. We cannot see the diaphragm, but that dome-shaped partition moves up and down when we breathe. The chest enlarges in all directions, due to the contraction of the muscles of the neck (scalene) and the muscles of the ribs (intercostal) and the diaphragm. All these muscles work together in such a way as to reënforce each other constantly. When these muscles contract, the chest enlarges, and the lungs also enlarge to fill the chest completely. The amount of these movements we can easily measure with a tapeline. Try it and see how 
much larger round your chest is after you breathe in (inhale) than after you breathe out (exhale). Now measure once more after you have inhaled all you can hold, and again after you have forced out all you can possibly exhale.

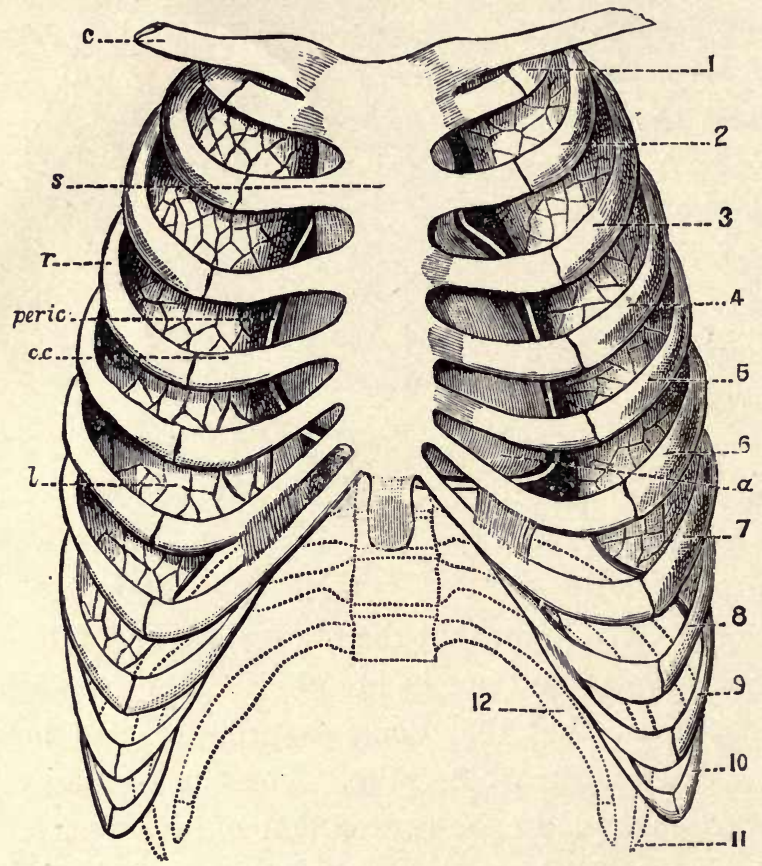

FIG. 21. - Showing the heart and lungs in position in the thorax. (From Huxley's "Elementary Physiology"): I-I2, ribs; $s$, breast bone; $c, c$, cartilages of ribs; $c$, collar bone; $l$, lungs; $a$, apex of heart; peric, pericardium, inclosing the heart.

Every time the chest enlarges, air is pushed in through the air passages to keep the lungs full. When the muscles relax, the chest grows smaller, the lungs 
are compressed, and air escapes freely through the air passages, and we exhale. We can easily understand how we exhale because, when the chest grows smaller, air is pushed out through the air passages just as water may be squeezed out of a sponge. But how do we inhale? What pushes air into the lungs through the air passages? This is not quite as easy to understand. The atmosphere is exerting a pressure of about fifteen pounds on every square inch of surface. Since the air in the lungs and the atmosphere outside are connected by means of

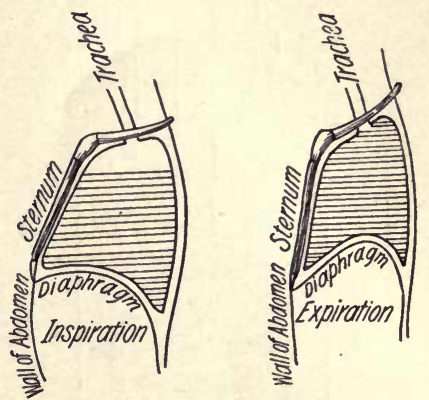

FIG. 22. - Showing positions of the diaphragm, sternum, and walls of the abdomen in inspiration and expiration (Zuppke).

open tubes, the air passages, the atmospheric pressure in the lungs must remain about fifteen pounds to the square inch. Now, when the lungs enlarge, air must be forced into them to keep the pressure the same as it is outside. We may say that the atmospheric pressure forces air into the lungs when the chest enlarges, and we inhale.

This constant rhythmic change in the volume of the air-tight chest makes inspiration and expiration alternate all the time from birth to death, with no attention whatever on our part. We never need to think about breathing, because the nervous system is so beautifully and perfectly adjusted that it keeps up this important process with never failing accuracy and faithfulness. 
Coughing, sighing, crying, laughing, sobbing, sneezing, yawning, snoring, singing, and talking are all

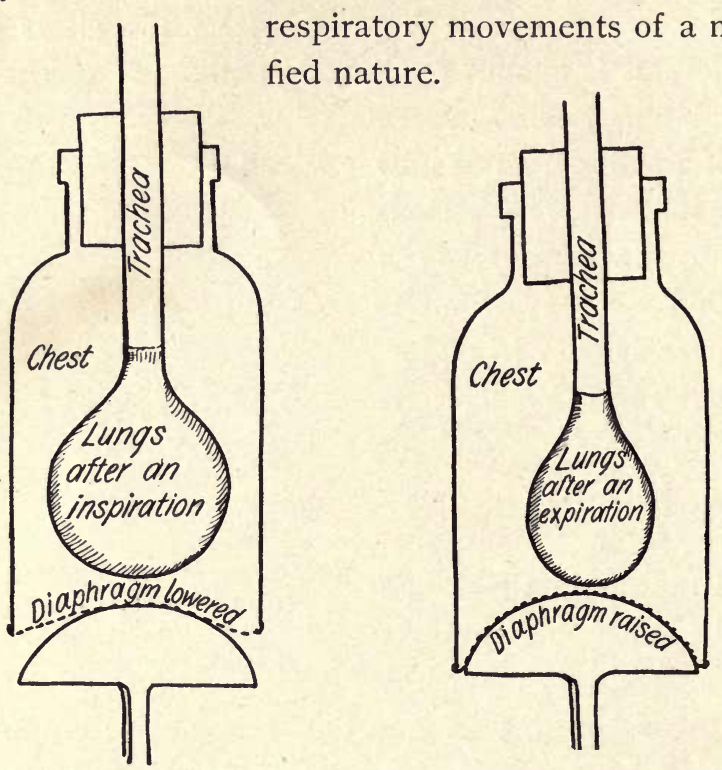

FIG. 23. - Showing how the movement of the diaphragm changes the capacity of the lungs (Zuppke).

Cut off the bottom from a bottle. Tie on a piece of dentist's rubber for a bottom and attach a small elastic bag to a piece of glass tubing that extends through a well-fitting cork, as shown in the figure. The bag represents the lungs; the glass tubing the windpipe; the bottle the chest; the dentist's rubber the diaphragm. When the diaphragm is pushed up, the capacity diminishes and the rubber bag collapses. Explain. Compare with the action of the lungs.

51. Capacity of the Lungs. - It is not possible to determine accurately the capacity of the lungs. By means of a spirometer it is easy to measure the amount of air inhaled and exhaled in ordinary quiet breathing. 
This is about thirty cubic inches and is called the tidal air.

We can also measure the amount of air that we can force out by the most violent effort after an ordinary expiration. This is about one hundred cubic inches and is known as the reserve, or supplemental air. After an ordinary inspiration we can inhale about one hundred

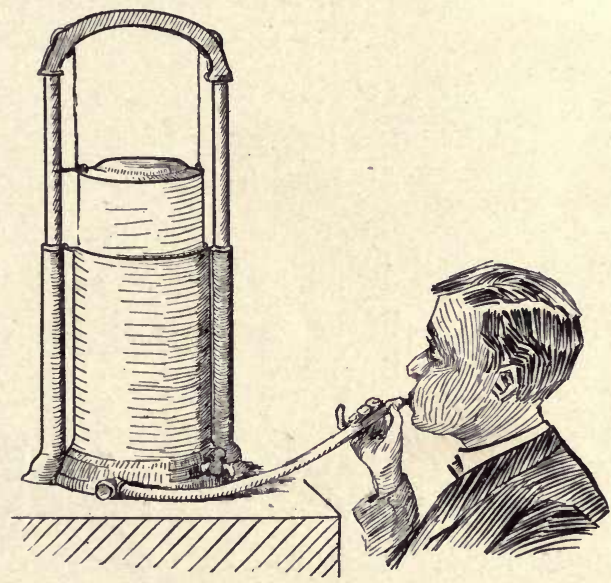

FIG. 24. - Testing the lungs on the spirometer (Zuppke).

cubic inches more. This we call the complemental air. Thus after a forced inspiration we can exhale the complemental, the tidal, and the supplemental air, amounting in all to about two hundred and thirty cubic inches. This is called the vital capacity, or, simply, the lung capacity. But after a forced expiration there still remains in the lungs about one hundred cubic inches which cannot be expelled by any possible means. This 


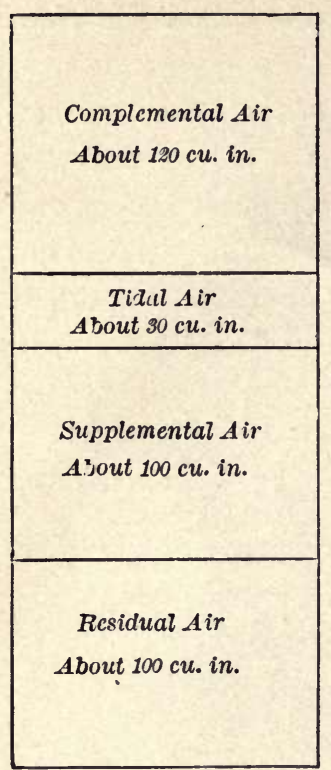

FIG. 25. - Showing lung capacity.

is called the residual air. The total lung capacity is about three hundred and thirty cubic inches for an average adult.

The figure to the left shows in a clear way the lung capacity and will help you to remember it.

52. How Air gets into the Blood. - We have just learned how air gets into the lungs and how much the lungs can hold. Let us now see how the air gets from the lungs in to the blood, and how the carbon dioxid and other wastes formed in the cells of the tissues get from the blood into the air sacs of the lungs. The air sacs are exceedingly thin-walled, spherical pouches. On the outer surface of these thin sacs are very small, delicate blood capillaries so closely packed together that they really form a little film of blood covering the whole outer surface of the sacs. This film, if spread out, would have an area of over fifteen hundred square feet. Large surfaces of blood and air are thus brought close together.

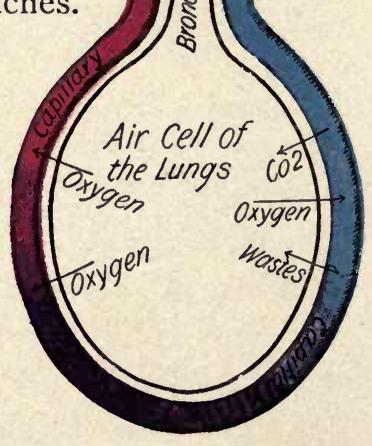

FIG. 26. - Showing the relation of capillaries to air cells in the lungs (Zuppke). 
It is a well-known fact that gases, liquids, and even solids that are perfectly dissolved can pass through delicate, living membranes. That is just what happens in the lungs. The oxygen passes through the walls of the air sacs and capillaries and enters the blood, where it is picked up by the red corpuscles, which then carry it to the tissues all over the body. The carbon dioxid and other wastes that are found in

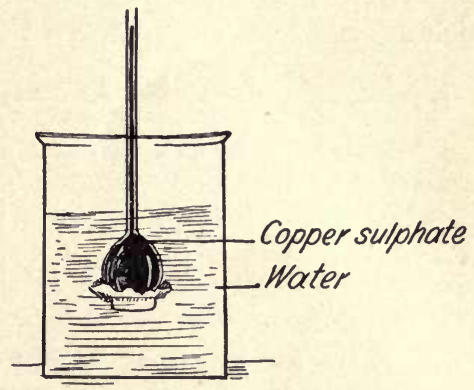

FIG. 27. - Showing osmosis (Zuppke).

the blood enter the air sacs of the lungs in a very similar way and are exhaled. This exchange of substances through a membrane is called osmosis.

I. Take a fresh hen's egg and remove the shell from the larger end so as to expose the delicate membrane beneath. Immerse the - egg, large end up, in a glass of water and set it aside for a few hours. The water will slowly pass through the delicate membrane, causing it to bulge out. The water soaks through the thin animal membrane just as the gases do in the air sacs of the lungs.

2. Tie a piece of bladder tightly over the bottom of a small bottle from which the bottom 'has been removed. Fill the bottle with a strong solution of copper sulphate. Fit a cork with a piece of glass tubing to resemble the thistle tube shown in the figure. Immerse the bottle in a glass of water. The next day the water will have risen in the glass tube, and some of the copper sulphate will be found in the glass, showing that there has been an interchange of substances through the membrane. An Argand lamp chimney may be used instead of the bottle. Alum, sugar, or common salt may be used instead of copper sulphate. 
53. Changes in the Air. - The air we inhale is a mixture of oxygen, nitrogen, carbon dioxid, argon, and more or less moisture. As it comes from the lungs the same things are found in it, but their proportion has been very much changed, as is shown by the following table:-

\begin{tabular}{|c|c|c|c|c|c|}
\hline & Nitrogen & OXYGEN & $\begin{array}{c}\text { CARBON } \\
\text { DIOXID }\end{array}$ & $\begin{array}{l}\text { ORGANIC } \\
\text { MATTER }\end{array}$ & $\begin{array}{l}\text { WATERY } \\
\text { VAPOR }\end{array}$ \\
\hline Inhaled air & 79 & $2 \mathrm{I}$ & .04 & none & variable \\
\hline Exhaled air & 79 & I6 & 4.0 & a little & saturated \\
\hline
\end{tabular}

I. The air has lost oxygen. The cells all over the body consume oxygen in performing their various functions. Oxygen is a very important element that easily combines with many substances.

2. The air has gained a large amount of carbon dioxid. When the foods are oxidized in the cells to furnish heat and energy, a large quantity of carbon dioxid is formed, which is a waste and must be removed from the blood. There seems to be an exchange in the lungs, oxygen going into the blood and carbon dioxid leaving it.

3. Good fresh air is quite free from organic impurities. In the body a large amount of these wastes is constantly made and poured into the blood. These wastes are removed in part through the lungs. The characteristic odor of exhaled air is due to this decaying animal matter.

4. The amount of watery vapor in the inhaled air varies from time to time, depending upon the amount of 
moisture in the atmosphere. The exhaled air is always saturated, i.e. it has all the moisture it can possibly hold at that temperature.

5. The temperature of the air we breathe varies with the time of day and season. The air as it passes from the lungs has the temperature of the body, about ninetyeight degrees $\left(98^{\circ} \mathrm{F}\right.$.).

Hence we are constantly taking from the air oxygen and giving in exchange carbon dioxid and poisonous organic substances. It is the presence of this organic waste that makes it so dangerous to rebreathe the same air and makes ventilation so important.

I. Get a few small pieces of unslacked lime and put them into a fruit jar. Fill the jar with water, and set it away for a day or two. When the lime has all settled to the bottom, carefully pour off the clear water into another bottle and label it limewater.

2. Exhale air into the limewater and observe how milky the limewater becomes.

3. Exhale on a dry, clean mirror, and notice how the moisture collects on it. Have you ever noticed how the moisture exhaled from the lungs condenses on cold frosty mornings ?

4. Exhale on a thermometer bulb for a few minutes and notice that the mercury rises.

54. Rate of Breathing. - The number of times we breathe per minute varies with age, position of body, and exercise. The rate at different ages is about as follows : -

Infants soon after birth . . . . . . . 44

Child from I to 5 years . . . . . . . 26

Youth, 15 to 20 years . . . . . . . 20

Early manhood, 20 to 25 years . . . . . 19

Manhood, 25 to 30 years . . . . . . . 16

Middle life to old age . . . . . . 18 
Count the number of respirations per minute of different persons without letting them know what you are doing. How does the number vary with age? Exercise? Position of body?

The average rate for an adult when reclining is about thirteen, sitting, about nineteen, and standing, about twenty-two.

The breathing is increased very much when we run or do any hard physical work. Why? We know that when we exercise vigorously the muscle cells work harder. They need more food and oxygen to furnish the energy necessary to keep up the exercise. But you will remember that oxidation manufactures carbon dioxid. When we run, all the large muscles used pour this carbon dioxid and other wastes into the blood very fast. Now, if we did not breathe faster to remove these wastes, they would accumulate in the blood and cause disease and death.

But how do the muscles of the chest know that they should work harder to remove the animal wastes? That is a hard question to answer in a simple way. The wastes are, of course, washed along in the blood stream and so reach all parts of the body. When they come in contact with a group of nerve cells at the upper end of the spinal cord they act like a poison to them. The nerve cells send a command to the muscles of the chest by means of several nerves and tell them to contract faster, so that these wastes may not accumulate in the body. Thus we see that the rate of breathing is carefully regulated and controlled by a special group of nerve cells. 


\section{SUMMARY OF THE MAIN POINTS}

I. The oxygen of the air is necessary to cause the slow combustion or oxidation of the foods in the cells of the body.

2. The air reaches the lungs through a number of organs which form the air passages. They are all composed of plates and rings of cartilage held together by connective tissue, and lined with a mucous membrane.

3. The nasal passages are large, irregular, winding passages in the nose that warm the air, remove particles of dust and dirt, and contain the nerves of smell. We should breathe through the nose rather than through the mouth.

4. The pharynx is a funnel-shaped organ back of the nose and mouth from which there are seven different openings.

5. The larynx is just below the back part of the mouth and serves as an air passage and as the organ of voice.

6. The trachea is about four and one half inches long, extending from the larynx to the two bronchi. It is usually called the windpipe.

7. The bronchial tubes extend to the lungs, where they get smaller and lighter until they terminate in very small, thinwalled air sacs.

8. The lungs are the central organs of respiration. They are pinkish, spongy, elastic masses completely filling the chest. Each lung is covered with a closed sac called the pleura.

9. The diaphragm, intercostal muscles, and the muscles of the neck work together and enlarge the chest at regular intervals.

10. The atmospheric pressure and elasticity of the lungs make the lungs follow the chest in its movements.

I I. The lungs of the average adult hold about three hundred and thirty cubic inches of air. At each ordinary inspiration about thirty cubic inches of air is inhaled. 
I2. The exchange of gases in the lungs through the walls of the capillaries and air sacs is called osmotic action.

I3. Breathing changes the temperature and composition of the air. Rebreathing the same air is dangerous because it contains too little oxygen, too much carbon dioxid and organic poisons.

I4. The average rate of breathing per minute is thirteen when lying down, nineteen sitting, and twenty-two standing.

15. The presence of carbon dioxid and organic wastes in the blood irritates the nerve cells which regulate the muscular movements in breathing. 


\section{CHAPTER VI \\ HYGIENE OF RESPIRATION}

55. Disease Germs in the Air. - Along with the air there may be inhaled fine dust, injurious gases, and many kinds of disease germs and other impurities floating about in the atmosphere. Some of these do little or no harm, but others irritate the delicate mucous membrane and even cause disease. Among the maladies that afflict the air passages or enter the body through them are the following: colds, catarrh, adenoid growths, bronchitis, asthma, pneumonia, diphtheria, consumption, mumps, measles, scarlet fever, chicken pox, and smallpox.

Many infectious and contagious diseases are due to little germs that are inhaled and then attack the mucous membrane directly or enter the blood and are carried to the organs in which they can best do their deadly work. We call these "air-borne" diseases. Most of these maladies could be avoided if all people realized the value of pure air and understood the nature and causes of the more common diseases of this kind.

56. Diseases of the Air Passages. - No organs of the body are more subject to disease than the air passages. The delicate mucous membrane is well supplied with 
small blood vessels that easily become gorged with blood (congested) when any part of the body is exposed to cold. The phlegm that gathers in these organs when one has an ordinary cold seems to be a natural salve to protect the inflamed membrane against irritating foreign substances.

Catarrh is an inflammation of the nasal passages that continues for a long time and may become the cause of ulcers. A "cold in the head" is due to an inflammation of the mucous membrane of the pharynx and the tubes that extend to the ears and eyes. When the congestion is confined to the larynx, as when a cold makes it difficult or impossible to talk, we call it laryngitis. A similar inflammation of the trachea and bronchial tubes is known as bronchitis. The little muscle fibers of the bronchioles that lead to the air sacs may be-

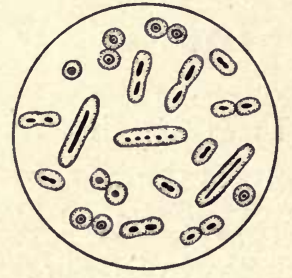

FIG. 28. - Bacteria of pneumonia (Pratt). come irritated and contract so as to prevent the air from entering the sacs as freely as it should; such a condition of difficult breathing is sometimes called asthma.

The inflammation may not remain in the air passages only but extend down into the air sacs themselves. They may become so filled that breathing becomes painful and difficult. This condition may bring on the disease known as pneumonia.

All of the diseases mentioned are not mere congestions and inflammations. They are due to attacks of certain germs. The congestion affords an excellent 
condition for these little germs to gain a foothold. The air in temperate climates always contains large numbers of these germs, which we inhale freely every day, but which are harmless as long as the body does not offer them a favorable soil in which to grow and multiply.

The most dreaded and fatal of all diseases known is consumption. From ten to twenty per cent of all deaths in temperate regions are due to this terrible disease of the lungs. One person in every seven falls a

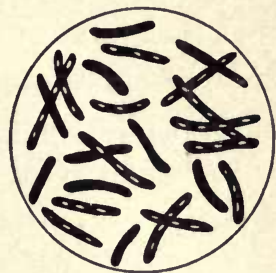

FIG. 29. - Bacteria of consumption (Pratt). victim to the "great white plague." In the state of Massachusetts, during a period of twenty years, statis-

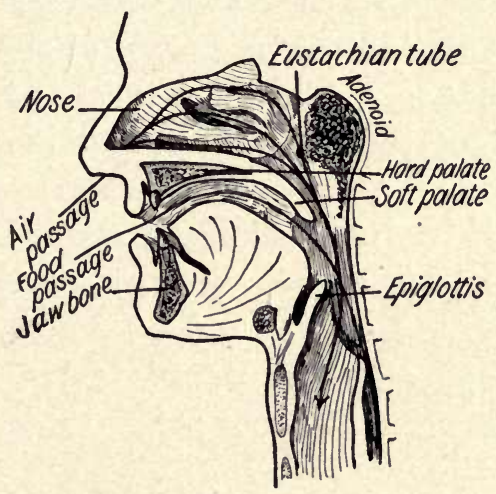

FIG. 30. - Showing the location of adenoid growths (Zuppke). tics show that fourteen per cent of all deaths reported were due to consumption, and that the mortality was greatest between the ages of twenty and thirty years. The germs reach the lungs and there multiply so rapidly that the parts affected soon become useless.

Adenoid groweths occur very often in the back part of the nose and in the pharynx of young, rapidly growing children. They obstruct the nasal passages and make 
nose-breathing impossible. Air must then be taken through the mouth. If these growths are not removed, they may become so large as to fill the upper part of the pharynx and impair the hearing by closing the tubes that lead to the ears. All who find it difficult to inhale enough air through the nasal passages should consult a skillful physician.

57. Sources of Impure Air. - What may make the atmosphere impure and dangerous to breathe? On the seashore, in the country, and on mountains the air is quite fresh and invigorating, but there are many ways of polluting the air in our homes and in the cities. Let us see what some of them are.

I. Burning. - Whenever wood, coal, oil, coal gas, etc., are burned, a large amount of impurity is produced, some of which passes off into the air as carbon dioxid and other gaseous substances. All smokestacks and chimneys pour volumes of such impurities into the atmosphere.

2. Decaying. - All animaland vegetable matter allowed to decay pollutes the atmosphere with its poisonous matter for a long distance.

3. Breathing. - Man and all other animals exhale carbon dioxid and organic wastes that are poisonous to rebreathe.

4. Sewer Gas. - If the plumber has not done his work well, air from the sewer escapes in the house. Such air contains very dangerous gaseous compounds and various disease germs that are thrown into the air by the bubbles which burst on the surface of the putrefying sewage. 
5. Factories. - The manufacture of ammonia, hydrochloric acid, and other things by chemical works, and the making of glue, candles, leather, and bricks pollute the air of our cities with dangerous, nauseous products.

6. Old Wells and Close Cellars. - The carbon dioxid, marsh gas, and organic impurities that form at the bottom of old wells and in close, dark, and dirty cellars are responsible for many diseases.

7. Marshes and Stagnant Pools. - The formation of organic matter and marsh gas by the slow decay of vegetables in damp, swampy places makes them sources of contamination. Malarial fevers are due to germs that abound in such localities.

Many other causes might be named which tend to make the air unfit to breathe by robbing it of oxygen, by pouring into it useless and dangerous gases, and by filling it with disease-producing germs (bacteria). It would seem that with all these sources of pollution the air would become utterly unfit for breathing. We shall see why it does not.

I. Burn a candle in a wide-mouthed bottle. When it goes out add a little clear limewater and shake thoroughly. What do you infer?

2. In the same way try the burning of paper, wood, etc.

3. Test the gas that escapes from fermenting liquids. See section 37 .

58. The Air Purified. - There are several natural means by which the air tends to purify itself.

I. Diffusion. - All of the gases of the atmosphere are kept in constant motion and so tend to become equally 
mixed throughout the entire world over land and sea. Although such a uniform distribution is never reached, yet this means prevents the air from becoming entirely unfit for breathing in certain places. If it were not for the principle of diffusion of gases, people could not live in large cities.

2. Winds. - All the time there are currents of air moving from place to place which not only aid in the mixing of gases but move the entire body of air and tend to distribute the temperature equally.

3. Rain.-Gases, dust, and other impurities are taken up by the raindrops and washed out of the air. Snow in the winter has a similar purifying effect. The moisture and oxygen of the air change many impurities of the atmosphere by oxidizing them to harmless products.

4. Vegetation. - Plants take carbon dioxid from the air, and water from the ground as their food. The green cells of the leaves change these two substances into starch by the aid of the heat which the sun furnishes. When the plant puts carbon dioxid and water together to form starch, it has quite a large amount of oxygen which it does not need, and this it gives back to the air. The plant inhales carbon dioxid and exhales oxygen. In animals the very opposite occurs. The plant purifies the air for us, and we purify the air for the plant.

59. Ventilation. - Everything we eat, drink, and wear should come in contact with life-giving, germ-destroying oxygen and sunshine. How pale and sickly a plant looks that is kept in a dark, close room! The rooms in 
which we work and sleep as well as the clothing we wear should be thoroughly ventilated.

The subject of ventilation would require no attention if we lived in the open air all the time. But how can we get enough fresh outdoor air to breathe in our schoolhouses and homes? This is really not a simple question to answer, although one of great importance. At each breath we exhale about thirty cubic inches of air or about five hundred cubic inches per minute. We should not rebreathe the air exhaled, for it contains too much injurious matter; but after it has mixed with about one hundred times its volume of fresh air it is again safe to inhale. A person requires then about thirty cubic feet of air per minute. For forty persons in a schoolroom we should take in from the outside at least one thousand two hundred cubic feet of fresh air per minute and allow an equal volume of foul air to escape.

Careful estimates show that there should be an allowance of at least six hundred cubic feet of space for each person in the room.

The matter of ventilation is one of prime importance and should receive the thoughtful attention of those who construct private and public buildings. Schoolhouses, churches, public halls, and theaters should be provided with ventilating flues as well as with doors and windows.

Fill a pint fruit jar with water and enter a room. Pour out the water and the air of the room will enter to fill the fruit jar. Now pour two tablespoonfuls of clear limewater into the fruit jar, cover 
it tightly with the hand and shake thoroughly. If the limewater turns milky the ventilation needs immediate attention. If the limewater is not changed at all, the amount of carbon dioxid in the air is comparatively small.

60. Method of Ventilation. - If the room is heated with a hot-air furnace, the entrance of fresh air will take

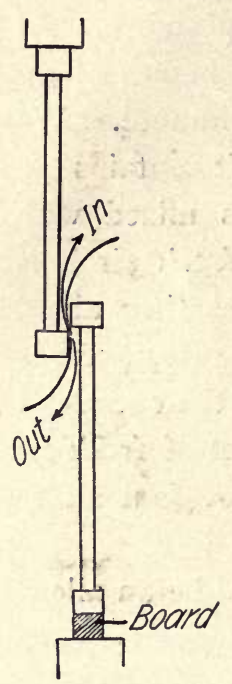

FIG. 3r. - Window ventilation (Zuppke). care of itself. The pure air from outside enters the furnace jacket, where it is warmed, and then it passes up into the room. Care must be taken to keep the foul-air flues open, so as to permit the bad air to escape. This is one of the most satisfactory means of heating and ventilating at the same time.

If the room is heated with a stove, you must provide for a similar circulation through the room. Fresh air must come in from outside, pass through the room, and escape as fast as it becomes unfit for breathing. How can this be done? Open windows are dangerous, for it is impossible to avoid drafts in some part of the room in very cold weather. A simple method, if the room is large, is to fit a board tightly under the lower sash of every window. It should be as wide as the window and just high enough to permit good circulation between the two sashes, as shown in the figure above.

Another method is to lower the upper sash and provide some means for throwing the fresh air upward as 
it enters; or the lower sash may be raised and means provided for directing the entering air upward. These are inexpensive but quite effective means of ventilation.

61. Chest Freedom. - The air we, breathe may be perfectly pure and fresh, and yet the cells of the body may suffer because they do not receive enough oxygen. You remember that the chest acts like a pump which

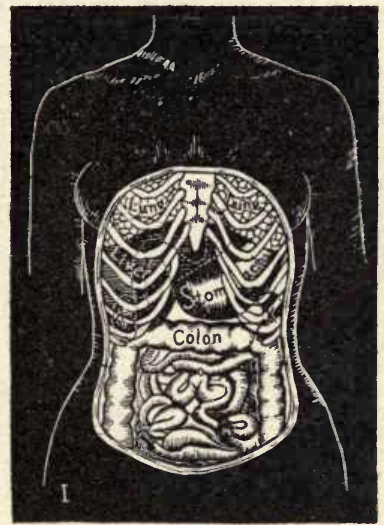

Natural.

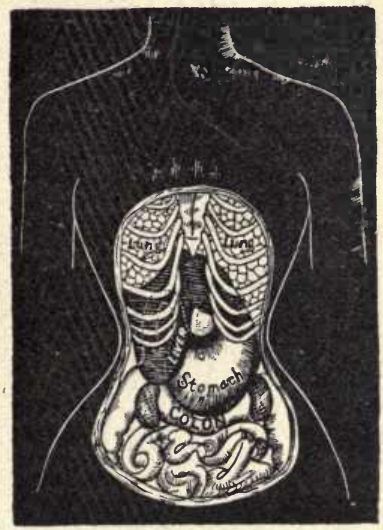

Deformed.

FIG. 32. - Showing a natural and a deformed chest. (From Kellogg's "Outline Studies.")

at every natural inspiration pumps about thirty cubic inches of air into the lungs. Now, if the chest does not do its work as it should, an abundance of good wholesome air may be present, and yet only a small amount get into the lungs. How may the work of the chest be hampered? In the first place, by clothing that is improperly made or that does not fit. Clothing may be so tight about the waist that the chest cannot enlarge 
freely. A child may be so accustomed to improper clothing that slowly and gradually his chest becomes permanently deformed.

Careless positions in standing and sitting may cause the chest to become so deformed as to make natural breathing impossible. When a person becomes roundshouldered and flat-chested the upper part of the thorax cannot enlarge as it should. The result is that the apex

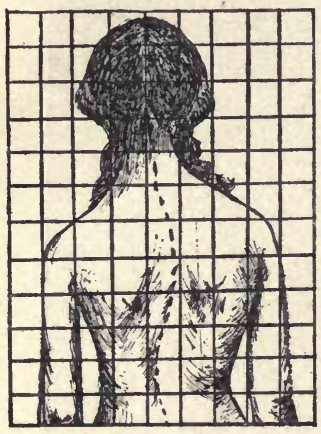

Right curve.

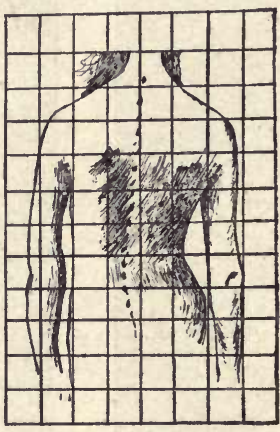

Left curve.

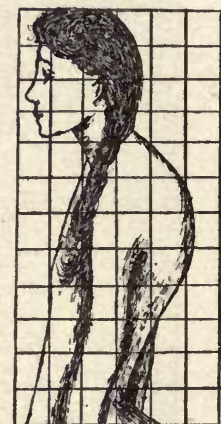

Round shoulders.

FIG. 33.- Showing deformed chests. (Drawn by H. Meyer from photographs.)

of each lung remains unused. A pupil who sits day after day at a desk that is either too high or too low soon finds that one shoulder is higher than the other and that the spine is curved to the right or to the left. Under any of these conditions the chest cannot expand as it should, and lung diseases are easily contracted.

Sometimes persons are born with small or deformed chests and are more likely to contract the diseases which attack the lungs. Consumption is probably seldom if ever inherited, although weak and imperfectly 
developed chests frequently are. Weak chests may be strengthened by regularly taking proper respiratory gymnastics.

62. Proper Breathing. - The chest may be enlarged up and down by the action of the diaphragm, from front to back by the action of certain muscles of the neck, and from side to side by the use of the muscles of the ribs. Natural breathing exists only when all of these muscles work as they should and cause the chest to enlarge in all of these directions. Tight clothing, bad habits in standing and sitting, and improper school desks work together to deform the chest and decrease its capacity for breathing. Proper breathing makes use of all parts of the lungs. Among civilized people women use the upper part of the lungs chiefly, while men breathe mostly with the lower part; among savages this difference does not exist.

63. Alcohol. - The nerves controlling the movements of the chest and the size of the blood vessels are easily paralyzed by alcohol. As a result the delicate capillaries of the lungs dilate too much, causing a congestion and inflammation, which tends to diminish the capacity of each little air sac and thus reduce the total lung capacity. A still more serious effect of the habitual use of alcoholic beverages is that alcohol gradually diminishes the power of the capillaries to dilate; they become less and less responsive to the ordinary stimulation of the nerves. We can now understand why persons who use alcoholic beverages are especially liable to take pneumonia and other diseases of the lungs. 


\section{SUMMARY OF THE MAIN POINTS}

I. The air always contains bacteria which get into the air passages and lungs and may cause some of the most fatal diseases known.

2. Exposure to drafts and colds may cause congestion in the capillaries of the mucous membrane. Such congestions are favorable for the growth and development of harmful bacteria.

3. Among the diseases of the air passages are colds, influenza, catarrh, bronchitis, adenoid growths, diphtheria, asthma, pneumonia, and consumption.

4. The atmosphere contains impurities that come from various sources, as combustion, decay, respiration, sewage, factories, old wells and close cellars, marshes, stagnant pools, etc.

5. There are many natural agencies at work to purify the atmosphere, as diffusion, winds, rain and snow, growth of plants, etc.

6. The exhaled air contains impurities enough to pollute several times its volume of pure air. Therefore, it is necessary for each person in a room to have about thirty cubic feet of fresh air to breathe every minute.

7. The air we breathe, the food we eat, the water we drink, the clothes we wear, and the bed we sleep in, all need careful ventilation.

8. Buildings in which many persons work and live together, as churches, factories, theaters, and schoolhouses, need to have special provisions for the entrance of fresh air and for the exit of foul air.

9. The chest should be free to expand in all directions, thus enabling us to use the entire lung at each inspiration. Proper breathing makes use of all parts of the lungs constantly. 
Io. Clothing tight about the waist, careless postures of the body, improper school desks, and a naturally small and weak chest are conditions that make it difficult to supply the blood with a sufficient amount of oxygen.

II. Alcohol tends to reduce the breathing capacity of the lungs by causing the capillaries of the lungs to dilate, thus diminishing the size of the air sacs. It also predisposes the tissues of the lungs to certain diseases. 


\section{CHAPTER VII}

\section{DIGESTION}

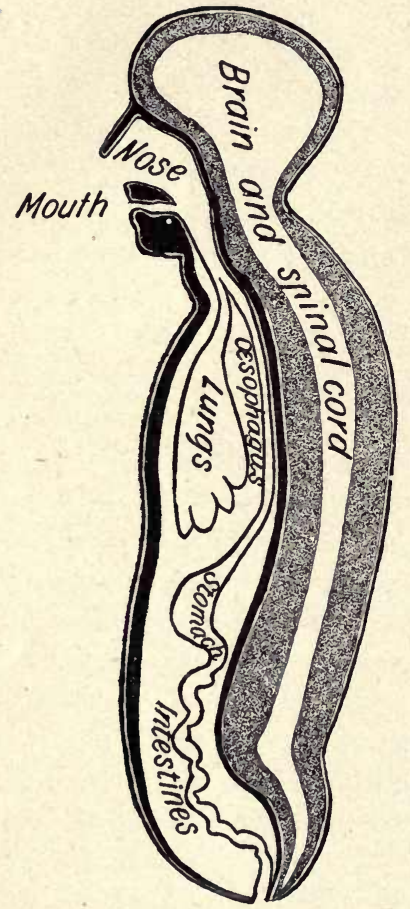

FIG. 34. - The plan of the human body. (From Mivart, by Gunnison.)
64. Review. - We have learned that each cell of the human body must have foods to keep it repaired and to give it heat and energy. The materials which the cells can use are proteids, carbohydrates, fats, salts, water, and oxygen. We have seen that oxygen enters the blood through the lungs and that it is then ready to be carried to all the tissues of the body. We must now learn how water and solid foods get into the blood. The oxygen of the air enters the blood without being changed in any way, for the oxygen in the blood is just like the oxygen in the atmosphere. The water also mixes with the blood, un- 
changed. But potatoes, beefsteak, eggs, bread, and, in fact, all the solid food materials must be changed very much before they can enter the blood and be of value to nourish the cells. We shall now find out how the solid foods are changed into blood.

65. The Alimentary Canal. - The air reaches the blood through a series of organs called air passages, and the other foods enter the body by means of a series of organs which together constitute the alimentary canal, or digestive tract. The alimen-

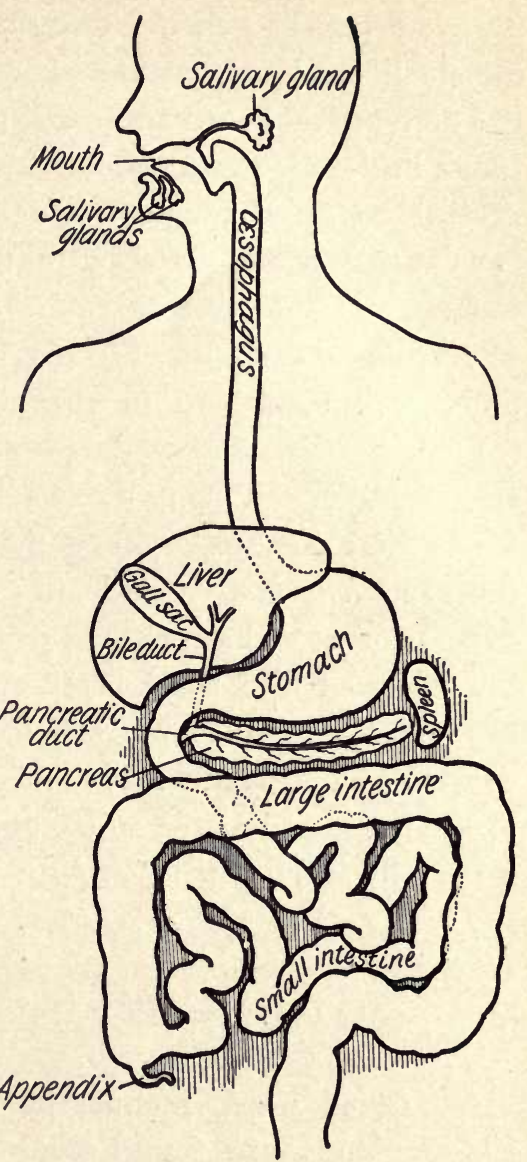

FIG. 35. - The alimentary canal (Zuppke).

tary canal is a long tube that extends from the mouth to the end of the large intestine. It is a canal through the body, with enlargements at certain places. This tube consists of the mouth with the teeth and tongue, 
the pharynx, the gullet or œsophagus, the stomach, and the small and large intestines.

There are no bones and cartilages in this tube as are found in the air passages, but its walls are made up of several coats that extend through its entire length. (I) On the outside we find a thin, serous covering whose function is quite like that of the pleura of the lungs. It serves to keep the surfaces that move upon each other well oiled and in that way prevents friction. (2) The next is a heavy, muscular coat consisting of two separate layers all along the canal, except in the stomach where there are three. The outer layer has muscle fibers that run lengthwise, while in the inner they are all circular or extend around the canal, and in the stomach the fibers of the third layer run obliquely. (3) The third is a very thick mucous membrane that lines the entire digestive tract. This canal extends from the mouth to the lower end of the spine, but it is so coiled up that it is really about thirty feet long.

Ask your butcher to get a pig's stomach for you. In size, shape, and general structure it is quite like man's. Study the various coats as carefully as you can. Notice the velvety mucous membrane on the inside.

66. Glands. - A number of very important organs called glands are found along the alimentary canal. These glands pour certain fluids into the canal, which aid in changing solid foods into blood. Such organs are the salivary glands of the mouth, the gastric glands of the stomach, the intestinal glands, the pancreas, and the liver. 
To increase the surface that can produce such fluids, the mucous membrane may become folded up in various ways, giving rise to the different kinds of glands. While the glands differ much in their outward appearance and size, all have the same general structure and all take material from the blood to manufacture important body fluids which perform special functions.

The important thing to remember is that a gland is merely a thick mucous membrane, either straight or folded in some way, containing many blood vessels and nerves, and having the power to

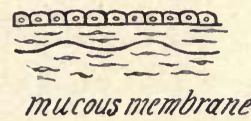

mucous membrane
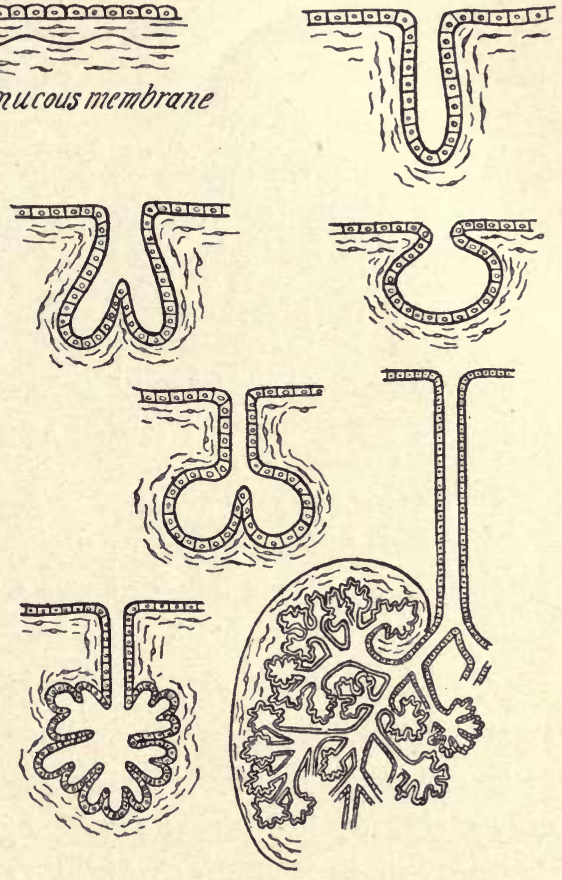

FIG. 36. - Showing the structure of glands. Modified from Huxley. (Zinns.) separate from the blood important fuids called secretions.

67. The Mouth. - The mouth is the first organ to receive the food. It is a rather irregular-shaped cavity extending from the lips in front to the soft palate be- 
hind. On the sides it is bounded by the cheeks, above by the hard palate, and below by the muscles and connective tissues that form the floor. It contains the teeth and the tongue, two very important organs of digestion, and receives the saliva through a number of small ducts leading from the three pairs of salivary glands. The tonsils are two olive-shaped organs, one on either side, at the back part of the mouth. They produce a fluid that probably helps in swallowing.

In the mouth the food is cut and ground up by the teeth, mixed with saliva, moved about by the tongue, and finally pushed back into the pharynx.

Study carefully your own mouth as to shape, size, and organs, as teeth, tongue, tonsils, and palate. This may easily be done with the aid of a small mirror.

68. The Teeth. - At birth a child has no teeth. The first set begins to appear at the age of from six to ten months and to disappear at about the sixth or eighth year. These are called milk teeth. This set consists of twenty teeth - ten in each jaze. The four flat, cutting teeth are called incisors; the one sharp, tearing tooth on either side of the incisors is the canine; and the two double grinding teeth back of each canine are the molars.

Is it not strange that this set should disappear in youth and another take its place? Yes, but we shall understand why when we learn that a tooth does not grow larger after it is once fully cut. Our hands, feet, and heads grow, but our teeth do not. A bone grows 
and when broken has the power to repair itself, but a tooth does not. The milk teeth are too soft and delicate to do the work which the teeth must do later in life.

The second or permanent set contains thirty-two teeth when complete, but the last four, known as the wisdom teeth, appear late, usually between the ages of seventeen and twenty-five years. In addition

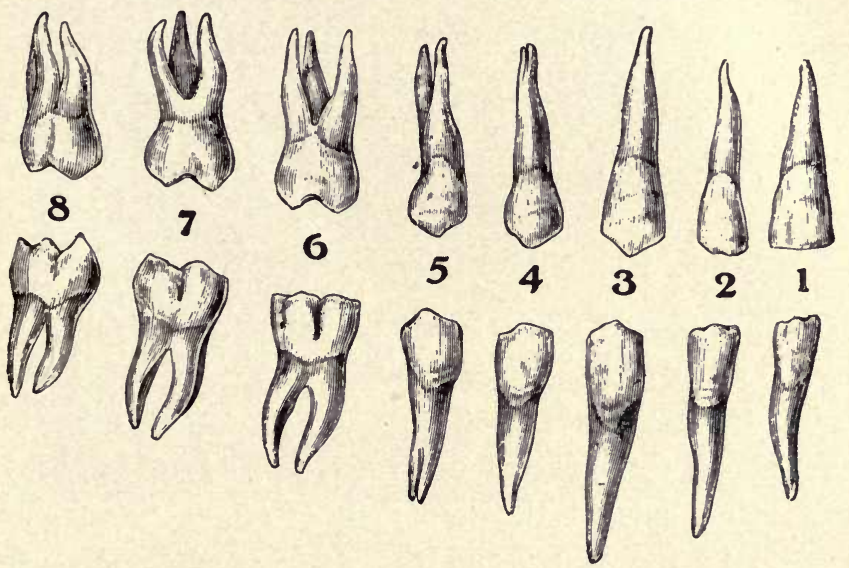

Fig. 37. - Showing permanent teeth. (From Heitzmann's "Anatomy.") $\mathrm{I}, 2$, incisors; 3 , canine; 4,5 , bicuspids ; $6,7,8$, molars.

to the twenty of the first set, the second has three more molars on either side in each jaw, so that an adult has four incisors, two canines, four premolars or bicuspids, and six molars in each jaw. These are all larger, stronger, and more durable than the milk teeth.

Get from a dentist a handful of teeth. Ask him to saw one crosswise and another lengthwise to show the general structure. Make drawings and describe one of each class. 


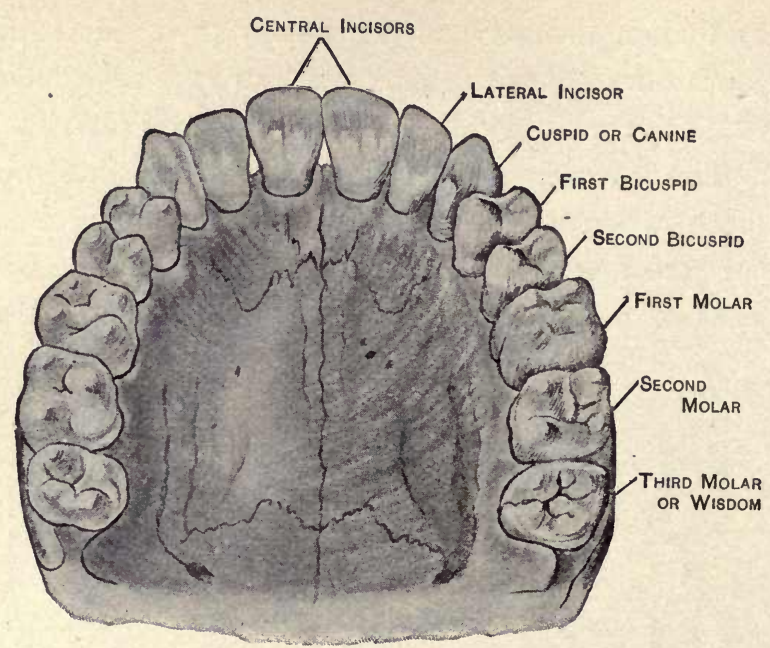

FIG. 38. - Upper jaw, showing permanent teeth in place. (From Hopkins' "Care of the Teeth." D. Appleton \& Co.)

69. Structure of the Teeth. - The external appearance shows three parts : the crown, or the visible portion projecting beyond the gum; the root, or the portion hidden in the gum; and the neck, or narrow border between the crown and the root.

A tooth sawed through the middle from crown to. root shows that it is made of four different things. The main part of the framework of a tooth is a bonelike substance called dentine. The dentine of the root is covered with cement and that of the crown with a very hard, highly polished substance, called enamel. Enamel is the hardest substance in the body; it serves to protect the tooth. There are no blood vessels and nerves in the enamel, and for that reason a tooth cannot 
repair itself. We should be very careful not to crack or in any way injure the enamel.

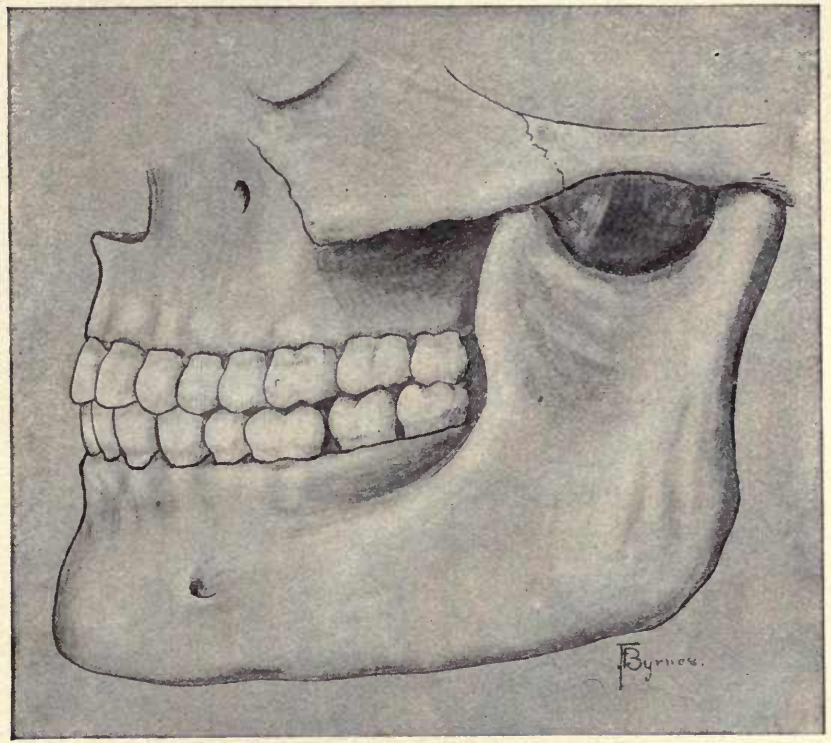

FIG. 39. - Showing how the upper and lower teeth fit together. (From Hopkins' "Care of the Teeth." D. Appleton \& Co.)

There is a large space in the middle of the dentine, called the pulp cavity, that is filled with connective tissue, blood vessels, and nerves. At the very tip of the root we find a small opening, through which the blood vessels and nerves enter the tooth. It is by means of these vessels that the central por-

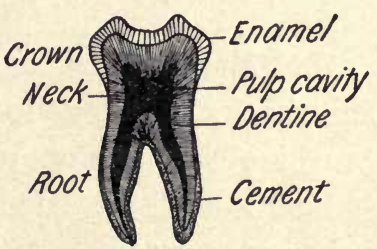

FIG. 40. - Showing the structure of a tooth (Zinns). 
tion is nourished. A dead tooth is one in which the dentist has taken out the nerve and blood vessels and has filled the root with something else.

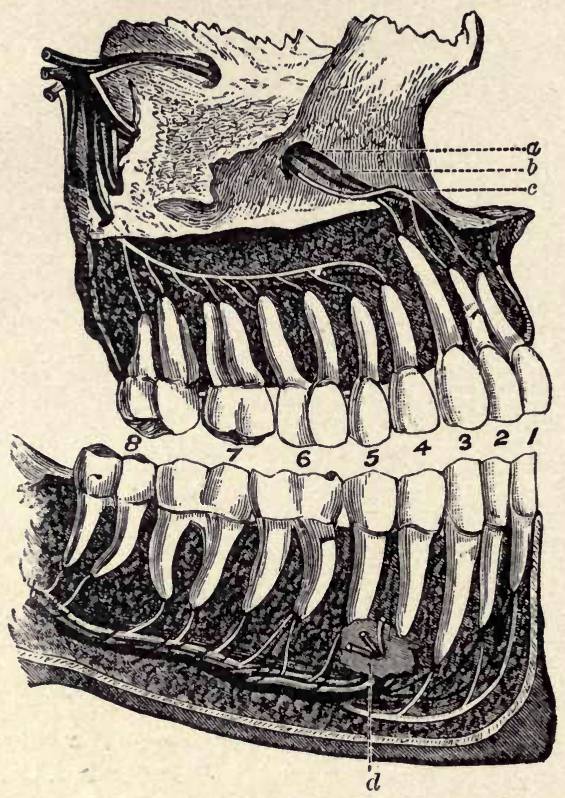

FIG. 4I. - Showing how the blood vessels and nerves reach the teeth. I, 2, incisors; 3 , canine; 4,5 , bicuspids; $6,7,8$, molars; $a$, vein; $b$, artery; $c$, nerve; $d$, vein, artery, and nerve. (From Johonnot and Bouton.)

70. Mouth Digestion. - The large, strong muscles of the cheeks enable us to use the teeth for biting, tearing, crushing, and grinding the solid foods. Cooking has helped to soften the foods, yet in order to dissolve them it is necessary to chew every mouthful thoroughly. It is said of W. E. Gladstone, the great English statesman, 
who lived to be a very old man and yet possessed the vigor of manhood to his very end, that he always chewed every mouthful thirty-three times.

The saliva, or spittle, is poured into the mouth while the food is being masticated and is well mixed with it. The saliva is very useful, as it keeps the mouth moist all the time, aids in swallowing, and begins the digestion of starchy foods. Now, if we chew well and eat slowly, the saliva has an opportunity to act on a large amount of starch.

The proteids and fats are not changed in the mouth except that they are broken up or ground into fine particles and so prepared for the other digestive fluids. Most of the salts and sugars are dissolved in the saliva and are then ready to enter the blood.

Where does the saliva come from? The three glands shown in the diagram manufacture it. They are the parotid, a little below and in front of the ears; the submaxillary, at the angles of the lower jaw; and the sublingual,

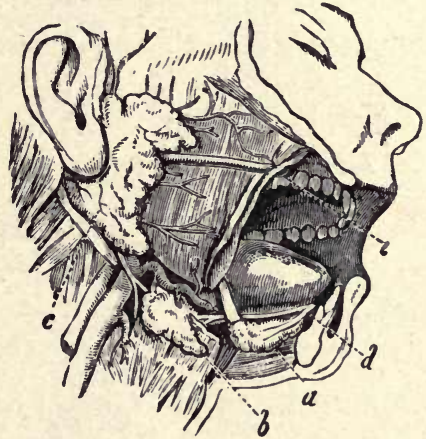

FIG. 42. - Showing salivary glands. (From Huxley.) $a$, sublingual, $b$, submaxillary glands with their ducts opening under the tongue at $d ; c$, parotid gland with its duct opening at $e$.

in the floor of the mouth. These glands pour three or four pints of saliva into the mouth daily. Chewing and talking cause the saliva to flow freely. Tasting, seeing, 
smelling, and even talking about foods makes "the mouth water," especially when one is hungry.

I. Put into a test tube or small bottle a little boiled starch, a little saliva, and about twice as much water. Shake it up well and heat it just a little (not over $100^{\circ} \mathrm{F}$.). After a few minutes add iodine and notice that the color is not blue, showing that there is no starch present. What has changed the starch?

2. Repeat the experiment, taking raw starch. What is the inference?

3. In place of iodine, add Fehling's solution, which may be obtained at a drug store, and boil it for a moment. The precipitation of copper shows that sugar is present. The starch has been changed to sugar.

71. Swallowing. - After the food has been thoroughly chewed and moistened with saliva it is ready

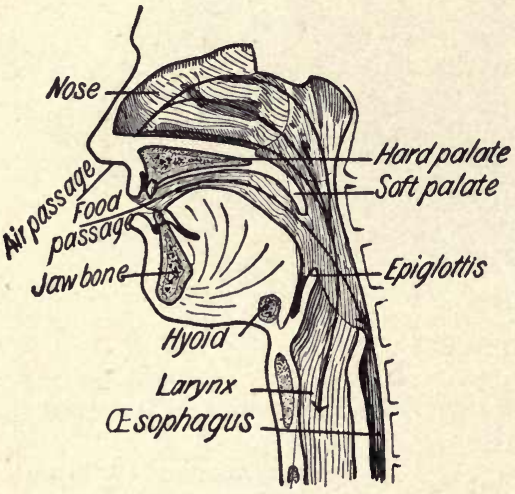

FIG. 43. - The beginning of the food and air passages (Zuppke). to go into the stomach. The movement through the pharynx and œsophagus into the stomach is called swallowing or deglutition. The food does not fall through this tube, because one can swallow lying down or even standing on his head. Did you ever watch a horse drinking from a pail on the ground? The water goes up into the stomach in this case.

The tongue presses up against the hard palate and 
pushes the food into the back part of the mouth; the soft palate rises to close the opening into the nose; the epiglottis closes the opening into the larynx and trachea; and the muscles of the back part of the mouth contract and push the food into the pharynx. The food is now in the pharynx, and there is but one opening by which it can leave. The mouth, nose, and larynx are all closed. The muscles of the pharynx contract and

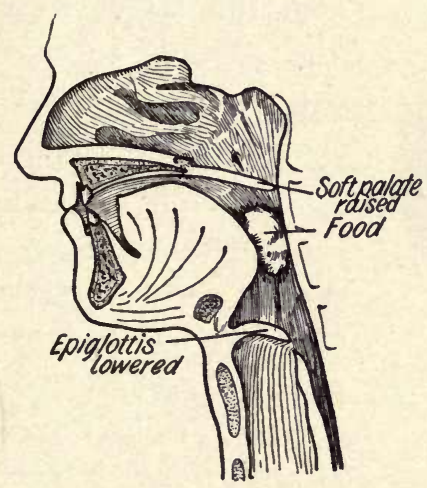

FIG. 44. - Food in the pharynx in swallowing (Zuppke).

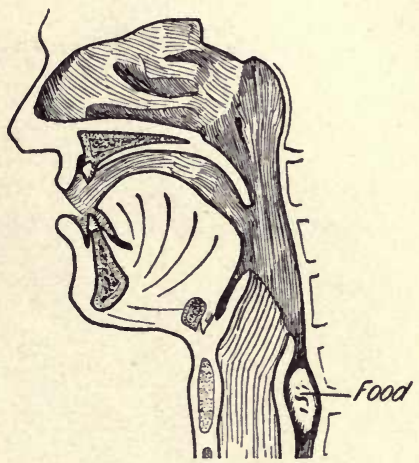

FIG. 45.-Food in the œsophagus on its way to the stomach (Zuppke).

crowd the food down into the osophagus. Sometimes it happens that a particle of food gets into the larynx and trachea, and it is only by violent coughing that it can be expelled.

The asophagus is a tube about nine inches long, extending from the pharynx to the stomach and is closed except while food is actually passing through it. By the action of its muscular fibers, which we have learned run both longitudinally and circularly, the foods are 
pushed along through the œesophagus into the stomach. A similar muscular action occurs in the other organs of the alimentary canal.

72. Stomach Digestion. - The stomach is the greatest enlargement of the alimentary canal, being about ten inches long and from four to six inches across and having a capacity of about four pints. It is located just

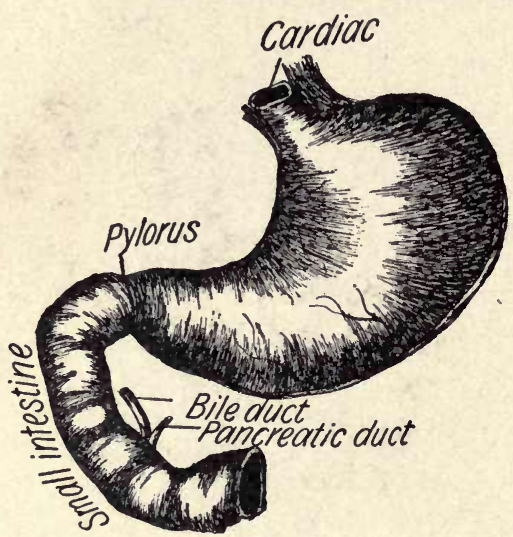

FIG. 46. - Outside of the stomach, front view. (From Heitzmann's "Anatomy." Becker.) below the diaphragm, with the larger end (the fundus) to the left side. It has an opening for the food from the oesophagus to enter, called the cardiac orifice, and one for the food to pass out into the intestines, called the pyloric orifice. These openings are carefully guarded by strong, circular muscles, so that after the food enters the stomach it cannot leave until it is thoroughly digested. Then the pylorus relaxes, and the mass slowly enters the intestines.

The stomach differs from the other organs of the digestive tube in that it has three layers of muscles instead of two; the longitudinal on the outside, the circular next, and the oblique or transverse on the inside. The mucous lining is quite thick because it is 
folded up to form pocket-like glands over the entire surface.

The millions of these little glands pour a fluid into the stomach, called gastric juice. This fluid is very important to digestion, as it contains an acid and a substance called pepsin, that together can digest proteids. It is estimated that from ten to truenty pints of gastric juice are made every twenty-four hours. As soon as the food enters the stomach the gastric juice begins to ooze from the mouths of these little glands, and the muscles commence to contract lengthwise, then crosswise and transversely. This vigorous churning motion, which is kept up for several hours after each full meal, so completely

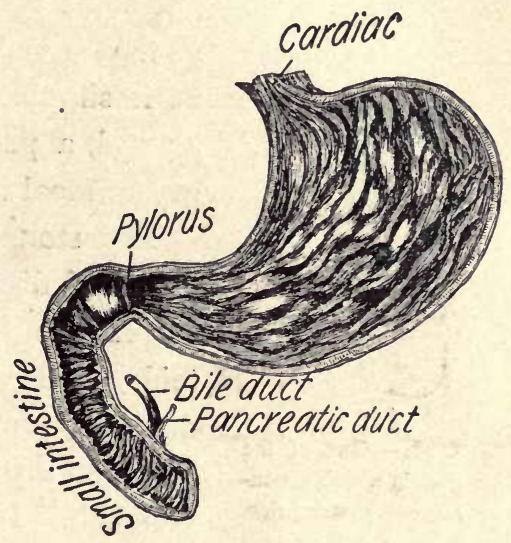
FIs. 47. - Inside of the stomach, front view. (From Heitzmann's "Anatomy." Becker.)

mixes the foods and gastric juice that the entire mass becomes acid and of a uniform, thick soupy consistency, having a grayish color. The proteids, like beefsteak, cheese, and eggs, are changed into peptones by the chemical action of the acid and the pepsin. The entire mass is then known as chyme.

If we chew the foods carefully, eat slowly, and do not overload the stomach, it will do its work easily and 
well. But if the pieces are too large or the amount too great the juice cannot get at the foods as it should, and

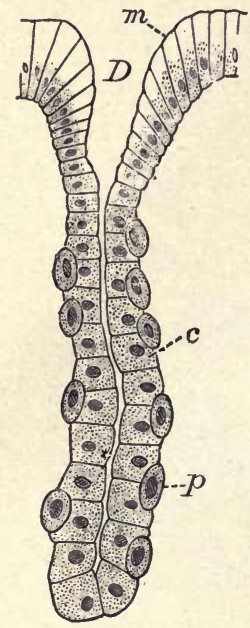

FIG. 48.- One of the glands which manufactures gastric juice. (From Huxley.) $D$, mouth of the gland; $m$, epithelial cells ; $c$, central cells which make pepsin; $p$, parietal cells which make acid. the muscles get tired out before all the foods are dissolved. The stomach is a hard-working organ, but it should not be abused. After it has worked hard for three or four hours it should get some rest before the next meal, so that it will be ready to do its work as it should. If the stomach is not abused, a person will always be hungry at meal times.

The stomach is a very important organ of digestion, for it serves as a storehouse for foods, dissolves proteids, and destroys many kinds of disease germs by means of its acid; and yet a person can live without a stomach. In a few cases of serious diseases the stomach has been entirely removed. The œsophagus was sewed directly to the intestines, and the person recovered and lived for years afterwards. We see that it is possible for a person to live without a stomach. That is because the digestive fluids of the small intestine can do all that the gastric juice does. But a person who has had his stomach removed cannot eat as much at one time as he could before, and hence he is obliged to take food at shorter intervals. 
Table showing the Time Required to digest Certain Foods IN THE STOMACH

$\begin{array}{cc}\text { Foods } & \text { TIME } \\ \text { IN } \\ \text { HOURS }\end{array}$

Rice, boiled .

Tripe, soused . . . . . I

Pigs' feet, soused . . . . I

Soup (barley) . . . . . $\mathbf{I} \frac{1}{2}$

Salmon trout, boiled or fried $\quad I_{2} \frac{1}{2}$ Apples, sweet, raw . . . $\mathbf{I} \frac{1}{2}$

Venison, steaks, broiled . . I $\frac{1}{2}$

Eggs, fresh, whipped . . . $\mathbf{I}_{\frac{1}{2}}$

Milk, boiled . . . . . 2

Codfish, cured, dried . . . 2

Cabbage, raw . . . . 2

Tapioca, boiled . . . 2

Liver, broiled . . . . . 2

Turkey, roasted . . . $2 \frac{1}{4}$

Milk, raw . . . . . $2 \frac{1}{4}$

Potatoes, baked or roasted . $\quad 2 \frac{1}{4}$

Gelatin, boiled . . . . $2 \frac{1}{2}$

Goose, roasted . . . . . $2 \frac{1}{2}$

Hash, meat, vegetables . . $2 \frac{1}{2}$

Lamb, broiled . . . . $2 \frac{1}{2}$

Oysters, fresh, raw . . $\quad 2 \frac{1}{2}$

Pig, roasted . . . . . $2 \frac{1}{2}$

Chicken, roasted . . . $2 \frac{3}{4}$

Corncake, baked . . . . $2_{4}^{3}$
Foons

TIME

IN
HOURS

Beefsteak, broiled . . . 3

Apple dumpling . . . 3

Chicken soup . . . . . 3

Eggs, soft boiled . . . . 3

Mutton, broiled or boiled - 3

Pork, stewed . . . . 3

Oysters, stewed . . . . $3^{\frac{1}{2}}$

Beef, roasted . . . . $3 \frac{1}{2}$

Bread, wheat . . . . $3 \frac{1}{2}$

Butter . . . . . . $3 \frac{1}{2}$

Eggs, fried or hard boiled . $3^{\frac{1}{2}}$

Beef, fried . . . . . 4

Duck, domestic, roasted . . 4

Salmon, boiled. . . . 4

Veal, roasted . . . . 4

Cheese . . . . . . 4

Pork, fried . . . . . . $4 \frac{1}{4}$

Cabbage, boiled . . . $4 \frac{1}{2}$

Duck, wild, roasted . . . $4 \frac{1}{2}$

Pork, boiled . . . . $4 \frac{1}{2}$

Veal, fried . . . . . $4 \frac{1}{2}$

Pork, roasted . . . . $5^{\frac{1}{4}}$

Suet beef, boiled . . . . $5 \frac{1}{4}$

These observations were made by Dr. Beaumont in his treatment of Alexis St. Martin, who had a gunshot wound which left an opening into the stomach from the surface of his body. The doctor was able to make many interesting and very important observations, for he could look into the stomach at any time and study the 
gastric juice and its action on the various foods. Similar observations have been made in other cases since.

Get a few grains of pure pepsin from the drug store and make some artificial gastric juice by mixing together one grain of pure pepsin, four tablespoonfuls of warm water, and about ten drops of strong hydrochloric acid. Label it gastric juice. It is now ready for use.

I. Put some gastric juice into a small bottle or test tube and add soft-boiled egg. Watch carefully for ten or fifteen minutes.

2. Repeat, using a few fibers of raw beefsteak. Notice carefully what happens.

3. Repeat, using still other proteid foods. What do you learn from these experiments?

73. Intestinal Digestion. - The portion of the alimentary canal into which the foods pass from the

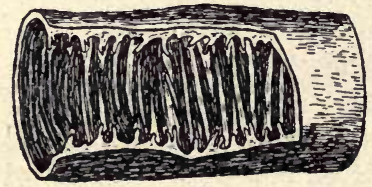

F1G. 49. - Small intestine cut open to show the folds of the mucous membrane. (Drawn by Mater.) stomach is called the intestines. The intestines begin at the smaller and lower end of the stomach at the right side and form the remainder of the digestive tube. The first portion or small intestine is about twenty-five feet long and one inch in diameter, while the second or large intestine is about five feet long and two inches in diameter. The intestines consist of an outer, thin serous. coat, of a middle, muscular coat having two layers of fibers (the longitudinal and the circular), and of an inner, very heavy lining of mucous membrane. The entire wall varies in thickness from one sixteenth to one eighth of an inch. The tube is very much coiled up in the abdomen, 
as can be seen from Figure 35. We see that the large intestine extends up to the liver at the right side, across the abdomen in front of and below the stomach, and down at the left side. These three parts are known as the ascending, the transverse, and the descending colon. The last portion of the large intestine is the rectum.

The mucous membrane of the intestines has millions of tubelike glands all over it ; they are important, as they produce a fluid, the intestinal juice, which helps to digest the starchy foods. The intestinal juice also helps to prepare the acid foods as they come from the stomach for the digestion in the intestines.

On the left

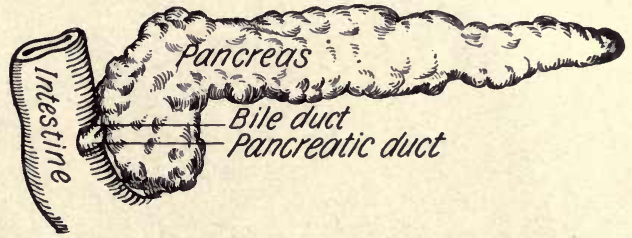
FIG. 50. - The pancreas, front view (Zuppke). side of the body, just below the stomach, is the most important digestive gland of the body. It is the pancreas, or abdominal sweetbread. The pancreas is pinkish yellow in color, about six inches long and two inches wide.

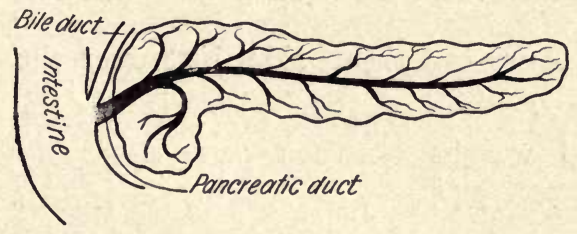

FIG. 51. - The pancreas cut open to show the ducts (Zuppke).
A duct which runs the entire length of the pancreas from left to right empties into the small intestine a little below the py-

lorus. The chief business of the pancreas is to manufacture a liquid called pancreatic juice, which is poured 
into the intestines through its duct. The pancreatic juice is the most important digestive fluid, for it contains substances which act upon starches and proteids, and besides it has a substance that can act upon fats and oils, changing them into an emulsion, or into soap. The pancreatic juice does all that the other juices do and does it better and more quickly. The pancreatic and intestinal juices complete the process of digestion, doing what was poorly done or left undone by the other digestive fluids.

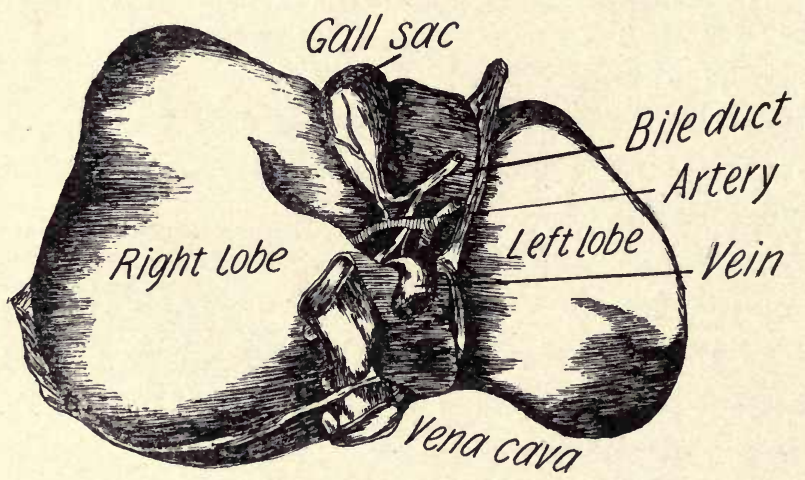

FIG. 52.- Under surface of the liver. Modified from Heitzmann. (Becker.)

The liver, located on the right side just over the stomach, is the largest gland of the body. It is dark brown in color and weighs between three and four pounds. This large gland is very important, for it does many useful things. One of the functions of the liver is to manufacture a fluid called bile. The bile is poured into the intestines through the bile-duct, which unites with the duct from the pancreas, and together they 
pierce the intestine about two inches below the pylorus. Bile is made all the time, and when there is no food in the intestines, it is stored up in a little bag called the gall-bladder. This is located on the under surface of the liver, with the larger pear-shaped end toward the front.

Bile is of a golden yellow color in man and has a very bitter taste. About two or three pints are manufactured daily. It is not able to digest food alone, but it is very important because it makes the pancreatic juice work much better. One of the chief functions of the bile is to aid the pancreatic juice in breaking up the fat into very small droplets that can enter the blood. It stimulates the muscles of the intestines to more vigorous action. Part of the bile is a waste product of the liver, which is excreted through the intestines.

Thus we see that the small intestine is a very important place for the digestion of foods. Here we find the intestinal juice, the pancreatic juice, and the bile, all active in changing the foods not yet dissolved so that they may pass through the walls of the intestines into the blood vessels. The act of digestion is now complete. The contents of the small intestine has a milklike appearance, and the entire mass is known as chyle. It is now ready for absorption.

Get a few grains of pancreatin, dissolve it in a pint of water, and add a little baking soda.

I. Test its action upon soft-boiled egg, shreds of raw beefsteak, or crumbs of cheese. Keep the solution warm for fifteen or twenty minutes.

2. Test its action upon boiled starch.

3. Put pancreatic juice into a test tube or small bottle and add a 
little oil. Shake thoroughly for a minute and notice that the oil is changed to a creamy liquid, called an emulsion. Milk is a good example of an emulsion. Lather is an emulsion.

74. Places of Digestion. - We may sum up the places of the digestive changes as follows: (I) In the mouth the foods are cut, ground, and softened, and some of the starchy material is changed into sugar by the action of the saliva. (2) In the stomach a large amount of food may be stored up for digestion, most of the foods are softened by the churning action of the muscles, and some of the proteids are dissolved by the action of the gastric juice. (3) In the small intestine the starchy foods are all converted into sugars, proteids are dissolved, and fats and oils are broken up into small droplets so that they may enter the blood.

75. Peristalsis. - We have learned that the food passes through the œesophagus by a peculiar contraction of the longitudinal and circular muscles to which is given the name peristalsis. The stomach churns the food by constantly throwing it back and forth, now pressing in one direction and now in another.

In the small intestine there is a muscular movement which thoroughly mixes the foods with the various digestive fluids and also forces the contents along through the winding course of the canal. As the food is thus moved along from the mouth through the various parts of the alimentary canal, its bulk is increased by the addition of saliva, gastric juice, bile, pancreatic juice, and intestinal juice, and it becomes more and more nearly liquid. The only solids found in the chyle are 
the indigestible material that formed part of the foods, as shreds of elastic tissue and hairs from meats, husks or coverings of grains of corn, wheat, oats, peas, and beans, the coloring matter of all greens and vegetables, the hard vegetable capsules that cover the granules of starch in potato, corn, etc., the seeds of small fruits, and pieces of food that were not ground fine enough by the teeth. The liquid is absorbed into the blood, but the solids pass on into the large intestine and are expelled from the body daily by this peristaltic motion.

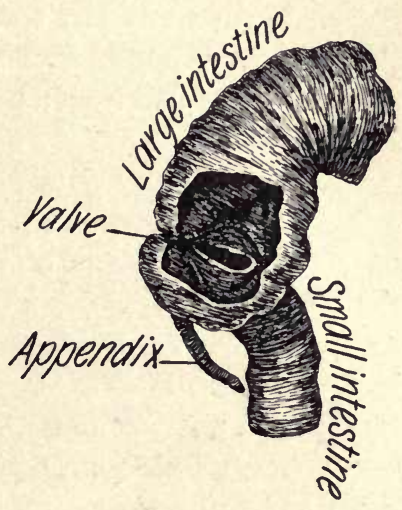

FIG. 53.- Showing the valve between the small and large intestines. (Drawn by Mater.)

\section{SUMMARY OF THE MAIN POINTS}

I. The alimentary canal is a long, muscular tube with enlargements at certain places in which the solid foods are dissolved so that they can enter the blood.

2. A gland is a mucous membrane well supplied with blood vessels and nerves that can pick out of the blood certain material to form secretions. The important digestive glands are : the salivary, the gastric, the intestinal, the pancreas, and the liver.

3. The mouth is the first organ of digestion. Here the foods are cut and ground into fine particles, mixed with saliva, and pushed into the pharynx. In the mouth are the teeth, the tongue, and the tonsils. 
4. The teeth are very important organs of digestion. They are made of dentine covered with enamel on the crown, and cement on the root. They are filled with connective tissue, blood vessels, and nerves.

5. There are twenty teeth in the first set and thirty-two in the second. A tooth does not grow after it is once fully cut and cannot repair itself; hence the teeth should be properly cared for.

6. The salivary glands pour from one to three pints of saliva into the mouth daily, which serves to keep the mouth moist, to dissolve some of the foods, and to change some of the starches into sugars.

7. Swallowing is accomplished by the proper action of a large number of muscles. The food passes from the mouth through the pharynx and œesophagus into the stomach.

8. The stomach is the greatest enlargement of the digestive canal and an important organ of proteid digestion. The gastric juice comes from the innumerable gastric glands and contains an acid and pepsin. The amount of gastric juice secreted daily varies from ten to twenty pints.

9. The stomach has three separate layers of muscles, which enable it to contract in all directions and to thoroughly churn the food.

10. The time it takes to digest a meal depends upon the amount and kind of food taken, the mode of cooking, the general health of the person, and the kind and amount of exercise taken. The food remains in the stomach from two to four hours.

II. After the food has been properly changed in the stomach it passes through the pylorus into the small intestine.

I2. The glands of the intestines, the pancreas, and the liver all pour secretions into the intestines.

I3. The pancreatic juice is the most important digestive fluid, for it can do all that the other juices do, and besides it changes fats and oils into an emulsion, or into soap. 
14. The intestinal juice is secreted in very small quantities. It aids the pancreatic juice in acting upon starches and sugars.

I5. The bile aids the pancreatic juice in changing the fats. It stimulates the walls of the intestines to greater muscular action and to secretion.

I6. In the mouth starches are changed into sugars; in the stomach proteids are dissolved; and in the small intestine starches are changed into sugars, proteids are dissolved, and fats and oils are changed into tiny particles so that they can enter the blood.

I7. The bulk of the contents of the alimentary canal is greatest in the small intestine, where it is a milklike substance with some indigestible solids floating in it.

18. The liquid material can enter the blood, but the solid is a waste that must be ejected from the large intestine at regular intervals. 


\section{CHAPTER VIII}

\section{FROM THE ALIMENTARY CANAL TO THE HEART}

76. Review. - We have now learned what parts the various digestive organs play in the preparation of foods for the blood. We have seen that proteids, carbohydrates, and fats are the only foods that must undergo chemical changes in order to be dissolved. Water, salt, and oxygen can enter the blood unchanged. We have learned that the carbohydrates are changed into sugars, the proteids are dissolved, and the fats and oils are broken up into very small droplets and a small amount is changed to soap. We have seen how the oxygen gets through the walls of the air sacs of the lungs, and into the plasma of the blood, where it is picked up by the red corpuscles.

We shall learn in this chapter how the peptones, sugars, fats, salt, and water get through the walls of the body and into the blood. You will remember that the alimentary canal is a tube extending through the body, and anything that is in the stomach or in the intestines is in the alimentary canal but really not in the body. The digestive tract is lined with a delicate mucous membrane which serves as a sentinel to protect the body against substances that are not dissolved and to 
pick up those things that may enter the blood. There is no way of getting from the alimentary canal into the blood except by passing through this membrane.

77. Absorption. - Foods in the form of a liquid can pass through the mucous membrane in any part of the alimentary canal, through the delicate walls of the blood capillaries, and become part of the plasma. The word absorption refers to this soaking through the walls, but it is not simply a soaking process, for the cells are active in picking up the little particles of food and passing them on into the plasma of the blood. We know that the sap of trees goes up through the little plant cells to the leaves by passing from cell to cell by a process called osmosis. Now, in a similar way, the foods enter the plasma. We may say that absorption is in part soaking through the walls, in part osmosis, and in part due to the action of the living cells of the walls themselves.

Foods may be absorbed all along the alimentary canal, but there are some places where absorption occurs more readily than at others. The largest amount is absorbed from the small intestine. Here we have a very large surface of mucous membrane so made as to favor rapid absorption of all kinds of foods. Next in importance is the large intestine, where water and salt are absorbed chiefly. Water, salt, some sugars, and some peptones may be absorbed from the stomach, but the amount is comparatively small. A very little water, salt, and sugar may enter the blood from the mouth and even from the œsophagus. 
78. Absorption of Fats. - Although fats and oils are acted upon by the pancreatic juice, and by the bile, which together break them up into very small droplets surrounded by a thin film of soap, they are never really dissolved as the other foods are. They are still butter, lard, tallow, oils, etc. They are not digested but simply emulsified. In the intestines a small amount of
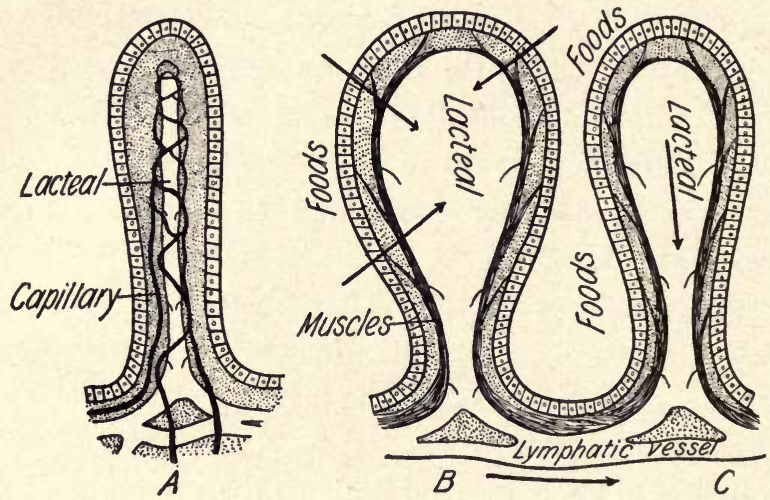

FIG. 54. - Villi of the small intestine (Zuppke): $A$, the lacteal at rest; $\mathrm{B}$, the lacteal filled up with foods; $C$, the muscles contracting and forcing the foods out into the lymphatic vessels.

soap is formed to aid in the absorption of the fats. Water and oil will not mix. Oil of any kind on the hands is washed off with difficulty without soap.

Fats and oils are not absorbed with the other foods; they have a route of their own. The mucous membrane of the small intestine has millions of little projections called villi all over its vast surface. A villus is merely a fold of the mucous membrane, in the center of which is 


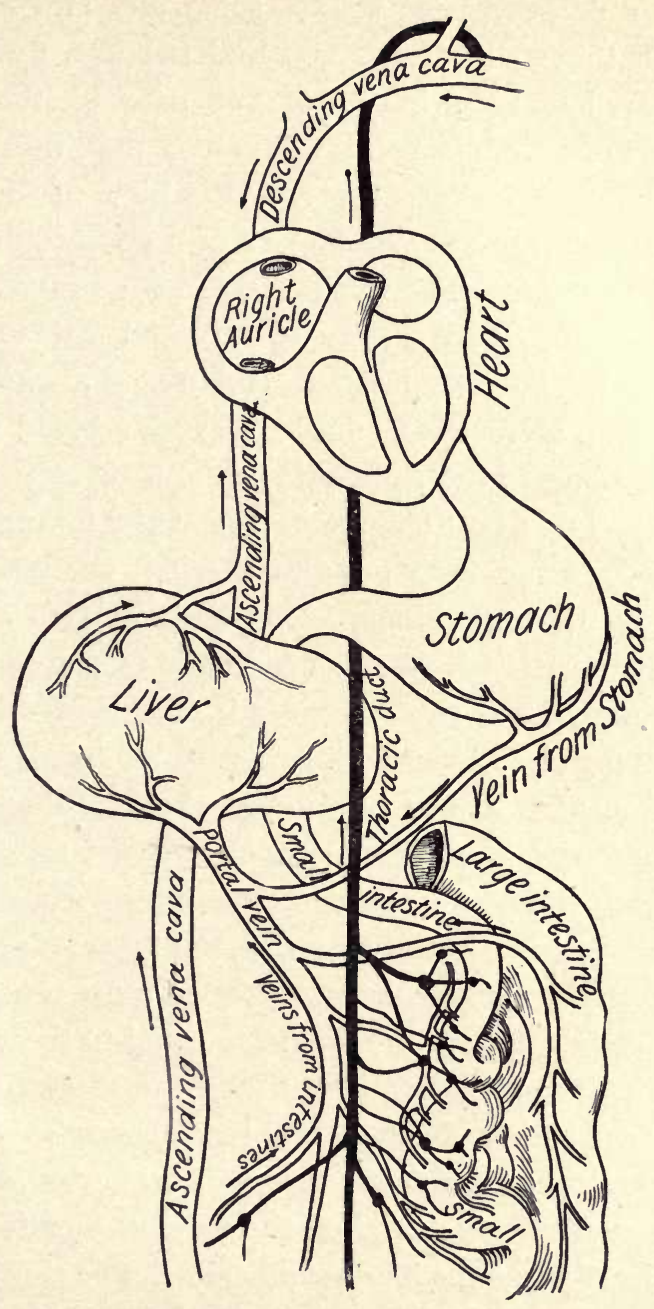

FIG. 55.- Showing the two routes of foods in absorption (Zuppke). 
a small duct called a lacteal. The fats and oils pass through the walls of the villi and get into these little lacteals; but they have not yet reached the blood. The lacteals from several villi unite and form larger tubes, known as lymphatic vessels, which finally empty into a single trunk about the size of a goose quill; called the thoracic duct. The fats together with a small amount of the other foods are carried up through the thoracic duct and emptied into the left subclavian vein at the base of the neck. Here they mingle with the blood and are washed along to the right side of the heart.

A very important change occurs in the fats in absorption, and during their passage through the lymphatics. There are little swellings, lymph nodes or glands, on the small lymphatic vessels, in which the fats are changed. The butter, lard, suet, goose oil, etc., that we eat are here changed to human fat. Every animal has a kind of fat peculiar to itself. In the thoracic duct and in the blood of man we find neither lard nor tallow; they have been changed to human fat during absorption.

We have traced the fats and oils into the blood and to the right side of the heart. Let us now see how the other foods get from the digestive canal to the right side of the heart.

79. The Other Foods.-Peptones, sugars, salt, and water are the other foods that we left in the intestines. These pass into the cells of the mucous membrane and then directly into the blood capillaries. The capillaries of the stomach and intestines unite to form many veins, all of which empty into the portal vein. The portal vein is 
a large blood vessel that gathers up the blood from the stomach, the spleen, and the intestines, and carries it to the liver.

Peptones and sugars are also changed during absorption. As the peptones pass through the cells of the mucous membrane they are changed into a form of albumin that can be used to build up and repair the cells of the body. Sugars are also changed by the same cells. Water and salt are not changed. In the portal vein leading to the liver we find albumins, sugars, water, salt, and some fats. Before these foods reach the heart they must pass through the liver, where other changes occur. We must now study the liver.

80. The Liver. - The location, size, color, and some of the uses of the liver we learned in the last chapter. The liver is made up of five lobes, each consisting of many lobules. Each lobule receives blood from a small branch of the portal vein and from the hepatic artery. The lobules consist of very small cells that do many things besides manufacturing bile.

If more proteid foods, as cheese, eggs, and meats, are eaten than the body needs, they are changed into sugars or fats in the liver cells. The albumins cannot be stored up in the body, while the sugars and fats can. All of the sugar that is not needed at once by the cells of the body is stored up in the liver for future use. Fats, water, and salt are not changed. The liver cells have the power to select from the blood, as it passes through them, certain germs and poisons that sometimes get into the body with the foods. They can also 
destroy harmful substances made in the various cells of the body. So we see that the liver is a very important organ, for it does many things to keep the blood pure and to keep the right amount of the different foods in the blood.

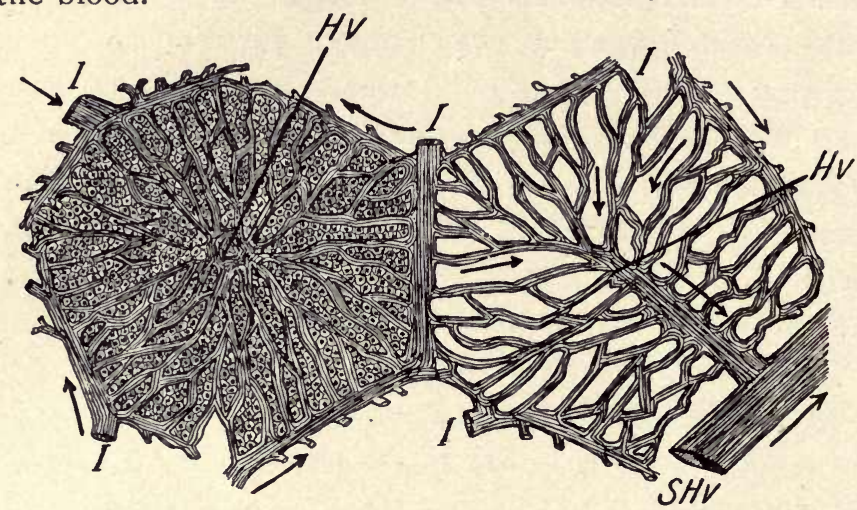

FIG. 56. - Showing two lobules of the liver. (Modified from Schäfer by Zinns) : I, portal vein bringing blood to the lobules; $H V$, beginning of hepatic vein formed by the union of the capillaries within the lobule; $S H V$, hepatic vein carrying blood away from the lobules.

The sugars stored up in the liver pass into the blood whenever the body needs them, and they reach the heart through a large blood vessel called the ascending vena cava.

81. Foods in the Right Heart. - The fats are absorbed by way of the lacteals and lymphatics, or by the indirect method, and all the other foods by way of the blood capillaries and the liver, or by the direct method. The two again unite in the blood in the right side of the heart. The bread, meat, potatoes, etc., that we eat are changed in digestion, so that they get into 
the body, and are further changed in absorption, so that they can be used to nourish the cells and to give us strength. The proteids are now albumins, the carbohydrates are a kind of sugar, the fats and oils are human fat, and the water and salt are unchanged. The plasma of the blood is about ninety per cent water, and dissolved in it are all of these foods.

82. The Large Intestine. - We have learned that the food reaches its largest bulk in the small intestine because the quantity absorbed up to this point is less than that of the digestive fluids added. The rapid absorption of all kinds of foods from the small intestine, and of water and salt from the large intestine, diminishes the contents very much. Toward the end of the colon the contents become quite solid in consistency, and take on a darker color.

Many kinds of bacteria are found in both the small and large intestines. They live here and decompose many of the undigested food materials. But they do no harm if the large intestine is emptied every day. In this way many useless substances taken with the foods and some waste products formed within the body are removed.

\section{SUMMARY OF THE MAIN POINTS}

I. Absorption means the transfer of foods from the alimentary canal into the blood.

2. Foods get through the mucous membrane by soaking through, by osmosis, and by the action of the living cells.

.3. From the mouth and the œsophagus there are absorbed some water and salt, and sometimes small amounts of sugar. 
From the stomach some peptones are absorbed in addition to the above. The small intestine is the most important organ of absorption, for from it fats and oils are absorbed by the lacteals, and peptones, sugars, water, and salt by the capillaries. From the large intestine water and salt are absorbed.

4. In the cells of the villi and in the lymph nodes of the lymphatics the fats are changed to human fats. The fats pass up through the thoracic duct and enter the blood in the left subclavian vein at the base of the neck.

5. The other foods enter the blood capillaries directly and are carried into the portal vein which leads to the liver.

6. In absorption the peptones are changed to albumins, and the sugars are also changed somewhat. The water and salt are not changed.

7. The liver may change the albumin not needed at the time into fats or sugars and then store up the sugar for future use.

8. The liver destroys certain disease germs, removes poisons, manufactures bile, serves as a storehouse for sugars, destroys worn-out red corpuscles, and oxidizes certain harmful substances made in the body.

9. The fats absorbed by the indirect route and the other foods by the direct route are again brought together in the right side of the heart and form the nutritious part of the plasma.

10. The materials that cannot be absorbed from the alimentary canal accumulate in the large intestine and are expelled at regular intervals. 


\section{CHAPTER IX}

\section{HYGIENE OF DIGESTION AND ABSORPTION}

83. Pure Foods. - One of the most important problems for us to consider is how to obtain pure, wholesome foods. No question is of greater moment to health. Foods are often impure because they contain disease germs and dangerous parasites. It is well known that typhoid fever, cholera, trichinosis, and numerous other diseases are due to impure foods. Meat from diseased, overheated, wounded, immature, or emaciated animals is very dangerous, and should not be used for food. Fruits and vegetables unripe, overripe, decayed, or stale are unwholesome, and should never be eaten. Milk from cows that are diseased, or that are fed on "swill milk," "distillery slops," refuse from vinegar factories, garbage, and other unclean or unwholesome foods, or that are kept in overcrowded, unclean, or otherwise unhygienic stables, is dangerous, and should not be used for food.

Besides being unclean and containing disease germs, foods are often impure and unwholesome because they have been adulterated with cheaper and less nutritious substances. Every state has enacted laws which make the sale of adulterated foods an offense punishable by a 
fine or imprisonment. Such laws are wise and just, and should be enforced in every town and city. Every intelligent citizen should do all he can to discourage the sale and use of impure, unwholesome, or adulterated foods of all kinds.

84. Adulterated Foods. - Milk is more often adulterated than any other food. The watering and skimming of milk are the chief ways of adulteration, but sometimes a substance is added to give it a better color. This makes the milk less nutritious, and it is more likely to contain disease germs. Milk is such an important food in every household that the utmost efforts should be made to keep it pure and clean. Butter is sometimes made from lard, tallow, and cotton-seed oil instead of from rich cream. Such imitations are called butterine or oleomargarine. It cannot be maintained that butterine is unhealthful, provided it is made of pure, clean materials, but it is very often sold for good, pure butter. Many of the states have laws requiring all butterine to be properly labeled, and some require a conspicuous sign stating the fact that butterine is there sold or used. Fats, oils, and grease are sometimes used in the manufacture of cheese, but any such inferior and adulterated product put on the market should be labeled "imitation cheese."

Molasses, sirup, sugar, honey, etc., are often mixed with glucose, dextrose, starch sugar, or other starchy preparations. Candy may contain glucose, poisonous coloring matter, and harmful flavors. Flour and bread, baking powder, saleratus, fruit jelly, coffee, chocolate, 
lard, olive oil, vinegar, liquors and wines, drugs and medicines, and, it is said, in Paris, even eggs, are among the things that are made cheaper and less wholesome by various processes of adulteration.

85. Cooking. - We have already learned some reasons for cooking foods. Let us now see the relation of cooking to digestion. Nearly all foods, both vegetables and meats, are softened by cooking so that they may be more easily changed by the digestive juices of the alimentary canal. Proper cooking of foods is really a kind of digestion, or the first step in the process of changing foods into blood. Fats are an exception. Cooking makes fats more difficult to digest, since they are changed chemically when exposed to a high temperature even for a short time. That explains why potatoes, eggs, and meats when fried are less digestible than when cooked in any other way. Frying is the least wholesome mode of preparing foods, because the butter used permeates the entire mass so that neither the saliva nor the gastric juice can act upon the foods to any extent. They must go undigested until they reach the small intestine, where the pancreatic juice acts upon them.

Boiling is the mode of cooking generally employed for vegetables. It is better to boil than to fry meats. Baking and roasting come next in importance, but broiling is by far the most wholesome way of preparing meats. By this method all the juices of the meats are saved, the high heat sealing them up at once.

Scientific cooking, by utilizing foods to their full extent with the smallest amount of waste, will do much 
to cheapen the expense of living and to contribute to health and happiness by presenting the foods in a pleasing, palatable, and digestible form, so as to stimulate the appetite and aid the digestive processes. Cooking is an art that can be mastered only by careful study and intelligent, persistent practice. Every young woman should regard it a rare accomplishment to be able to cook and serve foods so that they will be of the greatest nutritive value.

86. Care of Teeth. - Most persons do not sufficiently realize the value of the teeth as organs of digestion. It is a fact that many cases of indigestion and nervousness arise from insufficient mastication because of poor teeth. Our teeth must be kept in condition for daily use. A tooth that has a cavity should be filled if it is worth saving, and if not, it should be removed. If several teeth are wanting, they should be replaced by artificial teeth.

Bacteria are the chief cause of bad teeth. Many harmless bacteria are found in the mouth, but others produce poisonous substances that cause the teeth to decay. Of course there are other minor causes that tend to destroy the teeth, as taking into the mouth iron, acids, etc., biting too hard substances, scratching, or in any way injuring the enamel.

Particles of foods lodge between the teeth and unless removed at once afford excellent food material for bacteria. These little organisms attack the teeth and form cavities in them. The discolored tartar so often seen on teeth is due to the action of bacteria. The remedy is difficult and expensive, but prevention in most cases 
is simple. Knowing the cause of a disease, one may be able to prevent it. The one important thing is to keep the teeth free from food materials for the bacteria. How can this be done? There is but one way. The teeth must be carefully and thoroughly cleansed after each meal.

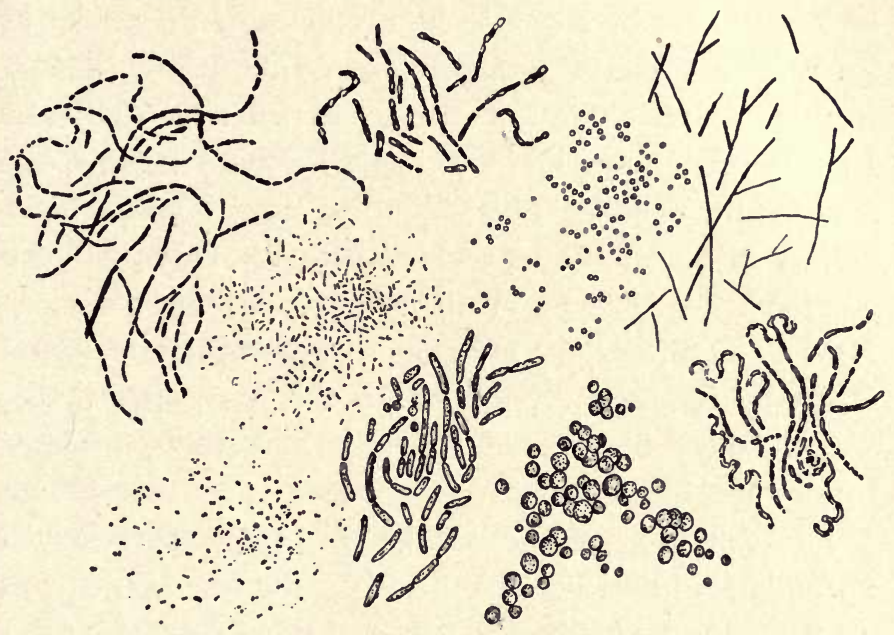

FIG. 57. - Bacteria commonly found in the mouth. (Hopkins" "Care of the Teeth." D. Appleton \& Co.)

We should early form the habit of properly caring for the teeth daily. A good cleansing once a month will not take the place of the daily care they should receive. The particles of food between and around the teeth should be removed with a wood or quill toothpick after each meal. Food between teeth that are close together may be easily removed with a fine silk thread or with a small rubber band. A soft toothbrush and 
lukewarm water should be used at least twice a day, or, still better, after each meal and just before going to bed at night. Besides, it may be well to clean each tooth occasionally with a chisel-like piece of hard wood. This gives the teeth a smooth polish, and makes it easier to clean them with a brush. About twice a year they should be looked over by a dentist and repaired if they need it.

87. The Appetite. - A person who lives as he should may safely trust his appetite as to what he shall eat. In this matter the lower animals have no trouble, but man is always concocting something new to give greater variety to his diet, and so stimulate his natural desire for food. This leads to disturbances of various sorts. How many things that a person dislikes at first he learns to eat by repeated attempts. In this way an artificial appetite may be created for any new thing whether wholesome or injurious.

The condition of the mind and nervous system has a wonderful influence upon the appetite as well as upon digestion and nutrition. A cheerful disposition and a joyous nature give rise to good digestion and more perfect nutrition, while worry, envy, jealousy, excitement, and other undesirable states of mind lead to digestive disturbances that make good health an impossibility even when a person takes the best of care of himself. A pure-minded, cheerful, contented, industrious person is likely to have a good appetite and good digestion. We can now understand the phrase, "laugh and grow fat," and see why a change of scene and a long vacation are often the best of medicines. 
Poor digestion frequently comes from nervousness, when the stomach is not diseased at all, because nerve strain, from whatever source, shows itself first of all in disturbing the appetite and the nutrition. A decayed tooth, defective eyes and ears, and even an irritating corn on a toe may be the remote cause of indigestion. If the true cause of the trouble could be removed, it would not be necessary to make any changes in the diet.

88. Hygiene of Eating. - What a person eats is generally determined by what he likes and can get. As a rule taste is a safe guide, but by forming bad habits of eating, an unnatural craving for foods neither digestible nor nutritious may result. We should form a taste for good, wholesome foods that agree with the digestive organs and avoid all that are harmful even if they are palatable.

Food should be taken at the same hour each day and at regular intervals of from four to five hours. If this is done, it will not be necessary to eat between meals and so deprive the stomach and the glands of the rest they should have. Loss of appetite and indigestion are often caused by eating at all hours. It is a good thing to rest a few minutes from physical and mental work just before taking a full meal. That will aid digestion very much. Severe exertion immediately after a full meal is equally injurious because physical and mental exercise drain the blood away from the stomach and glands, where it is needed to properly digest the foods. We should form the habit of eating 
three good meals a day and resting a few minutes before and after each if we wish to be well and strong.

Another important caution is to eat slowly and masticate thoroughly. It is essential to chew the foods thoroughly, so that the digestive fluids can act on each particle. Eating slowly gives the saliva time to mix thoroughly with the foods in the mouth and to change some of the starches into sugars.

Drinking water at meals does little harm unless the foods are washed or "rafted" down into the stomach. That, of course, is the danger to be avoided, for eating rapidly and washing down the food is certain to cause indigestion. Ice-cold and very hot foods and drinks should be avoided. They may injure the teeth by cracking the enamel, and the stomach by delaying digestion until the normal temperature can be restored.

When and how we eat and drink are almost entirely matters of personal habit which, when once formed, are difficult to change. Happy is the youth who forms habits that shall be his friends all through life. He should take daily a sufficient quantity of pure, wholesome, plain foods selected from vegetables, meats, and fruits, and eat at the same hour each day under as pleasant surroundings as possible. It is not necessary to have a great variety at any meal, but it is important to have the right proportion of each food stuff. Let us eat to live and not live to eat.

89. Dress and Digestion. - We have learned in the chapter on Respiration that the postures of the body and the mode of dressing the chest are of great 
importance to proper breathing and good health. What was said there applies also to digestion. A lounging, careless position in sitting and standing tends to displace the abdominal organs. Tight lacing about the waist depresses the stomach, intestines, kidneys, and liver, weakens the muscles of the abdomen, interferes with abdominal breathing, and deranges the organs situated in the pelvic cavity. These organs thus crowded downward day after day soon become permanently fixed in these abnormal positions. See Figure 32 on page 67 .

We are told by physicians that the displacement of the abdominal and pelvic organs is the cause of constipation, biliousness, headache, backache, general weakness, and many other ailments of a more serious nature. All the difficulties, suffering, peevishness, and petulance due to these disorders may be avoided if we form correct habits of standing, sitting, and lying, and wear clothing fitting loosely about the chest and waist.

All garments of men, women, and children should be suspended from the shoulders and not from a belt worn about the waist. They should be loose enough to permit the utmost freedom for enlarging the chest in breathing and for the natural functioning of the abdominal and pelvic organs. The conventional dress of women is particularly faulty in this matter, and intelligent and cultured women should do their utmost to institute a crusade against this unhygienic practice so fashionable at present. It has been well said that fashion makes cowards of us all. 
90. Diseases of the Alimentary Canal. - We have seen that many disease germs enter the body with the air we breathe and cause certain diseases of the air passages. The alimentary canal is another important channel through which thousands of bacteria get into the body daily. The germs of typhoid fever, dysentery, and cholera can get into the body only by this means, while those of consumption, diphtheria, and scarlet
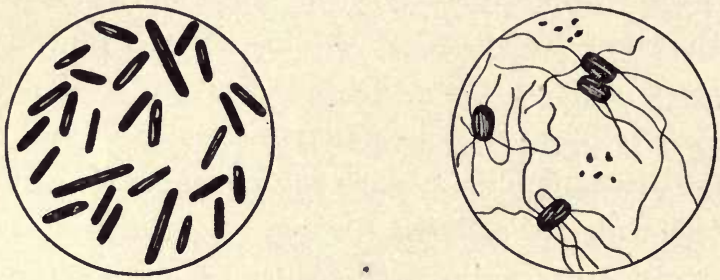

FIG. 58. - Bacteria of typhoid fever (Pratt).

fever may enter the body either with the air or with the foods. These diseases will be discussed in a later chapter.

Among the other important ailments of the digestive tract are dyspepsia, intestinal indigestion, liver trouble, and appendicitis. Dyspepsia is a disease of the stomach and may be due to a great variety of causes, but the most common are coarse, indigestible, poorly cooked articles of food, rapid eating, bad teeth, insufficient mastication, lack of variety in diet, and excessive use of alcoholic beverages. If our foods are plain and wholesome, varied more or less from day to day, properly cooked, eaten slowly, well masticated, and the amount taken not too large, the stomach will do its work well. 
The foods remain in the small intestine for about twelve hours and undergo very important chemical changes. If the foods have not been properly prepared for the action of the intestinal fluids, neither digestion nor absorption is carried on as it should be, and the foods will not serve their purpose. The causes of dyspepsia, together with insufficient clothing to keep the abdomen warm, and neglect to empty the large intestine at least once a day, are among the most frequent causes of intestinal indigestion. Mental and physical overwork always derange the stomach and the intestines.

If, for any reason, the functions of the liver are impaired, digestion and absorption will be" disturbed, and all the tissues of the body will suffer. The causes of jaundice and other liver troubles are numerous and of a rather complicated nature, but by keeping the body in good health it is not likely that, this organ will become diseased. Unwholesome foods, alcoholic beverages, and constipation are generally connected with liver troubles.

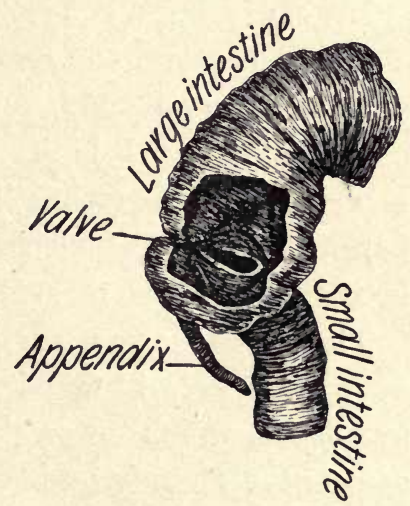

FIG. 59. - Showing the appendix. (Drawn by Mater.)

At the lower end of the cæcum there is a small organ about two and one half inches long known as the vermiform appendix. As far as known it serves no purpose in man. It is a dangerous little organ because it is the 
seat of the disease known as appendicitis. The cause of this disease, which is quite common, is unknown at present. It was once thought that grape seeds and other small, hard substances taken into the stomach might lodge in the appendix and give rise to an inflammation, and so cause appendicitis. But such substances rarely cause the disease.

91. Alcohol and Digestion. - The delicate mucous lining of the alimentary canal is greatly irritated by coming in contact with alcohol. There are two organs of digestion which seem to be especially vulnerable to the attacks of alcohol. The first of these is the stomach. The blood capillaries of the stomach enlarge, causing a congestion of the mucous membrane. The glands secrete an excessive amount of gastric juice when thus stimulated. In time the gastric juice becomes diminished both in quantity and in digestive power. The stomach will not respond to an ordinary natural stimulus if alcoholic beverages are habitually used. This leads to a loss of appetite and dyspepsia.

The second organ to be seriously affected by alcoholic beverages is the liver. You will remember that the foods which enter the capillaries of the stomach are carried directly into the portal vein and to the liver. All of the alcohol absorbed from the stomach must go straight to this organ. The liver capillaries become enlarged with blood, and the cells cannot do their work as they should. This first enlargement may be followed in time by fatty decay of the liver substance, which causes an abnormal increase in size, or by a 
shriveling of the true liver substance which causes the peculiar nodules that give it the name "hob-nailed" or "gin-drinker's" liver. Either of these conditions unfits the liver to perform its numerous duties.

92. The Large Intestine. - By a little effort the large intestine may be trained to empty itself every morning. This is a very important matter, for, if the useless and harmful substances are retained too long, they weaken the intestines, impair digestion and absorption, cause diseases of the liver, and lead to various other disorders. Loss of appetite, drowsiness, headache, biliousness, and constipation are among the symptoms that result from neglect of this very important personal matter.

\section{SUMMARY OF THE MAIN POINTS}

r. Many foods contain disease germs and hence are dangerous to eat. Milk, water, meats, vegetables, and fruits must be cared for properly after they are brought to the house.

2. Typhoid fever, cholera, dysentery, and trichinosis are often due to impure or spoiled foods.

3. Foods are sometimes made impure by adulteration with cheaper and less nutritious substances. Milk, butter, cheese, molasses, jelly, sirup, sugar, tea, honey, candy, flour, bread, baking powder, saleratus, coffee, chocolate, lard, olive oil, vinegar, liquors and wines, drugs and medicines, are among the things that are adulterated.

4. Cooking is the first step in the process of digestion. Boiling, roasting, baking, stewing, broiling, and frying are common modes of preparing foods.

5. Teeth must be kept clean and free from particles of food. They should be cleaned with a brush and tepid water at least twice a day. 
6. Avoid extremes of temperature in foods, and hard, metallic toothpicks, as they tend to injure the enamel.

7. A natural appetite is a safe guide to follow in the selection of foods, but the appetite may easily become perverted.

8. A cheerful disposition and a joyous nature give rise to good digestion and perfect nutrition; while worry, envy, jealousy, etc., lead to digestive disturbances that make good health and happiness impossible.

9. Foods should be eaten at regular intervals of several hours, so that the digestive organs may have their needed rest. Rest of a few minutes before and after full meals is a great aid to digestion.

ro. Eat slowly, masticate well, drink little at meals, be cheerful and happy, and select plain, wholesome foods that are well cooked, if you wish to be well and strong.

I I. Dress about the waist should fit loosely, so as not to push out of place the abdominal and pelvic organs. All garments should be suspended from the shoulders and not from a belt worn about the waist.

I 2. Dyspepsia, intestinal indigestion, and liver troubles are among the common diseases of the digestive organs. They come from unhygienic habits of eating, drinking, and living.

I3. Alcohol has a specific effect upon the stomach, intestines, and liver ; it tends to impair their functions permanently if used habitually.

14. The large intestine should be trained to empty itself every morning. 


\section{CHAPTER X}

\section{CIRCULATION OF THE BLOOD}

93. Review. - We have learned that the human body is made up of millions upon millions of very tiny cells, each of which must have food and oxygen. The cells derive their nourishment from the blood as it circulates through the various tissues. Oxygen from the air, water, and solid foods changed and dissolved by the digestive fluids, all get into the blood and form the part which the cells need to nourish them.

The cells cannot move about in search of food, and so blood must be carried to every organ and tissue of the body. The amøba, you remember, is a single cell and has the power to move about freely in the water from which it can obtain its food. But all higher animals, and plants, as well, have a fluid of some kind circulating within them for the purpose of carrying food materials to each and every cell and removing waste substances and worn-out parts. In the tree the sap forms this circulating medium, and in animals it is the blood.

Neither plants nor animals can live without such a circulating medium, which is truly a "river of life," carrying to every cell life-giving material, and remov- 


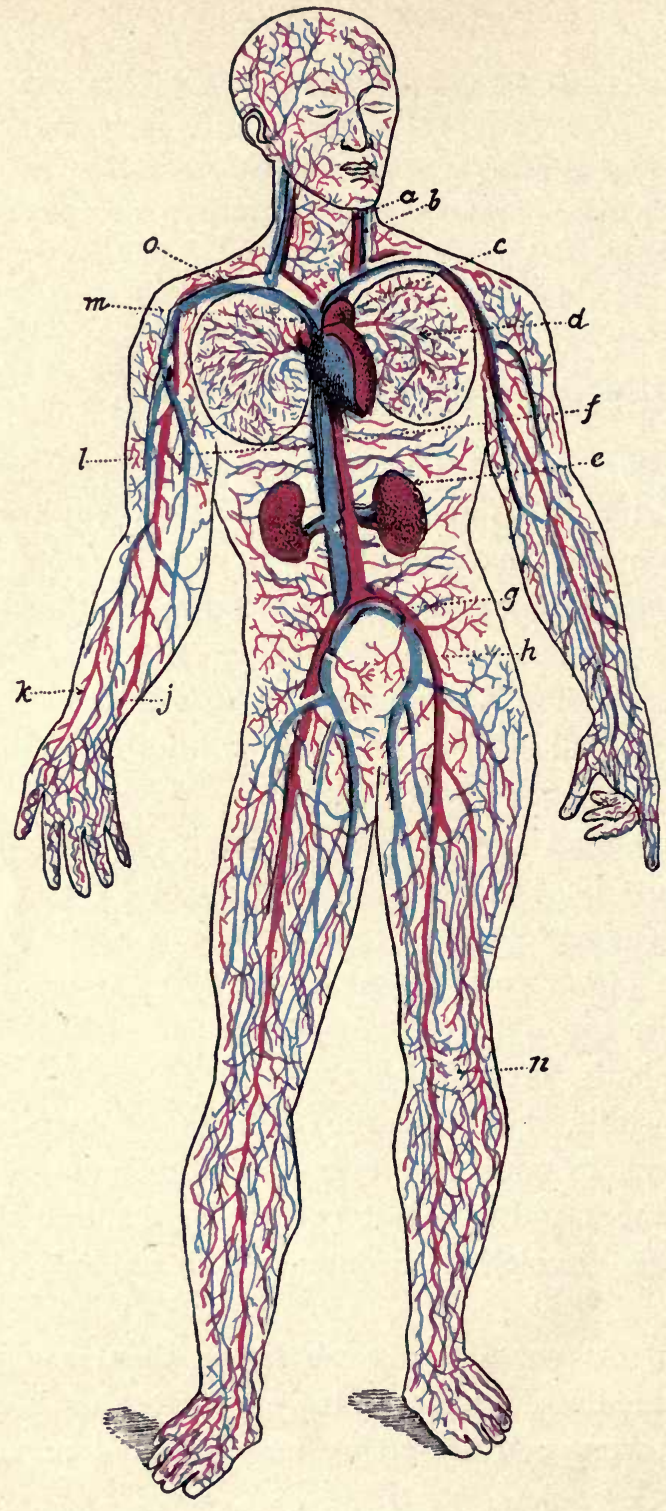

营苛

$>$ 든

듀 면

응

ن

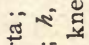

ช

पे 㫕

돈.

$\checkmark$ E

¿ ำ

ए 듕응

类

可

$\supseteq \infty_{0}$

屯.

원

त)

돌

끈 융

ชี ผ

ㄷํ ‥

ह

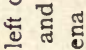

$0.1>$

고

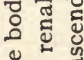

돈

范

월

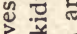

휴

능

W

졸

틀 ๘

1 를

$8 \neq 5$

ن 
ing from every cell the substances which would cause disease and death.

94. The Heart. - In studying absorption we learned that the foods taken into the blood from the alimentary canal both by the direct and the indirect methods are brought together in the right side of the heart.

The heart is about the size of a person's clenched fist. In an adult it is about five inches long and three and

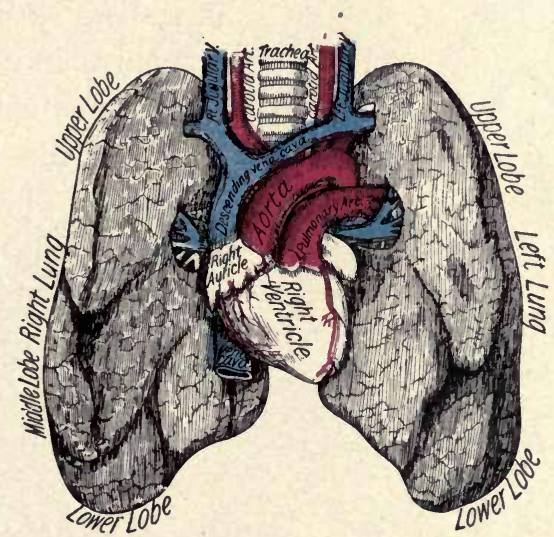

FIG. 6I. - The lungs, heart, and large blood vessels, front view (Zuppke).

one half inches thick, and weighs about ten ounces. It is situated at the center of the chest between the lungs, with its apex inclined to the left and front. For this reason you can feel the heart beat best if you place your hand over the left side of the chest on a level with the lower part of the breastbone. The heart has a saclike covering, resembling the pleura of the lungs, folded around it; this is the pericardium. There is a small amount of fluid in this sac, which serves to oil 
the surfaces and enables the heart to work with very little friction.

The heart is a hollow, muscular organ divided into two separate parts, the right and left sides, by a strong

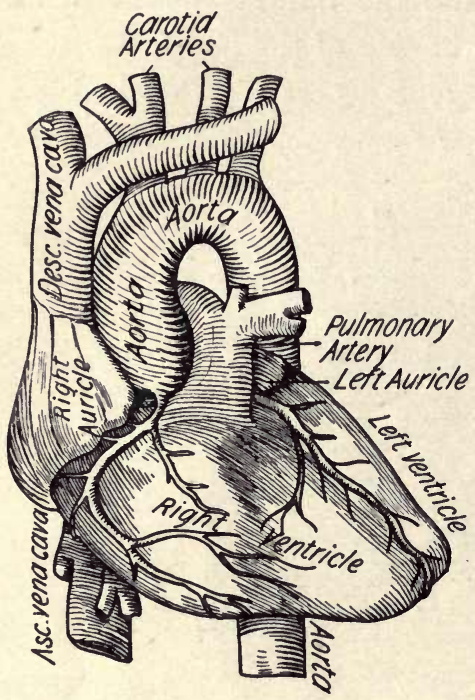

FiG. 62. - The heart and large blood vessels, front view (Zuppke). partition which extends from the base above to the apex below. Each side consists of two chambers with an opening between them. The upper is called the auricle, and the lower the ventricle. The muscular walls of the ventricles are much thicker and stronger than those of the auricles, and those of the left ventricle are nearly three times as thick as those of the right. The reason for this difference will appear when the functions of these chambers are described.

Get a sheep's heart from your butcher and observe especially the four chambers, the thickness of the walls, the valves, and the openings.

95. Valves and Openings of the Heart. - The right auricle has several openings through which the blood, returned from all parts of the body, enters. The right ventricle has one opening by which the blood enters 
from the right auricle, and one by which the blood leaves it through the pulmonary arteries and goes to the lungs. The left auricle has four openings through which the

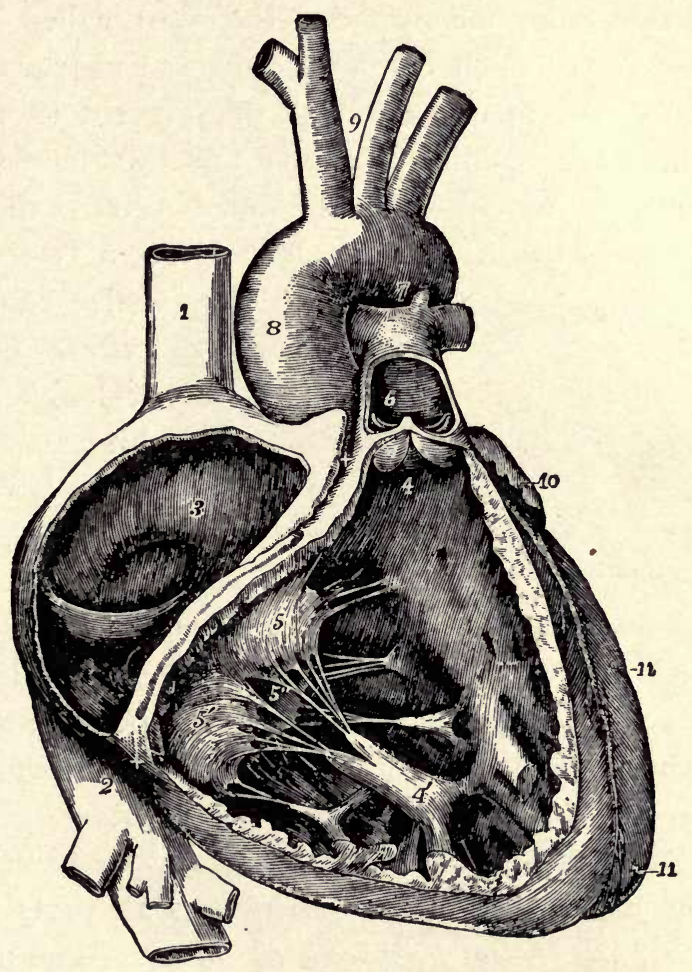

FIG. 63. - Interior of the right auricle and ventricle. (Thornton's "Human Physiology") : I, descending vena cava; 2 , ascending vena cava ; 3 , right auricle; 4 , semilunar valves; $5,5^{\prime}, 5^{\prime \prime}$, tricuspid valve; 6 , pulmonary artery; 7 , arch of aorta; 8 , aorta; 9 , large branches of the aorta; 10, left auricle ; $\mathrm{Ir}$, left ventricle.

blood, returning from the lungs, enters. In the left ventricle there are two openings; one between the 
auricle and ventricle, and one through which the blood escapes into the aorta.

These openings are all guarded by gateways, or folds of the thin lining membrane of the heart, called valves. All the valves open one way only, and so permit the blood to flow in one direction, but prevent its return. Guarding the opening between the right auricle and ventricle is a large, three-pointed valve called the tricuspid. The one in the left side is a two-pointed

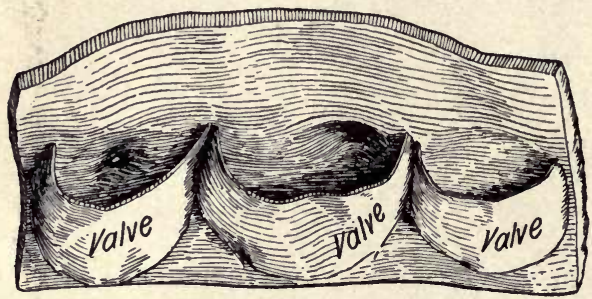

FIG. 64. - Aorta cut open, showing semilunar valves (Zuppke). valve called the mitral because it looks like a bishop's cap. The valves between the ventricles and the arteries áre called the semi-

lunar valves from their half-moon shape. Sometimes the valves of the heart do not work as they should, and the person suffers from valvular heart disease.

96. Blood Vessels. - The arteries are the vessels that convey blood from the ventricles to all parts of the body. They always lead from the heart. The arteries have thick, strong, tough walls made of muscles, elastic tissue, and a lining of very thin, smooth membrane. The muscles enable the arteries to enlarge whenever more blood is needed in any part of the body and to contract when a smaller amount is required. There are nerves which regulate the size of the arteries, causing 


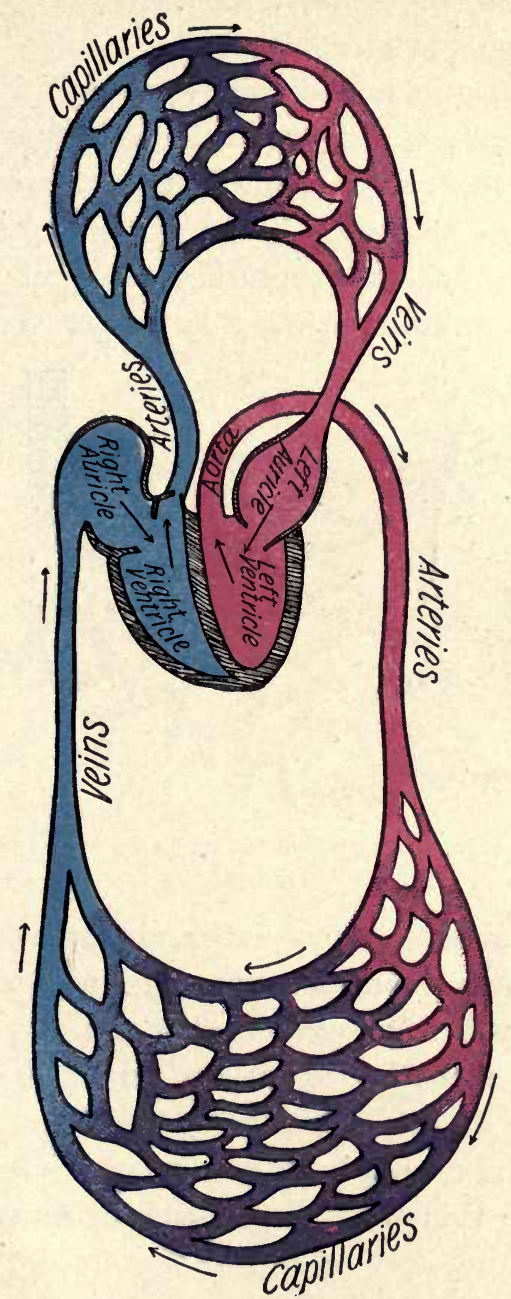

FIG. 65. - Showing the plan of the circulation (Zuppke). 
them to dilate or contract as the supply of blood in different organs may require.

The arteries divide and subdivide until they are very small and finally end in capillaries, which are the smallest blood vessels of the body. The capillaries permeate every part of the body. You cannot prick yourself with a needle without rupturing some of these little tubes. The walls of the capillaries are very thin, con-

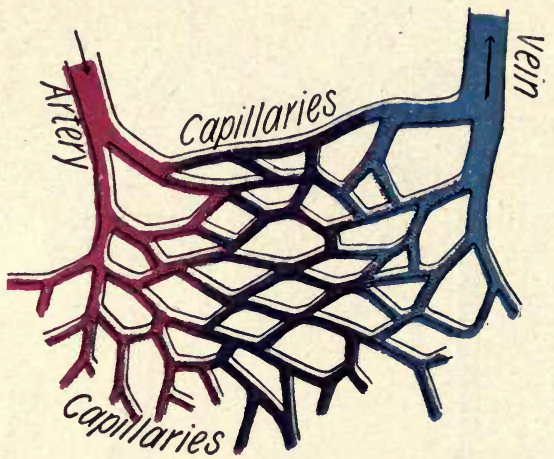

FIG. 66. - Showing the relation of the capillaries to an artery and a vein (Zinns).

sisting of a single layer of flattened, elongated cells held together by a small amount of cementing material. They are such small vessels that the corpuscles must pass through one by one, and so arranged as to be able to carry blood to each and every living cell of the body. It is from the capillaries that some of the blood escapes through the thin walls and comes in contact with the cells.

Although the capillaries are numerous in all parts of the body, they are exceedingly short, being only a small 
fraction of an inch in length. They combine and form larger vessels known as veins. In all parts of the body may be found small veins which unite to form larger and still larger ones, until there are only two great trunks, the ascending and descending vene cave, that empty into the right auricle. The function of the veins is to return the blood from the capillaries to the heart. The veins differ from the arteries in that their walls are
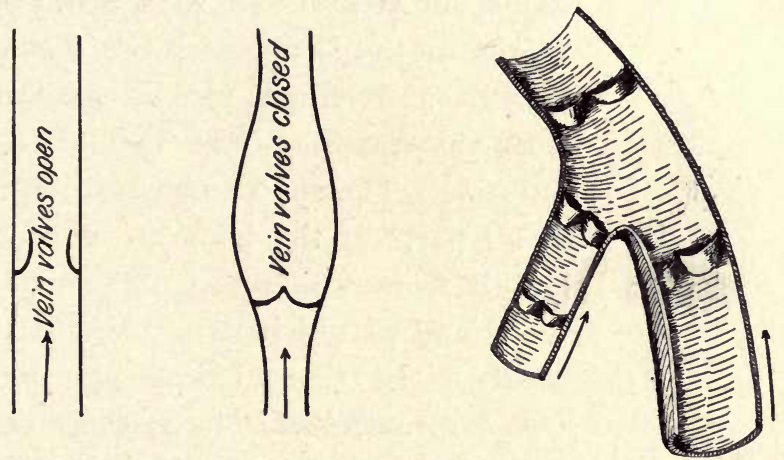

FIG. 67.- Showing valves in veins (Zuppke).

lighter and less elastic, and in that they are provided with valves which do not obstruct the flow of blood toward the heart but prevent its return to the cells. They lie nearer the surface of the body than the arteries and form the purple-looking streaks which we frequently see on the hands and arms of a thin person. Blood containing considerable oxygen is bright red in color; but as it returns from the cells, where it has exchanged most of its oxygen for carbon dioxid and other waste materials, it is very dark red. The purple color is due to 
the fact that very dark red blood is seen through the yellowish skin. The blood escaping from a cut vein looks bright red because the moment it comes in contact with air it takes up oxygen which changes its color at once.

97. Lymphatics. - Some of the blood that exudes from the capillaries and forms part of the lymph around

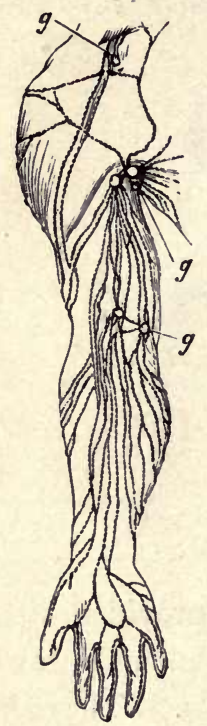

FIG.68.- Lymphatics of the right arm. $G$, lymph glands (Huxley). the cells does not again enter the capillaries but is returned to the blood by means of the lymphatics. We studied lacteals and lymphatics in connection with absorption of fats from the small intestine. The spaces between the cells in all parts of the body are filled with lymph from which the cells get their foods and to which they give off their wastes. In these lymph spaces the lymphatic capillaries have their beginning. They serve to return most of the cell wastes into the blood, carbon dioxid being the only waste that enters the capillaries and is returned through the veins. The lymphatics resemble the veins in their structure, but they are much smaller, have thinner walls, and have valves closer together.

The lymphatics may be said to begin in lymph spaces in all parts of the body. Uniting, they gradually grow larger until they form two main ducts which empty into the veins at the base of the neck. The left thoracic 
duct returns the lymph from the entire body below the diaphragm, from the left arm, and from the left half of the chest, head, and face. It empties into the subclavian vein of the left arm. The right lymphatic duct is much smaller, returning the lymph from the right arm and from the right side of the chest, head, and face. It empties into the right subclavian vein. The lymph passes through lymph nodes found along the course of the lymphatic vessels. In these the lymph may undergo certain changes, and so become fitted for use in other parts of the body.

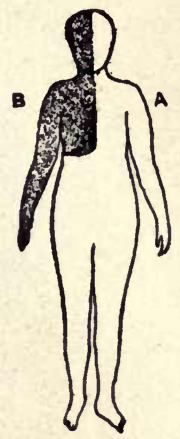

The lymphatic vessels are very important. When they work properly all of the wastes produced by the cells are drained off into the blood and not permitted to stagnate in the lymph spaces.

FIG. 69. - Parts of the body drained by each lymph trunk. (Buchholz): $A$, the left thoracic duct; $B$, the right lymph trunk.

In this way the cells have new and fresh foods carried to them as they need it, and the wastes removed as fast as they are produced. Sometimes they do not work as they should, and the lymph accumulates in the spaces around the cells, causing a disease known as dropsy.

The proper work of the lymphatics depends to a large extent upon physical exercise. Muscular movement serves as a natural massage for the lymphatics, and pushes the lymph onward toward the heart. A sufficient amount of healthful exercise makes one feel better, even in hot weather, because, when the lymph is 


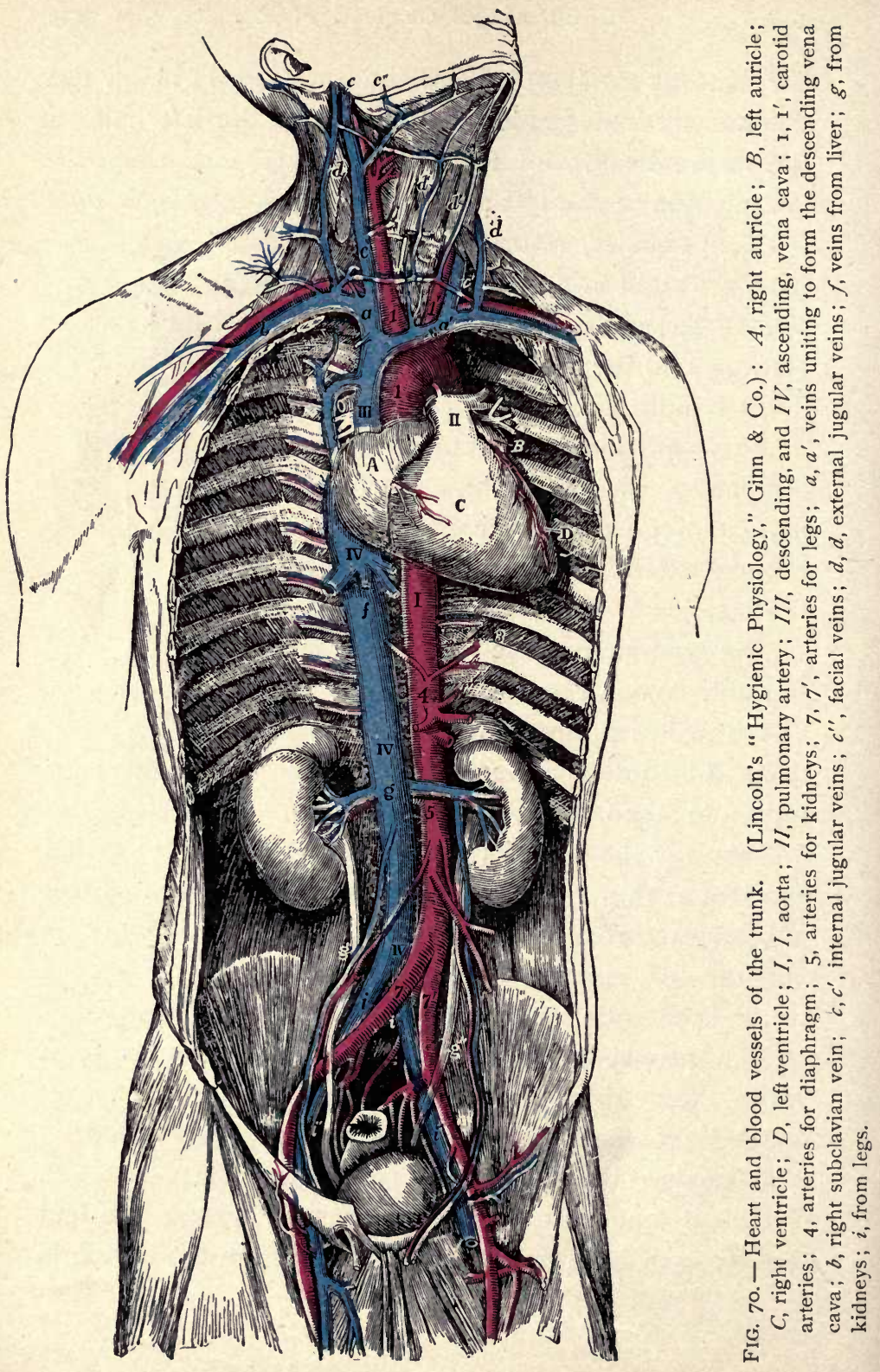


properly returned into the blood, poisonous waste materials are at once removed and so cannot interfere with the free and natural action of the cells. Exercise opens all the drainage tubes and renovates the entire organism.

98. Course of the Blood. - We saw that the ascending vena cava returns the blood from the lower extremities, the pelvic and abdominal organs, in fact, from the entire body below the level of the heart; and the descending vena cava returns the blood from the head, arms, and chest, or from the body above the level of the heart. These two trunks empty into the right auricle. As soon as the right auricle is full its muscular walls begin to contract. The blood cannot return into the large veins but must flow into the right ventricle. When that chamber is filled it begins to contract. Then the tricuspid valve closes and prevents the blood from returning into the auricle. The only opening left is the one into the pulmonary arteries which carry the blood to the lungs.

You remember how the dark blood that comes to the capillaries of the lungs is exposed to the oxygen of the air sacs. Here the blood loses carbon dioxid, organic impurities, etc., and gains a very large amount of oxygen. In this way the blood is said to be purified. The dark red, almost black, blood becomes bright red or scarlet. It is now sent back through the pulmonary veins to the left auricle.

The blood passes the mitral valve and goes into the left ventricle. When that chamber is full, the blood is forced out into the aorta. The mitral valve closing pre- 
vents the reflow of the blood into the auricle. The aorta is the largest artery of the body. It gives off branches that go to the head and arms, and then it bends down and gives off branches to muscles, to the stomach, the liver, the spleen, the kidneys, and to the intestines. In the lower part of the abdomen it divides into two

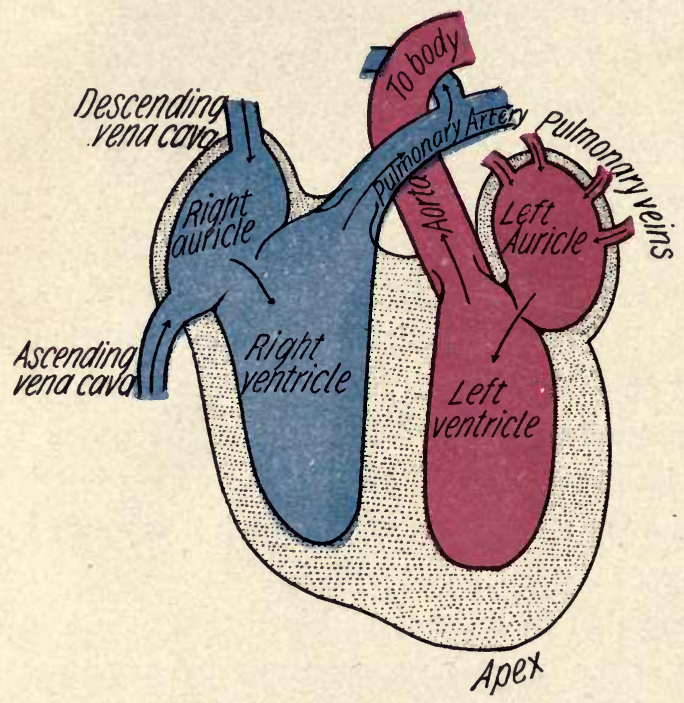

FIG. 71. - Showing the course of blood through the heart (Zuppke).

large branches called the right and left common iliac arteries. The largest branch of each of these is called the external iliac, and farther down it is called the femoral, which carries the blood to the leg and foot.

The arteries continue to divide until the vessels are smaller than the finest hair. The blood is now in the capillaries, from which some of it exudes to become part 
of the lymph around the cells. The capillaries unite to form the small veins. The blood then continues to flow on in larger and larger veins until it returns to the right auricle. Then it goes to the lungs as before and back to the left heart. In this way it keeps on circulating day and night, from birth till death. A study of figures 60 and 70 will show the course of the blood through the larger vessels.

Let us trace the blood from the right auricle to the stomach and back again: right auricle, tricuspid valve, right ventricle, semilunar valve, pulmonary arteries, capillaries of the lungs, pulmonary veins, left auricle, mitral valve, left ventricle, semilunar valve, aorta, arch of aorta, thoracic aorta, abdominal aorta, gastric artery, capillaries of the stomach, gastric vein, portal vein, capillaries of liver, hepatic vein, ascending vena cava, right auricle. In the same way blood may be traced to any part of the body.

99. Rate of Blood Flow. - The blood does not flow at a uniform rate in all parts of its course. We know that water in a stream flows most rapidly where the bed is narrowest, and for the same reason the blood flow is most rapid in the aorta and diminishes in rate throughout the arteries. In the capillaries it moves very slowly. For, although the capillaries are very small, they are so numerous that their combined area is many times that of the aorta. In the veins the blood flows faster again and increases in rate toward the heart. Figure 72 indicates the combined area of the blood vessels in different parts of the system. The rate of 
flow is so great that the blood makes one circulation from the heart to the tissues and back to the heart

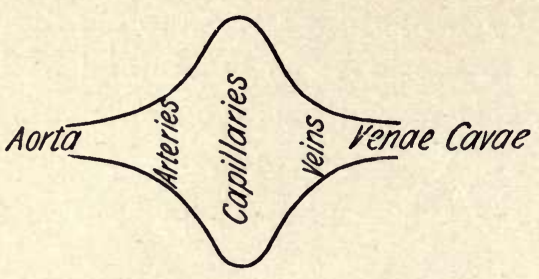

FIG. 72. - Showing how the blood vessels compare in area (Zuppke). in about twenty-two seconds. It takes the blood longer to go to the toes and fingers than to parts of the body nearer the heart. The entire quantity of blood passes through the heart about three times per minute.

100. What makes the Blood Move? - There are a number of different causes which together keep the blood in constant motion. The most important cause is the contraction of the muscles of the heart. When the strong, thick muscles of the left ventricle contract, the blood is pushed into the aorta with great force. The continued pumping of the heart keeps forcing more and more blood into the aorta and thus pushing it along through all the blood vesisels. The elastic walls of the arteries aid the heart very much in forcing the blood along.

The heart works like an automatic pump. There are two nerves going to the heart which control and regulate its activity. One of these stimulates the muscles of the heart and makes them work faster, as when we are running hard; the other checks the muscular action and makes the heart beat slower. These two nerves act like the governor of an engine. They determine the rate of the heart beat, and so the 
amount of blood that is to go through the heart all the time.

101. The Heart Beat. - The heart beats on an average about seventy-two times per minute. The rate, however, varies widely with rest and exercise, health and disease. Besides, some persons have naturally a higher average and others a lower.

\section{TAble Showing Variations with Age}

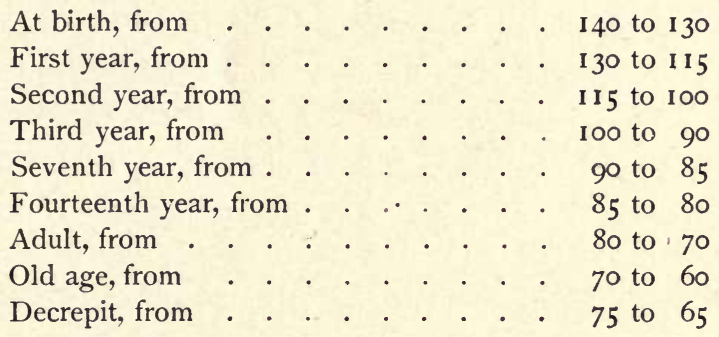

Count your own heart beat per minute at different times of the day, for different positions of the body, and under different conditions of exercise and rest. Each person should know his own pulse.

When does the heart rest? The two auricles contract at the same time and force the blood into the ventricles. Then they relax and rest while the two ventricles work together and force the blood into the arteries. In this way the auricles and the ventricles rest a little more than half the time. It is an interesting fact that the muscles of the heart contract in about the same time, whether it beats slow or fast. Now the faster the beat, the shorter must be the period of rest between the beats. 
102. Sounds of the Heart. - No machine can work without noise. If you place your ear over the region of the heart, two distinct sounds can be detected. They occur in quick succession, followed by a short pause. The first of these is a long, dull sound, caused, we think, by the sudden sharp contraction of the ventricles. The second is a sharp, short click caused by the closing of the semilunar valves. These two sounds are said to resemble the syllables "lōb," "dŭp."

To the physician these sounds indicate the condition of the heart. He has an instrument, called the stethoscope, by means of which he can study the heart sounds very accurately. Any change in their normal pitch, force, or rhythm means a certain organic disturbance or disease.

103. The Pulse. - When the ventricles contract blood is forced out into the arteries, and their walls dilate to make room for it. At every beat of the heart

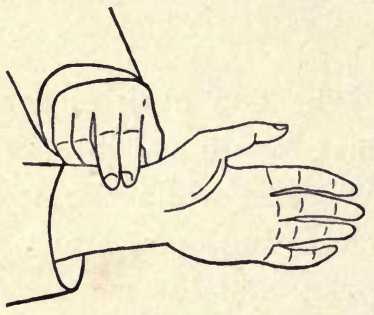

FIG. 73. - Showing how to find the pulse (Scheinert). the arterial walls bulge out, for they are as elastic as rubber tubing. Then the walls contract and push the blood onward, causing a similar wave elsewhere. These pulsations in the arteries, due to the contraction of their elastic walls, constitute the pulse.

As a rule, the larger arteries lie near the bones and quite removed from the surface of the body, but at certain places they come near the surface. Pulsations 
of the radial artery at the wrist, the temporal artery just in front of the ear, and the carotid on either side of the larynx can be easily felt.

104. Alcohol and Tobacco. - Alcohol acts upon the blood, the arteries, and the heart itself. It impoverishes the blood by acting upon the corpuscles, thus decreasing its capacity for carrying oxygen. The effect upon the blood vessels is to dilate them. For this reason the skin looks flushed and red; the capillaries become enlarged; and the person feels warm while the body is really giving off a large amount of heat, which must lower the temperature of the body. It is said that deposits of fat are made in the walls of the arteries and of the heart, thus weakening and predisposing them to disease.

The nerves controlling the heart and arteries are paralyzed by alcohol. The heart now acts like a runaway horse, beating very rapidly and attempting to fill the much distended blood vessels.

The nicotine of tobacco acts as a poison on the nerves of the heart. This is probably its most harmful effect upon the body. The heart beat becomes irregular and less vigorous. The nerves are no longer as delicate and sensitive as they should be. The smoker's heart goes on beating at nearly the same rate day and night, thus robbing the heart of a certain amount of rest that is necessary to keep it in a perfectly healthy condition. It is believed by scientists that many of the cases of fatal heart disease may be traced to the use of tobacco. 


\section{SUMMARY OF THE MAIN POINTS}

I. The heart is the central organ of circulation. It is a hollow, muscular organ situated in the chest, between the lungs, and covered with the pericardium.

2. The heart is five inches long, three and one half inches wide, weighs about ten ounces, and consists of four chambers, - two auricles and two ventricles.

3. The tricuspid valve is on the right side between the auricle and ventricle, and the mitral on the left; and the semilunar valves are at the beginning of the arteries.

4. All blood vessels leading from the heart are called arteries. They have heavy, elastic, muscular walls, and carry blood to all organs and tissues of the body.

5. The arteries grow smaller and smaller until they shade off into the very thin walled capillaries. These are so numerous everywhere that you cannot pierce the skin with a fine needle without injuring several of them.

6. The capillaries unite and form larger vessels, called veins, which grow larger and larger until there are only two great trunks. The veins return the blood from the capillaries to the right auricle.

7. Lymphatic capillaries begin in lymph spaces all over the body and serve as drainage tubes to return most of the wastes into the blood.

8. The thoracic duct returns the lymph from the entire body below the diaphragm and from the left half above the diaphragm. The right lymphatic trunk is much smaller; it returns the lymph from the right half of the body above the diaphragm.

9. A moderate amount of daily exercise is essential to the proper circulation of both blood and lymph. The wastes stagnating in the lymph spaces lead to disease. 
Io. The blood flows from the right ventricle to the lungs, where it is oxygenated; then it returns to the left heart, from which it is forced out into the aorta that distributes it by means of its numerous branches to all the capillaries of the body. From the capillaries it enters the veins and is brought back to the starting point.

I I. The blood completes one entire circulation in about twenty-two seconds. The rate of flow is fastest in the aorta and arteries, slower in the veins, and slowest in the capillaries.

I 2. The chief function of the heart is to pump blood into the aorta under an immense pressure that causes the walls of the aorta to bulge out greatly. These elastic walls contract and force the blood onward in its course.

13. The heart beats about seventy-two times per minute in the adult. The two auricles work together and then the two ventricles. In this way the heart rests a little more than half the time when beating at the normal rate.

14. The first sound of the heart is long and dull, and occurs when the ventricles contract. The second is short and sharp; it occurs when the semilunar valves close.

I5. The walls of the arteries are elastic, like rubber tubes, and distend when blood is forced into them by the ventricles.

16. Alcohol acts on the red corpuscles, causing them to shrink. It acts upon the walls of the arteries and the heart, causing fatty degeneration, and in this way weakening them. Alcohol and tobacco both have a specific action upon the nerves that control the size of the blood vessels and the action of the heart. 


\section{CHAPTER XI \\ FOODS IN THE TISSUES}

105. Review. - We have traced the foods and oxygen into the blood and have studied the organs by which the blood is distributed to all parts of the body. As yet the foods have been of no value, in fact they have been an expense at every step without yielding any return. Energy has been used in cooking and preparing foods for the table, and then mastication, digestion, and absorption have cost much labor. Then, by the hard work of the heart, they are forced through the arteries, capillaries, and veins. But while the blood passes through the thin-walled capillaries much of the oxygen, albumin, sugar, fats, water, and salt exudes through the walls of the capillaries and forms part of the lymph. Now the foods are within reach of the cells; they are soon to serve their real purpose.

106. The Lymph. - We have learned something about the lymph in former chapters. It is quite like blood in composition except that it contains no red corpuscles because they cannot pass through the walls of the capillaries. It is about ninety per cent water, and the remainder consists of solids held in solution. The cells select from the blood what they need for their own use, 
and so we find in the lymph all of the foods that occur in the blood. Albumins, sugars, fats, water, salt, and oxygen are all present in the right proportions.

The cells give off their worn-out and waste materials to the lymph. These are carbon dioxid, water, ammonia compounds, and many other products in small quantities. Some of these wastes may be of value elsewhere in the body. The cells live in this liquid medium,

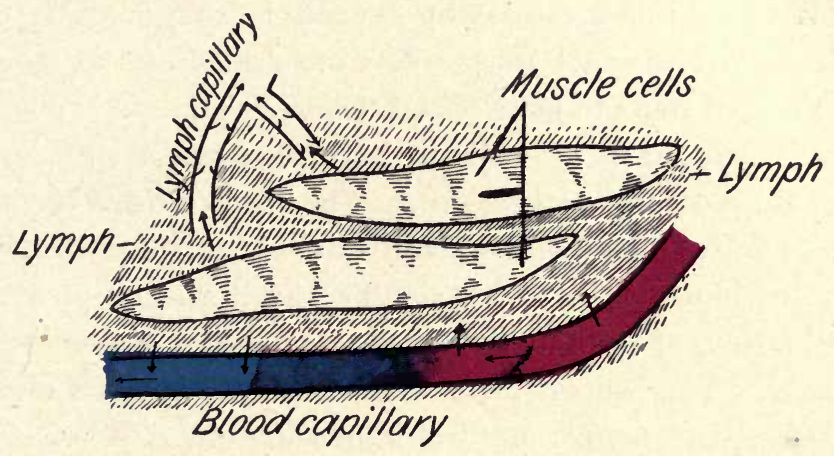

FIG. 74. - Showing the relation of blood capillaries to muscle cells and to lymph capillaries (Zuppke).

in which they find all the foods they need and to which they can give all their useless and worn-out matter. The lymph serves a very important purpose in the body.

107. The Cell. - The foods found in the lymph are taken into the cells and used for various purposes. The albumins are used to repair the cells as fast as they are worn out. The cells would wear out and die if we did not eat enough proteid food stuffs to keep them repaired. The albumins may also be oxidized and liberate heat. All growth is due to the albumins. 
The sugars and fats enter the cells and are made to combine with oxygen, i.e. to burn like coal in a furnace, and produce heat to keep us warm. When coal is burned it produces a certain amount of ash, and so these foods leave wastes that must be removed from the cells. In some strange way part of the heat derived from the oxidation of the foods is changed to other forms of energy and enables us to play, to work, and to think.

We now understand why oxygen is so necessary to life. Coal will not burn when the drafts of the stove are closed so as to shut off all the air. The foods could not be burned in the cells if there were not a sufficient quantity of oxygen present. The oxygen is made to unite with sugars, and as a result we get heat, water, and carbon dioxid. In a similar way it will unite with the carbon of the fats and yield heat, water, and carbon dioxid. The process of growth and cell repair requires an adequate supply of this important gas. When we do not breathe a sufficient amount of good, pure air, the foods cannot be properly oxidized. Instead of the wastes that should be formed there are produced partially oxidized products of a very harmful nature.

Water is indispensable not only in the blood and lymph, where it serves as a solvent, but also in the cell itself. The protoplasm of the cell has a large percentage of water. The normal activity of the cell cannot be carried on without a liberal supply of water. Hence it is a good thing to drink pure, fresh water freely. Salt is not oxidized, but it seems to be important in stimulating and regulating the activity of the cells. 
108. The Wastes. - The oxidation of foods in the cells gives rise to certain waste products that must be removed. The albumins form water and carbon dioxid, and ammonia compounds, as kreatin. From the sugars and fats, carbon dioxid and water are the important wastes. Salt and water leave the cells in the form in which they reached them.

These wastes are produced in the cell and then given off to the lymph. What becomes of them? Most of the carbon dioxid enters the capillaries of the blood and is carried back to the heart by means of the veins. Then it goes to the lungs, where it is given off to the air sacs and exhaled. The other wastes reach the blood through the lymphatics. In the lymph spaces all over the body there begin small lymphatic capillaries. Much of the water, salts, kreatin, etc., enters the open mouths of these tiny vessels and is drained away by them. These wastes reach the blood through the great lymph trunks that empty into the subclavian veins. Now the wastes are in the blood.

109. Changes in the Blood. - Some of these products may be of value to other cells and so are kept in the blood. There are many organs of the body whose chief business it is to change the blood as it circulates through them. The liver is an organ of this kind. We have learned some things about the liver in former chapters. Besides doing the things mentioned before, this large and important organ serves as a crematory for certain waste products that come from the cells. Here urea is manufactured from ammonia compounds. The 
urea then enters the blood and is carried along in it until the kidney is reached, where it is picked out and removed from the body.

Among the other organs that are especially helpful in changing the blood as it passes through them may be mentioned the pancreas, the thyroid bodies, the adrenals, the lymph nodes and perhaps the spleen. The adrenals are small bodies just above the kidneys, and it is thought that they produce a substance that has an important action upon the heart and arteries.

The thyroid bodies are situated in the neck, one on either side of the trachea near its upper end. They are dark red in color and somewhat granular in structure. Sometimes these bodies enlarge very much, causing the disease known as goitre. These bodies are important in two ways: first, they remove from the blood certain poisons made by the action of the cells; second, they produce a substance which is of use in keeping all the organs of the body in a good condition. When the thyroid bodies do not work as they should the blood is deprived of their product, and the person suffers from a disease known as thyroid starvation.

In children such a condition may result in a form of idiocy (cretonism). A person suffering from thyroid starvation may be helped by eating prepared thyroid glands obtained from the sheep or the calf. The large packing houses have put on the market prepared thyroid glands for this purpose.

The splecn is located in the abdomen to the left of the stomach. It is an oblong, flat, reddish gray body that 
has an abundant blood supply. The spleen is small during digestion, but grows larger a few hours after meals, reaching its greatest size about the fifth hour, and then it slowly diminishes to its usual size. It is always small in starved animals. This organ has been carefully studied by scientists, but they cannot say as yet what functions it performs. It is thought by some that it aids the liver in changing certain ammonia compounds, that it manufactures white corpuscles, and that it helps to destroy the worn-out red corpuscles.

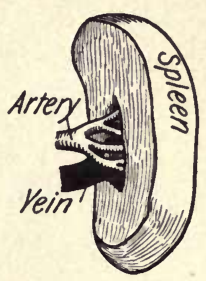

FIG. 75. - The spleen, front view (Zuppke).

The spleen has been entirely removed in cases of disease without causing any serious injury. It may be that other organs carry on its functions when the spleen is removed.

110. Animal Heat. - The oxidation of foods in the cells gives rise not only to these harmful waste products but also to a large amount of heat. We know the fire in a furnace or stove will go out when the fuel is consumed. If we wish to have it burn at a uniform rate fuel must be added from time to time. The temperature of the human body is kept at about $98 \frac{1}{2}^{\circ} \mathrm{F}$. in health. Even a very slight variation from the normal temperature is accompanied by either a fever or a chill. In man a temperature of $102^{\circ} \mathrm{F}$. means that combustion is too rapid, and something should be done to restore it to the normal. During periods of starvation or great prostration, and in certain diseases, the temperature may fall several degrees below the normal. A temperature of $92^{\circ} \mathrm{F}$. usually proves fatal. 
One of the most important purposes of the foods we eat is to furnish heat to keep us warm so that all the cells may do their work as they should. The oxidation of fats liberates much more heat than can be obtained from any other food stuff. That is the reason why so much fat and oil is eaten by people living in cold countries. It is really the best food stuff to keep them warm. In warm climates, however, very little fat is eaten. The proteids and carbohydrates, when completely oxidized, are about equally valuable as heat producers; they liberate about half as much heat as the same weight of fat does.

About ninety per cent of the heat produced daily comes directly from the oxidation of the foods eaten. A small amount comes from the warm substances taken into the body, and from the friction caused by the movement of the blood, the action of the muscles, and from still other sources.

111. Loss of Heat. - The amount of heat produced every twenty-four hours is very great, and yet the temperature of the body remains unchanged. What becomes of it? About one fourth of the heat may be transformed into mechanical energy and used in doing work. The remaining three fourths is slowly lost; it keeps up the temperature of the body, and then some of it radiates from the skin into the surrounding air, which is usually cooler than the body. The air we inhale, the water we drink, and many of the foods we eat are cooler than the body, and hence some of the heat is used in raising the temperature of these things. All of the wastes 
that leave the body, as the exhaled air, the sweat, and the material excreted from the kidneys and bowels, carry with them a large amount of heat.

112. Regulation of Temperature. - Some animals take on the temperature of the medium in which they live. If you place a frog, a lizard, or a fish in cold water for some time, its blood will be nearly as cold as the water. Should you raise the temperature of the water slowly, they would adapt themselves to great changes. The temperature of their blood depends upon and is regulated by their environment. Such animals are said to be cold blooded.

In man and the higher animals the production and loss of heat are controlled by the nervous system. The skin is the important regulator of the loss of heat. When the pores of the skin are open and the sweat glands are busily at work, a large amount of heat may be lost by perspiration. Again, the capillaries of the skin may dilate and expose a large amount of blood to the surface of the body, from which heat will radiate rapidly. All this is controlled by the nerves of the skin.

The kind and amount of clothing we wear are important factors in regulating the loss of heat from the skin.

\section{SUMMARY OF THE MAIN POINTS}

I. Lymph is blood without red corpuscles. It contains all the foods and wastes of the cells.

2. Albumins are the building and repairing foods. No growth occurs without them. They are also oxidized. 
3. The fats and sugars are oxidized and produce heat. Their wastes are carbon dioxid and water.

4. Water and salt are not changed in the cells but are important in building up and repairing and in stimulating the cells to activity.

5. Carbon dioxid, ammonia compounds, and all other waste materials formed in the cells are given off to the lymph.

6. The carbon dioxid enters the blood capillaries and is carried to the lungs, where it is selected out of the blood and exhaled from the body.

7. The other wastes are drained off through the lymphatics which finally empty into the subclavian veins near the base of the neck.

8. The liver, pancreas, thyroid bodies, adrenals, lymph nodes, and perhaps the spleen are active in producing important changes in the blood as it circulates through them.

9. The useless proteid products are changed to urea in the liver and thrown back into the circulation.

ro. The oxidation of foods in all cells of the body produces a large amount of heat that is used to maintain the body temperature at $98 \frac{1}{2}^{\circ} \mathrm{F}$. and to furnish energy. Friction produces a small amount of heat.

I I. The heat is lost by (I) radiation from the skin, (2) the escape of watery vapor from the lungs and skin, and (3) the excretion of material from the kidneys and bowels.

I 2. There are nerves which regulate the production and the loss of heat. 


\section{CHAPTER XII \\ THE SKIN AND THE KIDNEYS}

113. Review. - We have traced the foods from the time they entered the mouth through the many changes of digestion, absorption, circulation, and oxidation in the cells, until they were finally changed into useless substances. They have served their purpose. The removal of the wastes from the body is just as important to health as the taking of nutritious foods. A large city has trains and boats bringing food to supply its inhabitants, but equally important and often more difficult to solve is the problem of how to get rid of the garbage and sewage.

In the body we find certain organs whose chief business it is to remove the wastes from the blood and to eliminate them from the body. The lungs, intestines, skin, and kidneys together keep these useless and harmful products from accumulating in the blood. They are the organs of excretion. We have learned that the lungs remove carbon dioxid, and the large intestine removes certain indigestible parts of the foods and wastes poured into the alimentary canal. We shall now study the skin and the kidneys to see what part they play in removing the wastes from the body. 
114. The Skin. - The skin is a soft, tough, loosely fitting covering of the entire surface of the body. It is really somewhat like the mucous lining of the respiratory and digestive organs. Under the skin we find a layer of fatty substance which serves as a kind of blanket to keep us warm in cold weather, protect the delicate parts beneath against injury, and to round out the form, making it more beautiful. In old age, long sickness, and starvation this fat may be used by the cells, and the person grows thin and the skin becomes wrinkled.

The skin consists of a thin outer layer, the epidermis, cuticle, or scarfskin, and of a thicker under layer, the

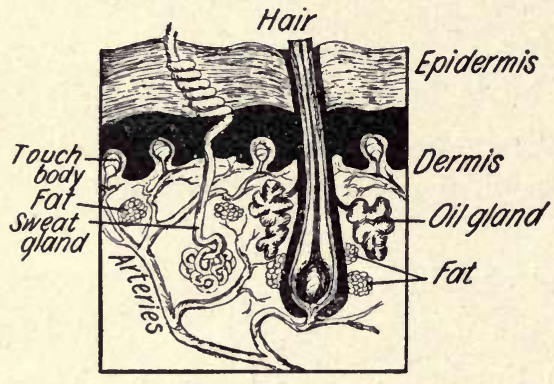

FIG. 76. - A vertical section of the skin (Newell). dermis, cutis, or true skin. The raised part of a blister is the epidermis. When this is cut away the dermis may be seen below.

The epidermis consists of round and flat epithelial cells closely packed together so as to form a very firm but thin protecting membrane for the dermis. On the soles of the feet and the palms of the hands the epidermis is quite thick. A callus may develop in the epidermis whenever it is subjected to pressure for a long time. There are neither nerves nor blood vessels in the outer layer. The rounded 
epithelial cells in the under surface are nourished by lymph that comes from the capillaries of the dermis, while the flattened, dead, horny, or scaly cells of the outer surface need no nourishment. These cells are continually dropping off. In the deeper parts of the epidermis we find very tiny particles of coloring matter known as the pigment. In different persons and races the pigment varies in color from a pale pink to a dark brown or black; and in amount, from none at all in albinos and a little in white persons, to a great abundance in deep-black negroes. Sometimes the pigment is not evenly distributed, but occurs in patches called freckles. The complexion depends upon the kind and amount of pigment in the scarfskin.

The dermis is well supplied with blood vessels and nerves. The epidermis dips down into the true skin between little projections called papilla. In these papillæ of the dermis are located the nerve endings which enable us to have sensations of touch, pain, and temperature.

115. Glands of the Skin. - In the skin are found two kinds of glands secreting very different fluids. They are the oil or sebaceous glands, and the sweat glands.

The sweat glands are long, convoluted tubes extending down into the true skin and opening by small pores on the surface of the epidermis. These glands occur in the skin everywhere but are most numerous in the palms of the hands and the soles of the feet. It has been estimated that in man there are between two and three millions of sweat glands. These glands are constantly active, se- 
creting sweat. Usually the secretion evaporates as soon as it reaches the surface of the skin, and you would not know that the glands were at work at all. This we call insensible perspiration. On very hot days or during vigorous exercise the amount may be so great as to accumulate in drops that can be seen on the surface of the skin. This we call sensible perspiration. About two

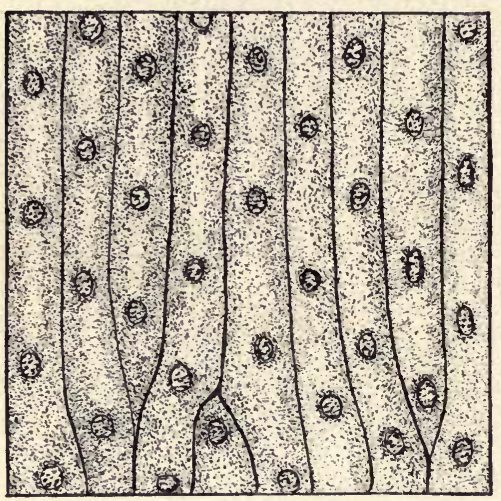

FIG. 77. - A piece of skin of the palm of the hand, showing pores of the sweat glands, and grooves between the papillæ (Newell).

pounds or one quart of perspiration is produced on an average every twenty-four hours, and a very much greater amount on a very hot day. The purpose of the sucat glands is to remove from the blood organic wastes, salts, and water; and hence we call them true organs of excretion. They have still another function more important than this. A large amount of heat, about eighty per cent of all that leaves the body, escapes through the skin. It is the perspiration evaporating from the surface of the skin that cools the body when there is danger of becoming overheated. In this way the skin regulates the body temperature.

The oil or sebaceous glands are situated near the roots of the hairs and pour their secretions into the little 
pits, called hair follicles, in which the roots of the hairs are embedded. They secrete a natural oil for the hair and skin. This keeps the skin in a soft and pliable condition and protects the body against absorbing too much moisture from the air. These glands are especially numerous on the face but occur all over the body except on the soles and palms.

116. Appendages of the Skin. - On the end of each finger and toe the true skin is covered by a piece of very much modified horny epidermis called a nail. The sides and root of the nail are covered by folds of the skin in such a way as to make a little pocket, out of which the nail appears to grow. The nails, like the epidermis, are without nerves and blood vessels. The nail itself is colorless and quite transparent.

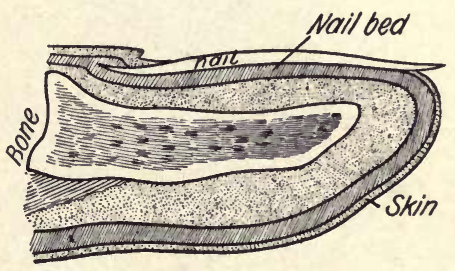

FIG. 78. - A vertical section of a finger naii (Zuppke).

The pink color is due to numerous capillaries in the nail bed beneath. Nails grow by the formation of new cells at their roots, which slowly push the nail forward. If the epidermis overhanging the root and the sides of the nail is not carefully pushed back every few days, it may become broken and tear up into the flesh, forming the so-called hangnails. The hangnails should not be pulled out but cut off close to the skin. Besides being very painful, they offer little openings through which poisonous matter may enter the blood. The nails should be washed with soap and warm water and carefully cleaned 
with a nail brush. A knife should never be used, except for trimming the nails. It is best to cut the finger nails in a curved direction and the toe nails straight across.

The entire body, except the palms and soles, is cov. ered with a growth of hair, fine and scanty in some

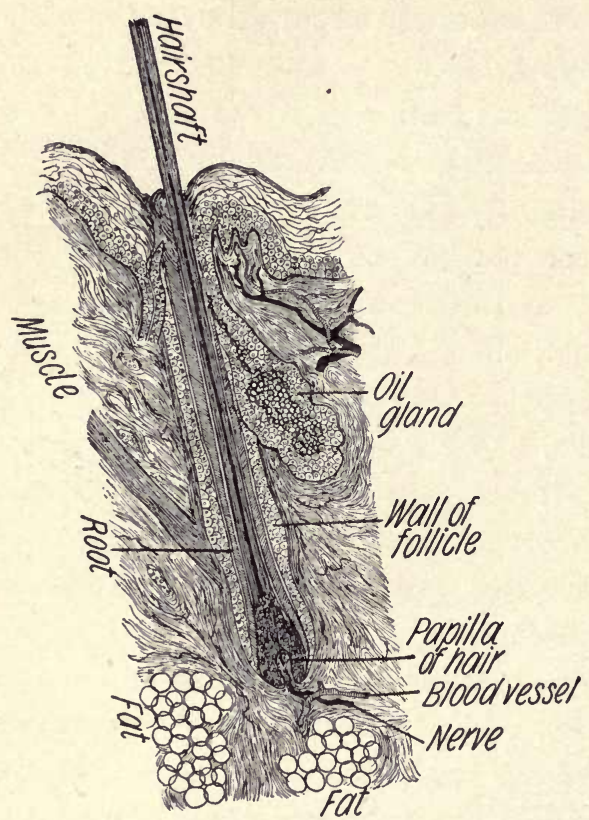

FIG. 79. - Showing a hair follicle. (Modified from Heitzmann by Zinns.) places and coarse and abundant in others. A hair consists of two parts: a shaft above the surface of the skin, and a root beneath, placed in a little sac or pocket of epidermis called the follicle. Sometimes the follicle extends down through the true skin into the layer of fatty tissue below. Blood vessels enter the follicle at the lower end, carrying nourishment to the root, where the hair grows by the constant formation of new cells which slowly push the hair upward.

The color of the hair is due to small air bubbles and pigment cells in the hair substance. In old age no color- 
ing matter is deposited in the hair, and it becomes gray. Nerves and little fibers of muscles are in contact with the hair follicles. It is by means of these muscles that the skin ruffles to form goose pimples and the hairs
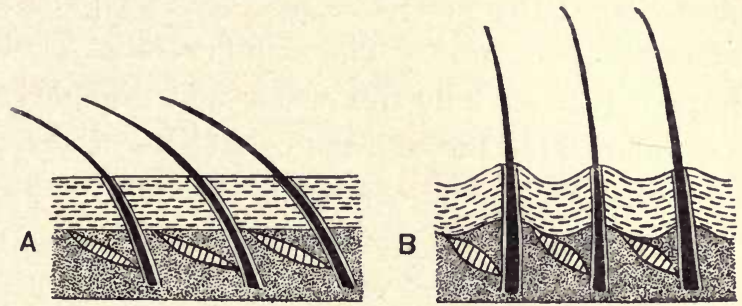

FIG. 8o. - Showing, in $A$, muscle fibers at rest and hairs in usual position, and, in $B$, muscle fibers contracted and hairs standing on end. (Modified from Hall by Zinns.)

"stand on end." The hair has various useful functions besides serving to adorn the human body. The growth on the head protects us against cold, and excessive heat from the sun's rays, and against the effect of blows. The eyebrows, eyelashes, and the hair of the nose and ears all serve as protecting organs.

The hair should be washed or shampooed often enough to keep the scalp clean and free from dandruff. For this purpose any good toilet soap may be used. A stiff hair brush and a coarse comb with blunt teeth should be freely used to keep the scalp in good condition and the hair in order. If the scalp is pale and the hair thin, a daily massage of a few minutes will improve the circulation, and tend to increase the growth of the hair.

117. Care of the Skin. - We have seen that the skin is one of the chief organs for removing wastes, ranking 
next to the kidneys in the excretion of water and organic matter, and have also learned that it is the chief organ for controlling and regulating the body temperature. It forms-an admirable protecting membrane, being tough and firm, and at the same time very pliable; this is its most important function. The skin is also an organ of respiration, for not only are water and organic waste products eliminated through the capillaries of the skin, but quite a large amount of oxygen is taken in through it. In certain diseases the patient is immersed in a warm nutrient bath, as milk, and enough food may enter the blood through the skin to nourish the body. We may then call it an organ of absorption. It is also the organ of touch and temperature. Because it does so many things it should be given special care. How can we care for the skin? There are really only two important things to bear in mind. One is regular bathing and the other proper clothing. Of course the kind and amount of food, exercise, and rest, as well as the general condition of the body, are important in keeping the skin in a good, healthy condition.

118. Bathing. - The value of bathing as a sanitary measure is not sufficiently understood and appreciated at present by most people. Let us see what some of the results are. In the first place bathing serves to cleanse the skin from dirt, oils, and waste matters that continually accumulate on it. The perspiration pores may be closed up if all such matter is not washed off. Keeping the pores open and the skin clean aids very much in preventing colds, fevers, skin eruptions, and 
contagious diseases of all kinds. It also increases the digestive and assimilative powers in general.

Baths may be classed as hot, warm, tepid, cool, and cold water baths, depending upon the temperature of the water used; and as Turkish, Russian, Roman, mineral, sea, and mud baths. The cold bath should be taken the first thing in the morning or some time after breakfast. Its chief value is in contracting the pores and blood vessels of the skin and driving the blood to the internal organs; increasing the respiration; diminishing the pulse; lowering the temperature; and stimulating the nervous system. Upon coming out of the bath a reaction should follow at once. The capillaries dilate, the respiration and heart beat become normal, the temperature rises somewhat, causing a feeling of warmth and buoyancy. This reaction may be hastened by rubbing the skin vigorously with a rough towel. Many find a cold sponge or shower bath preferable to a plunge, especially during cold weather. A cold bath taken every morning renders a person almost immune against colds which are so common at certain seasons of the year. A person not accustomed to the cold bath must exercise great care in becoming habituated to it.

The warm bath has a very different effect and is taken at a different time and for quite another purpose. It opens the pores and dilates the capillaries of the skin; forces the blood to the surface; increases the perspiration; quickens respiration and the heart beat; raises the body temperature; and soothes the nervous system often to such an extent as to make the person 
drowsy and sleepy. When the muscles feel sore, as after severe physical exertion, a warm bath will afford almost immediate relief. Those who find it difficult to go to sleep may find a warm bath just before retiring very helpful.

The tepid and cool bath have no special physiologic virtue and are taken for the purpose of cleansing the skin. The other baths are generally employed for their medical effects, when recommended by a physician, and need not be discussed here.

Many suppose the sea bath to possess wonderful virtues. The novelty, change of scene, fresh, pure ocean air, together with the cheerfulness with which seashore life is accompanied, go far to make up the advantages said to come from sea-bathing.

The soap used in bathing serves to dissolve the grease and oil, and so is necessary to a thorough cleansing. Any good toilet soap may be safely employed by most persons. The so-called medicated soaps possess little virtue.

The best time to take a bath is a short time before a meal or from three to four hours after it. The very strong can take a bath any time of day, but most persons must exercise some judgment in the matter. Those who take a cold bath will find it most invigorating in the morning; it should never be taken after fatiguing exercise or just before retiring. Both the kind and time of bathing are subject to wide individual differences and should be adapted to the age, occupation, and general health and temperament of the person. No 
specific directions can be given for all to follow. Just as in eating and in many other matters, each person may choose for himself within certain general limits that apply to all.

119. Clothing. - The chief purposes of clothing are: (I) to help the skin regulate the body temperature by keeping in the animal heat in cold weather and by permitting it to escape in warm weather; (2) to protect the body against heat, dust, and other uncomfortable and harmful influences of our environment; (3) to satisfy the feeling among civilized nations that the body as a whole should be covered; and (4) to adorn and beautify the body by wearing clean and well-fitting garments. The last purpose is often allowed to become so important as to interfere seriously with the physiologic and hygienic purposes mentioned first.

All clothing should fit all parts of the body loosely. Tight clothing should be avoided, for it checks the circulation of the blood, interferes with the natural functions of the organs and with physical comfort in general. All parts of the body should have the utmost freedom. The arms and legs should not be restricted in their movement; the chest should be free to enlarge in all directions; and the stomach, liver, kidneys, and intestines should not be pushed out of position. There is, perhaps, no part of the body more abused from poorly fitting clothing than the feet. How often shoes are purchased to "fit the head" and not the feet! Swellings, corns, bunions, ingrowing nails, and other deformities and diseases of the feet are in every case the result of shoes 
that do not fit the feet. Shoes may be too large, too small, or uncomfortable for some other reason. The French heel and the long, pointed toe do not fit any foot. Tight bands, as elastic garters or elastic shoe

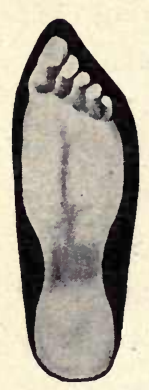

A

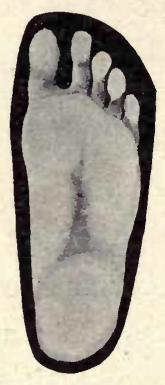

B
Fic. 81. - Showing, in $A$, a foot distorted by tight shoes, and, in $B$, a natural foot (Zuppke). tops, interfere with the circulation of the blood, causing the veins to enlarge permanently. Tight clothing may seriously impair the health. In this whole matter the one important caution to heed may be stated in this way: All clothing should permit the utmost freedom of movement to all organs and members of the body and contribute to the fullest extent to our physical comfort.

The amount of clothing should be ample to keep the body in a comfortable condition, but not tend to cause free perspiration. There is danger in wearing more clothing in cold weather than is really necessary, because any part of the body constantly overheated becomes tender and highly sensitive to the slightest ordinary changes in temperature. Mufflers, tippets, or fur collars worn about the neck are the cause of many a sore throat and cold. The parts of the body that require most clothing are the stomach and chest, the back and shoulders. More clothing is necessary in the evening than during the day, for the system liberates less heat at night. Damp and wet garments are dangerous because 
they take heat from the body and hence lower its temperature very fast. All garments worn at night, as well as the bedclothes, should be thoroughly aired and sunned every morning so as to keep them perfectly dry and free from disease germs.

120. The Kidneys. - The kidneys are bean-shaped organs, about four inches long and two inches wide, located in the back part of the abdomen, just below the last rib, one on either side of the backbone. They are covered with a capsule of fat. In $m$ appearance the kidneys in man are quite like those of the sheep. There are two quite distinct layers in the kidneys, the cortex on the outside and the medulla on the inside. In structure, the kidney resembles the skin in many ways. If you can imagine a small piece of skin turned inside out, with the

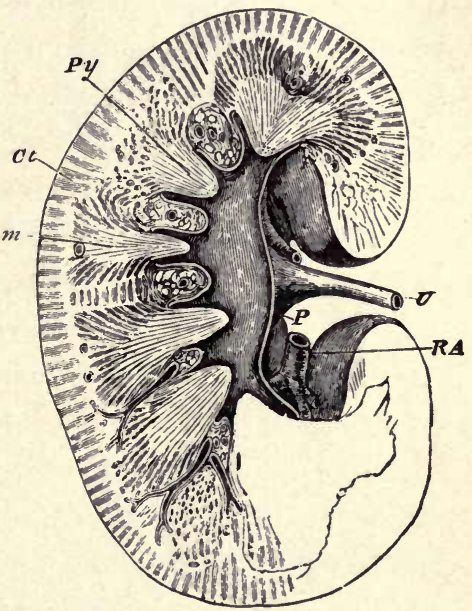

FIG. 82. - A longitudinal section of the kidneys (Huxley) : $C t$, cortex ; $m$, medulla; $P y$, pyramid in the medulla; $P$, pelvis; $U$, ureters; $R A$, renal artery. two layers thickened considerably and folded up in the shape of a bean, you have some idea of the real structure of the kidney. Like the skin they contain glands in the cortex, and many long, fine tubules winding back and forth in the cortex and medulla. These 
tubes finally empty their excretion into an open space near the concave surface of the kidney, called the pelvis. The glands, tubules, and pelvis are lined with a mucous membrane, thick in some parts and thin in others.

The kidneys are very useful because they are the principal organs for the removal of water, urea, and

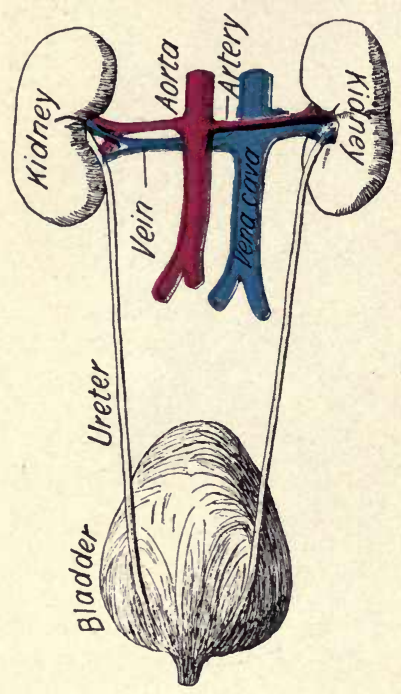

FIG. 83. - The kidneys and bladder (Cheever). other waste matters. In warm weather the skin probably removes as much water as the kidneys do. The skin also excretes some salt and urea, but most of these wastes are removed through the kidneys. Urea is manufactured from ammonia compounds in the liver. It then enters the blood and is distributed to all parts of the body. When the renal arteries carry it to the glands and tubules of the kidneys, it is picked out of the blood and poured into the pelvis. The solid urea and other poisonous wastes are dissolved in a large amount of water; this is known as urine. All urine is carried from the pelvis of the kidneys to the bladder by means of the ureters, slender ducts about sixteen inches long. The bladder serves as a reservoir for the urine, from which it is periodically discharged from the body. About three pints of urine are discharged from the body every day. 
121. Diseases of the Kidneys. - The chief causes of diseases of the kidneys are the following: exposure to cold, failure to keep the skin clean and its pores open, excessive use of alcoholic beverages, indulgence in harmful condiments, as mustard, pepper, etc., displacement of these organs due to unhygienic postures of the body and tight clothing, infection by certain bacteria, and habitually eating too much rich foods that are imperfectly oxidized in the cells. How do colds affect the kidneys? There is a close relation between the skin and kidneys, and when the pores of the skin are closed, and the blood is driven to the internal organs because of prolonged cold, the kidneys must excrete the wastes ordinarily removed by the skin, and at the same time care for the extra amount of blood forced to them. This extra work the kidneys will do as long as they can, but sooner or later they become diseased from inflammation and overwork.

All diseases, as measles, scarlet fever, etc., accompanied by an eruption or rash on the skin, cause a congestion and inflammation of the kidneys that make them weak and especially liable to disease. During and inmediately following such diseases, it is necessary to see that the kidneys are not exposed to cold nor overworked.

If the kidneys be removed from an animal, it can live only a few hours. The poisonous wastes accumulate in the blood and soon cause blood poisoning. When these organs are diseased, the functions of all the organs of the body are impaired. The proper removal of the 
wastes is a very important matter that cannot be neglected without serious danger.

122. The Effect of Alcohol upon the Skin and Kidneys. - We have already learned that alcohol acts upon the blood vessels, causing them to dilate and so giving the skin a characteristic flushed and red appearance. The body feels warm, but as a matter of fact heat rapidly radiates from the engorged capillaries of the skin, causing a greater loss of heat and a consequent lowering of the temperature. The nerves controlling the surface circulation and regulating the body temperature are paralyzed by alcohol.

The effect of alcoholic beverages upon the kidneys is very marked. The delicate capillaries going to the glands and tubules dilate, causing congestion and inflammation. Under this condition the kidneys are stimulated to overaction. Besides this the structure of these organs may be so changed that they cannot properly perform their functions. The irritation due to the continued use of alcoholic drinks is thought to be one of the chief causes of the fatal disease of the kidneys named "Bright's Disease," after the English physician who first described it. In this dreaded disease the functions of the kidneys are so deranged that albumin is excreted instead of urea and other wastes. The good albumin so important in building up and repairing the cells is eliminated from the body, while useless and harmful waste matters remain in the blood. In the disease known as diabetes an excessive amount of sugar appears in the excretion from the kidneys. 


\section{SUMMARY OF THE MAIN POINTS}

I. The skin consists of an outer layer, the epidermis, and below this a thicker layer, the dermis or true skin.

2. The most important function of the skin is to protect the body against foreign substances. It is firm and tough, but very pliable.

3. A thick layer of fatty tissue is deposited under the dermis. This serves as a food supply in case of sickness, as a blanket to keep us warm in cold weather, and to give roundness and beauty to the human body.

4. The epidermis consists of epithelial cells held together by a small amount of cement. No blood vessels, nerves, or lymphatics occur in it.

5. In the deeper parts of the epidermis are found the pigment cells that give color to the skin.

6. The dermis is well supplied with blood vessels, lymphatics, and nerves.

7. The sweat glands of the skin are for the purpose of removing water, salt, and small amounts of other wastes. About a quart of perspiration is excreted on a temperate day.

8. The oil glands secrete a small amount of oil which lubricates the hair, keeps the skin soft and pliable, and protects the body against moisture.

9. The skin is the most important organ for controlling the body temperature.

10. The nails and hairs are two important structures made of highly modified epidermis. They serve to protect and beautify the body when properly cared for.

I I. The functions of the skin are to serve as a protecting covering; to regulate the body temperature ; to remove certain waste products ; to furnish the sense of touch and temperature ; to aid in respiration; and to act as an absorbing surface. 
12. The skin may be kept clean and in a healthy condition by proper bathing whenever necessary. This may be twice a week or oftener, depending upon the season and occupation.

13. A cold sponge, shower, or plunge bath taken in the morning has a very invigorating effect upon the entire system. A warm bath is most beneficial after severe muscular exertion, and in the evening before retiring.

I4. A bath should not be taken immediately before or after a full meal or severe physical or mental exertion. About three hours after a full meal the body is in the best condition for a bath of any kind.

15. The clothing should permit the utmost freedom of movement to all organs and members of the body, and contribute to the fullest extent to physical comfort.

r6. All garments worn at night, as well as the bedclothes, should be thoroughly aired and sunned so as to keep them perfectly dry and free from disease germs.

17. The kidneys are the most important organs for the excretion of salt, water, and urea; they also excrete other wastes. They coöperate with the skin and lungs in keeping the blood free from all organic waste products. Disease of any one of these organs throws an extra amount of work upon the others.

I8. Disease of the kidneys results in serious impairment of health. The skin and lungs cannot assume the functions of the kidneys.

I9. Diseases of the kidneys may be due to numerous causes, such as : exposure to colds, use of alcohol, condiments, and too much rich food, dislocation of abdominal organs, and infection by certain bacteria. 


\section{CHAPTER XIII}

BONES AND JOINTS

123. Uses of Bones. - The bones of the human body are so put together as to form a complete human figure in size, shape, and general outline; they constitute the framework of the body. The bones form protecting walls for some of the most delicate organs, as the brain, the eye, the ear, and the heart and lungs. Muscles are attached to bones which serve as levers for moving any part of the body and for locomotion. We could not stand, walk, and run about if we had no bones to give strength and firmness to the body.

In all there are two hundred and six bones of various sizes and shapes, joined together by strong bands called ligaments. This large number of bones makes possible the great freedom of movement, as in the wrist, fingers, ankles, toes, spine, neck, and other parts.

124. The Skeleton. - The two hundred and six bones of the body that together constitute the skeleton may be grouped into three classes: those of the head, the trunk, and the extremities.

The bones of the head may again be divided into those of the cranium, the face, and the ears. In the cranium, which is a firm, thick case for the brain, there 
are eight separate bones very firmly bound together. These bones are as follows: one frontal, two parietal, two temporal, one ocipital, one ethmoid, and one sphenoid. You will find all but one in the diagram below. The

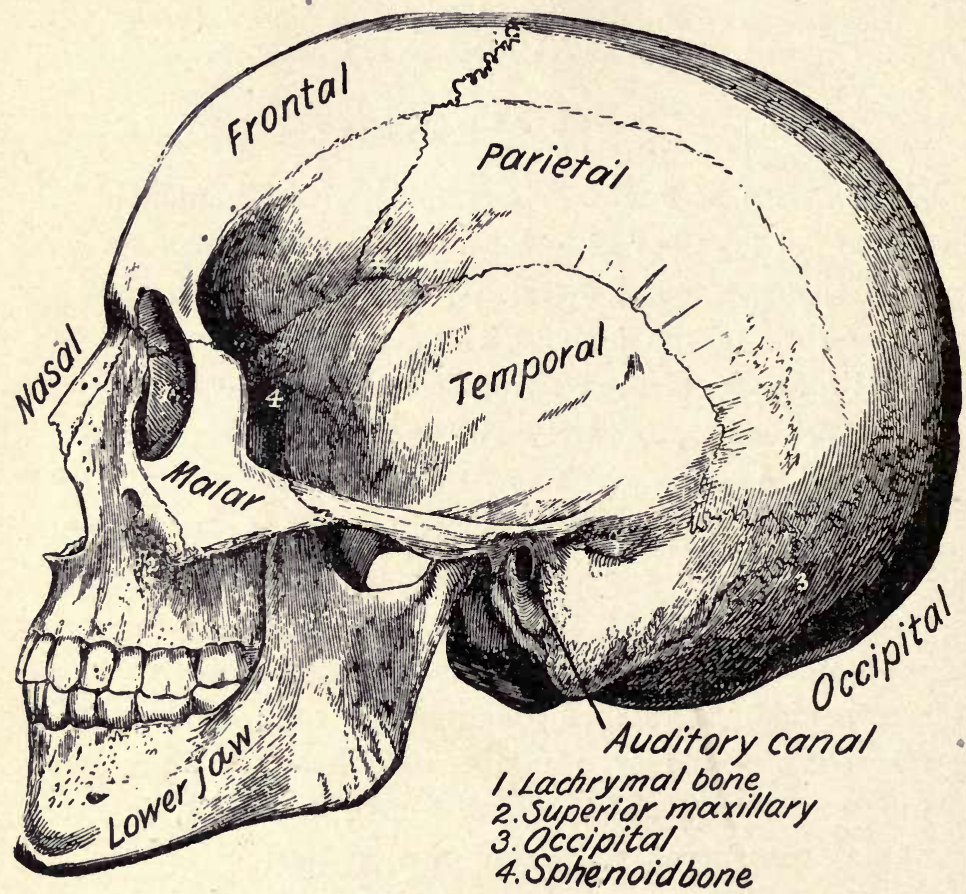

FIG. 84. - The skull, side view.

face has fourteen bones, all except the lower jawbone being firmly held together so as to allow no movement to speak of. The bones of the face are as follows: one lower jawbone, two upper jawbones, two malars or cheek bones, two nasals forming the bridge of the nose, 

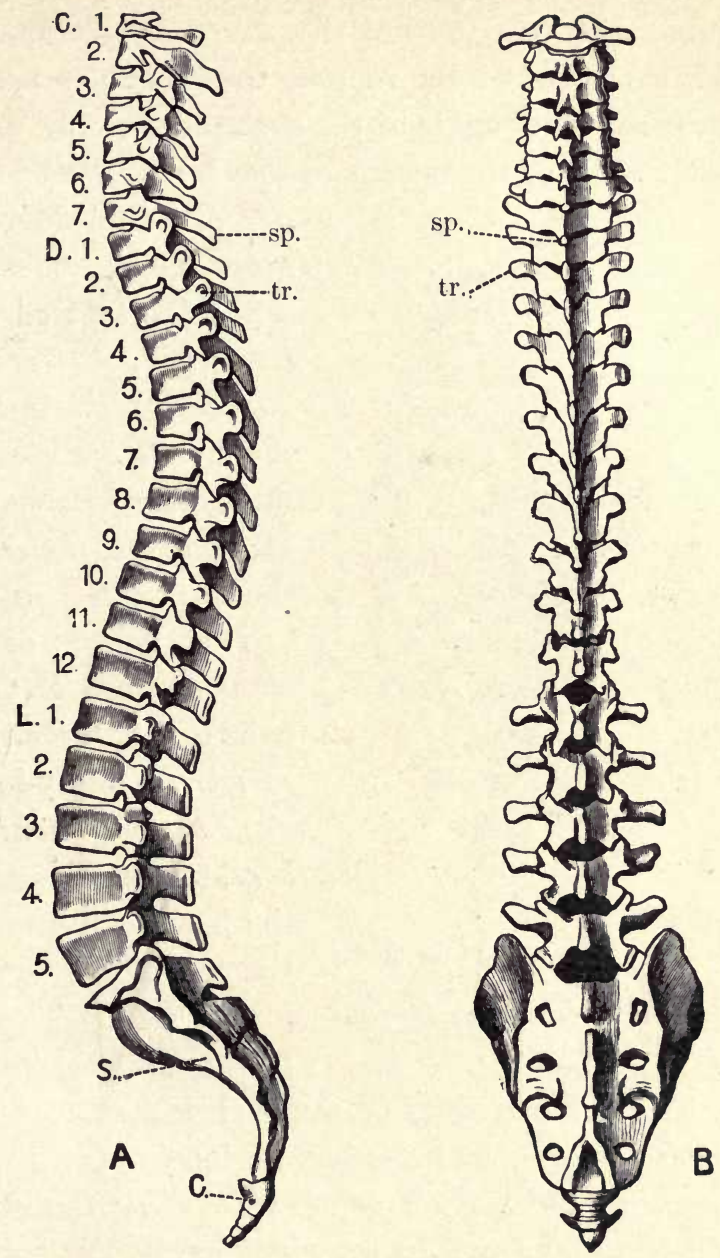

FIG. 85. - The vertebral column (Huxley) : $A$, side view, left side; $B$, back

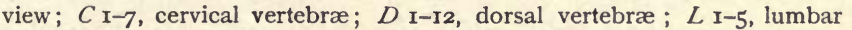
vertebræ; $S$, sacrum; $C$, coccyx; $s p$ and $t r$, processes or projections on the vertebræ. 
one vomer between the nostrils, two palate bones forming the back part of the roof of the mouth, two lachrymal near the inner angle of the eyes and forming part of the outer walls of the nose, and two turbinated or scroll-

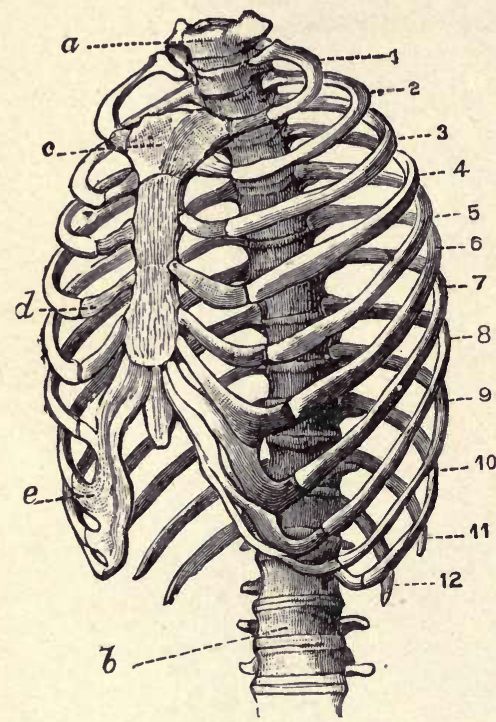

FIG. 86. - The bony walls of the thorax (Huxley): $a b$, vertebræ; I-I2, ribs; $c$, sternum; $d$, cartilages uniting the ribs and the sternum.

like bones inside of the nose. These bones form five important cavities: two orbits, two nostrils, and the mouth. Inside of the middle ear there are three small bones: the malleus, the stapes, and the incus.

The bones of the trunk are the ribs (twelve pairs), the backbone or vertebre (twenty-four in all), one sternum or breast bone, the hyoid bone near the base of the tongue, the pelvic girdle, consisting of two hip bones and the sacrum and coccyx.

Each upper extremity or arm consists of the upper arm, the forearm, and the hand. The upper arm has three bones: the scapula or shoulder blade, the clavicle or collar bone, and the humerus, a long, hollow bone extending from the elbow to the shoulder. In the forearm there are two quite long, slender, hollow bones known as the radius on the thumb side and the ulna 
on the little finger side. In the hand there are eight carpal or wrist bones arranged in two rows, five metacarpal or palm bones extending from the wrist to the fingers, and fourteen phalanges in the fingers.

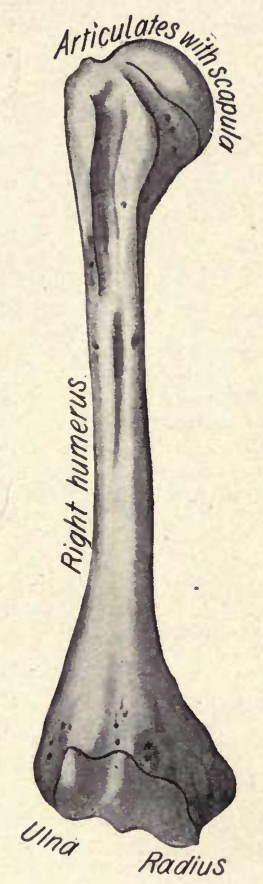

FIG. 87. - The right humerus (Zuppke).

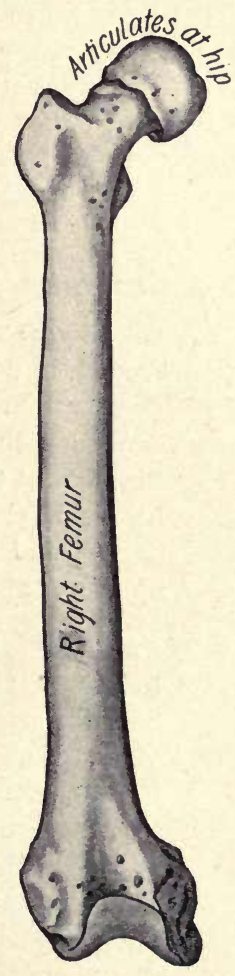

Fig. 88. - The right femur (Zuppke).

The lower extremities are quite like the upper in the number and general structure of the bones. Each leg consists of the thigh, the calf or lower leg, and the foot. The femur or thigh bone is the longest and strongest 
bone of the body. The lower leg has two lor er bones, the tibia or shin bone, and the fibula much smaller bone. At the knee there is a peculiar threesided, caplike bone known as the patella or kneepan. The foot has seven irregular tarsal bones in the heel and ankle, five metatarsal bones in the instep, and fourteen phalanges in the toes.

\section{Table of Bones.}

Bones of the Head.

The Cranium:

Frontal, in the forehead . . . . I

Temporal, in the temples . . . . 2

Parietal, at the sides and top of the head 2

Occipital, at the back of the head ... I

Ethmoid, sievelike bone between the nose and the brain . . . . . I

Sphenoid, at the base and sides in front I

The Face:

Inferior maxillary, or lower jawbone - I

Superior maxillary, or upper jawbone . 2

Malar, or cheek bones . . . . . 2

Nasal, forming bridge of the nose . . 2

Vomer, partition between the nostrils . I

Palate, the back part of the roof of the mouth and the sides of the nose . . 2

Lachrymal, between the orbit and the nose . . . . . . . . . . 2

Turbinated, scroll-like inside of the nose 2

The 7wo Ears:

Malleus, or hammer . . . . . . . 2

Incus, or anvil. . . . . . . . . 2

Stapes, or stirrup . . . . . . . 2 


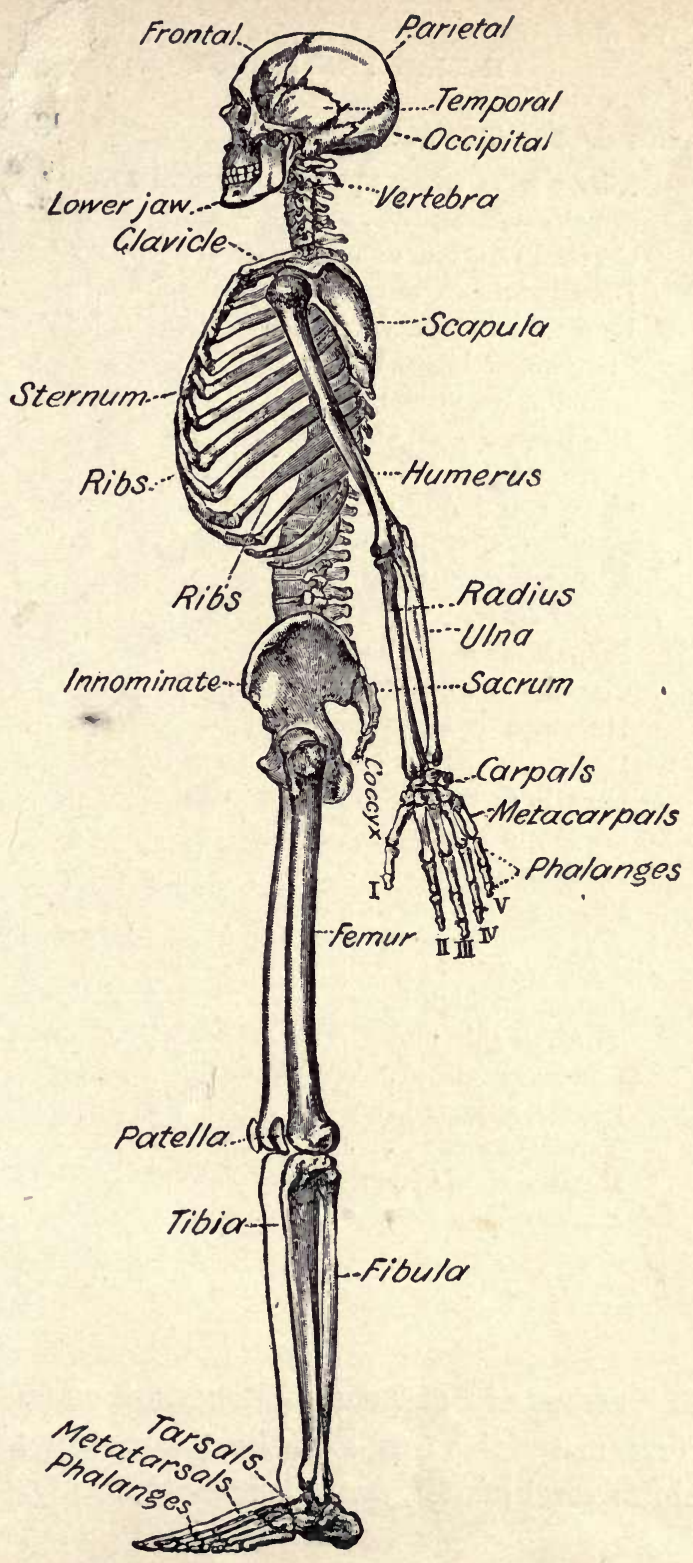

FIG. 89. - The skeleton. 
BONES OF THE TRUNK.

Ribs, 7 pairs true; 3 pairs false; and 2 pairs floating . . . . . 24

Cervical vertebræ of neck . . . . . 7

Dorsal vertebræ of back . . . . . 12

Lumbar vertebræ of loins . . . . . 5

Sternum, or breast bone . . . . . I

Hyoid at base of tongue . . . . . I

Hip bone, one on either side . . . . 2

Sacrum, below lumbar vertebræ . . . I

Coccyx, at end of vertebral column . . I

BONES OF THE EXTREMITIES.

The Trwo Upper:

Scapula, shoulder blade . . . . 2

Clavicle, or collar bone . . . . . . 2

Humerus, in upper arm . . . . . 2

Radius, in forearm . . . . . . . 2

Ulna, in forearm . . . . . . . 2

Carpal, in wrist . . . . . . 16

Metacarpal, in palm . . . . . . 10

Phalanges, in fingers . . . . 28

The Two Lower:

Femur, or thigh bone . . . . . 2

Tibia, or shin bone . . . . . . . 2

Fibula, in calf . . . . . . . . 2

Patella, at knee . . . . . . 2

Tarsal, in ankle . . . . . . . I4

Metatarsal, in instep. . . . . 10

Phalanges, in toes . . . . . 28

126. Composition of Bone. - Bones are made of hard and firm material so as to make them strong. They contain mineral matter, lime and potash mostly. In the 
adult the mineral matter makes up about two thirds of the entire bone. The other portion is animal matter or connective tissue. By placing a small bone like a sheep's rib in a mixture of one part muriatic acid and six parts water for two or three days, the mineral matter can be dissolved, leaving the bone so soft that

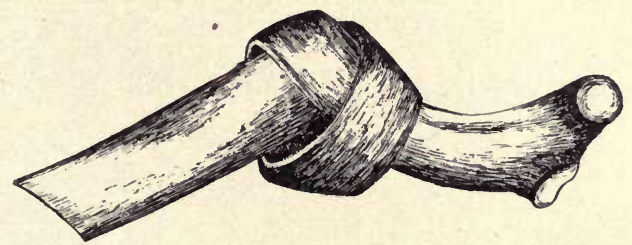

FIG. 90. - A sheep's rib tied into a knot after the mineral matter was removed (Johnstone).

it may be tied into a small knot. By placing a bone in a fire for a short time, the animal matter can be burned away, leaving a very brittle bone.

In children the bones are soft and may be easily bent out of shape because they have a large amount of animal matter and as yet very little mineral matter. This is why children's bones are not easily broken. Slowly the bones of the growing person become hard and firm because more and more lime displaces the animal matter and they grow strong but become brittle. In old age bones break easily and heal slowly when broken.

127. Structure of Bone. - Most of the long bones are hollow through the center. The cavities are filled with soft yellow marroze. This form of structure makes them stronger and very much lighter than they would 
be if they were solid. At the ends a long bone is rather spongy, while the shaft is very compact in structure.

Under the microscope a thin slice of bone presents an interesting appearance. Little canals appear run-

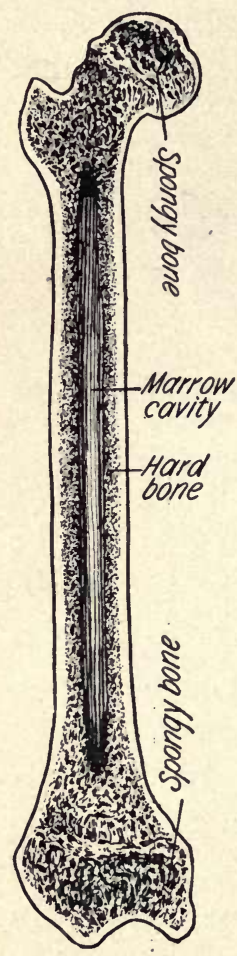

FIG. 9I. - The right femur cut open (Zuppke). ning in all directions, and small lakes can be seen throughout the entire mass even in its most solid parts. Blood and lymph flow through these canals and permeate the bone from the outside to

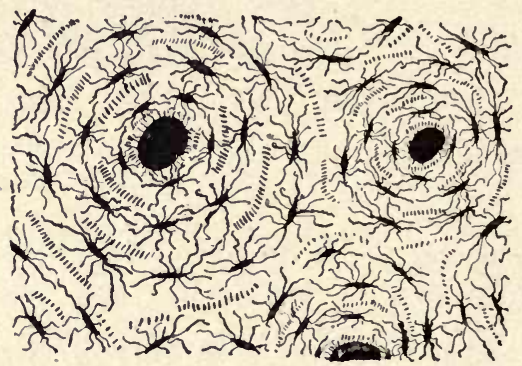

FIG. 92. - A cross-section of bone, highly magnified (Kocher).

its very center. Bones grow, and hence must have food material carried to them and waste matter removed from them.

Bone is covered with a very thin, tough connective tissue membrane called the periosteum, and the hollow shaft of the long bones is lined with a somewhat similar membrane known as the endosteum. These are very important membranes. They fit over the bony surface very smoothly and thus serve to protect the bone. Muscles can more easily attach 
themselves to the periosteum than to the smooth bone itself. The most important function of these membranes is to carry nourishment to the bone substance and to keep it in a healthy condition. Blood vessels and lymphatics pass into and through the bone from

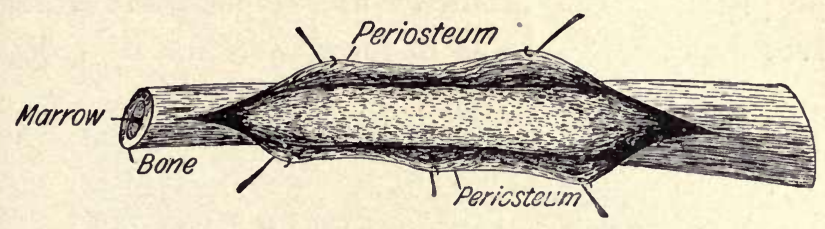

FIG. 93. - The periosteum, partially removed (Johnstone).

the periosteum and endosteum. If the periosteum is removed from any part of a bone, that portion of the bone soon dies from a lack of nourishment. If a bone is diseased and a piece of it cut out, but this membrane left uninjured, it will form new bone in place of the old in a very short time. At the ends of the bones a layer of cartilage takes the place of the periosteum.

I. Get a large bone and cut it across and study its structure carefully. Cut the enlarged end of a bone and notice how its structure compares with that of the shaft.

2. Remove all the muscle from a portion of the bone, and run the point of a knife along its surface. A thin membrane may be peeled off. This membrane is the periosteum.

3. Examine a slide of bone, if possible, under the microscope. Notice how numerous the channels are through which the blood is carried to all parts of the bone.

128. Cartilage. - That which we call the gristle of meat is cartilage. It is really young bone in which there is as yet little mineral matter. Cartilage is firm 
enough to retain its shape, and elastic enough to spring back when bent out of position. The ends of the nose and the ears are examples of cartilage.

Cartilage occurs in all places in the body where a certain amount of stiffness and firmness and at the same time pliability and elasticity are required. Cartilage serves many uses, such as to form the walls for certain

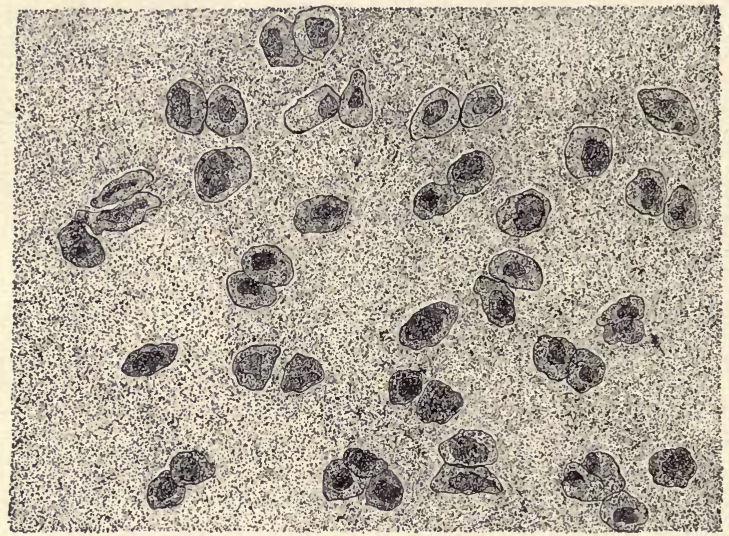

FIG. 94. - Cartilage, highly magnified (Buchholz).

organs, as the larynx and trachea, to form enlargements of the bones, to furnish a smooth surface at joints, to deepen the socket for certain joints, to form cushions between certain bones, and to form projecting organs like the nose and ears.

129. Joints. - Wherever two bones come together we have a joint. At some joints there is little or no motion, while at others there is great freedom in both the amount and the direction of the motion. At a joint 
the bones are covered with a thin layer of cartilage which is very smooth and well oiled. A closed sac of very thin connective tissue occurs between the adjacent surfaces of some joints. It secretes the synowial fluid, which keeps the surfaces moist and enables the bones to move with little friction.

The bones are held together by means of strong bands of connective tissue known as ligaments. In some cases a bone has a large head that fits into a deep socket of another, as at the hip and shoulder, so that the air pressure alone may be sufficient to keep them in place. But even those bones have a large number of very strong ligaments as well as muscles that extend from one bone to the other and hold them together very firmly.

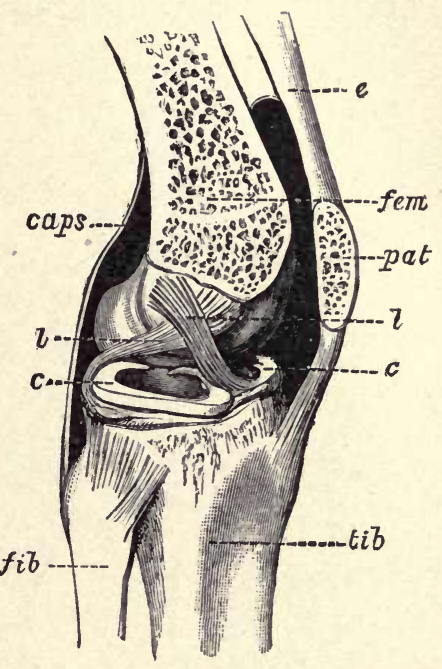

FIG. 95. - The right-knee joint. The outer half of the femur and patella cut away. (Huxley.) fem, femur; pat, patella; tib, tibia; $f i b$, fibula; caps, capsule of joint; $l, l$, ligaments ; $c$, cartilage; $e$, tendon.

Joints may be divided into several classes - as the ball-and-socket, pivot, hinge, saddle, gliding, and suture. Where the round head of one bone fits into a deep cavity or socket of another, as at the hip and shoulder, in such a way as to permit rolling motion in any direction, we have a ball-and-socket joint. The pivot joint is 
one in which one bone turns or rotates upon another as is shown in turning the forearm. In the hinge joint one bone moves upon another in two directions only, back and forth, like the blade of a jackknife or a door on its hinges. The joints at the elbow, the knee, the fingers,

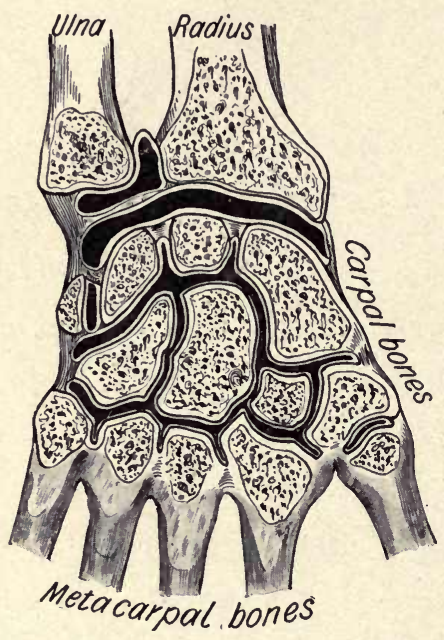

FIG. 96. - The bones of the wrist. The outer part cut away to show the arrangement. (From Heitzmann by Zuppke.) and toes are examples of this class. The saddle joint is illustrated in the joint between the thumb and the wrist. In the gliding joint one plane surface glides on another, as the carpal bones of the wrist and the tarsals of the ankle. The bones of the cranium are so dovetailed together as to permit of no real motion, and such joints are known as sutures. Several different kinds of sutures occur among the bones of the head.

I. Procure a sheep's knee and study the way the two bones fit together and how they are held in place.

2. Cut the several ligaments and trace each in both directions.

3. Notice the kneepan and see how it serves to protect the joint.

130. Posture. - The bones of a young child are so soft that they can be easily bent because the amount of lime in them is small. That is why a child should not be encouraged to stand or walk when too young. The 
bones are too weak to bear up the weight of the body and therefore become bent, resulting in "bowlegs." Every healthy child will learn to walk soon enough if left to take his own time.

Many young persons form the bad habit of standing on one foot, sitting bent over, walking in a careless,
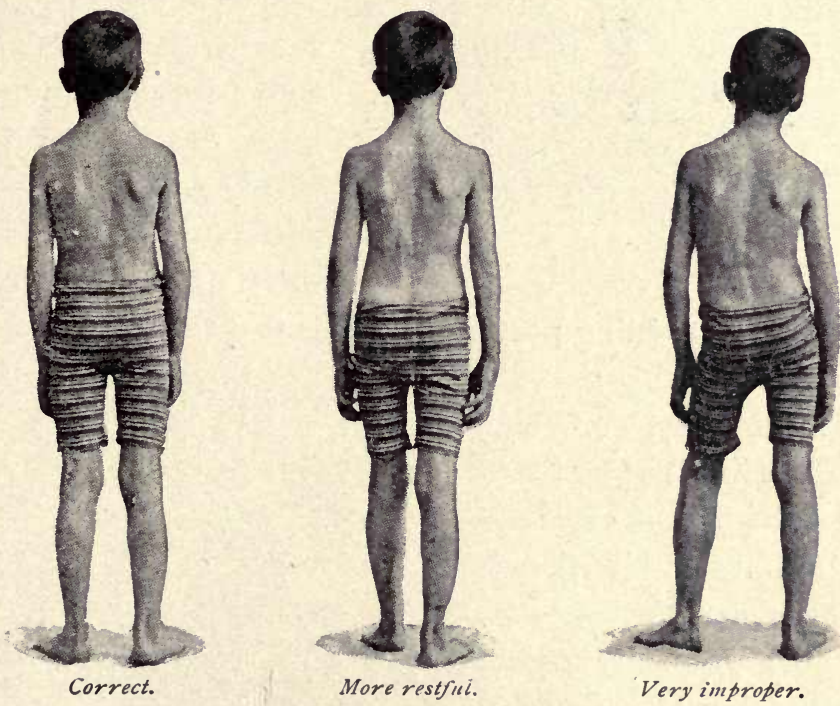

FIG. 97.- Postures in standing. (From Shaw's "School Hygiene.")

indifferent manner, and sleeping with the head on a thick pillow. By doing these things habitually the growing bones of the young become hopelessly deformed. We all admire the straight back, the square shoulders, the full chest, and the graceful gait. They are the result of easy and natural positions of the body in lying, sitting, standing, and walking. 


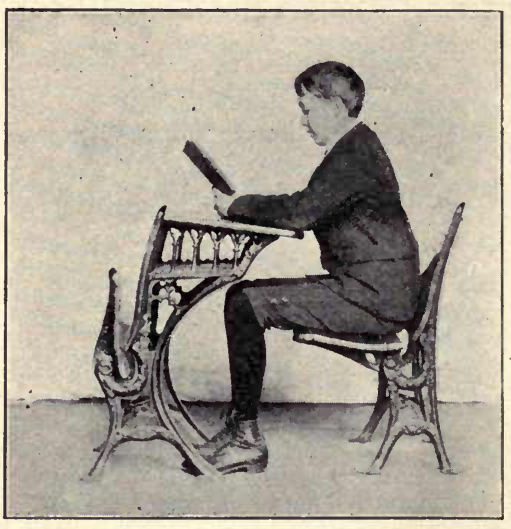

FIG. 98.-Correct position at school desk.

The correct, natural, easiest standing position demands that the feet be placed as when toeing a line, and that the weight of the body be thrown equally upon the two legs. In such a posture the trunk is evenly poised, and all parts of the body are in their natural places. The correct sitting posture demands that the pelvis rests equally on the seat, with the body erect and the head so placed that the line of direction falls within the line joining the bones of the pelvis resting on the seat. This may be called a symmetrical posture, as it is the easiest to maintain for any length of time, because it requires the smallest

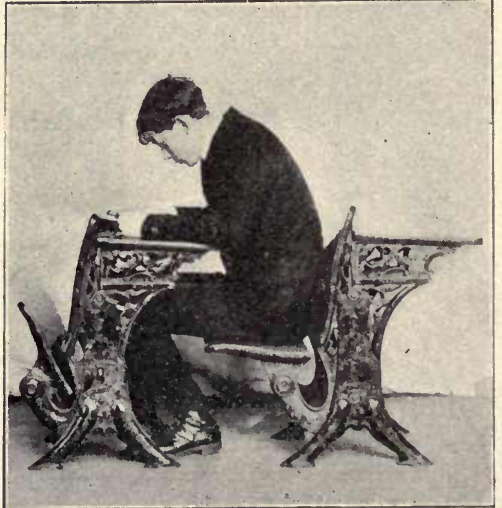

FIG. 99. - Desk and seat too small. Head and spine bent, and legs and feet cramped. expenditure of muscle energy, and leads to physical beauty and proper carriage. 
Often the clothing may be the cause of physical deformity. Tight bands at the wrists of the growing child are sure to result in a deformed bone. Tight lacing about the waist when young will permanently deform the chest, diminish the capacity of the lungs, and push out of place

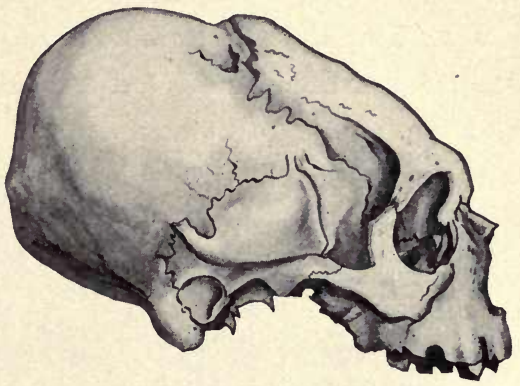
the abdominal and FIG. 1oo.-Skull of a Flathead Indian child pelvic organs. The (Zuppke).

feet become tender and deformed by wearing tight and otherwise unhygienic shoes.

There is a tribe of Indians inhabiting the mountains of Idaho known as the "Flatheads," because they bandage the head of every young child in such a way that it becomes permanently long and flat. The Chinese think

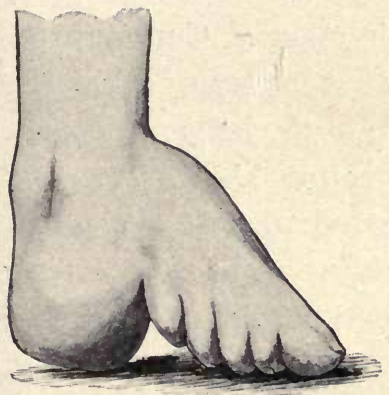

FIG. ror. - Foot of a Chinese woman (Zuppke). it fashionable for ladies to have small feet. They secure this by tightly bandaging the feet of the little girls. Among the ignorant and superstitious savage and heathen people there may be some excuse for thus deforming the body, marring its beauty, and impairing its vigor, but among civilized and enlightened nations the fash- 
ionable long, narrow foot, the high heel, and the deformed waist cannot be defended. Fashion makes us do very strange things indeed.

131. The Curved Spine and Round Shoulders. - One of the most common deformities among young men and women is a curved spine and round shoulders. The spine may bend either to the right or the left, forward or backward. In some cases there is a combina-

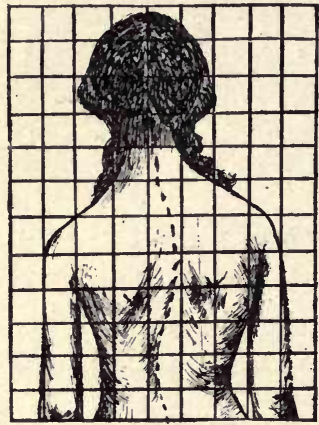

Right curve.

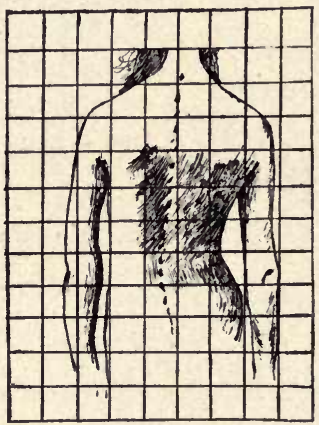

Left curve.

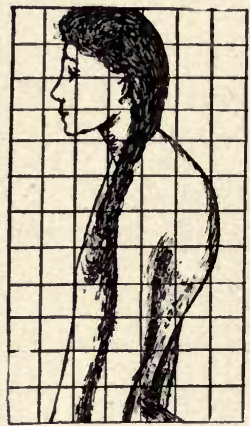

Round shoulders.

FIG. 102. - Showing deformed chests. (Drawn by H. Meyer from photographs.)

tion of two or more of these directions. Curvature of the spine may be due to a great many causes, but the most common is improper posture of the body on account of seats and desks that are either too high or too low or for some other reason are not adapted to the pupil. Under such conditions one shoulder may be raised above the other, causing lateral curvature of the spine, or the body may be bent forward as in reading and writing, causing a fold across the abdomen in the region of the stomach which curves the spine backward, displaces 
the abdominal organs, and compresses some of the large blood vessels so as to disturb the action of the heart. Just as harmful is the slipping forward in the seat so frequently seen in the schoolroom. The visceral organs now press against the spine, crowding it back and causing a curvature; the shoulders drop forward, causing a flatness and compression of the chest which seriously disturbs respiration and circulation. When the seat is so high that the feet must dangle in the air all day long because they cannot reach the floor, the strain

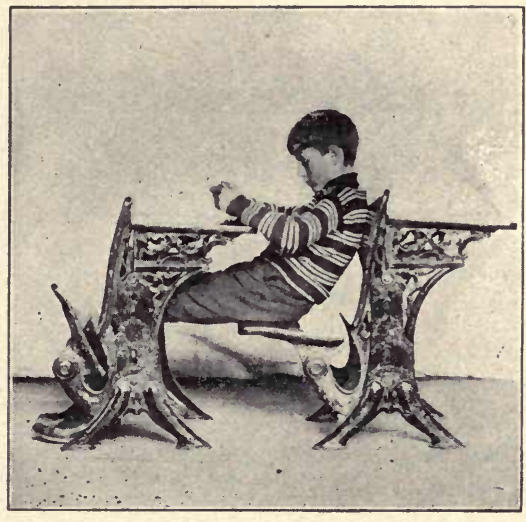

FIG. I03. - Incorrect position frequently seen in the schoolroom.

on the femur is sufficient to deform it. The discomfort and fatigue may be patiently borne, but the pupil cannot do as good school work as he could under more favorable conditions. Mental work depends to a large extent upon physical comfort.

Such improper positions assumed day after day for a series of years tend to fix the bones of the spine, chest, and shoulders and cause permanent deformity. To obviate all these difficulties schoolrooms should be supplied with single adjustable seats and desks, and then sufficient time taken to adjust the seat and desk of each 


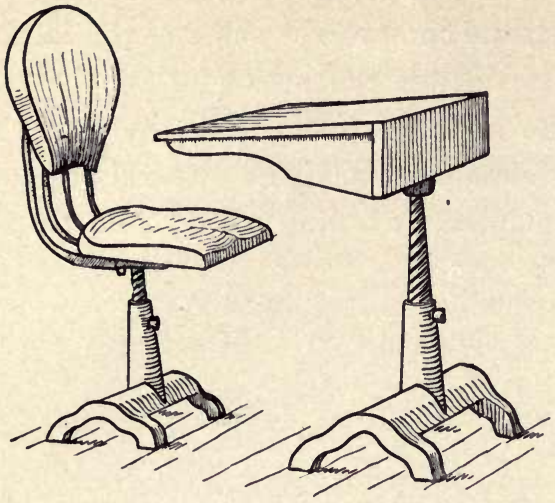

FIG. 104. - An adjustable seat and desk. From a sketch furnished by Dr. Mosher. (Zuppke.) pupil at least once a term. The seat and desk shown here are raised and lowered in the same way as are revolving office chairs.

Besides being adjustable, a good, comfortable school desk must afford sufficient room for

the legs and feet to take easy, natural positions, so as not to cramp the blood vessels in any way. The back
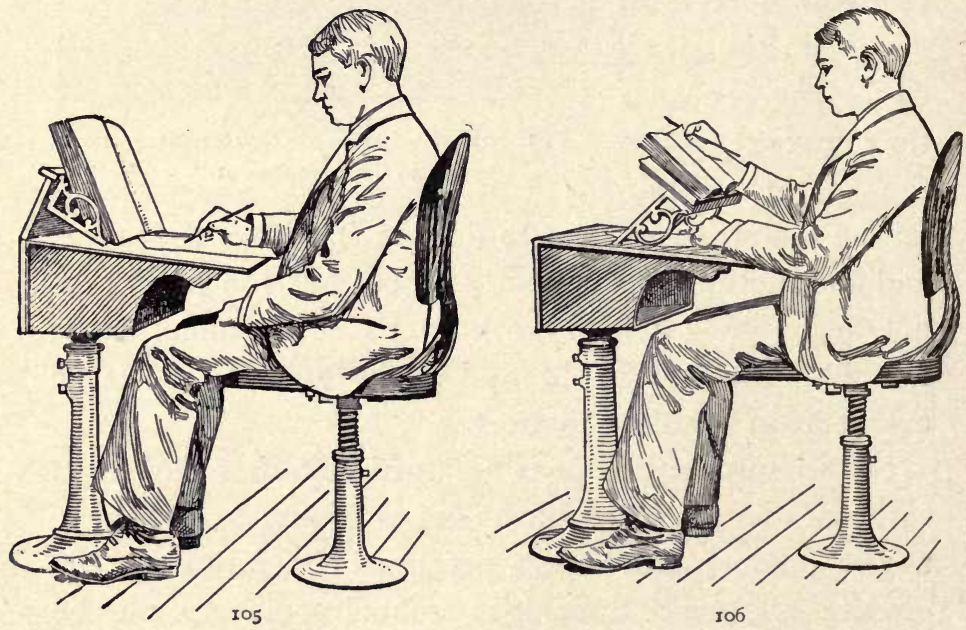

FIG. I05. - An adjustable seat and desk as used for writing. From Dr. Mosher's "Hygienic Desks for School Children," Educational Review.

FIG. 106. - Same seat and desk as used for reading. 
of the seat must be so constructed that there is ample room to sit well back on the seat, and at the same time it must furnish a firm support for the loins. In this last particular most of the school seats are especially faulty.

\section{SUMMARY OF THE MAIN POINTS}

I. The bones serve (I) to form the framework of the body, (2) to protect certain soft and delicate organs, and (3) to form levers for the attachment of muscles.

2. The skeleton consists of two hundred and six bones fitted together and held in place by cartilage and ligaments.

3. Bones consist of animal and mineral matter. In early childhood the animal matter is the more abundant, but it is slowly displaced by mineral matter, which is far in excess in old age.

4. The long bones have a hollow shaft and enlarged, spongy ends. They are covered with periosteum and lined with endosteum, both of which are well supplied with blood vessels from which the bone substance draws its nourishment.

5. Cartilage is very much like bone that contains little mineral matter. It helps to enlarge the ends of long bones, and so makes better joints, and to form the walls of some of the internal organs.

6. A joint is the union of two bones, whether they move upon each other or not. There are several different kinds of joints, as ball-and-socket, pivot, hinge, saddle, gliding, and suture.

7. A synovial sac occurs between the bones of some joints. It contains a small quantity of synovial fluid which oils the surfaces to prevent friction.

8. The bones in childhood are very pliable and easily bent out of position, and therefore it is highly important always to maintain correct postures in lying, sitting, standing, and walking. 
9. The body is in the correct standing posture when the feet are placed as in toeing a line, and the weight of the body is thrown equally on the two legs.

ro. The body is in the correct sitting posture when the two bones of the pelvis rest equally upon the seat, and the line of direction falls within the line joining the points of support on the seat.

II. Clothing that does not fit properly deforms the bones and interferes with the functional activity of the organs.

12. Two of the most serious common deformities are a curved spine and round shoulders. These deformities compress the thorax and abdomen, and disturb the respiration, digestion, and circulation.

r3. School desks and seats are one cause of spinal curvature and round shoulders. Schools should be furnished with adjustable seats and desks. 


\section{CHAPTER XIV}

\section{MUSCLES AND EXERCISE}

132. Use of Muscles. - About one half of the weight of the body is due to the muscles, or lean meat, of which it is composed. Muscles are useful organs, for without them we could not live for a moment. Let us see what they do. Most of the muscles are fastened to bones, which they completely cover, so as to make the human form less angular and more beautiful in outline. Many of the vital organs of the body, as the heart, arteries, and stomach, are made almost entirely of muscle tissue. All motion of the body as a whole, and of its various parts, is accomplished by the contraction of the muscles that are attached to bones. Speaking and singing are accomplished by very delicately adjusted muscles of the chest, throat, and mouth. In fact, you cannot name a single function of the body or of any of its parts that does not depend directly or indirectly upon the action of muscles.

133. Description of Muscles. - The human body has over five hundred muscles which can be controlled by the will, and a large number over which we appear to have no control whatever. The first we call voluntary and the second involuntary muscles. 


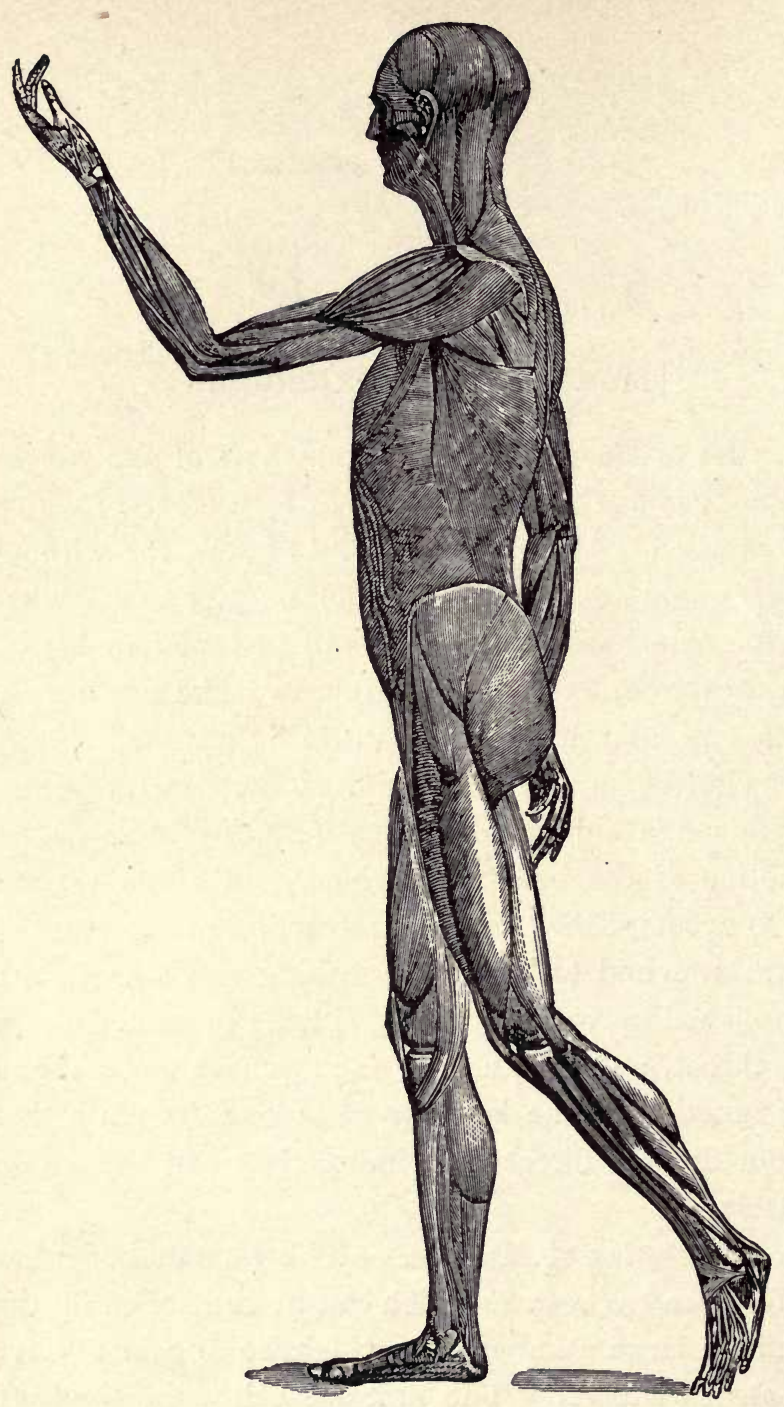

FIG. I07.- Superficial muscles, side view. 
As to shape, muscles may be grouped into many different classes, known by separate names as fusiform,

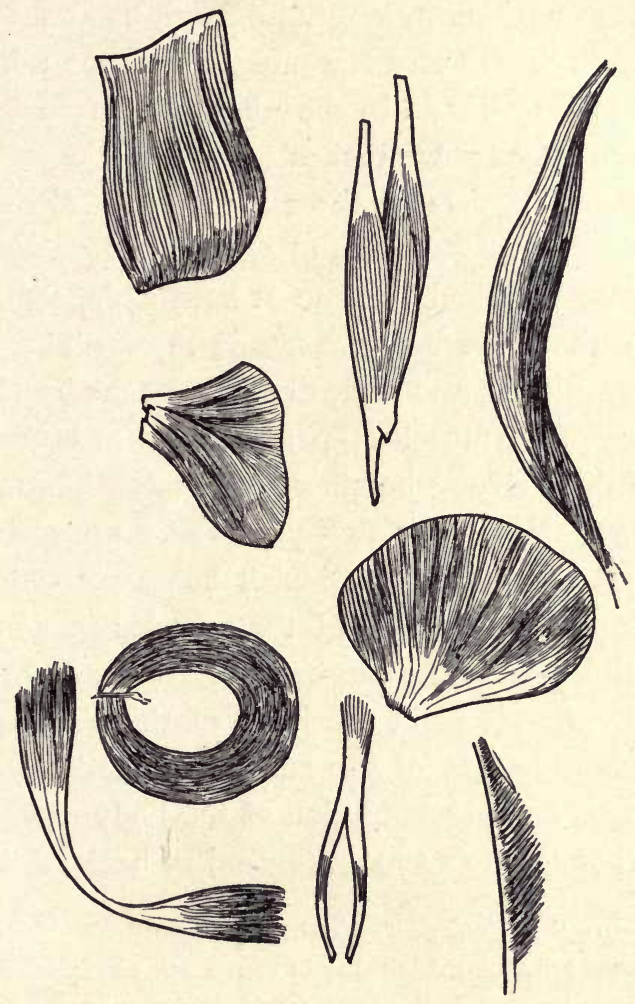

FIG. I08. - Muscles of different shapes (Zuppke).

penniform, bipenniform, tripenniform, digastric, polygastric, sphincter, etc. The figures above will give you some idea of the variety of shape found among the voluntary muscles. 
As to size we also find a great difference. Some are very short and slender, others are long and thick. In the ear there is a muscle so small that it measures about one sixth of an inch in length and weighs about a grain, while in the thigh there is a muscle that measures over two feet in length, and in the abdomen there is a thin, flat muscle over twelve inches wide.

A muscle consists of three parts: the beginning or origin, the end or insertion, and the middle or belly. Some muscles are attached to bone at both ends, some at one end only, the other being fastened to cartilage, skin, or to another muscle, and some are not attached to bones at all. Many of the muscles taper off at one or both extremities into thin, strong bands of connective tissue known as tendons. When the fleshy part of a muscle must be far removed from its insertion, it has a very long, slender tendon, as in the case of the muscles that move the fingers and toes. The largest and strongest tendon of the body extends from the bone of the heel up to the two largest muscles of the calf; this is the tendon of Achilles. The longest tendon of the body extends from the heel bone up to a small muscle just back of the knee.

I. Procure the lower part of a sheep's leg with the lean meat and the hoof on. Dissect out as many of the muscles as you can, tracing each in both directions. Find the origin, insertion, and belly of each muscle.

2. If the parts are placed in diluted alcohol for a few days they will harden somewhat and remain separate.

134. Structure of Muscles. - We are all familiar with the appearance and general structure of muscles as 
seen in beefsteak, corned beef, dried beef, lean mutton, boiled chicken, etc. When carefully examined, a piece of dark meat of the chicken, or corned beef, that has been "boiled to rags," shows many bundles of fleshy threads known as fibers, closely packed together and held in place by a very thin sheath. Each fiber when "teased out" with a fine needle will be found to consist of still smaller threads of flesh called fibrils. A single fibril, muscle fiber, or

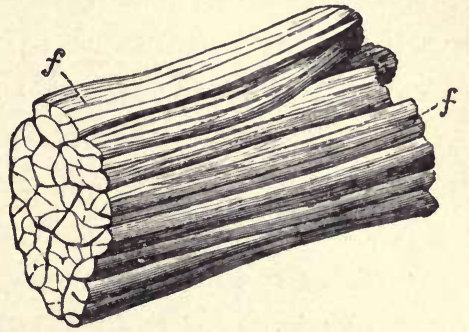

Fig. 109. - Showing several bundles of muscle fibers cut across. $f, f$, single bundles. (From Huxley.)

muscle cell, is covered with a very delicate membrane inclosing a soft semifluid substance known as myosin.

The involuntary muscle differs from the voluntary in that it is plain instead of striped, has few capillaries and therefore less color, and is shugish in its action.

135. How Muscles Work. - A muscle cell has the power to contract, or to become shorter and thicker under the influence of a stimulus. It changes its shape, but not its bulk. Since the muscle cells are placed side by side to form the thickness of a muscle, and end to end to form its length, it follows that the muscle as a whole grows shorter and thicker when its fibers contract. The longer a muscle, the greater the amount of contraction possible.

A muscle will not act unless it is stimulated in some way. Each muscle cell has a little nerve fiber going to 
it. Over this nerve a message may be sent from the brain, causing the muscle to contract. We can make a muscle do just what we please if we have learned how to stimulate it.

When a muscle contracts it pulls its ends nearer together; it gets shorter and causes motion in the part to which it is fastened. We say the muscle does work. In some way the heat obtained from the oxidation of foods in the muscle cells is transformed into mechanical energy and used in doing work. The thicker a muscle the greater the load it can move.

In every contraction a muscle consumes a certain amount of food material, causes the cells to break down somewhat, and produces waste products. The muscle cells must be repaired, and new energy must be stored up for future use. To accomplish this more food must get into the blood and be carried to the cells. Working gives us an appetite, and we now see the reason for it.

A muscle cannot remain strongly contracted for a long time without becoming tired. It is difficult to stand perfectly still in one position, to hold the arm straight out, or to look steadily at a quiet object. A contraction must be followed by a relaxation. The muscles are generally arranged in pairs so that when one contracts the other relaxes; when one works the other rests. The muscle used in bending the arm cannot straighten it, but another must be called into action.

I. By means of a tapeline, measure the muscles of the right arm (I) when extended, and (2) when flexed.

2. Measure the left biceps in the same way.

3. Measure other large muscles of the body. 


\section{Large Muscles.}

I. Muscles of the Head.

I. Occipito-frontalis, moves the scalp and eyebrows, and throws the forehead into transverse wrinkles.

2. Orbicularis palpebrarum, moves the eyelids and closes the eye.

3. Corrugator supercilii, used in frowning.

4. Levator palpebræ, opens the eye.

5. The recti, the four straight muscles of the eyeball.

6. Orbicularis oris, closes the mouth.

7. Buccinator, compresses the cheeks, and is used in mastication.

8. Risorius, draws up the angles of the mouth as in smiling.

9. Temporal, or muscle of the temple, raises the lower jaw.

I0. Masseter, or chewing muscle, raises the lower jaw.

\section{Muscles of the Neck.}

I I. Platysma myoides, draws down the lower lip and the angles of the mouth.

12. Sterno-cleido-mastoid, depresses the head and neck upon the chest.

13. Scaleni muscles, elevate the ribs in breathing.

III. Muscles of the TRUnK.

I4. Trapezius, draws the head backward, and elevates the shoulder.

15. Latissimus dorsi, draws the arm backward as in chopping or in striking down.

16. Rhomboideus, draws the shoulder back.

17. Erector spinæ, holds the spine erect.

18. Intercostals, move the ribs in breathing.

I9. Diaphragm, used in breathing.

20. External oblique, These muscles form the walls of

21. Internal oblique

22. Transversalis

23. Rectus abdominis the abdomen, pull the trunk forward, and compress the abdominal organs. 


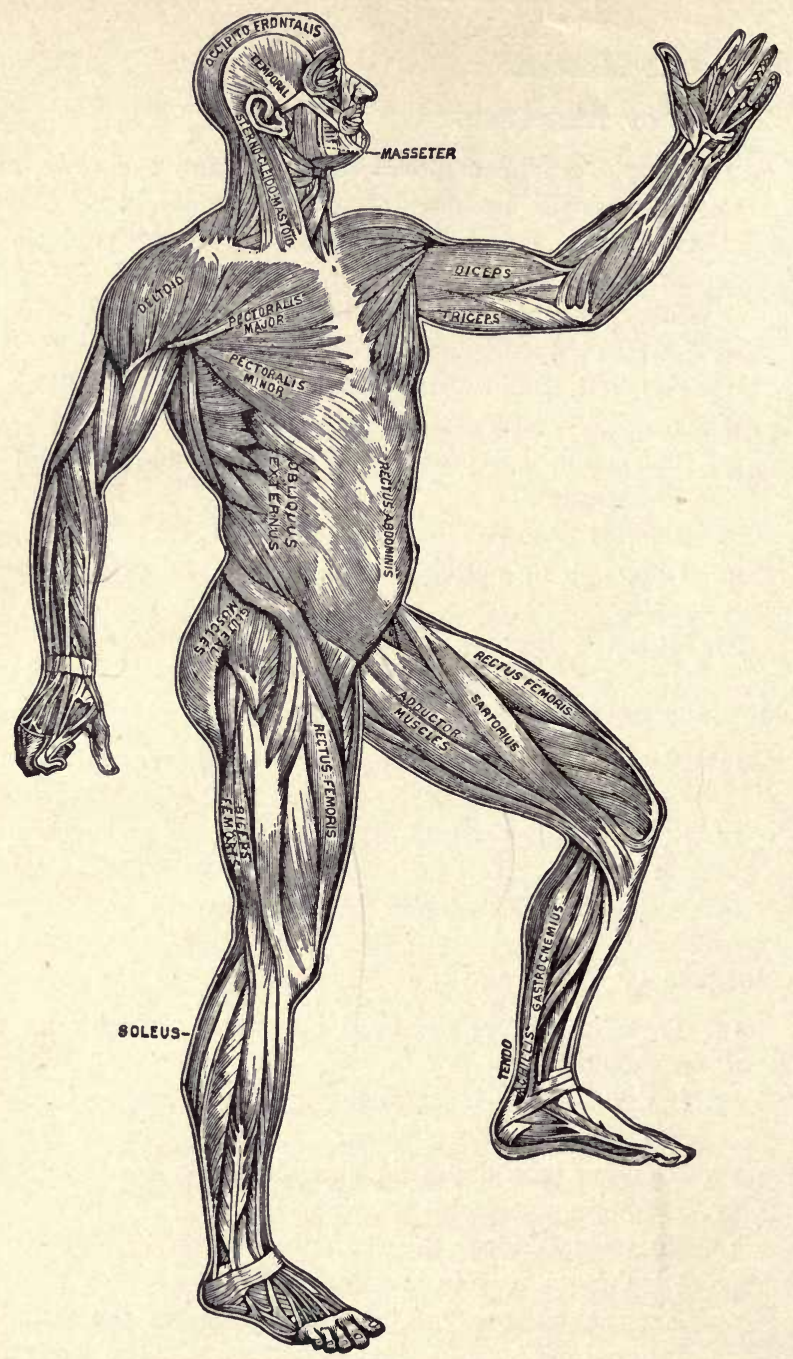

FIG, Imo. - Superficial muscles, front view. (From Blaisdell's "Health and Life." Gun \& Co.) 
iV. Muscles of the UpPer Extremities.

24. Pectoralis, draws the arm forward and brings it across the chest.

25. Deltoid, raises the arm at right angles to the trunk.

26. Serratus magnus, moves the shoulder forward and upward. With the trapezius it is used in supporting a weight on the shoulder and in pushing.

27. Teres major, aids in rotating and drawing the arm downward and backward.

28. Biceps, bends the arm at the elbow.

29. Triceps, straightens the arm at the elbow.

30. The flexors and extensors, move the hand, wrist, and fingers.

V. Muscles of the Lower Extremities.

31. Psoas

32. Iliacus

33. Pectineus

34. Adductors

35. Gracilis

36. Gluteus

37. Biceps

38. Sartorius, flexes the thigh upon the pelvis and rotates the thigh outward.

39. Quadriceps, straightens the leg at the knee, and aids in stooping and standing.

40. Gastrocnemius

41. Tibialis

42. Peroneus

43. Soleus

44. Extensors

45. Flexors
These muscles bend the thigh upon the pelvis, rotate the thigh inward, and aid in holding the body erect.

These muscles straighten the thigh at the pelvis, rotate the leg, and aid in standing erect. 
137. Food of Muscles. - Muscle cells become worn out by use. To keep them in good working order it is necessary to supply them with an abundance of nutritious food and oxygen. The proteids, you remember, are the building foods and are necessary to repair the cells after every contraction. The blood should always contain a sufficient amount of this class of food stuffs. A person who does much muscular work must eat meats, cheese, eggs, or other articles containing proteids. The heat and energy used by a working muscle can be obtained more easily from carbohydrates and fats than from proteids. There should be an adequate supply of these foods in order that the muscles may do their work with the greatest ease and economy. Water and salt are essential to the health and proper activity of muscle cells.

A sufficient amount of pure fresh air to oxidize the different foods in the muscles is of the utmost importance. If there is a lack of oxygen, the foods cannot easily be burned, and consequently there is a lack of heat and energy for the muscles to work properly, although there may be an abundance of food. The foods are at best only partially oxidized and so do not furnish as much heat as they should. And besides that, the wastes formed under such conditions are very poisonous, and difficult to remove from the blood.

The blood should contain all the different food stuffs in the right proportions, and an adequate supply of oxygen. The activity of the muscles depends upon the foods we eat and the air we breathe. 
138. Value of Exercise. - Next in importance to the quality and quantity of foods and air for keeping the muscles in a healthy condition, is the matter of exercise. The blacksmith has a large, strong right arm because he uses it so much. The muscles of the athlete grow strong because of constant exercise. A muscle that is not used becomes soft, flabby, and feeble.

Regular daily exercise of the muscles increases the action of the heart and lungs. More blood containing food and oxygen is pumped to all the organs of the body. The muscles used most reap the greatest benefit. Proper exercise is beneficial to both old and young. The young, growing person requires a greater amount of exercise than the adult. As long as a muscle is growing, exercise will tend to make it grow larger and to develop it better. That is why those who get a great deal of outdoor exercise look healthier and are better developed physically than those who live indoors most of the time. Exercise and sunshine make people well and strong.

Muscular exercise has a wholesome influence upon all the organs of the body. The digestive apparatus grows stronger; therefore more foods are eaten and they are better digested. The heart and lungs grow stronger and are able to do their work better. The lymphatics perform their functions of draining the wastes from the cells with greater efficiency. The skin, liver, and kidneys remove the waste materials from the blood more easily. The brain gets a larger amount of nourishment and the mind is clearer and 
more vigorous. The happiness, vigor, and usefulness of a person depend so largely upon his physical condition that it becomes a moral obligation to take proper exercise every day.

139. Amount of Exercise. - The amount of exercise a person should take depends upon his age, occupation, and general health. Very young children will take a sufficient amount of exercise if they are well and have an opportunity to move about freely, but often they are carried too much, and dressed in tight, heavy clothing. Nothing is better to make the baby well and strong than to strip off all its clothes and give it an opportunity to kick a few minutes daily on the floor, in a warm, sunny, well-ventilated room. A little later the child should be encouraged to walk, run, and play outdoors every day. The many natural sports and games of children are far better at this time than any artificial system of physical culture. The common games and sports, like drop-the-handkerchief, rollingthe-hoop, leapfrog, hare and hound, cycling, baseball, horseback riding, basket-ball, croquet, golf, fishing, tennis, rowing, and swimming are among the most healthful kinds of exercise for both boys and girls. Many of them are equally valuable for men and women.

Physical exercise taken in the gymnasium is usually less beneficial, because it so often is an irksome task in which the person feels no real pleasure, but simply does it for his health. The change of scene, the pleasurable state of mind, the agreeable companions, tend to increase the value of any exercise. 
Too much exercise is just as harmful as too little. Overwork is likely to cause the heart to dilate and its valves to weaken, the arteries to enlarge, and the respiratory organs to become diseased. Excessive exercise is always followed by great fatigue. The question of how much exercise to take must be solved by each person for himself.

140. Physical Training in our Schools. - No system of physical culture can take the place of the outdoor games and sports of which children are so fond. But the chief benefit of systematic exercise in the schools lies in the fact that it tends to a harmonious development of all the muscles of the body under the perfect control of the will. Baron Posse, a great leader in educational gymnastics, says, "It is not to produce great bulk of muscle, but to cause that already present to respond readily to volition; to improve the functional activity of the body; and to counteract and correct tendencies to abnormal development, especially those resulting from the artificial life of civilization." In any well-graded system of physical exercise the movements are so varied and numerous that no muscle, large or small, escapes its share of exercise. In the games and sports a few muscles get most of the exercise, while some are not used at all. In the gymnasium an attempt is made to exercise the weak and neglected muscles, so as to develop them in harmony with the rest; and to bring about a perfect control of every muscle, and economy, grace, and freedom in all the movements of the body. 
The simple exercises of any system can be given in the regular class room if necessary, without apparatus or musiz. During the gymnastic period the room should be well ventilated, so that an abundance of pure air may be carried to all the organs of the body. The exercise should be pleasant and short, but sharp and vigorous, otherwise it will be of little value.

141. Time of Exercise. - Exercise should be taken regularly every day, so that the body becomes used to it and does not feel fatigue too easily. A small amount of moderate exercise taken every day is more beneficial than a greater amount once a week. If the exercise is regular, a little more may be taken each succeeding day until the muscles become hard and strong, so that it is almost impossible to fatigue them.

Moderate exercise can be safely taken any time of day except immediately after a full meal. At such a time a large amount of blood is needed in the stomach and intestines, and if drained off to the muscles the foods will not be properly digested and absorbed. The best time for severe physical exertion is about two hours after a meal. The exercise indulged in after supper should be rather light.

142. Fatigue and Rest. - The fatigue of a muscle is due to two causes. The food supply in the muscle and in the blood is used up, and the cells become fatigued from a lack of nourishment. The second cause of fatigue is the formation of certain waste products by the action of the muscles, and their accumulation in the cells and lymph. The muscular stiffness and sore- 
ness that follow severe exercise when one is not used to it, come from the presence of a large amount of such poisonous wastes.

Rest and sleep give time for the removal of all these wastes. The cells may also be repaired by the proteid foods and stored with material for future use. If the exercise has been very severe, the wastes may poison the cells of the muscles so that they do not recover fully for several days. During perfect rest and in sleep the muscular activity is at its lowest point, and these reparative and recuperative processes are carried on most effectively.

143. Massage. - As understood and practiced at present massage means a systematic stroking, rubbing, tapping, pressing, or kneading of the skin and muscles by a person trained in this art. Each process is subject to a great variety of modifications, and may be either gentle or vigorous. It is now used as a mode of treatment in many different bodily disorders. It is extensively employed in certain nervous diseases, especially in those that require prolonged bodily rest.

Massage may take the place of exercise when persons are sick or too weak to endure physical exertion. The value of massage lies in the fact that by vigorous mechanical means poisonous wastes are pressed out of the tissues, lymph flow is stimulated, circulation is increased, muscle cells are excited to greater activity, and all the tissues of the body are made to function better. Nothing will set up the circulation and remove the waste products in a bruise quicker than good vigor- 
ous rubbing with the hands. A good vigorous rubbing of the entire body with the hands or with a rough, dry towel is an excellent form of exercise for anybody.

144. Alcohol and Tobacco. - It is a fact of common observation that alcohol acts upon the nerves in such a way as to make it difficult and impossible to control the muscles. The unsteady and staggering gait of the drunkard is an illustration. The young men on the baseball, football, track teams, and rowing crews in the best universities of this country are not allowed to drink alcoholic beverages of any kind, or to smoke cigars or cigarettes at any time. The reason for this is apparent.

The effect of stimulants and narcotics is most marked upon the nervous system. They act upon the muscles chiefly in an indirect way. But the presence of these drugs in the blood may affect the nutrition of the muscles, causing them to become weak and flabby, and therefore sluggish and irresponsive to all commands sent to them over the nerves. They lose their natural strength and power of endurance.

\section{SUMMARY OF THE MAIN POINTS}

I. The muscles cover the bony framework, making the form round and full, cause all movements, and form walls for some important organs.

2. There are about five hundred voluntary muscles in the body and a large number of involuntary muscles. Muscles differ widely in size and shape.

3. A muscle has an origin, an insertion, and a fleshy part 
called the belly. At one or both ends of some muscles we find a strong, thin band of connective tissue called a tendon.

4. A muscle is made of bundles of fibers held together by a thin sheath of connective tissue. A fiber consists of still smaller threads called fibrils or muscle cells.

5. The muscle cells are arranged side by side to form the thickness of a muscle, and end to end to form its length.

6. All muscles are well supplied with blood vessels, nerves, and lymphatics. They are well-nourished organs.

7. When a muscle contracts it changes its shape without altering its bulk. It becomes shorter and thicker because each muscle cell has the peculiar power to change its form in that way.

8. A muscle cannot remain contracted very long without becoming fatigued. It uses up food material and produces waste matter.

9. Most of the voluntary muscles are arranged in pairs, so that one bends a limb and the other straightens it.

Io. In order to keep the muscles in a healthy condition, they must have an abundant supply of wholesome foods, pure air, and proper exercise and rest at regular intervals.

I I. Proper exercise in which a person takes a lively interest improves the nutrition of all the organs of the body, and therefore conduces to health and vigor.

I 2. Over-exercise enlarges the walls of the heart and arteries, impairs the cardiac valves, injures the respiratory organs and the brain, and is followed by excessive fatigue.

I3. Physical training tends to a harmonious development and a perfect control of all the muscles of the body. It gives grace in carriage and ease in movement, and may be employed to develop the weak or neglected muscles.

14. Exercise should not be taken just before or immediately after a full meal. Moderate daily exercise should be taken by all. 
15. After exercise muscles need rest and sleep, so that the wastes may be removed and the cells repaired and stored with energy-producing food materials.

I6. Stimulants and narcotics make the muscles weak and flabby because of impaired nutrition. They become sluggish and do not respond to ordinary stimuli. 


\section{CHAPTER XV}

\section{SPECIAL USES OF MUSCLES}

145. Review. - In the last two chapters we have learned that the bones are so joined together as to permit freedom of movement in various ways; that there are ball-and-socket, pivot, hinge, saddle, and gliding joints, all of which allow more or less movement of the bones; and that most of the voluntary muscles are fastened to bones. These muscles are called skeletal muscles. The contraction of a skeletal muscle always causes some bone to move. It is the action of the muscles upon the bones that gives rise to motion of any part of the body and to movement of the body as a whole.

Standing, walking, running, swimming, gesturing, speaking, whispering, and singing are each accomplished by the action of different groups of muscles stimulated in a definite order. In this chapter we shall learn something about these special functions of the muscles.

146. Bones as Levers. - When a strong stick or a crowbar is used to move a heavy load, as in prying a stone out of the ground, it becomes a lever. There are three classes of simple levers in common use. They are known as levers of the first, second, and third class. In 
prying up a stone by bearing down on one end of the crowbar, it becomes a lever of the first class; the power is at one end, the load at the other, and the fulcrum

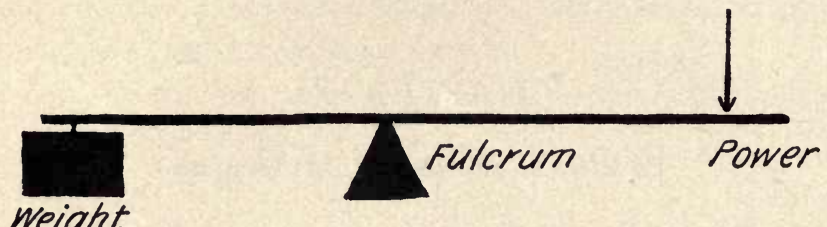

First Class.
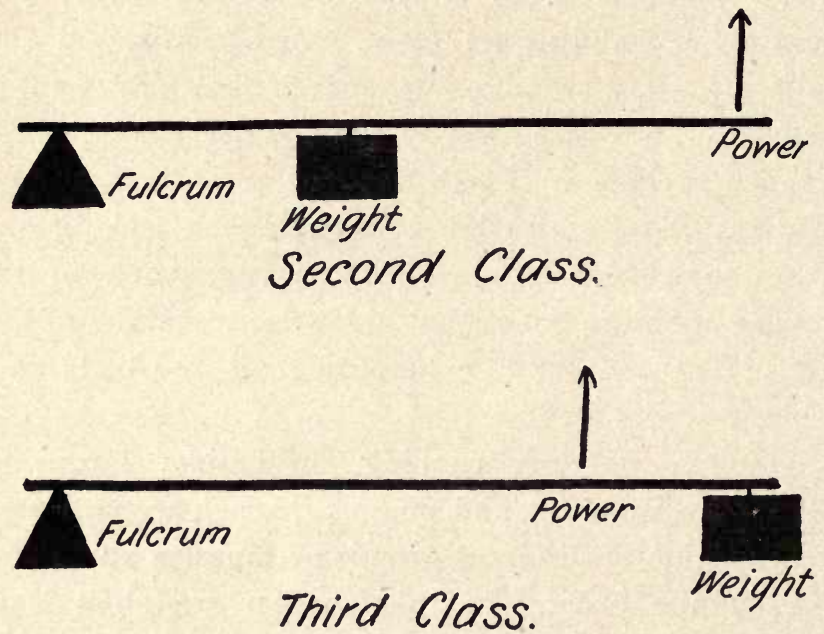

FIG. III. - Showing the three classes of levers (Zuppke).

somewhere between the two. If one end of the crowbar is under the stone and an attempt is made to lift it by pulling up on the other end, it is used as a lever of the second class; the power is at one end, the fulcrum 
at the other, and the load somewhere between the two. When the load is at one end, the fulcrum at the other, and the power between the two, the lever is of the third class.

All these levers are illustrated in the human body in the arrangement of the bones and muscles. The bones correspond to the crowbar; they are the levers; the contracting muscles attached to them furnish the power; and the body as a whole, any of its parts, or any object moved, serves as the load.

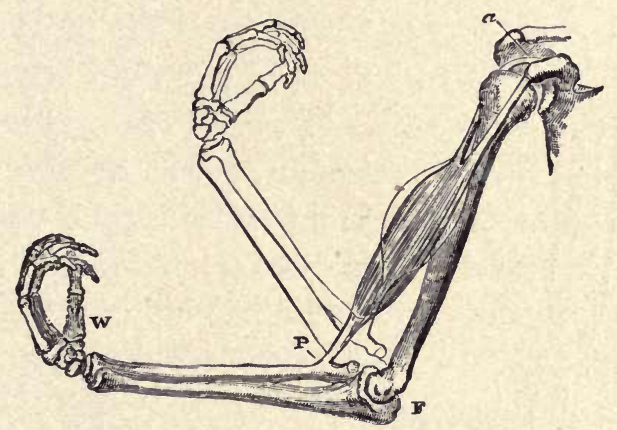

FIG. II2. - The bones of the arm, showing the biceps muscle and its tendons at $a$ and $P$. The action of the biceps illustrates a lever of the third class, $P$, power, $F$, fulcrum, and $W$, weight. (Huxley.)

When a weight is lifted by bending the arm at the elbow, the radius and ulna constitute the lever, the object on the hand the load, the elbow the fulcrum, and the muscles of the upper arm (biceps) the power. The muscles are attached to the bones a short distance below the elbow, so that the power is applied between the load and the fulcrum. Here we have a lever of the third class. In raising the body on tiptoe, the tarsal, 
metatarsal, and phalanges together constitute the lever. The phalanges constitute the fulcrum; the muscles of

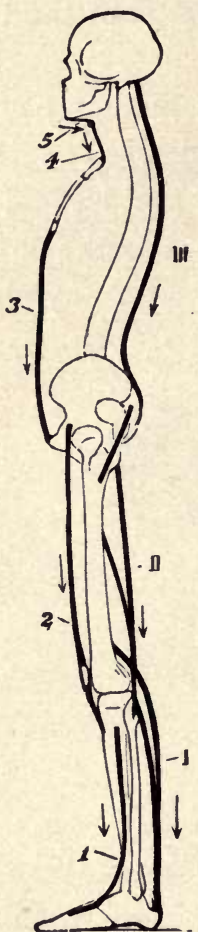

FIG. II3. - Showing the attachment of the most important muscles used in standing. The muscles at I, II, and III tend to keep the body from falling forward; and those at $1,2,3$, 4 , and 5 tend to keep it from falling backward. The arrows indicate the direction in which the muscles pull. (Huxley.) the calf, attached to the heel bone by the tendon of Achilles, furnish the power; and the weight of the body resting upon the ankle is the load. This illustrates a lever of the second class. In a similar way every muscular movement can be shown to fulfill the conditions of one or more of these levers.

147. Standing. - When lying on the back perfectly quiet, with every muscle relaxed, as in sound sleep, the skeletal muscles are doing no work. An infant cannot stand at birth, and yet its muscles may be used in kicking and throwing the arms about. It is only after the bones have gained sufficient strength; and the muscles have come under the control of the will, that the child can assume the erect posture.

Standing involves the use of many muscles and nerves. But after we have learned to stand, these nerves stimulate the vari- 
ous muscles so that they act correctly without any attention on our part. The muscles of the calf, knee, trunk, back, and neck, and many others, all work together in holding the body erect.

Sitting differs from standing in that the point of support is changed from the feet to the bones of the pelvis. The muscles of the legs are not active as they are in standing, but the same muscles of the trunk, back, and neck are employed as in standing.

The part the nerves play in standing and sitting can be best shown when a person becomes unconscious, as in fainting. He falls to the ground perfectly helpless, although the bones and muscles are not injured in any way. The brain sends no stimuli to the muscles, and they cease to act. The muscles, when in good condition, are the obedient servants of the brain, and respond to the slightest stimulation, but as soon as the brain does not stimulate them they relax, and wait for further orders.

148. Walking and Running. - In standing, both feet rest on the ground all the time; but in walking, part of the time both feet touch the ground, then the right only while the left swings forward, next the left while the right swings. The foot that is on the ground gives the body a slight push forward which would send it headlong to the ground if it were not checked by placing the other foot forward in time.

Walking seems to be an act of falling forward and catching one's self. This is accomplished by the use of a large number of muscles. Even the muscles of the 
arms, which are least concerned, aid somewhat in balancing the body. You will observe that the arm and leg on the same side swing in opposite directions. The fact that so many of the large muscles are employed in walking makes it one of the most beneficial forms of exercise.

In running, both feet never touch the ground at the same time, but both are in the air for a short period in each leap. The foot, as it leaves the ground, gives the body a much stronger push forward than in walking, and the body is inclined much more. Running is a valuable form of exercise, as it involves so many of the large muscles. One must be careful, however, to breathe properly, and not to continue such severe exercise too long.

In leaping, both feet leave the ground at the same time and are used in throwing the body forward. It is an excellent exercise for the young. Swimming is a mode of moving the body along in the water by the combined action of the muscles of the arms and legs. No form of exercise brings into use a larger number of muscles, or is better to give us general bodily strength than swimming.

149. Muscles of Expression. - Muscles of the face and other parts of the body are used to indicate feelings of pleasure, pain, sorrow, confidence, anger, fear, etc. The facial muscles are all flat, and attached to the skin in such a way as to cause the mouth and eyes to take a great variety of positions when they contract.

The muscles of expression may be trained by a little 
effort so as to give the countenance a pleasant appearance.

150. The Larynx and its Use. - In studying the air passages we learned something about this organ, called the voice box. The larynx is made up of nine separate pieces of cartilage held together by connective tissue and a number of delicate muscles. At the lower end
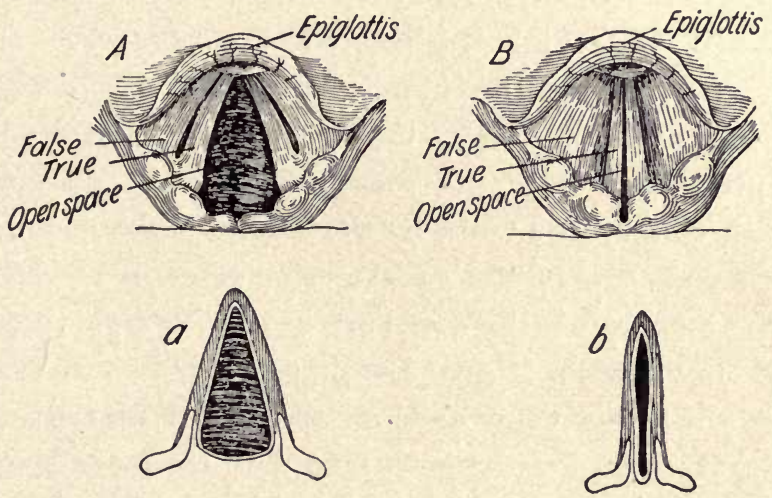

FIG. II4. - The larynx, top view (Zuppke) : $A$ and $a$, the vocal cords in resting position; $B$ and $b$, the vocal cords in position for producing voice.

the larynx is attached to the trachea by means of the large cricoid cartilage which has the shape of a signet ring. Above this is placed the large, irregular-shaped thyroid cartilage which forms the projection known as Adam's apple. The opening at the top of the larynx is guarded by a covering of cartilage fixed to the top of the thyroid; this is the epiglottis. Besides these three large single cartilages, the larynx has three pairs of smaller ones attached to the cricoid. 
The vocal cords are stretched across the opening in the larynx, being fastened behind, in front, and at the sides to some of the cartilages. The cords are two thin white bands of elastic tissue formed by folding the mucous membrane which lines the larynx.

Get a sheep's larynx from your butcher and notice the three large cartilages, the vocal cords, the lining membrane, and the muscles and connective tissue that hold the parts in place.

When air is inhaled the vocal cords move apart because some of the muscles of the larynx contract. During exhalation they move slightly together again. In producing voice the vocal cords are brought close together and made tense by the action of small muscles that move some of the cartilages. If air is forced out of the lungs when the cords are in this position, they are made to vibrate and give forth a sound.

If you place your hand on the throat and sing the scale, you will feel the larynx as a whole move slightly up for the higher notes and down for the lower. For the higher tones the cords are made more tense than for the lower. The pitch of the tones depends upon the tension of the cords and position of the larynx. The loudness depends upon the force with which air is expelled from the lungs or the distance over which the cords are made to vibrate.

151. Voice Sounds. - Sounds produced by the vocal cords may differ in pitch and loudness. But another very important characteristic of the human voice is its sweetness or quality. This depends chiefly upon the large resounding chamber of the pharynx, nose, and 
mouth. You can recognize a friend by his voice when you do not see him. The same keys on the violin, piano, and organ do not sound alike. Just so no two human voices are alike, even when pitched precisely to the same key. This individual peculiarity we call quality or timbre.

The lips, teeth, tongue, nose, and palate are used in modifying the sounds as they come from the vocal cords, and are able to change them in a wonderful way. If you pinch your nose so that no air can escape through it and then talk, you will see what an important part the nasal passages play in ordinary conversation. The loss of a single tooth is noticed in a person's speech. These organs change the size and shape of the various cavities through which the sound passes in speaking, and so control the mode of forcing the breath out. By such modifications the vozvel sounds are made from the pure Italian $a$ as in arm. The subvocals are made in a similar way, with the air passages more obstructed, as in the sounds $r, v, m, n$, etc. The aspirates are mere emissions of breath more or less modified by the same organs.

Speech is simply a proper combination of sounds to form words that stand for ideas. A child at birth has a voice, can produce sounds as in crying and screaming, but cannot speak. Language is acquired by a very slow process of imitation in which the child learns to control the muscles involved in producing the various sounds. He must also learn the meaning of the words used by others. 
152. Care of the Voice. - The air passages first need attention. Enlarged tonsils, adenoid growths, and polypi in the nose obstruct the sound waves so that the voice is dull and unpleasant. All such obstructions should be removed as soon as they appear, for they lead not only to permanent defects in the voice and speech, but to impaired health and dangerous diseases.

Proper singing is one of the very best ways to cultivate a pleasant and strong voice for speaking. All children should be encouraged to sing simple pieces within easy reach of their voices. Singing is an excellent exercise for developing a full chest, expanding the lungs, and gaining control of the muscles of the larynx. A child should not sing when suffering from any throat trouble or while the voice is changing. At no time should one sing until the larynx becomes fatigued, as excessive use of the voice tends to weaken the muscles and may result in permanent injury.

Proper breathing exercises under favorable conditions give one control of the respiratory muscles. This is an important matter in singing, reading, and speaking. One who does not breathe properly can never have full control of his voice. Exercises in articulation are valuable in giving distinct enunciation and correct pronunciation.

The delicate mucous membrane of the throat and the nose is . easily irritated and inflamed by dust of the street, smoke, alcoholic drinks, hot foods followed by ice water, strong condiments, and exposure to cold. When congested and inflamed the throat feels sore, the 
muscles and the vocal cords lose their power to respond to nerve stimuli, and the voice becomes harsh and disagreeable.

A sweet, pleasant, melodious voice under perfect control is a possession that should be as highly prized as good personal appearance. Much can be done to secure such a voice by regular, systematic training and proper care, if begun in early childhood. A celebrated singer, when asked why he practiced so regularly, said, "If I neglect to practice one day, I notice it; if for two days, my friends notice it ; and if for three days, the public notice it."

\section{SUMMARY OF THE MAIN POINTS}

I. The bones serve as levers for the skeletal muscles in all movements. There are three classes of levers, all of which occur in the body.

2. Standing involves the use of a large number of muscles that must be delicately adjusted in order to maintain the body erect.

3. The nerves play an important part in standing. All the muscles must be stimulated just enough to maintain a balance.

4. Walking is an act of falling forward and catching one's self. It brings into play many of the large muscles, and for that reason it is a very valuable exercise.

5. Running is quite like walking exeept that the body is inclined more, both feet are never on the ground at the same time, and the onward movement is usually more rapid.

6. There are many flat muscles in the head and face which are used in expressing feelings of the mind. They are called muscles of expression. 
7. The vocal cords are two thin folds of mucous membrane stretched across the open space in the larynx.

8. The cords move apart in inhalation, and together in exhalation. They may be stretched tight, and caused to vibrate by the breath as it is forced out of the lungs.

9. Difference in pitch depends upon differences in the tension of the vocal cords and in the position of 'the larynx as a whole.

Io. Loudness depends upon the force with which the breath is expelled from the lungs, and the distance it makes the cords move in their vibration.

II. Quality depends upon the size and shape of the pharynx, nasal cavities, and mouth.

12. The lips, teeth, tongue, soft palate, and nose modify the sounds made by the cords, and produce the various tones of voice.

I3. The air passages should be unobstructed by adenoid growths, enlarged tonsils, or polypi, and the respiratory muscles unhampered by round shoulders, flat chest, curved spine, or tight lacing.

14. Voice culture, singing, and breathing exercises are important means of training the voice. The voice depends upon the general health of the body.

I5. Much can be done to secure a strong, sweet, melodious voice, and a pleasant, agreeable manner of speech.

I6. Tobacco, alcohol, hot foods or drinks, cause a congestion and inflammation of the mucous membrane, and make the voice harsh and disagreeable. 


\section{CHAPTER XVI}

\section{THE NERVOUS SYSTEM}

153. Plan of the Nervous System. - We shall now learn something about the system that regulates, controls, and harmonizes the activities of all the cells and organs of the body, and makes us aware of the world about us and of our relation to it.

The great central organs of the nervous system are the brain and the spinal cord. There are nerves going from the brain to the millions of cells in all parts of the body. Nerves come to the brain from every part of the body. The nerves going to the brain carry stimuli to this central organ. It is because of these stimuli that we see, hear, taste, smell, feel, and know what is going on around and within us. The brain receives these stimuli and sends messages out over the nerves that go from it, which tell the muscles, glands, and other tissues what to do in order that the various activities and interests of the body as a whole may be properly and harmoniously carried on. It is the brain that controls the nutrition and function of every cell and makes it work at the right time and in the right way.

The brain with its incoming and outgoing nerves may be compared to the central railroad station with its 


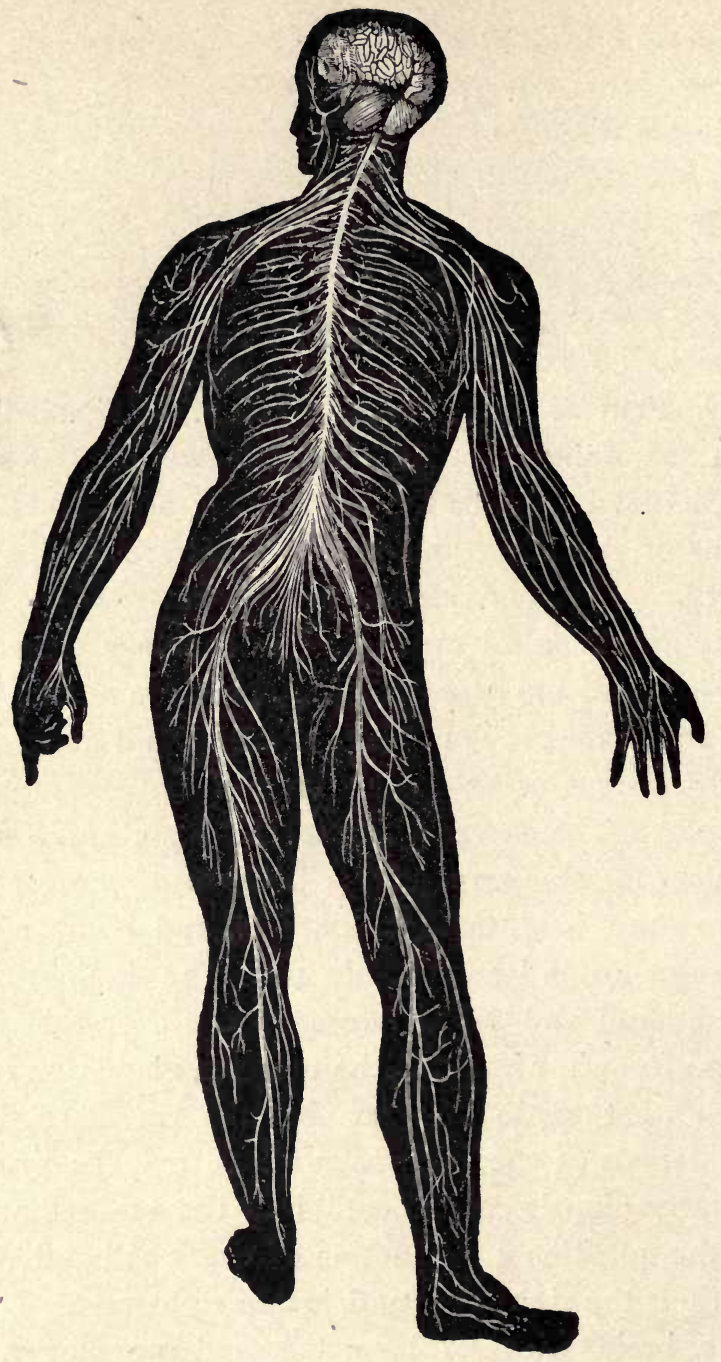

FIG. II5.-The nervous system. 
numerous telegraph wires running in all directions, by means of which the trains moving anywhere on the line are controlled. The train dispatcher, in the central station receives messages from every train on the road, so that he knows just where every train is located and how it is moving. He sends messages out to the conductors, giving them their orders so that their trains may not run into each other. A single mistake of either train dispatcher or conductor in sending a wrong message or in failing to obey orders, might result in serious loss of life and property. One man must plan and operate the entire system.

In much the same way the brain performs its duties, which are, however, very much more complicated. If the muscles did not receive orders from the brain and obey them, we could not walk or speak, the lungs and heart could not work, the foods could not be digested, in fact anarchy would reign supreme in the human body. We shall now study this wonderful system in detail.

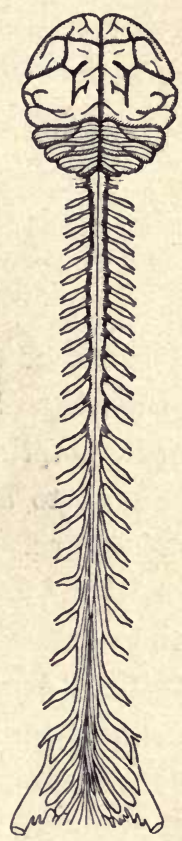

FIG. Ir6. - The brain and spinal cord, from behind (Pratt).

154. Nerve Tissue. - The nerve tissue consists of cells which in size and shape are very unlike those found in any other tissue. They have a cell body and a large nucleus, made up of a very soft, delicate substance. Each nerve cell sends out a principal projec- 
tion called the axone, and several shorter, treelike branches called dendrites. Every nerve cell has a cell

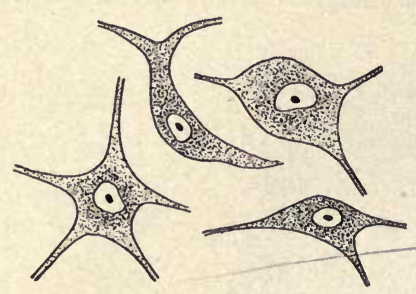

FIG. II7.- Nerve cells of a rat (Pratt). body, an axone, and dendrites. Some nerve cells with their projections are very long. A cell body located in the spinal cord of the neck, sends its axone out to the fingers, and some in the lower part of the cord send their axones to the toes. A single nerve fiber may extend the whole length of the arm or of the leg. Some of the cell bodies of the cord are large enough to be seen with the naked eye. Others are very small and have short axones and dendrites.

The dendrites serve to connect one cell with other cells and carry messages to the cell bodies of which they form a part. The cell body receives the message over the dendrites and directs it out over its axone. The axone carries the message

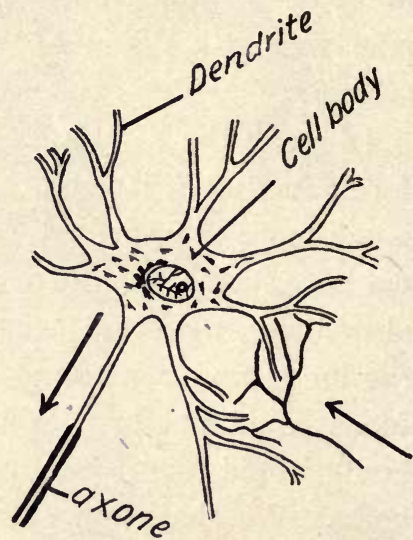

FIG. II8. - Human nerve cell, showing dendrites, cell body, and axone. (From Huxley.) from the cell body to a muscle or to a gland. Sometimes the dendrites are very long, bringing messages a long distance. 
All nerve tissue consists of such cells completely surrounded and held together by connective tissue and fat. These substances protect, pack in, and hold in place the delicate nerve tissue and enable it to carry on its functions properly and easily. The entire nervous system is made up of nerve cells and connective tissue.

Take a bit of nerve tissue and examine it under the microscope. Notice the size and shape of nerve cells.

155. The Nerves. - We saw that there are two kinds of nerves necessary, one leading to and the other from the brain. The former are called sensory or afferent, and the latter motor or efferent. Many of the nerves do not go directly to the brain, but reach it through the spinal cord, and for that reason are known as spinal nevies. There are thirty-one pairs of this kind. They carry stimuli from and send impulses to the muscles and glands of the trunk and the extremities. Those connected directly with the brain are called cranial nerves. There are twelve pairs of cranial nerves. The cranial nerves are distributed to the head and to the internal organs. All of the special senses except touch or feeling have this class of nerves coming from them. The olfactory of the nose, the optic of the eye, and the auditory of the ear are examples of cranial nerves.

In their appearance all nerves are quite alike. They are smooth, white, shining cords of various sizes and lengths. The great sciatic nerve of each lower limb is about one half of an inch wide, one sixth of an inch in thickness, and extends from the lower end of the spinal cord down to the toes, sending off branches all along its 
course. Some nerves are very short and so small that they can scarcely be seen with the naked eye.

If a nerve is cut across and examined under the microscope, it will be seen to consist of many very fine nerve threads or fibers, held to-

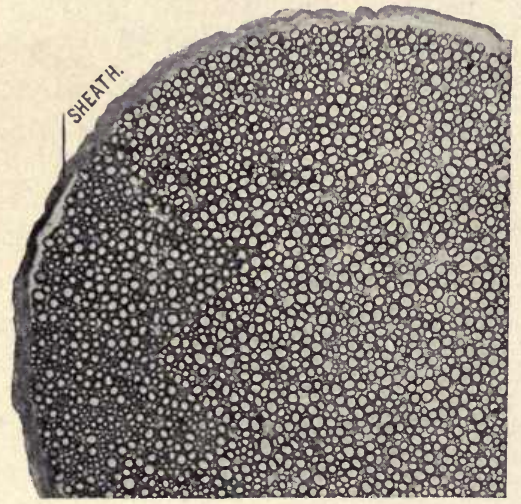

FIG. II9. - A section of a frog's nerve, showing the sheath and nerve fibers.

gether by fatty connective tissue and the whole surrounded by a sheath. Each fiber is an outgrowth of a nerve cell, an axone or a dendrite, and runs to its destination unbroken like a single continuous wire of a large cable. A large nerve has thousands of separate fibers.

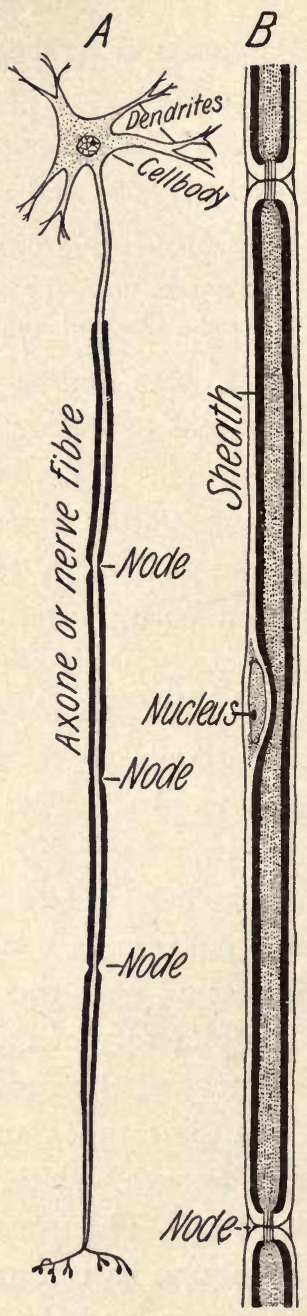

FIG. I20. - Showing $A$, a nerve cell with all its parts - dendrites, cell body, and axone; and $B$, a portion of a nerve fiber, highly magnified. (Drawn by Pratt.) 
A nerve fiber differs from a telegraph or telephone wire in that it carries messages in one direction only, while a wire will carry messages in either direction. A sensory fiber conveys messages to the brain or spinal cord, but never from it; while a motor fiber carries messages out to muscles and glands, but it cannot carry impressions to the brain. All of the spinal nerves and three pairs of cranial nerves contain both sensory and motor fibers and therefore are called mixed nerves.

156. The Spinal Cord. - The spinal cord is a great nerve trunk extending from the base of the skull down through the canal of the vertebræ or backbone. In the adult it is about eighteen inches long and three quarters of an inch in diameter. The spinal cord and brain are carefully protected by a bony covering, but besides this there are three membranes that closely invest these delicate organs and supply them with nutrition.

The outer part of the spinal cord is called white matter. It consists of bundles of nerve fibers that serve as ingoing and outcoming pathways for the sensory and motor mes-

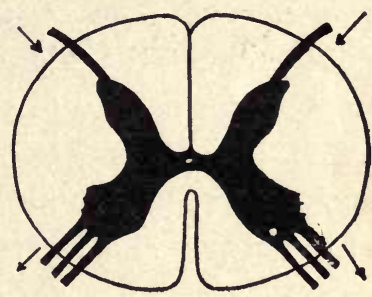

FIG. 121. - Showing the white and gray matter of the spinal cord (Pratt). sages carried to and from the brain. White matter always means nevve fibers and never does anything except carry messages. The entire surface of the body except the head and face is supplied with spinal nerves. 
The central portion of the spinal cord consists of nerve cell boties and is known as gray matter. In the cord we find the white matter on the outside and the gray on the inside. The nevve cells or gray matter do not carry messages; they have very different functions to perform. A collection of nerve cells that has some particular work to do is called a nerve center. The cells of the gray matter of the spinal cord are grouped into a great many nerve centers which perform important offices. These centers control most of our involuntary movements, and do a large amount of work that can be

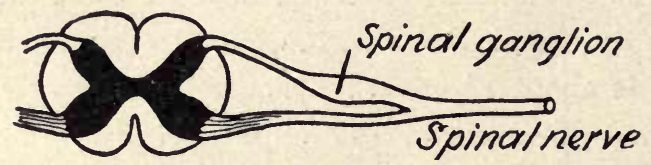

FIG. I22. - A cross-section of the spinal cord, showing a spinal nerve and its two roots (Huxley).

done without the aid of the brain. Certain sensory impressions carried to the cord do not reach the brain at all, but are reflected or turned back to muscles by such centers located in the cord; they act independently of the brain. These are reflex acts.

Get a piece of spinal cord from the meat market and examine it when fresh. It may then be hardened by using a mixture of two thirds alcohol and one third 2 per cent solution of formalin. When it is thus preserved, slices may be easily cut for more careful study with a magnifying glass.

Centers of the cord control the nutrition and growth of the cells of the body by telling them when and how much to eat, and by regulating their blood supply. 
The digestion of foods, the action of the liver, the distribution of blood, and many other important functions are under the control of these reflex centers. No thought need ever be given to the work of the spinal cord, and so the brain is left free to do other things.

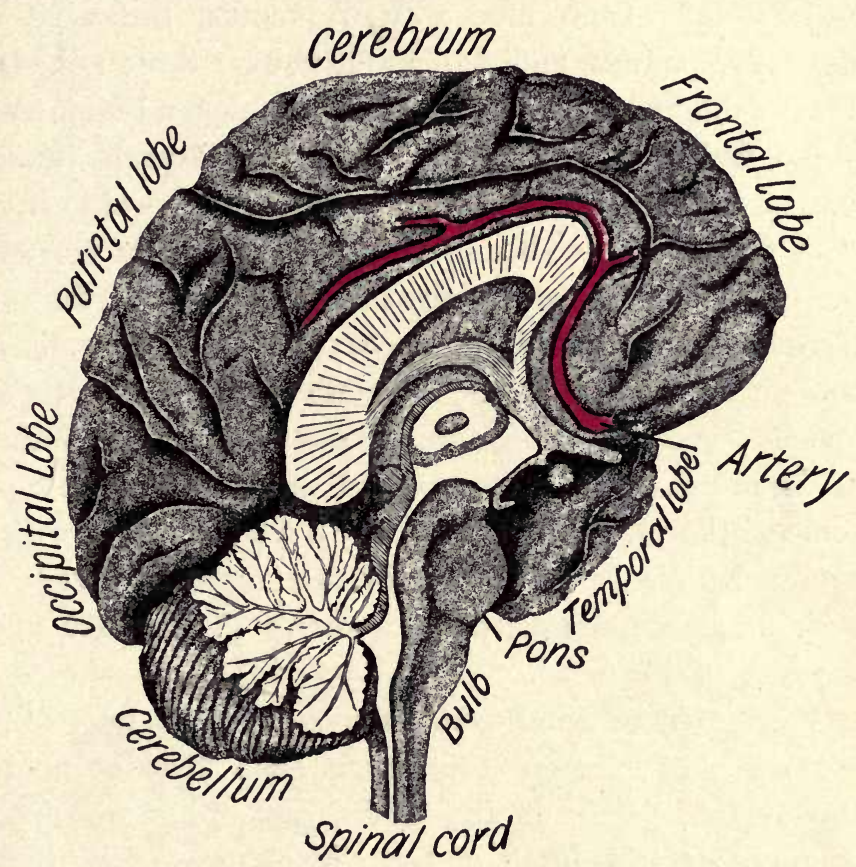

FIG. I23. - The left half of the brain, inner surface (Hebert).

157. The Brain. - The brain is the organ of the mind and the seat of consciousness. It enables us to see, hear, taste, smell, and feel ; to remember, imagine, and think; to love and hate; to will and execute. It is the organ of the human soul. 
The brain occupies the entire cavity of the cranium and consists of four parts or divisions, called the bulb, pons, cerebellum, and cerebrum. The cerebrum forms about four fifths of the whole mass and is by far the most important part of the nervous system. The elephant's brain weighs from nine to ten pounds, the whale's about five pounds, and man's a little over three pounds. The intelligence of an animal does not depend upon the actual weight of the brain. While the average brain weight in man is about three pounds, quite wide variations from this have been found. The brain of Cuvier, the French naturalist, weighed sixty-six ounces; that of Byron, the poet, sixty-four ounces ; that of Schiller, fiftysix ounces; that of Gauss, the mathematician, fifty-three ounces; and that of Dante fifty ounces. The brains of some idiots have outweighed these, while those of some of the most intelligent men have fallen below the average. We cannot maintain that there is always a very close relation between a man's intelligence and the size of his head.

The order of intelligence depends more upon the number and size of the nerve cells that occur in the surface layer of the brain, and therefore upon the number and depth of the convolutions or wrinkles which go to increase the surface area. The gray matter is on the surface in the brain and the white matter on the inside. The brain of the higher animals and of man is not smooth on the surface, as can be seen from the figures opposite. In civilized, highly educated, and intelligent people these convolutions are numerous and 


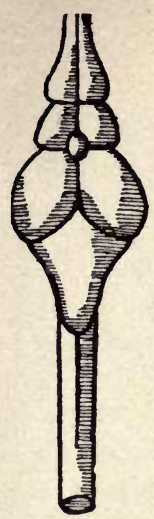

Fish.

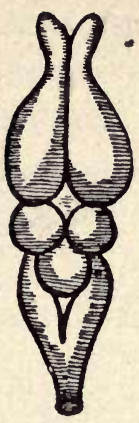

Reptile.

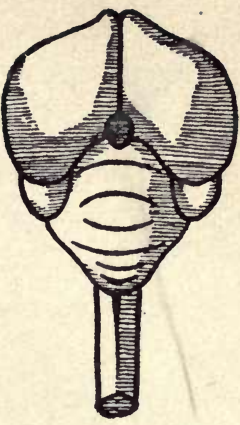

Bird.

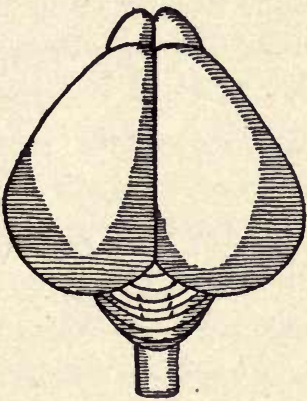

Marsupial.

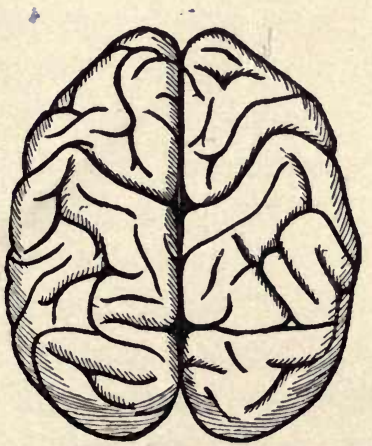

Ap :

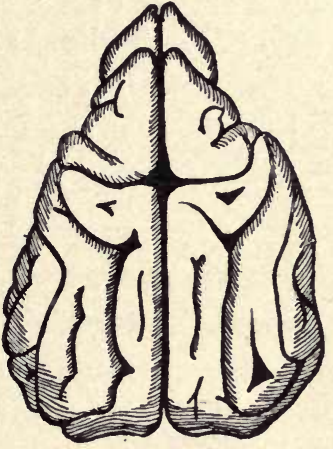

Dog.

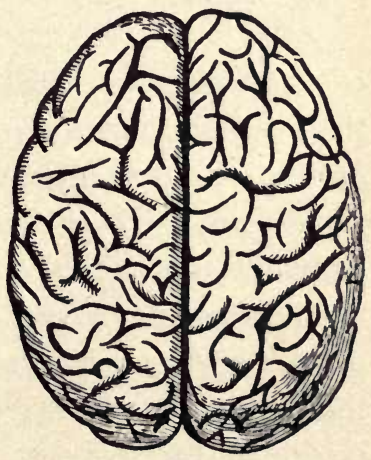

Man.

FIG. I24. - A series of brains, showing the development from the lower to the higher animals. (Adapted from various sources by Pratt.) 


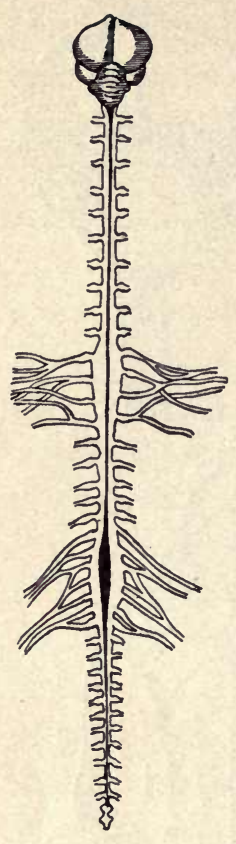

FIG. I25. - The nervous system of a pigeon. (Drawn by Pratt.)

deep, and so increase the amount of gray matter on the surface without any material increase in the brain weight.

I. Get a sheep's brain from your butcher and find the cerebrum, cerebellum, pons, and bulb.

2. Locate the frontal, parietal, temporal, and occipital lobes of the cerebrum.

3. Notice the fissures and convolutions in the different lobes.

4. Observe how the two hemispheres are joined together.

158. The Bulb. - The bulb or medulla is a slight enlargement at the upper end of the spinal cord. - It looks very much like the cord, but it has a rougher surface. The white matter of the cord continues up through the bulb and leads to cell bodies on the surface of the cerebrum. In the bulb most of the nevie fibers cross to the other side before they go in or out. This explains how the left side of the brain controls the right half of the body, and the right brain the left half. When the left brain is paralyzed, the organs on the right side of the body are affected; the right arm and the right leg do not work as they should, for the nerves do not stimulate them.

There are nerve centers in the bulb that control many of the higher reflex muscular activities, as breathing, masticating, sucking and swallowing, sneezing, hiccoughing, the secretion of digestive fluids and sweat, the 
heart beat, the tone of muscles, the size of blood vesseis, etc. Because so many important centers are located in the bulb, it has been called the vital knot.

The pons lies just in front of the bulb and serves chiefly as a bridge to connect the cerebrum with the other parts of the brain.

159. The Cerebellum. - The cerebellum or little brain has the gray matter on the outside and the white within. The white matter radiates from the center to all parts of the surface, giving it a treelike appearance when cut open, and for this reason it is called the tree of life. It forms about one eighth of the entire brain, and consists of two closely connected halves, each furrowed by numerous shallow convolutions.

The uses of the cerebellum are not fully known at present, but we know that it has to do with balancing the body in standing, walking, and running, and in making the muscles work together in these movements. When the cerebellum of any animal is diseased, injured, or removed, it is unable to guide and control its muscles of locomotion.

160. The Cerebrum. - The cerebrum is nearly divided into two hemispheres by a deep longitudinal cleft or fissure. Each hemisphere is marked by several deep fissures and many small ones, which divide it into four main parts called lobes, each having numerous convolutions. These lobes are known as the frontal, parietal, temporal, and occipital. See figures 123 and 126 . The gray matter, which varies in thickness from one twelfth to one sixth of an inch, forms the entire outer surface 
of the cerebrum. It extends down into every fissure and up over every convolution, and in this way the area of the gray matter is increased many fold.

The cells of the cerebrum are also grouped into definite centers, each having its own work to do and never attempting anything else. The centers may be said

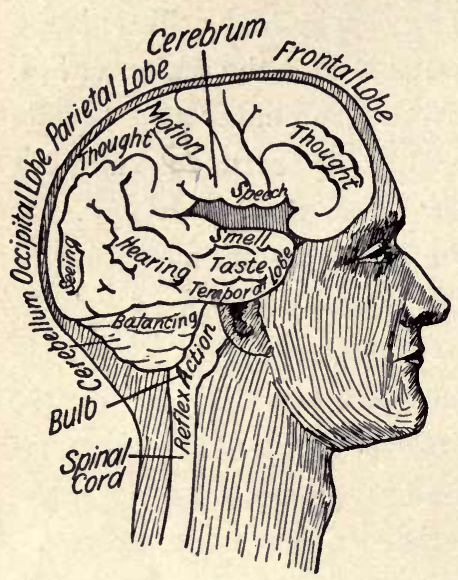

Fig. 126. - Showing the lobes of the brain and their functions (Zuppke). to belong to one of three kinds; namely, sensory, motor, or association. The sensory areas are those parts of the cerebrum to which impressions are carried by the sensory nerves. We notice in the diagram that a part of the occipital lobe is the center for sight, the temporal for taste, smell, and hearing, and the upper and inner part of the parietal for touch. The motor areas have to do with sending messages out over efferent nerves to the different voluntary muscles of the body. We see in the diagram that the parietal and a small part of the frontal lobes constitute the motor area. If any cells of the motor area are stimulated with electricity, a definite muscular response will always follow. By such experiments the use of every part of the motor area has been fully mapped out. The association areas are neither motor nor sensory, but are very highly developed in man, 
and doubtless have some important function. It is now believed by some scientists that the three association areas are thought centers. The sensory impressions, it is claimed, are carried from the sensory areas to the association areas, and from them to the motor area by means of nerve fibers which connect these

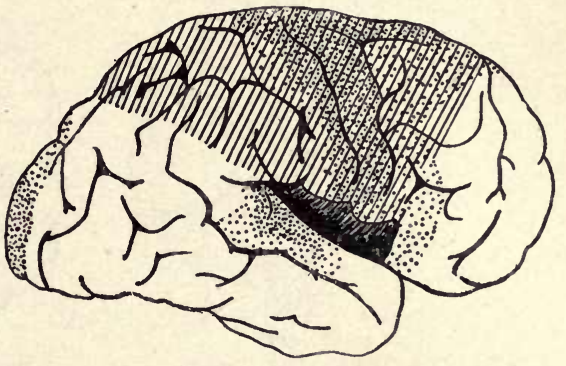

FIG. 127. - Outer surface of the right hemisphere. The dots indicate the sensory, the lines the motor, and the clear spaces the association areas. (Modified from Flechsig by Pratt.)

parts with each other. These association areas may be the centers for memory, imagination, and judgment.

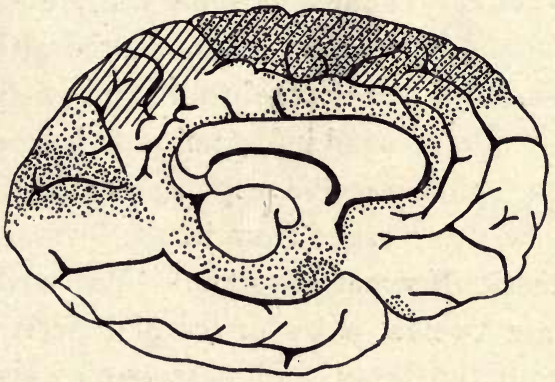

FIG. I28. - Inner surface of the left hemisphere. The dots indicate the sensory, the lines the motor, and the clear spaces the association areas. (Modified from Flechsig by Pratt.) All this, however, is largely theoretical at present.

The brain has three kinds of nerve fibers. First, those that carry impressions up from the spinal cord to the sensory areas, and down from the motor areas; they are called projection fibers. Second, those that connect different parts of the two hemispheres with 
each other; they are called commissural fibers. Third, those that connect the lobes and convolutions in each

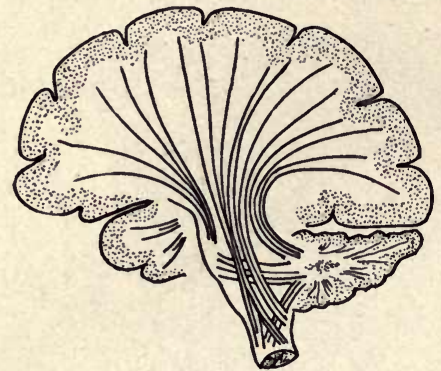

FIG. 129. - Projection fibers (Zuppke).

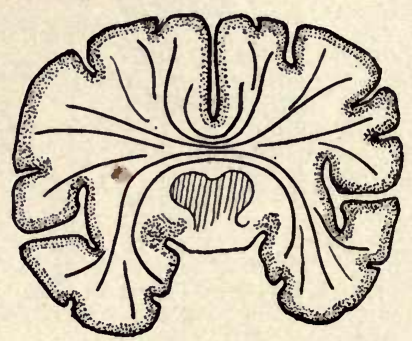

FIG. 130.-Commissural fibers (Zuppke).

hemisphere; they are known as association fibers. By means of the different kinds of nerve fibers every part

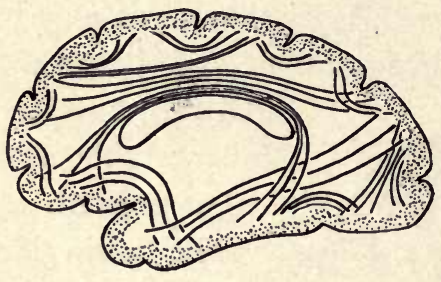

FIG. I31. - Association fibers (Zuppke). of the body, fingers and toes, elbows and knees, shoulders and hips, eyes and ears, is connected with the cerebrum and may send information to it, and receive responses and messages from it.

161. The Sympathetic Nervous System. - We have learned that there are twelve pairs of cranial nerves which branch off from the brain, and pass out of the skull through openings in the bones and distribute themselves to many organs of the head, chest, and abdomen; and thirty-one pairs of spinal nerves which connect the cord with the skin, and with all the skeletal muscles except some about the head and face. Besides 
these there is another group of nerves and nerve centers known as the sympathetic system. It consists of a chain of ganglia - forty-nine in all - located on either side of the spinal cord, extending from the base of the brain to the coccyx. It has also four great ganglia, situated a little in front of the chain, together with numerous smaller ganglia located in the visceral organs. Many nerves connect all these ganglia with each other, with the spinal cord and brain, and with the organs of the chest and abdomen. The largest of the four ganglia is called the solar plexus. It is located behind the stomach and in front of the aorta, and sends branches to all the organs of the abdomen, as the stomach, liver; spleen, pancreas, kidneys, and intestines. These ganglia all give off nerves that supply the visceral organs, glands, and the walls of the arteries and capillaries.

These ganglia and nerves help to regulate the size of the blood vessels, control the action of the involuntary muscles of all the visceral organs, as lungs, heart, stomach, and intestines, and regulate the activity of the secreting glands. They seem to exercise an important control over the vital processes that are carried on unconsciously.

Most of the internal organs have nerves from the sympathetic system and from the cerebro-spinal system, as the other is called. The two systems form one complete, unified nervous apparatus.

162. Mind and Brain. - We know that the mind and the brain are very closely connected, but just what their relation to each other is no one can tell. When 
the mind is active more blood goes to the brain, oxidation is increased, the temperature rises, and the brain cells become fatigued. When the brain is seriously injured or diseased, the mind does not work as it should; the person behaves in a strange way. He cannot remember, imagine, and reason as he once could; his feeling and will power are lost or enfeebled; his whole mind, with all its powers and capacities, hopes and ambitions, has become so deranged that he cannot be held responsible for what he does, and we call him mad or insane.

Sometimes a person suddenly loses the ability to speak. A judge of the Supreme Court in one of our states, after spending an evening in pleasant conversation with some friends at his house, retired at his usual time, apparently in the best of health. The next morning he could not utter a single sentence. The power of speech was gone. He was as helpless as if he had never learned to talk. After a vacation of several months he recovered fully. Cases of this kind are known to physicians, for they are not uncommon. The loss of speech is sometimes due to the formation of a blood clot over the speech area of the brain caused by the rupture of small blood vessels. In such cases the skull has been opened and the hard clot carefully removed without injuring the delicate brain tissue, and the ability to speak was regained in the course of a few weeks. When no operation is performed, the clot may in time be completely absorbed so that the patient recovers. 
While we do not know just how the mind and the brain are related, we do know that a strong, sound, and vigorous mind demands a trained, healthy, and wellnourished brain and body.

\section{SUMMARY OF THE MAIN POINTS}

I. The nervous system controls, regulates, and brings into harmonious relation all the cells, tissues, organs, and systems of the human body.

2. The nervous system consists of nerves and nerve centers. There are nerves from every cell in the body going to the brain, and from the brain to all the muscles and glands.

3. A nerve cell consists of a cell body with a large nucleus, a main projection, the axone, and a number of treelike prolongations called dendrites. They vary much in size and shape.

4. The dendrites carry messages to the cell body, and the axone away from the cell body.

5. A nerve consists of a large number of nerve fibers bound together with connective tissue and fat into a single trunk. Each fiber is either an axone or a dendrite of some nerve cell.

6. As to origin, we divide nerves into spinal and cranial, and as to function, into sensory, motor, and mixed.

7. The white matter of the cord forms pathways for the ingoing impressions and the outgoing impulses, and the gray matter, the central portion, consists of nerve centers for many of the lower reflex acts.

8. The brain is the central organ of the nervous system, and consists of the bulb, the pons, the cerebellum, and the cerebrum. It weighs about fifty ounces in man, and has a very rough or furrowed surface.

9. In the bulb at the upper end of the spinal cord, most of the nerve fibers cross to the opposite side. The gray matter 
is grouped into nerve centers, which control many of the higher vital functions, as breathing, heart beat, swallowing, secretion, etc.

I0. The pons, or bridge, is a mass of nerve fibers connecting the bulb, cerebellum, and cerebrum.

I I. The cerebellum, or little brain, is the organ which makes the muscles used in sitting, standing, walking, and balancing work together in the right order, and gives us our bearings in space.

I2. The cerebrum is the largest part of the brain, forming about four fifths of the entire mass. It consists of two hemispheres, each having four main lobes, known as the frontal, parietal, temporal, and occipital.

I3. There are numerous nerve centers in the cerebrum, each having its special function to perform. The three important areas are known as the sensory, the motor, and the association.

14. The sensory areas receive impressions from the sensory nerves coming from all parts of the body. The motor areas send out messages over the motor nerves to the muscles and glands. The association areas connect the sensory and the motor areas of the brain, and may serve as the centers for thought.

I 5. The ganglia and nerves of the sympathetic system supply all the organs of the chest and abdomen. These organs are also supplied with spinal and cranial nerves, so that they have a double nerve supply.

16. The brain and the mind stand in close relation to each other. If we wish a strong, active, vigorous mind, we must see that the brain is kept in an excellent physical condition. 


\section{CHAPTER XVII}

\section{CARE AND TRAINING OF THE NERVOUS SYSTEM}

163. Food and Air. - The spinal cord and the brain are sometimes called the master organs, because the growth and activity of every cell in the body are under their direct control. Glands and muscles act only when stimulated by nerves. Hence the nervous system is carefully protected against injury, and has a large proportion of the blood carried to it. The brain is about one forty-fifth of the weight of the entire body, but it receives about one eighth of the whole quantity of blood.

It requires a large amount of food to keep the delicate brain cells in a good working condition. The health of the brain and the kind and amount of work it can do depend upon the quantity and quality of the blood sent to it. The boy or girl who eats only coffee and rolls for breakfast, and attempts to do hard school work all forenoon on that scanty and unhygienic meal, must not be surprised if he becomes exhausted and suffers from headache in the latter part of the morning exercise. A schoolboy needs a good supply of nutritious and easily digested food three times a day, and a light lunch in the middle of the forenoon, if he wishes to do the best kind of mental work. 
The amount and kind of air breathed is next in importance to the food eaten. Since the brain needs so much food, it must have an equally abundant supply of pure fresh air to oxidize the food. The "school headaches" are the result of hot, close, poorly ventilated schoolrooms, in which the same air must be breathed over and over again, until the pupils become so drowsy and listless that they cannot get their lessons. Such a condition is sure to cause severe headaches and other disorders.

164. Exercise. - The brain, like the muscles, must be given a moderate amount of exercise daily to keep it well and strong. It becomes delicate, weak, and sickly if not used, just like the muscles of an arm carried in a sling. Studying may at first be hard work, and very fatiguing, but if kept up day after day, with proper intervals of rest, it will soon become easy, so that difficult tasks are a real pleasure.

In studying exercise, we learned that, in order to use all the muscles of the body, a great variety of movements is essential. In the same way a single power of the mind can be exercised and all the others neglected. Variety in mental work is just as important as in physical work to call into activity all the capacities and powers of the human mind. The cerebrum alone contains, on its outer surface, over $9,200,000,000$ cells which can be used. In order to bring all these cells into action, so that they may grow and develop as they should, a very great variety of mental exercise and a wide range of interests are indispensable. 
165. Education. - Education means the proper exercise of all the parts of the brain so as to bring about a symmetrical development of the various brain centers. One of the chief reasons why we study so many different branches in the schools is to exercise and develop the whole brain. This trains the intellect, the emotions, and the will, and develops character.

In early life all the senses should be properly and adequately exercised, and the larger muscles brought under the control of the will. The exercises of the kindergarten and the primary school are designed to train and develop the sensory areas of the brain, and to bring into relation with them the motor centers of the hands and feet. Nature herself has surrounded us with things beautiful and interesting, as the birds and butterflies, the flowers and trees, the rocks and streams, the clouds and stars, which are among the most valuable means of training the senses through close and accurate observation. Literature is full of references to objects in nature, and so may be useful in training the imagination if the reader will take the time to recall and picture each object mentioned. Manual training is the best possible means of exercising the motor areas of the brain.

Youth is the time when strong and lasting interests should be cultivated in the many things concerning man and nature about us; for as we grow older our interests must become more and more limited in their range until they are confined to our business or profession. The business man usually has little time or 
energy to devote to things not related to his own work, and therefore all his interests are likely to become centered in his own business. The same is true of the professional man. Unless a person gets a broad and liberal education, which trains and develops the whole brain, in youth and early manhood, he will not have a wide range of sympathies and interests in later life. Herein lies much of the value of a high school and college education.

166. Habit. - If a piece of paper is folded once, it will be impossible to remove the crease, and the paper will tend to fold in the same way again. The coat or dress sleeve will soon become wrinkled so that it is impossible to press the wrinkles out; they all reappear when the garment is put on. No one can wear your old shoes, for they have become fitted to your feet and cannot fit anybody else. If a young gourd be put into a bottle and allowed to grow, it will take on the shape of the bottle, whatever that may be, and will always retain that form. A young growing tree may be bent in any way, and in time it assumes that shape. "As the twig is bent so the tree is inclined."

These examples illustrate an important principle that shows itself on every hand, and is known as the law of habit. This law applies to animal life as well, and man is no exception. There are two principles of this great law to be remembered. First, habits are most easily formed in early life, as in the young plant, and in childhood and youth. At this time the tissues are most easily bent and fashioned because they are still plastic. 
Second, habits are most easily formed during periods of most rapid growth and of greatest nutrition. The young tree can be best bent during the spring and early summer, when the sap flows freely. Physical habits can be acquired most easily during the years of rapid physical growth. Mental habits are most readily formed when the brain grows fastest, because every mental habit is due to a change of some sort in the brain structure. While the brain is plastic, the nutrition good, and the growth rapid, habits are formed which permanently change the structure of the brain cells. Habits are formed for life because we cannot get rid of our brains. We can now understand why it is so difficult to break a habit.

The formation of habits begins in early infancy. The nurse feeds the infant at regular intervals of about two hours, and it always gets hungry on time. If the infant is put to sleep at ten o'clock, it soon gets sleepy at that time every day. So we have habits of sleeping, eating, working, walking, standing, breathing, thinking, feeling, and willing. Some one has aptly said, "Man is a walking bundle of habits." All our personal or physical habits are fixed for life before the age of twenty is reached, and our business or professional habits before thirty.

By forming good, useful habits, the entire nervous system becomes our most powerful ally, the brain becomes our strong friend; but if bad, slovenly habits are formed, the nervous structure becomes a hostile foe and a dangerous enemy. Habit simplifies all of our move- 
ments and makes them more accurate. It makes many matters of daily routine, as dressing and undressing, entirely mechanical, and leaves the mind free to do other things.

167. Fatigue and Overwork. - Whenever brain cells work they consume foods, produce wastes, and become fatigued. Up to a certain point brain activity is conducive to health, but if too long continued or too severe,

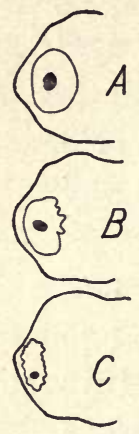

FIG. 132. - Showing changes in a nerve cell due to fatigue. $A$, resting ; $B$, stimulated one hour; $C$, stimulated six and one half hours. (From Hodge.) the cells may be so injured that ordinary rest and sleep cannot restore them. Fatigue is due (I) to the consumption of the foods stored in the cells and lymph, which causes the cells themselves to shrink in size and become rather irregular in outline, and (2) to the formation of poisonous wastes that accumulate in the cells and in the blood. The brain centers may be so poisoned by the waste products that one does not realize how fatigued he really is. Unless these wastes are removed, the cells repaired, and new foods stored up for future use, the brain may become permanently injured. Food, oxygen, rest, and sleep must alternate with periods of activity if we would keep our bodies in a healthy condition.

Mental overwork is possible. Frequently, however, the real cause is not the amount of work actually accomplished, but the conditions under which it is done. If a 
person insists on studying immediately after a full meal, when the blood should go to the stomach instead of to the brain, indigestion, so common among brain workers, must be the result. The head and the stomach cannot be active at the same time without bringing on serious disturbances. Mental work should be done when the brain has been repaired and refreshed. The morning is the best time to study. During the day the mental

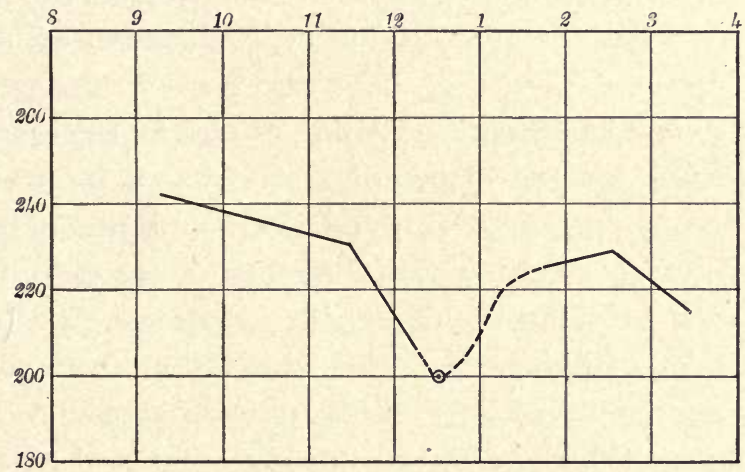

FIG. I33. - Showing how the ability to do physical work varies from hour to hour during the school day. The numbers at the top represent the hours from 8 A.M. to 4 P.M., and the numbers at the left, units of work. (From " Report on Child Study Investigation in Chicago," by Dr. Christopher.)

powers slowly decline in vigor, being low late in the forenoon, and again, late in the afternoon. After supper there may be a slight increase in power due to the nourishment taken, but the waste products are still in the blood and interfere with mental work of a high order.

"Early to bed and early to rise, Makes a man healthy, wealthy, and wise." 
Physicians tell us that grief, anxiety, and worry are common causes of a nervous breakdown. A few years ago there was formed in this country the "Don't Worry Society," which now numbers in its membership hundreds of brain workers from all professions. One of the very best ways to prevent worrying is to keep the brain and the body in general in a healthy working order. Have pleasant and interesting work to do; take a delight in doing whatever falls to your lot; and find a few minutes each day for quiet and perfect relaxation of every muscle.

168. Rest and Sleep. - While exercise is necessary to the growth and development of the brain, it must be followed by periods of rest and sleep. By rest we may mean either complete relaxation of mind and body from all forms of mental and physical exertion, or simply a change of employment. The latter is by far the more important. After one kind of physical labor another may be restful, and after mental work physical exercise usually proves very refreshing. This is because when certain brain centers have been active for a time they may be rested by calling other centers into activity. But the waste products formed by the working cells go on accumulating in the blood and must in time give rise to fatigue and complete exhaustion.

The wastes in the blood, together with the change in the circulation to the brain after a period of exercise, are the causes of natural sleep. Sleep is the great reparative agent for the tired and fatigued brain cells. During sleep respiration is decreased, the heart beat is 
slower, the temperature falls a little, and the activity of all the cells is at a minimum. But certain very important changes occur that make sleep absolutely necessary to life and health. Let us see what they are. (I) The heart, lungs, and certain other organs are at work all night, slowly removing from the cells and the blood the waste products accumulated during the day. (2) The brain cells are repaired so as to render them more responsive to the sensory impressions or stimuli that are carried to them. (3) The cells are supplied with an abundance of food material for future use. (4) Not only the brain, but all the organs and tissues of the body are renovated, repaired, and stored with energy-yielding materials. Of course these changes can occur only when the blood contains an abundance of nutritious food stuffs and an ample supply of oxygen.

The amount of sleep required varies with age, occupation, and conditions of health, and may depend somewhat on personal habits. The adult needs about eight hours in every twenty-four for sleep, while the child under five should have at least twelve hours. The brain worker needs a little more than the laboring man. Sleep should be taken at the same time every day. If for any reason the person does not get the required amount of sleep, it shows itself in both mental and muscular work. For children and youths loss of sleep is a very serious matter, because, as long as they are growing, all the cells of the body are laying up a supply of energy for all future years.

Some persons find it difficult to go to sleep, and resort 
to artificial measures to induce sleep. For most persons, physical or mental exercise is sufficient to cause sound and natural sleep. Those who are troubled with insomnia will find simple suggestions like the following helpful:-

I. Never go to bed hungry. If the stomach is empty, eating a piece of bread and butter, or crackers, or drinking a glass of milk may help you to go to sleep.

2. Some persons find a warm bath taken leisurely just before retiring very helpful.

3. Take moderate outdoor exercise of some kind before retiring.

4. Sleep in a cool, well-ventilated room, on a hard bed, with light covers.

5. Spend considerable time in getting ready to go to bed, but be careful to keep the feet warm.

6. Do not review the events of the day after going to bed. Better seek to quiet the mind by thinking of pleasant monotonous themes, repeating poetry, counting your respirations, or still better by giving the stomach something to do, as suggested above.

7. If the sleeplessness comes from digestive disorders, the diet should be carefully looked after.

8. Prolonged insomnia is a serious matter and should be treated by a skillful physician.

9. Going to bed at the same hour every night and getting up at a regular time often cures cases of insomnia. Regularity in all personal habits is important to good health.

169. Alcohol. - We have already seen how alcoholic beverages inflame the stomach and intestines and cause 
indigestion; how they harden the liver tissue and impair its function; how they dilate the capillaries of the skin and disturb the action of the sweat glands, and increase the loss of heat; how they harden the kidney tissues; how they overstimulate the muscles, heart, and arteries, and so weaken them and impair their functions; how they diminish the size of the air sacs of the lungs and so decrease the breathing capacity; and how they lead to a loss of appetite for nutritious foods, and create a craving for a constantly increasing quantity of alcohol to satisfy the abnormal appetite. But the soft and delicate nerve tissue of which the brain and nerves are composed are affected more profoundly than any other tissue, and perhaps more than all other organs put together. The delicate nerve tissue undergoes two important changes : first, the protoplasm of the cell body and of the fiber are in part destroyed; and second, connective tissue and fat are deposited in the cell and take the place of the destroyed protoplasm. These changes in structure are accompanied by many disturbances in the activities of the nerve cells.

The moral sense is perhaps the first to suffer from the effects of alcohol, then the will power is lost, and finally the intellectual activities are impaired. In writing of the person who habitually uses alcoholic beverages, Dr. Madden says : "Sense of dignity, of honor, of moral obligations, of personal conduct, no longer move him as formerly. He thinks only of escaping from them. It is a well-known fact that the will power is early and profoundly affected in alcoholism. The sub- 
ject loses the power to control his own actions, and he is willing to be led by very slight influences. Last to fail, as a rule, is intellectual power. It may show itself after prolonged excessive indulgence, even after the body is become a wreck. Sometimes it is, in a fitful way, present to the last. The drunkard is indifferent to all social and other questions which give interest to the lives and intercourse of the healthy. His conversation is broken and his ideas fragmentary. Finally, the memory fails in a marked degree, and he soon reaches a stage of mental degeneration which renders him unfit for any useful calling."

The relation of the use of alcoholic beverages to poverty, crime, suffering, immorality, debauchery, and insanity is too well known to require any special discussion here. It is believed that alcoholism in the parent is often the cause of feeble-mindedness, epilepsy, and nervous disorders of all kinds in the offspring. Dr. Frick of Zurich says that about fifty per cent of the inmates of institutions for feeble-minded children, for epileptics, and for deaf mutes are the children of drinking parents.

170. Tobacco. - Tobacco, whether chewed, snuffed, or smoked in a pipe, cigar, or cigarette, contains a narcotic poison called nicotine which has an injurious effect upon the nervous system, especially of the young. It stunts the growth of the body as a whole, irritates and weakens the nervous system, makes the user cross and peevish, and unfits him for the best society. Upon the adult the effect may be less marked; and yet the use of 
tobacco must be looked upon as a useless and expensive habit.

Opium, chloral, and other similar drugs contain narcotic poisons, and should never be used by either young or old unless prescribed by a reputable physician and taken under his direction. The moral effect of the use of these narcotics may be even greater than that of alcohol. The only safe rule for a long, healthy, useful, and happy life is never to touch any of these drugs.

\section{SUMMARY OF THE MAIN POINTS}

I. One eighth of all the blood is used by the brain. It requires a large quantity of nutritious food and pure air to keep the brain in a good, healthy, working condition.

2. The brain cells should be used regularly and systematically in a large variety of exercises, so as to call into action all the different centers.

3. When nerve cells function they consume food material, produce waste products, and become fatigued.

4. Worry, anxiety, and grief are probably more frequently the cause of a nervous breakdown than mental work.

5. Change of occupation is restful because new nerve centers are called into action, hence we should not continue too long at the same task.

6. Natural sleep is nature's most powerful reparative agent. The wastes are removed, and the cells repaired and stored with new energy-yielding materials.

7. An infant sleeps most of the time, a child under five requires about twelve hours, an adult about eight. The brain worker needs a little more sleep than the laboring man.

8. Regular habits of sleeping are just as important as a regu- 
lated life in other matters. Sleeping, eating, and working should all be carefully regulated as to time and amount.

9. Education is designed to exercise and develop all the brain cells, and to create a wide range of sympathies and interests in early life.

I 0 . When brain cells act they become so changed as to make it easier to act the same way a second time. This we call habit. Habits are due to changes in the brain structure.

I 1. The two important principles are: (1) Habits are most easily formed in early life. (2) Habits are most easily formed during periods of rapid growth and great nutrition.

12. Good habits become our strongest friends and allies, while bad habits are our worst enemies and most hostile foes.

I3. Alcohol affects the nerve tissues more profoundly than the other tissues. It tends to destroy the cell protoplasm and increase the amount of connective tissue and fat.

14. Alcohol weakens the moral sense, destroys the will, impairs the intellect, and causes poverty, crime, suffering, immorality, debauchery, and insanity.

15. Tobacco and other narcotic drugs are harmful to the nervous system, and should never be used unless prescribed by a reputable physician. 


\section{CHAPTER XVIII}

\section{THE SPECIAL SENSES AND SENSATIONS}

171. Sensations. - We have learned that the general plan of the nervous system is to have nerves run to the brain and spinal cord, which convey impressions from all parts of the body to the central organs, and then another class of nerves to convey messages issued by the central organs to the muscles and glands in all parts of the body. The first are sensory nerves and the second motor nerves. In this chapter we shall study the organs from which the sensory nerves start, and learn what the brain does with the impressions which it receives.

The brain receives impressions, and, in some way not understood by scientists, gives them meaning. We say the mind has the power to interpret these impressions or transform them into sensations. Every sensory nerve, whether from the eye or stomach, the ear or lungs, the tongue or toes, brings impressions from which we gain a knowledge of our own bodies and of the world about us. The moment an object comes in contact with the hand, certain little organs in the skin receive the impressions, and nerves carry these impressions to the sensory areas of the brain, and we become 
aware of the object. We become conscious of a sensation.

172. General Senses. - Many sensory nerves come from the internal organs, as the stomach, intestines, lungs, kidneys, heart and blood vessels, liver, etc. They give us sensations of hunger, thirst, faintness, giddiness, discomfort, fatigue, itching, burning, aching, shuddering, creeping, and the like. These sensations do not bring us any information of the objects about us, but they do tell us something of the conditions of the various organs. They tell us when we are to eat and drink, when we are tired and sick, when we need sleep and exercise, and a thousand other things important to health and happiness.

There are no special structures from which these nerves start. They begin in free nerve endings and give us general or common sensations. All other sensory nerves come from the eyes, ears, nose, mouth, and * skin, and give us the special sensations. We shall now study the special sense organs.

173. The Sense of Touch. - The true skin has little projections called papilla, quite close together. In these papillæ there are peculiar little end organs in which sensory nerves of touch begin. These end organs occur in the tongue, in the mucous membrane of the mouth and lips, and in the skin all over the body; they enable us to feel. They are most numerous on the tip of the tongue and in the ends of the fingers, and fewest on the middle of the back.

When these end organs are stimulated by objects, we 
get sensations of rough and smooth, wet and dry, soft and hard, and hot and cold. In the muscles, joints, and tendons, similar "touch bodies" are found which give us sensations that make muscular contractions accurate, and balancing, standing, and walking possible.

The sense of touch may be highly developed by regular exercise. • The blind read by passing the fingers over slightly raised letters or points. They distinguish their friends and all objects about them by the touch.
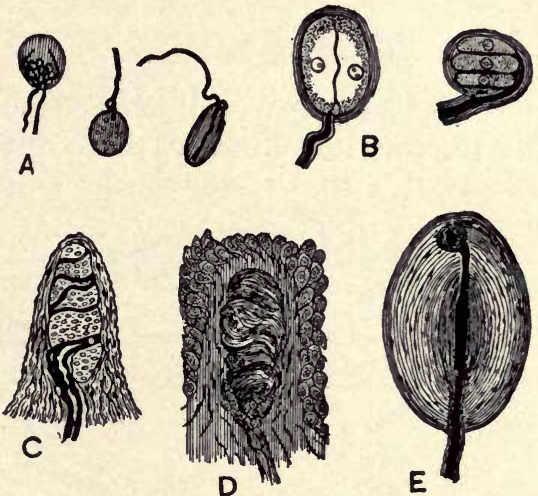

FIG. I34. - Different kinds of touch bodies. $A$, from the cornea of the eye; $B$, from the tongue of the duck; and $C, D, E$, from the skin of the fingers. (Drawn by Zinns.)

The quality of paper, silks, and other fabrics is determined by expert buyers very largely through the sense of touch.

I. Blindfold a member of the class and touch different parts of his body. Ask him to locate accurately the part touched.

2. Touch the palm of the hand with a colored pencil and have him find the exact point with another pencil. Measure the distance between the two points. Repeat this several times on the same part of the body.

3. Try different parts of the body in the same way.

4. With the points of a pair of scissors slightly separated touch the tip of the index finger. How far apart can you feel the points as two when placed on the skin at the same time? 
5. Try the palm, the back of the hand, the forearm, the elbow, the tip of the tongue, the back of the neck, etc.

6. Cross your middle finger over the forefinger of the same hand and touch the tip of the tongue to the crossed ends. What sensation results? In the same way, touch the point of the nose.

174. The Sense of Taste. - The tongue is the principal organ of taste. If you examine the upper surface of the tongue carefully, three different kinds of papillæ

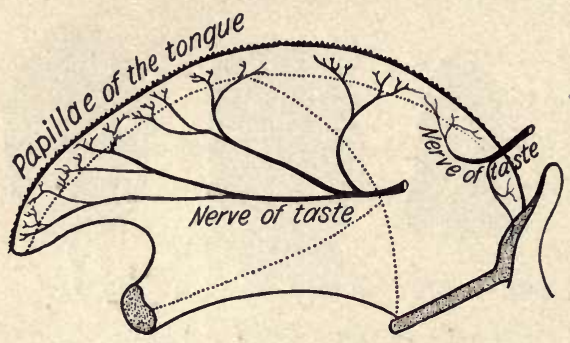

FIG. I35. - The tongue, showing the nerves of taste and the papillæ. (Drawn by Zuppke.)

will be found. On the back part of the tongue there are from seven to eleven rather large circular papillæe. On the tip and sides the papillæe are slender, and when largely developed, as in the cow and cat, they give a roughness to the tongue. Papillæe of a third class are scattered over the tongue among the others. There are papillæ on the tongue, soft palate, and pharynx. In the papillæe occur little structures known as taste buds in which the nerves of taste begin. The taste buds are sensitive to sweet, sour, bitter, and salt. These are the chief sensations of taste. It is interesting to know that the tip of the tongue is most sensitive to sweet, and the back of the tongue to bitter. No substance can be tasted until it has been dissolved and some of the solution comes in contact with the nerve endings in the taste buds. 
Taste guides us in the selection of foods and gives an added pleasure to eating. It may be highly cultivated by constant practice, as is shown in expert tea tasters and French epicures.

I. Rub your hand over a cat's tongue and notice how rough it feels. Compare with a cow's tongue.

2. Put a drop of vinegar on the back, on the tip, and on the sides of the tongue. Which is most sensitive?

3. In the same way try a bit of sugar, a little salt, and some quinine.

4. What do you learn from exercises 2 and 3 ? Explain.

175. The Sense of Smell. - The mucous membrane of the nasal cavities contains the sensitive ends of the nerves of smell. They are most numerous in the upper half of the nasal cavities, and are quite removed from the direct current of air that constantly passes through the nose in breathing. That is why we "sniff and smell" to detect a faint odor.

Any substance

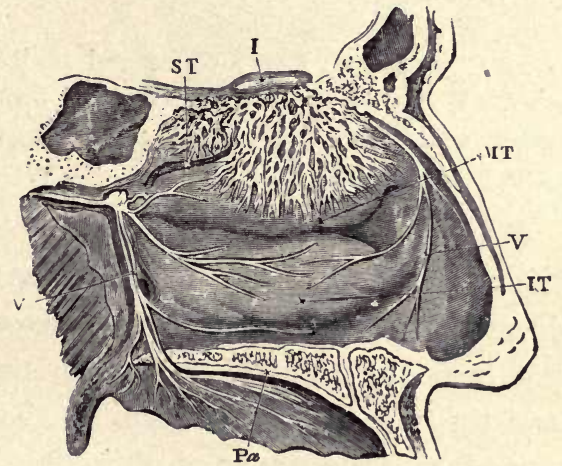

FIG. 136. - The outer wall of the left nasal cavity. $I$, the nerve of smell and its branches; $V, V$, cranial nerve; $S T, M T$, and $I T$, turbinate bones; and $P a$, hard palatc. (From Huxley.)

that can excite the nerve of smell gives off to the air very fine particles, called effluvia. The particles dissolve 
on the moist mucous surface in the nose, and then stimulate the end organs of smell. The sense of smell aids us in the selection of good foods and in the avoidance of bad air. In some of the lower animals, as the bloodhound, for example, this sense is much more highly developed than in man.

Taste and smell are so closely associated that it is often difficult to separate them. Apple and onion taste very differently to us, but they taste quite alike to the person who has lost the sense of smell. Highly flavored foods, alcohol, and tobacco tend to blunt these senses.

I. Blindfold a member of the class, and pinch his nostrils firmly, and then have him try to distinguish between apple, potato, and onion by the sense of taste.

2. Chew some roasted coffee and notice carefully the taste and odor. Repeat, but pinch the nostrils firmly all the time. What difference do you observe? When a person has a cold in the head some foods are tasteless. Can you tell why ?

176. The Sense of Hearing. - We come now to consider one of the most important senses in man. How dreary and gravelike the world would seem if we could not hear the song of the birds, the hum of the bees, and the voices of our friends! The sense of hearing can receive the waves of air caused by the vibrations of a sounding body and give them meaning. What is sound? We shall try to find out. The vocal cords of a person vibrate as the air is forced out of his lungs, and produce a wavelike disturbance in the air. Between his lips and your ear there are waves of air which you can interpret, and so understand what he says. 
The organ of hearing is the ear. It has a very complicated structure, but we shall try to understand the different parts, and see how they work. The three parts of the ear are known from their location as the external, the middle, and the inner ear.

177. The External Ear. - This consists of two parts. The first is an irregular shell of cartilage or gristle, covered with skin, that projects from either side of the head. It serves as a funnel to catch the waves of air and to direct them to the middle ear. The second is the auditory canal, which is about one inch long and arched upward slightly near the middle. It extends to the middle ear and serves to conduct the sound waves to the eardrum.

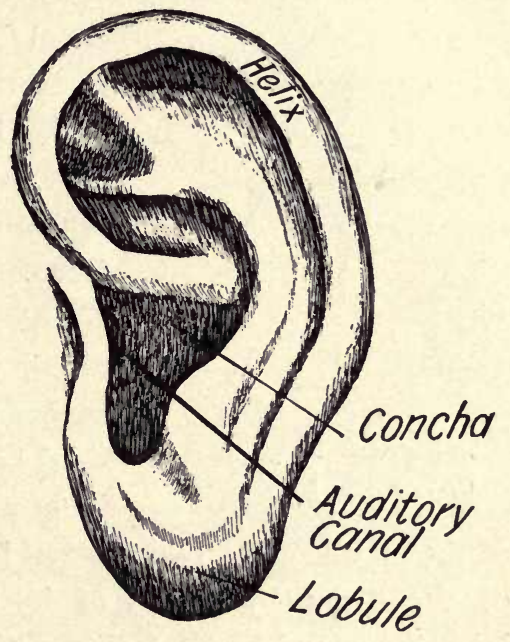

FIG. I37. - The external ear (Cheever).

The auditory canal consists of cartilage and bone covered with skin. On the outer two thirds occur small glands that secrete earwax or cerumen. This is a yellowish sticky fluid that soon unites with some of the thin scales of the epidermis, and hardens to a pasty consistency. The wax has a bitter taste and serves to keep insects out of the ear, to moisten the parts of the 
canal, and to remove the little flakes of epidermis as they scale off. In a healthy ear there is very little wax and one never needs to remove it. Sometimes, however, it may collect in the ear and interfere with the free movement of the eardrum. It must then be carefully removed by a skillful aurist.

178. The Middle Ear. - This consists of a thin membrane, the drumhead, stretched across the auditory

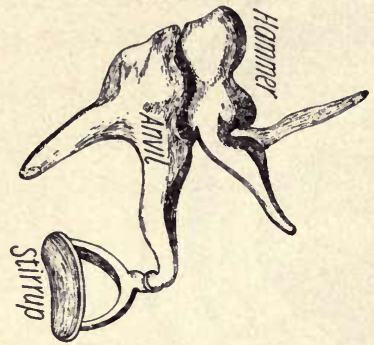

FIG. 138. - The chain of bones of the middle ear. (Drawn by Johnstone.) canal as its outer boundary. It is this membrane that vibrates in order to enable us to hear. If the earwax should accumulate on the outer surface of the drumhead, or if the drumhead should be punctured, we could not hear so well. Just beyond the drumhead is a chain of three small bones which bridges the cavity of the middle ear. The malleus is attached to the center of the drum by means of its long handle, the anvil joins the round head of the malleus with the small end of the stapes, and the large end of the stapes fits into an opening of the inner ear, called the oval window. These three bones are so shaped and fastened together that they transmit the sound waves to the internal ear precisely as they receive them, except that the waves are focused on a smaller area and much intensified. The Eustachian tube extends from the cavity of the middle ear down to the pharynx, and keeps the air 
pressure the same on the inner and outer surfaces of the drumhead. This tube and the entire middle ear are lined with mucous membrane. Hence, it is easily seen why a cold in the head, sore throat, catarrh, and adenoid growths affect our hearing. Anything that tends to close the Eustachian tubes or to obstruct the air passages makes the drumhead less sensitive to sound waves and impairs hearing.

Close the mouth, pinch the nostrils firmly, and then swallow. Because a little air is removed from the pharynx the eardrum is pushed in, causing the peculiar cracking sound.

179. The Inner Ear. - There is no more delicate or complicated organ in the body than the inner ear, which is the real end organ of hearing. It consists of a series of winding passages in the temporal bone, and may be divided into three parts : the small vestibule next to the middle ear

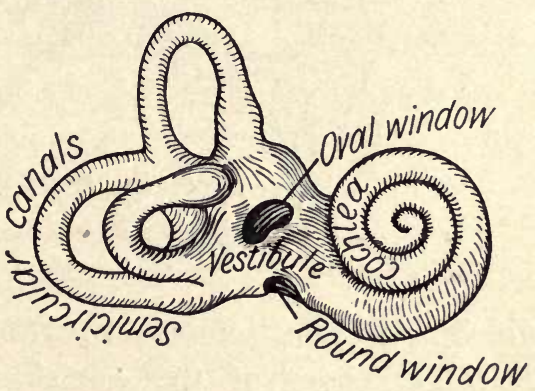

FIG. I39. - The inner ear, showing the shape of the bony labyrinth (Zuppke). communicates ; the

three semicircular canals or winding passages connected with the vestibule behind and above; and the cochlea or snail shell joined to the vestibule on the opposite side, in front and below. All these parts are filled with a liquid called perilymph, in which floats a saclike membrane, the membranous labyrinth, that has about the 
CHAP.

same shape as the bony labyrinth. Within the sac is another liquid called endolymph.

The auditory nerve, as the nerve of hearing is called, has fibers going to each of the semicircular canals, to the vestibule, and to all parts of the cochlea, where they spread out on the surface of the membranous labyrinth. The sound waves come in contact with the fibers of the auditory nerve; but only those distributed to the cochlea,

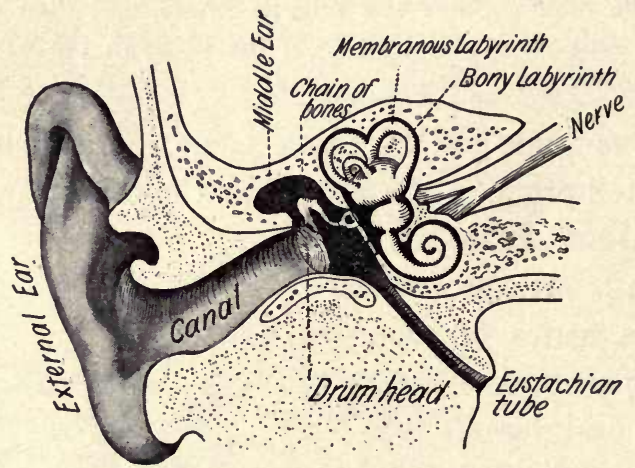

FIG. I40.- A section through the ear. (From Boas by Zuppke.)

which is the most important part of the ear, are used in hearing. Those of the semicircular canals and the vestibule carry to the brain impressions that enable us to judge of the position of the body in space and help to keep us right side up. We become dizzy if we swing about in a circle for a short time. This is because the liquid in the canals, which acts like a carpenter's level, is disturbed by the rotation of the body. The feeling of nausea and sickness that some persons experience from riding on a boat, train, street car, or carriage, and 
sometimes from swinging in a hammock, is due to the same cause.

180. The Course of a Sound Wave. - The cartilaginous funnel or concha of the external ear catches sound waves and directs them into the auditory canal, which conveys them to the drumhead. The sensitive membrane of the drumhead responds to the waves and vibrates like the diaphragm of the telephone. These vibrations are transmitted to the chain of bones of the middle ear, which modify, intensify, and focus the motion upon the membrane stretched across the oval window of the internal ear, into which the base of the stapes fits. The vibrations of the oval window set in motion both the perilymph of the bony labyrinth and the endolymph within the membranous sac. The waves enter the vestibule, pass through the semicircular canals and the entire cochlea, and back to the vestibule, where they pass into the middle ear at the round window. The motion of the liquids causes the membranous sac to vibrate, and this vibration irritates the delicate nerve endings. These nerve impressions are carried to the proper centers in the brain, and we hear. What a complicated process hearing is!

1. Hold a watch between the lips for a moment, and then close the teeth down on it and notice how loud it seems to tick.

2. Cover both ears and then uncover one and notice the result. Repeat several times. Explain.

3. Hold a vibrating tuning fork between the lips until it can no longer be heard. Close the teeth down on it and it will be heard again. When it can no longer be heard the second time, cover one or both ears and it will be heard a third time. Explain. 
181. Care of the Ear. - The delicate parts of the ear are well protected and need very little attention. Even the outer ear, if in perfect health, needs only to be kept clean. The auditory canal requires no care whatever except to remove the wax as it loosens and works out. The chief caution for most persons to remember is: Keep the concha clean and do not meddle with the auditory canal.

If there is "running" from the ear, or if the wax accumulates on the eardrum so as to impair hearing, you should consult an aurist at once. No pin, pencil, or toothpick should be used to loosen the wax or to clean the canal, for there is great danger of scratching, tearing, or puncturing the drumhead. If a foreign substance gets into the ear and cannot be easily removed, a doctor should be consulted at once. Sometimes a bug, ant, or other small insect crawls into the auditory canal. A light held close to the ear while the canal is straightened by pressing up the outer end may coax the insect to crawl out. If it does not come out soon or cease irritating the ear, it should be smothered by dropping in a little tepid water or sweet oil. A dead insect or a small foreign object may do little harm even if not removed for years. Most harm comes from the attempt to remove it. Small objects will often drop out at once if the part in front of the ear is rubbed in a rotary manner while the head is turned to the side.

Impaired hearing and deafness may be the result of scarlet fever, mumps, diphtheria, adenoid growths, colds, catarrh, a sudden blow on the head, loud noises, certain 
drugs, and many other causes. A person may suffer from defective hearing without being aware of it at all. It is important to test the ears of children by some simple method, as seeing how far they can hear the ticking of a watch with each ear separately.

Blindfoid a person and cover one ear, and then hold a ticking watch close to the other ear. Carry it away slowly and determine how far it can be heard. Repeat for the other ear. Are the two ears equally sensitive to sound?

182. The Sense of Sight. - Sight is probably the most important sense we have. The beautiful colors in nature and art would be entirely unknown, and life would lose many of its pleasures, if we could not see. Seeing is even more wonderful than hearing. We learned that the beautiful music of an orchestra and the sweet voice of a friend are simply vibrations of air. All objects that we can see give forth vibrations to the ether. The beautiful color of the rose is simply ether vibrations that can act upon the delicate eye in such a way as to cause sensations of sight. The vibrations of ether differ from each other and thus give rise to the different colors of the rainbow and their many shades and tints. We shall now study the eye and learn how we see.

183. The Eyeball. - The eyeball is spherical in shape, measuring about one inch from side to side and a little less from front to back. It is set in a bony cavity called the orbit, which is lined by a mass of connective tissue and fat. The back two thirds of the eyeball is inclosed in a capsule of serous membrane like the 
pleura and pericardium. The capsule and cushion of fat protect the eyeball and permit it to turn freely in all directions with very little friction.

The eyeball has three coats or layers. The outer is a firm and strong coat, white in color, that gives the eye its shape. The part at the back and sides does not permit light to pass through. This portion is called the sclerotic

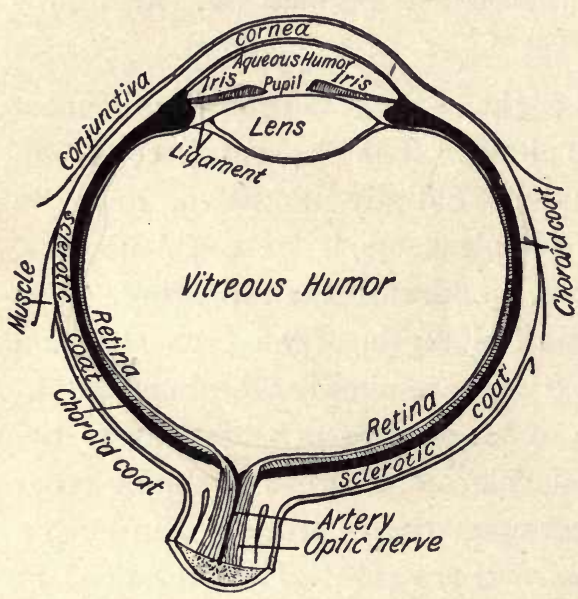

FIG. I4I. - A section through the eyeball (Zuppke). coat. The part in front is very transparent and forms a round window known as the cornea, through which light enters the eye. The second or middle is a more delicate though thicker coat, deep black in color, that serves to absorb all the extra light which would otherwise interfere with good clear vision. In this layer there are many blood vessels and nerves. This coat, known as the choroid, has the little self-regulating curtain just back of the cornea, which by changing the size of the small opening at its center, determines the amount of light that shall enter the eye. This part of the choroid coat is the iris, and the little window is the pupil. The iris gives color to the eyes, as it may be black, brown, 
blue, or gray. The third or inner coat is an extremely thin and delicate film called the retina. It is really an expansion of the optic nerve that forms a sensitive lining for the inner surface of the eyeball. Before an object . can be seen it must form an image on the retina.

184. Muscles of the Eye. - Each eyeball has four straight muscles attached to it, one above, one below,

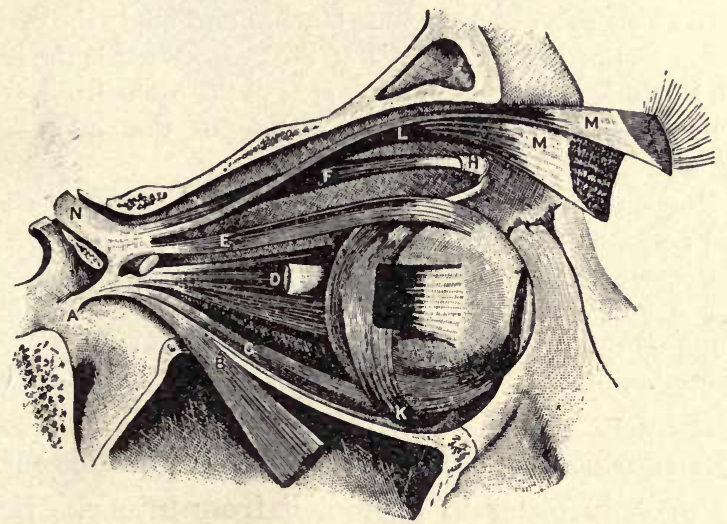

FIG. I42. - Muscles of the eyelsall. (From Blaisdell's "Life and Health." Ginn \& Co.) $A$, tendon of three recti muscles; $B$, external rectus, cut and pulled downward; $C$, inferior rectus; $D$, internal rectus; $E$, superior rectus; $F$, superior oblique; $H$, pulley of the superior oblique; $K$, inferior oblique; $L, M$, levator palpebræ; $-N$, optic nerve.

and one on either side; besides these four there is an oblique muscle attached to the upper part of the eyeball and one to the lower. By means of these six muscles the eye may be turned in any direction without moving the head at all.

The muscles of the two eyes usually work in perfect harmony, so that the eyes move together. Sometimes the 
muscles do not balance each other as they should; the inner may be too strong for the outer and then the eyes turn in toward the nose ; this is called "cross-eyed." If the outer muscles are the stronger the person is "walleyed." Oculists can cut the muscles just enough to straighten the eyes and make them work together properly. If this is necessary, it should be done in childhood.

I. Get a sheep's eye from your butcher and study the eyeball as a whole. Notice the six muscles of the eye. What is the function of each? Notice the cushion of fat around the eyeball.

2. Remove the muscles and fat and locate the optic nerve, the cornea, and sclerotic coat.

3. Notice the size and shape of the pupil of the eye. Find the iris and notice its shape and color.

4. Remove a strip of the sclerotic coat, so that a portion of the choroid may be exposed.

5. Lift up the choroid with forceps and cut through it carefully. The delicate retina can be seen below. Make drawings in each case.

185. Appendages of the Eye. - The eyeball is set deep in the orbit in order to protect it from injury. Besides this it is provided with eyelids, eyebrows, eyelashes, and tear glands to protect, keep clean, and moisten the more exposed parts of this delicate and important organ.

The eyelids are made of thin plates of cartilage covered with skin, and lined with a thin mucous membrane called the conjunctiva. The conjunctiva also covers the front of the eyeball except the central part of the cornea. The two lids may be brought together and thus cover the eyeball in front, protecting it against foreign bodies. They also distribute moisture over the surface of the cornea. The eyelashes are a row of fine 
hairs on the edge of each lid. The hairs have delicate nerves at their roots and so serve to warn us against

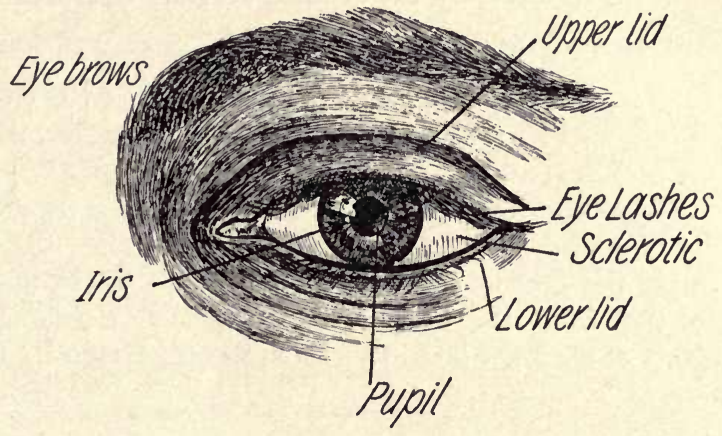

FIG. I43.- The left eye (Zinns).

small objects approaching the eye and against dust. The eyebrows protect the eye against dust and perspiration, and they give it shade.

The tear glands (lachrymal glands) are situated above and at the outer angle of the eye. They secrete the tears and pour them out under the upper lid, where they are distributed over the eye so as to moisten the entire cornea. Each lid has a small duct at its inner end, into which the moisture is collected after it has accomplished

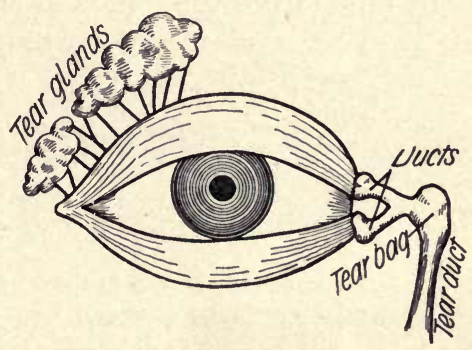

FIG. 144. - The lachrymal apparatus (Zuppke). its purpose. These two ducts unite and lead to the tear bag (lachrymal sac), from which a single duct leads to 
the nose. Sometimes this duct closes up, and then tears constantly gather at the inner angle of the eye. It should be opened by an oculist so that the tears may drain off as they should.

1. With a small mirror examine carefully the orbits of your own eyes. Notice that a ruler placed on the bones of the orbit does not touch the eyeball at all.

2. Study the eyebrows and notice their position, and the direction and color of the hair.

3. Study the eyelids. Notice a rudimentary lid at the inner corner of each eye. Do you find an opening on an elevation at the inner corner of the lower lid? This is the opening into the lachrymal canal.

186. The Inside of the Eyeball. - The eyeball is a large hollow globe filled with liquids. The space just back of the cornea is filled with aqueous humor, in which the iris floats. Beyond this we find the crystalline lens, which is about one third of an inch long and composed of a number of concentric layers like the coats of an onion. The lens curves out both in front and behind; we say it

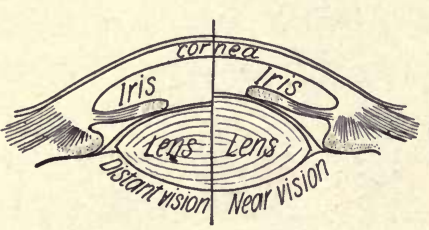

FIG. 14.5. - Showing changes in the lens in accommodation (Zuppke). is double convex. The main part of the eyeball is filled with the vitrcous (glassy) humor, that looks like the white of an egg and serves to keep the delicate retina in position.

The two humors and the crystalline lens bend the rays of light that enter the pupil of the eye so that they are brought to a point on the sensitive retina. The lens is important in focusing the light because it 
is suspended in a ligament which holds it in place and changes its thickness so as to adjust (accommodate) the eye for objects near by and far away.

I. Cut through the cornea of the sheep's eye and you will find a liquid called the aqueous humor.

2. Cut away the iris and find the lens. Notice its size, shape, curvatures, and transparency. Place the lens on print and notice the result.

3. Cut back on one side so as to remove the vitreous humor that fills the back part of the eyeball.

4. Find the blind spot, or the place where the optic nerve enters the eyeball.

5. Near the blind spot is a very slight depression at the center of the eyeball, known as the yellow spot. Find it.

187. The Course of Light. - The rays of light coming from an object radiate in all directions. If the eye is

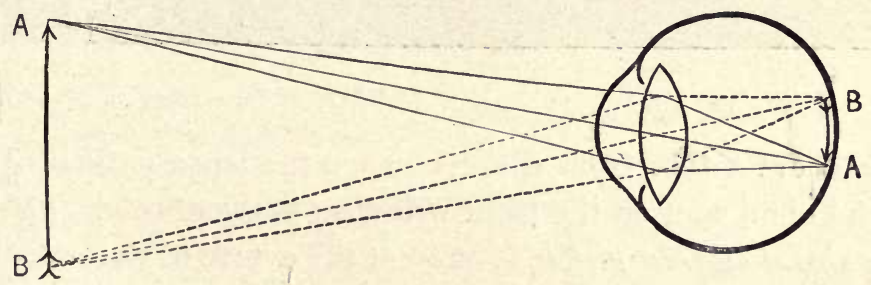

FIG. 146. - The formation of an image on the retina. (From Huxley.)

so turned as to receive some of the vibrations, those which fall upon the pupil enter the eye and pass through the aqueous humor, the crystalline lens, and the vitreous humor. The muscles of the capsule of the lens so change its curvature as to bring the rays to a focus on the retina. There is now an image of the object produced on the retina, and this image excites 
the delicate nerve endings. The impressions are carried over the optic nerve to the occipital lobe of the brain, where they are interpreted. The vibrations of ether pass through the conjunctiva, the cornea, the aqueous humor, the pupil, the lens, the vitreous humor, and then are received on the retina.

The point at which the optic nerve enters the eyeball is not sensitive to ether vibration, and, for that reason, is known as the "blind spot." To find the blind spot, close the left eye, focus the right steadily on the triangle below, and then move the book slowly until it

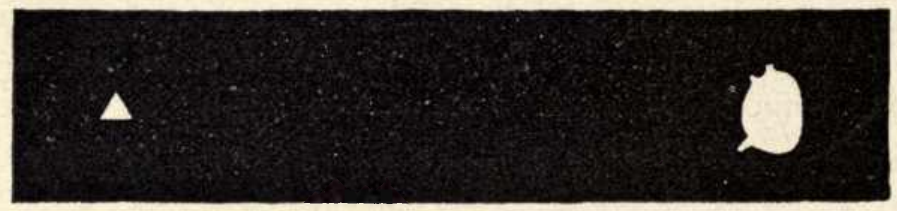

FIG. I47. - To find the blind spot.

is about a foot from the eye, when the large outline of the blind spot on the right will disappear entirely. The point of clearest vision, located at the centre of the retina just outside of the blind spot, is called the "yellow spot."

188. Defective Vision. - The lens, which is so important in bringing the rays of light to a focus on the yellow spot of the retina, may be defective. Then the rays cannot be properly focused. The lens may be too convex or the eyeball too long, so that the light is brought to a focus before reaching the retina ; this is called "nearsightedness." The book must be held very close to the eyes in order to read and the body bent over in writing. 
The lens may be too nearly flat or the eyeball too short, so that the rays of light focus behind the retina; this is called "farsightedness." The book must be held far from the eyes because objects near by cannot be seen well. The cornea may not curve uniformly in all directions, so that the rays are not all focused on the same surface; this is called

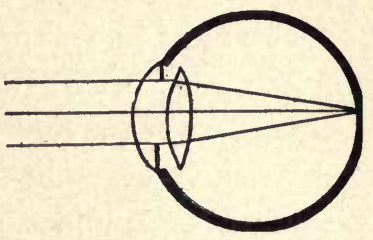

FIG. I48. - Parallel rays focused on the retina (Zuppke). astigmatism. The muscles of the two eyes may not

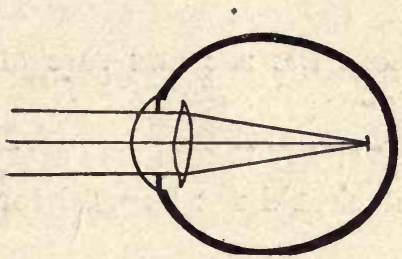

FIG. 149. - Parallel rays focused in front of the retina (Zuppke). work as they should in focusing upon near and far objects or in moving the two eyes together.

As a matter of fact, very few eyes are perfect in every respect. But most of the defects, if not too serious, are overcome by the wonderful power of accommodation which the eyes of the young possess. As long as a person is in good health or does little reading or studying, he may not know that his eyes are defective. When, however, general health fails, or much indoor work requiring close

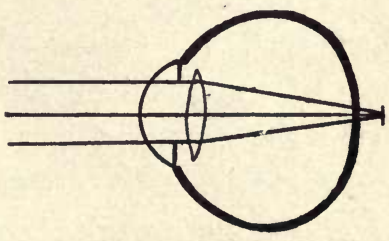

FIG. I50. - Parallel rays focused behind the retina (Zuppke). application of the eyes is attempted, the eye strain may be so severe as to cause serious discomfort and lead to 
dangerous nervous diseases. These defects should be corrected by using spectacles or eye-glasses, properly adjusted, or by an operation, as the case may require.

With a set of Snellen's test-types, make an examination of your own eyes. Test for nearsightedness, farsightédness, and astigmatism.

189. Care of the Eyes. - Although the eye is a delicate and sensitive organ, it has a wonderful power of accommodation, and, under favorable conditions, can do an immense amount of work. That is why the eyes are so often abused. It is only after they have become diseased and cause discomfort that they are given any special care by most persons. Let us learn a few of the more important things about the use and care of healthy eyes.

I. After diseases, like measles, diphtheria, and scarlet fever, the eyes are weak and should not be used for close work for several weeks. At such times it is an easy matter to permanently injure the eyes.

2. Do not overwork the eyes by reading, writing, sewing, or doing any kind of close work, when they smart or tingle. When the eyes are tired they should have rest.

3. Do not work facing a strong light. It should come from the rear and over the left shoulder to be most comfortable.

4. All close work should be done during the daytime and in the best of light. The twilight of the early evening has ruined many good eyes.

5. The position of the body is very important in the proper use of the eyes. You should not read lying 
down, or with the head bent over, as when working at a low desk. The habit of reading after going to bed is very injurious.

6. Reading on trains, on street cars, in carriages, or while walking about is a very severe strain on the muscles of accommodation, and should be avoided.

7. Books and papers should have large, clear type that is well leaded, good paper, not too highly sized, and lines not to exceed four inches in length. Poor, cheap books, with small, blurred, indistinct type, should be avoided if possible.

8. The head should always be held erect in reading, with the book or paper nearly on a level with the eyes and about fourteen inches away. Many habitually hold their work too close to the eyes and in that way overtax the muscles of accommodation.

9. When a small object gets into the eye it should be carefully removed. Often the tears will wash the object toward the inner corner of the eye, where it can be seen and easily taken out. If necessary, the lid may be turned inside out, as shown in the figure, and the object removed. Do not rub the eye.

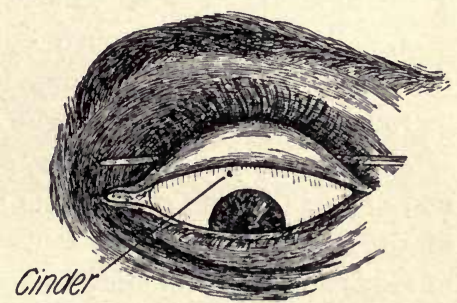

FIG. I5I. - The upper lid inverted (Zinns).

I0. The blackboard, slates, paper, and pencils used in the schools should be of the best quality and kept in good condition, so that no undue eye strain may result, 
I I. If the eyes cause discomfort, headache, or a dull feeling about the head, consult an oculist. Never have anything to do with the quack eye doctors or street venders of spectacles.

I2. Alcohol congests and inflames the conjunctiva and lids, impairs vision in acuteness and quickness, and may produce changes in the lens, retina, and optic nerve.

I3. Tobacco smoke irritates the delicate lining of the eyes and blurs the vision.

\section{SUMMARY OF THE MAIN POINTS}

I. Every sensory nerve brings impressions to the brain, from which we gain a knowledge of our own bodies and of the world about us. These impressions we call sensations.

2. The impressions received from the internal organs give us sensations of hunger, thirst, faintness, giddiness, discomfort, fatigue, itching, burning, aching, shuddering, creeping, etc. These are called general sensations.

3. There are little touch corpuscles in the papillæ of the dermis which serve as end organs of touch. They are most numerous on the tip of the tongue and on the ends of the fingers.

4. The tongue, soft palate, and pharynx are supplied with end organs of taste called taste buds. They give us sensations of sweet, sour, bitter, and salt. Taste guides in the selection of foods and gives an added pleasure to eating.

5. The mucous membrane in the upper part of the nose is provided with nerve endings that form the end organs of smell.

6. The ear is the end organ of hearing. It consists of the external, middle, and internal ear. The external consists of the concha and auditory canal; the middle, of the drumbead or tympanum, the chain of three bones stretching across a hollow 
chamber, and the Eustachian tube ; and the internal, of the bony labyrinth containing the membranous labyrinth which is surrounded by the perilymph, and which contains the endolymph.

7. The internal ear consists of three parts : the vestibule, the semicircular canals, and the cochlea. The auditory nerve sends fibers to all these parts.

8. Sound waves are caught by the concha and directed in through the auditory canal; they beat against the drumhead, causing it to vibrate; this imparts its motion to the chain of bones which intensify, modify, and focus the vibrations upon the oval window; here the vibrating membrane communicates its movement to the liquids of the ear which act upon the membranous labyrinth; and this excites the ends of the auditory nerves.

9. The ear is a very delicate and complicated organ and should receive a certain amount of care daily. If in good health, the chief caution is : Keep the concha clean and do not meddle with the auditory canal.

Io. The eye is the end organ of sight. The eyeball consists of three layers : the sclerotic coat and cornea, the choroid and iris, and the retina. The globe is filled with the aqueous humor, the lens, and the vitreous humor. The cornea is transparent, and the iris has an opening at its center, the pupil, which determines the amount of light that shall enter.

I I. The eyeball has six large muscles which turn it in all directions, and many small muscles which adjust the eye for far and near objects.

12. The eye is protected by the eyelids, eyelashes, eyebrows, lachrymal glands, tear ducts, and by the orbit itself.

13. The rays of light from an object pass through the cornea, the aqueous humor, the pupil of the iris, the lens, the vitreous humor, and are focused on the yellow spot of the retina. The impressions are then carried to the occipital lobe of the brain over the great optic nerve. 
14. Farsight, nearsight, and astigmatism are due to an imperfect eyeball or lens, and should be corrected by wearing properly fitted spectaclés or eyeglasses.

15. The eye is a delicate and sensitive organ capable of doing an immense amount of work under favorable conditions. Observe the cautions mentioned above, and use your good sense in all work requiring the use of the eyes. 


\section{CHAPTER XIX}

\section{BACTERIA AND DISEASES}

190. Bacteria. - We have already learned something of the deadly work of bacteria and other microörganisms in previous chapters, but shall now study them a little more closely to learn their relation to us in health and in disease. Bacteria are among the smallest and simplest forms of plant life known at present. They are so very small that it has been difficult to study them. But now many scientists are devoting their whole time to a careful investigation of microörganisms with the best and most expensive microscopes and other appliances that can be obtained.

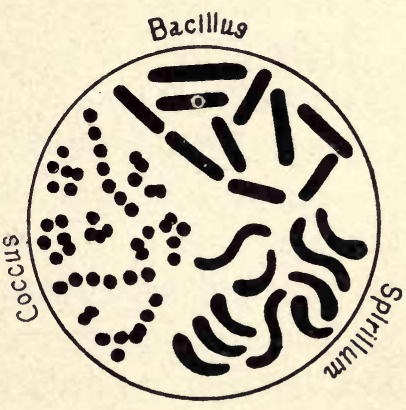

FIG. I52. - The three kinds of bacteria (Pratt).

The largest bacteria are only a ferw hundred-thousandths of an inch in diameter. They are either spherical, rod-shaped, or screw like, and are known as the coccus, bacillus, or spirillum respectively. Any of these forms may occur singly, or in pairs, and some of them even in long chains. They multiply and grow so rap- 
idly that a single one may produce over sixteen million in twenty-four hours, under favorable conditions. Like fine dust or tiny spores they are carried about everywhere by the wind and water. Some have a wonderful power to resist heat, cold, and moisture, and can live under influences which destroy all other forms of life.

Some kinds of bacteria are the causes of diseases among the lower animals and in man, while the majority are among man's most uscful agencies in many ways. We shall see how they are useful to man and what relation they have to diseases.

191. Bacteria as our Friends. - Some of these little organisms are very useful to us. All decay or decomposition of vegetable and animal matter is due to the chemical action of bacteria. In this way all dead organic matter is broken up into simpler substances that can be used by the growing plants. They serve as scavengers to clean up all dead organic wastes and at the same time send into the atmosphere a large amount of carbon dioxid which growing plants can use for food. The amount of carbon dioxid exhaled by man and the lower animals is not sufficient to supply the demands of the vegetable kingdom. The plants retain only the carbon and exhale the oxygen which we in turn breathe. The bacteria produce important commercial products, as many organic acids, and most of the saltpeter. The bacteria in the soils of field and garden are at work constantly changing and decomposing certain materials and preparing the food supply for the growing crops. The leguminous plants, as clovers, 
peas, beans, lentils, vetches, lupines, etc., have the power to use the free nitrogen of the air because in the little knots, balls, or tubercles found in their roots there are countless bacteria living as parasites and producing important nitrate compounds which the plants use for food. No plant can grow in a soil that does not contain nitrates unless it can produce them by the aid of bacteria. All leguminous plants are important as fertilizers because, when they decay, they give to the soil nitrates produced by bacteria. So useful are these tiny organisms that neither plants nor animals could live without them.

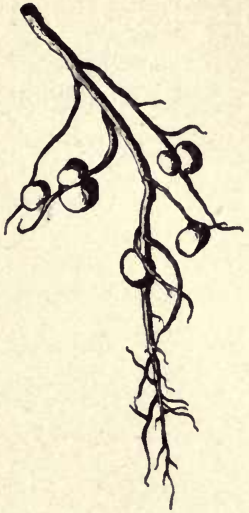

FIG. I53. - Tubercles on root of common bean (Johnstone).

192. Bacteria as Enemies. - The temperature, moisture, and food supply in certain parts of the human body furnish a favorable soil for some kinds of bacteria. They are very fond of albumins, such as occur in the blood and lymph. The mouth, throat, and intestines are always swarming with these little organisms, where they cause decay or decomposition of foods, or attack the blood directly when the capillaries become inflamed, as in colds.

The conditions under which the different kinds of bacteria grow vary greatly. The vast majority cannot grow in the human body at all, a few grow nowhere else, some grow only in certain of the lower animals, others in all alike, some will grow only in a single organ or 
tissue of the body, others almost anywhere. Many kinds of bacteria are entirely harmless when taken into the body, because they do not find conditions favorable for rapid multiplication. We think that all bacteria would produce diseases if they grew as fast in the body as they can under favorable conditions. It is well known that bacteria produce poisonous products to which diseases are due. There are then two important factors to consider: first, the ability to mu'tiply, and second, the capacity to mamufacture poisons. The disease germs may become so numerous as to interfere, by their very presence, with the circulation, and cause diseases in any part of the body. The chief danger comes from the poisonous products formed out of the body substances and foods and given to the blood or tissue cells. Just as soon as a sufficient amount of poison has been absorbed fever is produced.

Consumption, diphtheria, pneumonia, typhoid fever, cholera, lockjaw, malaria, grippe, smallpox, scarlet fever, measles, mumps, whooping cough, meningitis, erysipelas, scarlatina, leprosy, chicken pox, yellow fever, relapsing fever, anthrax, glanders, and dysentery are among the communicable diseases, many of which are known to be due to these little germs.

193. How Disease Germs get into the Body. - If we wish to war against the disease germs, we must know where they come from, how they travel from one place to another, and how they get into the body. Many germs can live in the body of the host, and may be transferred to another person by actual contact as, for 


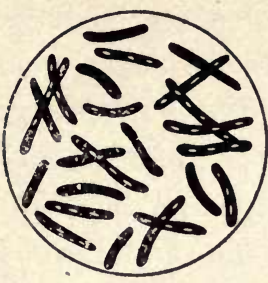

Consumption.

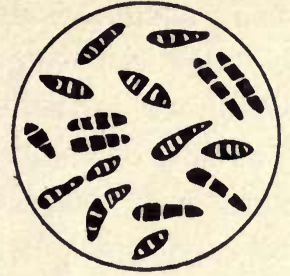

Diphtheria.

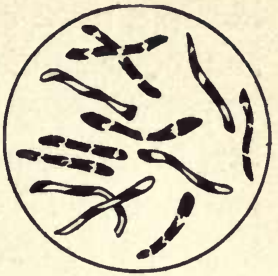

Diphtheria.

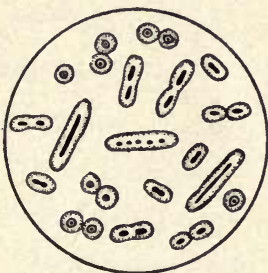

Precumonia.

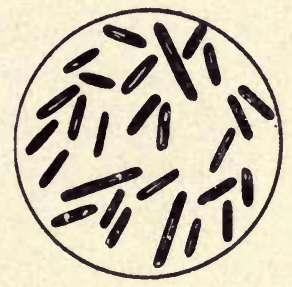

Typhoid.

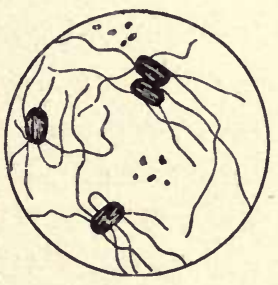

Typhoid.

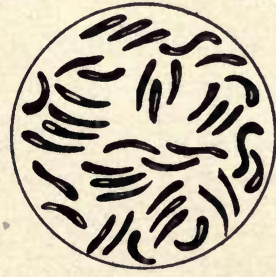

Cholera.
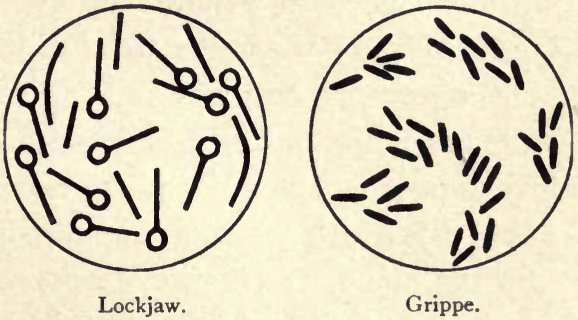

FIG. I54. - Several disease-producing bacteria. (Diagrammatic by Pratt.) 
example, those causing smallpox, measles, scarlet fever, and other eruptive diseases common to childhood. These are called contagious diseases. Some germs can live for a long time outside of the body, as in air, water, and foods. These are more dangerous to public health because they can be carried a long distance and attack a whole city or sweep over a continent almost in a day. Diseases of this kind are called infectious. Many diseases, as erysipelas, diphtheria, and consumption, belong to both classes.

Disease germs enter the body through the mouth and nose and get into the intestines and air passages. The germs found in the air, as those of diphtheria, scarlet fever, and consumption, get into the lungs through the ordinary processes of breathing. Germs contained in water and foods get into the alimentary canal and attack the organs of digestion. Those of typhoid fever, dysentery, and cholera belong to this class. These germs cannot travel through the air. The only way to guard against such diseases is to eat good, well-cooked foods and drink water that has been boiled. Some germs gain entrance through wounds or cuts in the skin. The germs of lockjaw always enter in this way, and those of boils, abscesses, and malarial fevers frequently do. Insects are important agents in conveying germs. Recent investigations show very conclusively that the mosquito injects the germs of malaria and yellow fever into the blood, and hence we may regard the mosquito as the most important agent in the spread of these diseases. 
194. Disease Germs in the Body. - It is impossible to keep out of the way of the many disease germs that surround us at all times. We breathe, eat, drink, and touch these little organisms every day and so cannot avoid taking them into our bodies. Why, then, are we not sick oftener? It is because the human body has a wonderful power of defense against germs of all kinds as long as it is kept in a good physical condition. It does not let the germs grow and produce disease if it can possibly help it.

If the body has the power to resist the action of bacteria, we say it is immune to the disease. Natural immunity is due to a high degree of vitality in all tissues and cells of the body and is thought to be inherited. Among the agencies and conditions that make the body subject to the invasion of disease germs we may mention poor or insufficient foods and impaired digestion; fatigue and exhaustion; exposure to cold, filth, and unhygienic surroundings; vicious habits and drunkenness; and, in fact, everything that tends to disturb the functions of any organ of the body. On the other hand, an abundance of good, wholesome food and pure water, an adequate supply of pure, fresh air, a sufficient amount of physical and mental exercise and rest, cleanliness, sobriety, and moderation, and, in short, a life well regulated in all respects, tend to fortify the body against such diseases.

We do not know just how the body destroys the germs or how it resists the action of the poisons which they produce, but we do know that the white corpuscles of 
the blood are active in destroying certain bacteria, that the plasma of the blood and lymph can kill bacteria, and that the serum of the blood may contain antitoxins which poison the bacteria. A person may become immune to certain diseases by vaccination, protective inoculation, and other methods in use at present. In some of the infectious diseases the body becomes so changed that a second attack seldom occurs, as in scarlet fever, yellow fever, smallpox, measles, and mumps; while in others the immunity lasts only for a short time, as in diphtheria.

If the body cannot successfully resist the growth of the germs or the poisons they produce, it must yield to the attack of the bacteria. Most of the diseases due to bacteria are commonly known as fevers, which must run a certain course. Of course, fever means simply a condition of the body in which there is a rise in temperature, and may be due to many other causes. The course of those due to germs may be described as follows :-

I. Infection, or the entrance of the germs into the body.

2. Incubation, or the period of growth in the body without any bad signs of their presence.

3. Onset, or the time the symptoms of disease begin to show themselves.

4. Height, or the time the fever reaches its highest point.

5. Decline, or the time the temperature falls to the normal. 
6. Convalescence, or the time it takes to grow strong and well.

We shall now consider more in detail a few of the common communicable diseases.

195. Consumption. - We have already learned that consumption destroys more lives in this country than any other disease. We are now beginning to understand the cause, nature, means of prevention, and treatment of this dreaded disease, and we may hope that as the general public becomes more intelligent on this subject fewer deaths will be caused by it. Consumption can be taken only from a person suffering from the disease. If the sputum is allowed to dry on the

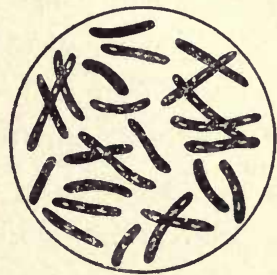

FIG. I55. - Bacteria of consumption. ground, the germs get into the air and must be inhaled with the air we breathe. We know that the germs of consumption occur in meats and milk from diseased cattle and unless destroyed by thorough cooking may get into the body, but we cannot say positively that they can cause consumption in man; most scientists think they can. There are, of course, many other ways in which persons can take the germs.

When healthy persons live with consumptives great care must be exercised, for it is easy to take the germs by sleeping in the same bed, using the same eating and drinking utensils, wiping on the same towel, kissing and caressing, and especially by carelessness in disposing of the sputum and excretions. 
If the inhaled tubercle bacilli find favorable conditions for their development, they multiply rapidly, causing inflammation and later the formation of tubercles in different parts of the lungs. Unless the disease is checked the tissues of the lungs become so involved that they cannot carry on their functions properly. The bacteria produce poisons which tend to undermine the health, and cause a loss of appetite and general debility. The disease usually begins with what is called a "cold on the lungs" and a cough. From the very first all excretions from the mouth and nose contain the germs and are the chief source of danger.

196. Pneumonia. - A specific germ is the cause of pneumonia. Pneumonia occurs both in hot and cold

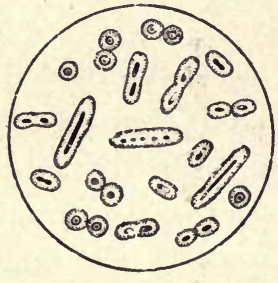

FIG. I56. - Bacteria of pneumonia. climates. In the northern part of our country it occurs chiefly in late winter and early spring. The germs are inhaled with the air and lodge in the air passages of the lungs, where they multiply very rapidly if conditions are favorable. Exposure to cold and moisture, and general debility due to exhaustion, alcoholism, or diseases of certain kinds, precede an attack of pneumonia. All such conditions tend to cause congestion and inflammation in the lungs, and in this way a good soil is prepared for the germs of this dangerous disease. We know that the excessive use of alcoholic beverages may predispose the body to this disease.

A person is not likely to contract pneumonia if he eats 
an abundance of wholesome foods at regular hours so as to maintain the nutrition of the body on a high plane; dresses warm and dry, so as to guard against the sudden changes in temperature; and bathes frequently, so as to keep the skin clean and the pores open.

The sputum of a person suffering from this disease contains the living germs; it should be disinfected at once. All articles, as clothing, bed linens, etc., soiled with the sputum should be thoroughly scalded as soon as removed. Remember that if the sputum is allowed to dry, the germs which it contains get into the atmosphere and may be carried abroad. The death rate due to pneumonia has increased very rapidly since $\mathrm{I} 890$.

197. Cholera. - The disease known

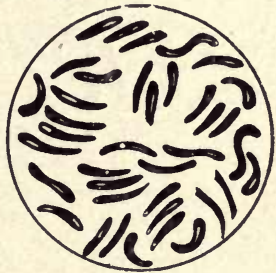

FIG. 157. - Bacteria of cholera. as Asiatic cholera is caused by a little comma bacillus, which sometimes occurs in long chains, and hence is often called a spirillum or a spiral-shaped bacterium. The germs are taken into the body through water or food that has become contaminated. Polluted water is probably the greatest source of danger. Flies and other insects may carry the germs to foods, as milk, meats, and fruits. It is well known that filth, bad foods, impure air, lack of proper clothing and shelter, all favor the spread of the cholera germ.

The disease germs attack the epithelial cells of the mucous membrane of the intestines. When the cells have become impaired in their functions or destroyed, 
the poisons produced are absorbed into the blood and finally paralyze the nerve centers controlling circulation and heat production.

198. Typhoid Fever. - This disease is due to a rodshaped bacillus. The germ enters the body through

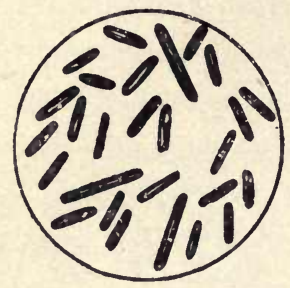

FIG. I58. - Bacteria of typhoid fever. water, milk, or other foods. The germ is contained in the excretions of patients, which are its only source so far as is known at present. The water polluted with typhoid germs used in the dairy or in washing vegetables is a frequent cause of this disease. Flies and other insects spread typhoid germs.

The typhoid germs get into the intestines and multiply rapidly. They injure the walls of the intestines, causing ulcers, and in severe cases, hemorrhages and perforations. For that reason the patient should not be given any solid foods at all. There is no danger of infection except from the excretions, which should be properly cared for, and from soiled sheets or clothing, which should be carefully disinfected as soon as removed.

199. Dysentery. - This is an infectious disease, especially common among children. It is due to an organism that does not belong to the bacteria. The disease-producing organism probably lives in the soil and water and gets into the body through the mouth with water and foods. The organisms develop very rapidly in the intestines and are numerous in the excre- 
tions from the bowels, which should be carefully disinfected. When dysentery prevails, all drinking water should be thoroughly boiled, and no uncooked vegetables should be eaten.

200. Diphtheria. - This disease is caused by a rodshaped bacillus. Diphtheria belongs to the class of infectious diseases, but is probably also highly contagious. The germs of diphtheria come from the mouth and throat of the patient. They may be coughed.up in bits of the membrane that forms in the throat, and lodge on the bedclothes, furniture, persons near by, and on the walls of the room. The germs may become completely dry, and still retain life and be able to cause the disease in another person. Diphtheria in the house of the dairyman has been known to infect the milk and cause a 'general outbreak among his patrons. Cattle probably never have the disease, but cats have taken it from children and carried it elsewhere.

The germs settle in the throat and soon cause a yellowish white membrane to form, which may completely obstruct the air passages. The disease is accompanied by sore throat,

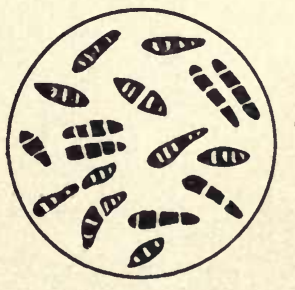

FIG. I59. - Bacteria of diphtheria. a croupy cough, and a choking sensation. Of course not every case of sore throat is diphtheria, but, if at all serious, it should be looked upon with grave suspicion. Diphtheria is one of the diseases that is being successfully treated to-day by the use of a germicide made from 
the serum of horses that have been inoculated with the disease germs; it is called diphtheria antitoxin.

201. Scarlet Fever. - This disease is probably caused by a germ, although as yet scientists have not been able to find out the real cause. The disease is contagious and infectious at all times, but especially in the later stages, when the epidermis begins to peel off in fine particles. These little particles may be carried from one person to another in various ways and by numerous agencies. Scarlet fever at the house of the dairyman has been known to infect the milk and cause the disease.

A rash or skin eruption occurs on the second day, on the chest and thighs. It soon spreads to all parts of the body. In about ten days the skin begins to peel off, and this may continue from one to five weeks. This is the time of greatest danger, and the patient should be kept isolated from all other persons during the entire time, and be properly cared for, because a cold is sure to affect the kidneys or ears, and may leave these organs permanently weak, or even result in death.

202. Measles. - The cause of measles is unknown, but it is one of the most contagious diseases of childhood. It usually begins with a cold in the head, and on the fourth day an eruption of the skin appears on the face, which later spreads to all parts of the body. The disease is most contagious in the early stages, before the rash appears, and for that reason precaution cannot be taken in time to prevent its spread. 
Measles often brings on diseases of the air passages, as bronchitis, pneumonia, and consumption. Death is more often due to such complications than to the disease directly. The only means of preventing its spread is to isolate the patient during the entire time and to disinfect all bedclothes, dishes, etc., used in the sick room.

German measles is a disease quite different from either measles or scarlatina, but the skin eruption resembles both. It is a contagious disease whose cause is not known. It is much milder than measles and rarely proves fatal.

203. Smallpox. - Smallpox is an infectious and highly contagious disease whose cause is not known, but it is believed to be due to bacteria. On the third day an eruption of the skin appears in the form of small round lumps, shotty eruptions, first on the forehead and face, but later all over the body. In these lumps a clear fluid is found in the early stages, later a yellow pus, and finally a scab is formed about the twelfth day. The scabs begin to fall off on the fourteenth day, and in the course of three or four days they all disappear, usually leaving pits or scars. The disease is very contagious from the first and until every scab has fallen off and every sore has fully healed.

The disease is inhaled from the air and probably never taken through water or foods. The patient should be isolated, and all articles about the patient and the room thoroughly disinfected or, still better, burned. No disease can be more easily spread abroad than smallpox. 
The most effective means of preventing and eradicating this loathsome disease is vaccination, which produces a very mild form of the disease that makes the person immune for a number of years. Vaccination has proved a great blessing to mankind, for it has saved millions of lives from this deadly scourge.

Chicken pox is a mild, "air-borne" disease in which appear skin eruptions that sometimes form small scabs. It is contagious and may be transmitted until the scabs have all disappeared. Small scars or pits are sometimes left that disfigure the face.

204. Mumps. - This is a very contagious disease of childhood and youth, in which the salivary gland below the ear becomes infected and very much enlarged. It is probably caused by bacteria, although we are not certain of that. Mumps is not very painful and seldom proves fatal. The only means of preventing the disease is complete isolation for about three weeks.

205. Whooping Cough. - This is a contagious disease of childhood. It is accompanied by a peculiar spasmodic cough, followed by a whoop (from which it gets its name) as the breath is inhaled. The lungs are invaded by the germs and may become so affected as to cause death. The disease may be communicated from one person to another through the breath and matter thrown off in coughing, but it is probably not carried by a third person nor in clothing. It is contagious from the first until the cough and whoop have entirely ceased, which usually continue for a period of from three to six weeks. During this time the patient should remain isolated. 
206. Malarial Fever. - This class of fevers is due to a specific organism which does not belong to the class of bacteria. It is not contagious. Two varieties of malarial fevers are known, although they are probably caused by the same organism. These fevers generally occur in low, marshy, swampy regions and are most severe near marshes that are periodically flooded. If the swamps are properly drained, the malarial fevers soon disappear.

The germs probably enter the body through the water we drink and the air we breathe, and through the bites of the mosquito and other insects. These fevers may be prevented in malarial regions by draining the damp soils, by locating residences on the most elevated places, by always sleeping indoors, by keeping the skin free from wounds and bites, by cooking all foods, by boiling the drinking-water, and by the daily use of quinine in small doses. The first is probably the most effective means of stamping out malarial troubles.

207. Yellow Fever. - This is an infectious disease whose cause is unknown. It occurs chiefly in low, swampy, tropical countries, but epidemics have swept over our country as far north as Philadelphia. Many claim that the poison causing yellow fever may be carried in clothing, in papers and letters through the mails, and in articles of merchandise shipped from one place to another. But the mosquito is doubtless by far the most important agent concerned in spreading this disease.

The introduction and spread of yellow fever may be largely prevented by maintaining good sanitary condi- 
tions. The streets should be clean and well drained, all garbage and excretions from patients suffering from the disease should be properly disposed of, and an abundance of clean, wholesome water should be provided for domestic purposes. All yellow fever patients should be isolated and their excretions carefully disinfected.

208. Grippe. - This disease, which has become very common of late, is due to a bacillus. It is highly con-

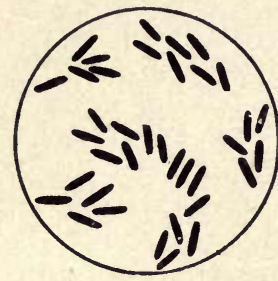

FIG. 160. - Bacteria of grippe. tagious, and that accounts for its rapid spread among persons collected in large numbers, as in schools, factories, and shops. The germs are probably inhaled and then develop rapidly in the mucous membrane of the air passages. The common symptoms are fever, chills, headache, and violent pains in the spine. Adults usually suffer much more than children from an attack of grippe or influenza.

If every case could be reported at once and the patient completely isolated until fully recovered, the spread of this disease might be checked.

209. Pink Eye. - This is a disease of the mucous membrane lining the lids and covering the front of the eyeball. It is caused by a specific disease germ. This disease is contagious and may be transmitted by anything that comes in contact with the matter discharged from a diseased eye. The hands and towels are the most common means of spreading the germs.

The eyes become red and inflamed and discharge a 
watery fluid which becomes sticky later, so that the eyelids may be firmly gummed together every morning. The eyes become weak and highly sensitive to ordinary light. The person afflicted should be isolated until he recovers.

\section{SUMMARY OF THE MAIN POINTS}

I. Bactèria are very small microscopic organisms belonging to the vegetable kingdom. There are three classes as to shape, - the coccus, the bacillus, and the spirillum.

2. Bacteria multiply very rapidly, and some kinds can resist cold, moisture, and heat so successfully that they can live under conditions which prove fatal to all other forms of life.

3. Most of these organisms are useful to man. They cause decay or decomposition in animal and vegetable matter, manufacture a large amount of carbon dioxid for the use of plants, act as scavengers to clean up dead matter about us, form certain commercial products, and make it possible for some plants to obtain nitrogen directly from the air.

4. Some bacteria can grow and develop best in the human body if favorable conditions are present.

5. Most of the diseases are due to the poisons which the bacteria produce in the body, and not simply to the presence of the organisms.

6. The bacteria get into the body through the air passages, through the alimentary canals with foods and water, and through bites and wounds in the skin.

7. The body, if in good health, has the power to resist the bacteria. The white corpuscles destroy vast numbers, the plasma of the blood and lymph kills many, and the serum of the blood may contain antitoxins which destroy the effects of the poisons produced by the germs.

8. If the tissues and organs have a high degree of vitality, 
the body can throw off the disease; but if not, the germs soon gain a foothold, and fevers are the inevitable result.

9. If the body will not take a certain disease, we say it is immune to that disease. Natural immunity means that an animal cannot take a disease under any circumstances. Artificial or temporary immunity may be brought about by antitoxins, by vaccination, or by an attack of the disease.

10. An abundance of good pure foods and pure water, an adequate supply of pure fresh air, a sufficient amount of physical and mental exercise and rest, and good sanitary surroundings, tend to fortify the body against all diseases.

II. Among the communicable diseases, many of which are due to bacteria, are the following: consumption, diphtheria, pneumonia, typhoid fever, cholera, lockjaw, malaria, grippe, smallpox, scarlet fever, measles, mumps, whooping cough, cerebro-spinal meningitis, erysipelas, scarlatina, leprosy, chicken pox, yellow fever, dysentery, anthrax, glanders, and relapsing fever. 


\section{CHAPTER XX}

\section{PUBLIC HEALTH AND PERSONAL HYGIENE}

210. The Problems. - In cities, towns, and in rural districts as well, the health and well-being of each person depend to a large extent upon the general sanitary conditions of the entire community. This fact is well understood to-day. Every nation, state, and city makes provisions through laws and ordinances for the protection of the health and safety of its people. There is not a single city or town which does not have its health department, boards, committees, inspectors, and examiners.

Some persons think the men employed in a large city to look after its sanitary and hygienic interests have little or nothing to doexcept when some dangerous disease gains a foothold. The fact is, if there is a good working sanitary organization, dangerous diseases never occur, or if they do, they are soon stamped out. What does it mean to keep a city in good sanitary condition? We shall get some idea of this from the kind and number of problems that come to its sanitary organizations. Let us see what some of these problems are.

I. To inspect all foods, as meats, vegetables, and fruits, shipped into the city and offered for sale. 
2. To inspect the milk sold in the city, and the places where it is produced.

3. To examine the water supply and warn the people when dangerous disease germs are found in it.

4. To examine the plumbing and sewerage and see that they are kept in a good sanitary condition.

5. To keep out communicable diseases and check their spread if any occur.

6. To remove and dispose of the garbage, ashes, offal, dead animals, and refuse of all kinds.

7. To repair, sweep, clean, sprinkle, and light the streets and to see that there are unobstructed public thoroughfares.

8. To inspect all public schools, public baths, lodging houses, restaurants, hospitals, and other public institutions and see that they are kept in a hygienic condition.

9. To control all public nuisances like smoke, offensive trades, filth on shores, public dumps, pond holes and swamps, stables, noises, and spitting on the streets.

Io. To maintain police and fire departments for the safety of life and property.

I I. To keep an accurate record of all deaths and births that occur in the city.

I2. To investigate and answer all complaints pertaining to the safety, health, and comfort of its citizens.

All these and numerous other matters receive attention in every large city. The departments of public health and general sanitation are among the most important in the organization of any densely populated community. 
211. Public Intelligence. - While every city and town is making an effort to maintain good sanitary conditions through its officers appointed expressly for that purpose, it cannot protect the public as it should without the hearty support and constant coöperation of its citizens. Not only should they see that their officers perform the duties assigned, but they should keep them informed as to dangerous or unsanitary conditions in any portion of the town and city.

Every good citizen should be informed on questions of public health, should know the dangers of unhygienic and unsanitary surroundings, and should be willing to lend his support to all movements that tend to protect the health and safety of the community. Ignorant persons are often unwilling to coöperate with the organized efforts for better sanitation, and for that reason it is almost impossible to check contagious diseases when they occur among them. When all people become intelligent on matters pertaining to public health and general sanitation, and live up to their knowledge, communicable diseases will be unknown, public health and safety will be increased, and human life prolonged by many years. The hope of our nation lies in the intelligence of the rising generation.

212. Foods. - In every city an effort is made to inspect all food products offered for sale. In New York there are about four hundred experts employed by the city who devote their entire time to the inspection and examination of meats, fish, milk, vegetables, and fruits. If any stale, diseased, impure, or otherwise unwholesome 
foods are found, they are destroyed at once. Every state and nation employs expert food inspectors to examine all imports and exports. In 1899 our government inspected 53,087,994 slaughtered animals, of which number I 59,519 were condemned and their sale prohibited. The inspection of meats and other slaughterhouse products is the most important work pertaining to foods that our government attempts. Usually the states deal with the question of adulterations and substitutions of foods, and the federal government and local authorities pay little attention to it. Massachusetts spends about $\$ 10,000$ annually on the question of adulteration of foods, and doubtless this amount is saved many times over to the people of the state.

Pure, wholesome; unadulterated foods are matters of such importance to the health and well-being of any people that the governments are maintaining inspection and experiment stations at great expense. The inspection laws should be strictly enforced in the rural districts and the small towns and villages, as well as in the large cities.

213. Water Supply. - To supply a large city with an abundance of pure wholesome water for drinking purposes is often no easy task, and yet no one thing is more essential to public health. The chief sources of the water supplies are ponds and lakes, storage reservoirs, rivers and streams, and deep wells. The many shallow wells still in use even in our large cities are the cause every year of hundreds of cases of typhoid fever and other "water-borne" diseases. Sometimes cities 
are too careless in disposing of the sewage, and the source of the supply of water becomes polluted by it. In cities situated on a river which serves as a sewer for one town and a source of water supply for others farther down the stream, it often happens that a few cases of typhoid fever, or other "water-borne" diseases, in one town are the direct cause of epidemics

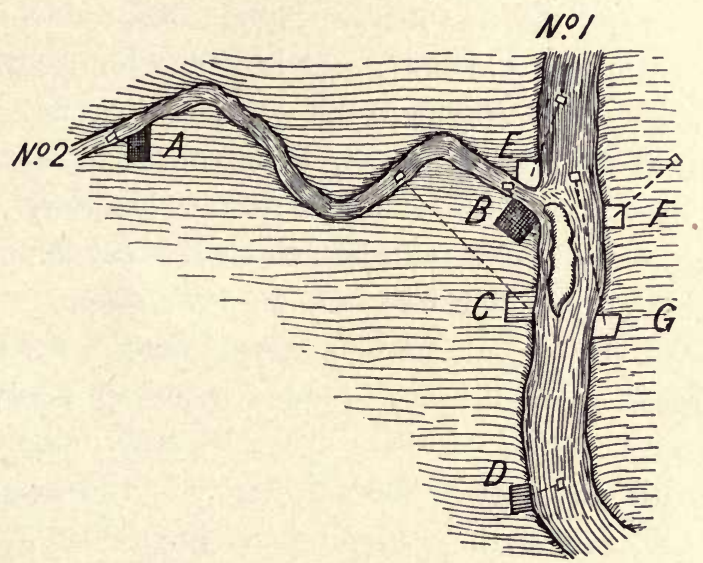

FIG. I6I. - Distribution of typhoid fever through pollution of a river. Intensity of epidemic shown by depth of shading. No. 2 flows into No. I; $A-G$, cities situated on the river; $\square$ water intakes. (Adapted from "School Hygiene," issued by State Superintendent L. D. Harvey, of Wisconsin.)

in cities located below. In some instances a single case has been the cause of an epidemic.

In the country, outbuildings and barns are frequently so situated that the surface waters are drained into a well near by. Most of the cases of "water-borne" diseases occurring in the rural districts are due to polluted water from bad wells. 
In many places where it is difficult to obtain pure, wholesome water, attempts have been made to purify it by artificial means. For the past fifty years filters have been used very extensively in Europe to purify the water for cities. We are now introducing them in this country. The safest and most effective way to purify water for private use is to boil it for at least twenty minutes. By this method all the disease-producing bacteria are killed, and the water becomes innocent. We cannot be too careful as to the water we drink.

214. The Air. - The subject of pure, fresh air has been discussed quite fully in former chapters. The matter of wholesome, odorless air is of great importance to our comfort and health. In low, damp, swampy localities the air always contains dangerous bacteria. Doubtless many diseases are due to damp, poorly ventilated basements. Cellars are especially dangerous if there are no cement floors to exclude the gases that may come from the ground beneath. Dead animals, waste matter, and excretions from the body must not be allowed to pollute the air we breathe; they should be promptly disposed of in the country as well as in the city. Of course not all bad odors are dangerous, neither is all odorless air safe to inhale.

In cities it is often quite impossible to get an abundance of pure, odorless air. The many factories and trades keep the air filled with odors of all kinds. While most of these are harmless, they are not agreeable, and our cities are doing a great deal to control all such nuisances. The plumbing must be inspected frequently, 
all garbage promptly removed, the filth of the streets kept from accumulating, the stables carefully cleaned and disinfected, and all other sources of offensive and dangerous air should receive the immediate attention of the sanitary organization.

215. Garbage. - One of the most important problems for every city is the disposal of its garbage, sewage, and other refuse. How shall the wastes and offal of all kinds, from private houses, hotels, restaurants, stores, markets, produce commission houses, and the like be collected and disposed of? The garbage should be put into a tightly covered can or pail for that purpose. It is then collected by the city at short intervals, from one - to seven times a week, and disposed of in some way. The cans or pails should be kept where they will not be offensive, and occasionally they should be carefully washed or disinfected.

The garbage is usually collected at public expense. New York City paid about $\$ 1,700,000$ in 1900 for collecting and disposing of its garbage, and over fifteen hundred persons were employed to do the work. Boston employed about one third as many men and paid about one third as much.

In the country it is an easy matter to dispose of the garbage in some way. It may be used as a fertilizer, buried in the ground, fed to animals, or burned in a stove. But in the city it cannot be burned without producing odors that are offensive to the public, and the first two methods cannot be employed at all for private disposal. For that reason the city itself must find some way for 
getting rid of the wastes. Various methods are now used.

Dumping garbage on vacant low grounds where it may serve to fill up low places is the simplest method, but this cannot be used except by some of the smaller cities. Such dumps are nearly always dangerous public nuisances. Dumping it in water is another method, but this cannot be safely used in most cities. It is usually worse than dumping on the ground, because the wastes pollute the water and become a nuisance for neighboring cities. Plowing it under as a fertilizer is being abandoned by most of the cities which tried this method, because it is a great nuisance and costs too much. Feeding it to animals, as swine, sheep, poultry, is a method employed by many of the smaller cities. There is a growing feeling against this method. At present the hog is the only animal to which garbage is fed extensively. This should be discontinued, for the pork is of an inferior quality and is more likely to contain trichinæ. In many cities garbage is sold for fertilizing purposes or for feeding animals. In I 898 the city of Boston received over $\$ 10,000$ from this source. Reduction processes are used in some of our large cities as a means of using the valuable oils and grease the garbage always contains. These processes are not yet perfected, so that the returns are not very large. Cremation or burning is the method used in Europe, and is being used more and more in this country. This is doubtless the most satisfactory method from a sanitary point of view, but it is quite expensive. 
Many kinds of furnaces have been invented for the purpose of burning garbage.

None of these methods seems to be entirely satisfactory, but it is hoped that the time will soon come when every city in the land will dispose of its garbage in a sanitary and, at the same time, economical way.

216. Cleanliness. - The one important condition of public health is cleanliness. Health demands not only clean air, clean, pure water, clean, wholesome, unadulterated foods, but, in addition to these, clean streets and alleys, clean public buildings and parks, clean private residences and yards, and cleanliness of person and clothing.

The streets must be cleaned, sprinkled, and lighted in order to keep them in good sanitary condition. Every city employs men to sweep the streets and remove the rubbish that collects on them from time to time. The city of New York paid over $\$ 8,000,000$ in I 900 to sweep, clean, and light its streets, and employed about thirty-six hundred men to do this work. Boston paid about one fourth that sum for a similar purpose.

The health departments make a careful inspection of all private yards, barns, and residences, and see that they are kept in a clean and wholesome condition all the time. In this matter public intelligence can do much to maintain good sanitary surroundings. We must remember that disease germs and filth of all kinds are closely associated, and therefore the only way to ward off diseases is to insist upon cleanliness in all respects. 
Public bathing and washing conveniences are provided in many cities. They should be kept clean and wholesome, for if they are not in good hygienic condition, they may be the means for spreading diseases. All who are careless or indifferent about the cleanliness of their person or clothing should be compelled to patronize such public necessities. No one has a right to endanger the life and health of those with whom he may come in contact, because of personal indifference to sanitary laws, or ignorance of them.

217. Diseases. - One of the great problems that the health officers have to deal with is that of communicable diseases. A city must prevent the importation of communicable diseases as far as possible. Of course quarantine can be successfully used only at seaports, except in a very few diseases. The health authorities should, however, attempt to keep the sanitary conditions excellent, so that the city as a whole may be immune. Each individual must do his part to keep himself and his premises in a good sanitary condition. If it were possible for the health officers to have the intelligent coöperation of every citizen within their jurisdiction, cities might become immune to most of the communicable diseases.

Diseases should be reported to the health officers immediately, so that means may be taken to prevent their spread. This is such an important matter that most of the states give the state board of health full authority to make all needful regulations relating to communicable diseases. Usually the physician and the 
head of the family are held responsible for reporting the diseases. In many states the school-teacher is asked to report every case occurring in his school or district.

Laws in the different states and cities are not uniform as to the diseases that shall be reported. The following are mentioned by most of them: smallpox, cholera, scarlet fever, diphtheria, croup, yellow fever, typhus fever, typhoid fever, measles, whooping cough, consumption, meningitis, and leprosy. A few cities require reports on chicken pox, erysipelas, mumps, relapsing fever, dysentery, trichinosis, plague, pneumonia, glanders, and malaria. The fines for failure to report communicable diseases range from twenty-five to one thousand dollars.

After the case is reported the posting of placards is required in most cities to indicate the fact that there is danger and the public should take warning. For the more dangerous diseases the patient should be isolated from the other members of the family or, still better, taken to a hospital until he recovers. If the patient is not taken to a hospital, all children and persons who come in contact with children should be kept indoors. Every city takes great pains to control these diseases so that they shall not spread. As soon as a case is reported and precautions taken to prevent the spread of the disease, the health officers should make a thorough investigation of the surroundings to ascertain the cause. A warning to the public as to the source of the danger is often the only means of checking the progress of a disease.

218. Schools and Diseases. - The health officers and teachers should suspend from school all children who 
have been exposed to any of the dangerous communicable diseases. The pupil who was sick and all other children living in the same house should not attend school until the placard has been removed and the house disinfected by the health authorities. It is best to require a certificate from the proper authorities before the pupils are permitted to return.

If a child sick with a dangerous contagious disease attends school even for a part of a day, the school should be closed and the room thoroughly disinfected. Whenever a contagious disease is likely to gain a strong foothold in a community, it is best to close the school entirely to keep the disease from spreading. The spread of so many communicable diseases can be traced directly to the schools, that parents and teachers should exercise the utmost vigilance to forestall epidemics.

219. Disinfection. - The process of killing disease germs and spores by physical means or by chemical agents is known as disinfection. We have already learned that adequate ventilation and abundant sunlight are important means of checking the growth of diseaseproducing organisms. When disease germs are present in large numbers, more radical measures must be employed to destroy them. We have learned that the excretions of patients suffering from some of the communicable diseases, as well as the sick rooms, clothing, bed linen, furniture, etc., may contain vast numbers of disease germs, which, if not destroyed, are sources of danger to the public.

The chief agencies used in disinfecting are heat: 
strong chemical solutions, and fumigation. Clothing, bed linen, and other things that can be washed may be thoroughly disinfected by boiling or steaming. Articles that cannot be submitted to such a treatment, and excretions and drains, may be disinfected by using carbolic acid or corrosive sublimate. These are both very dangerous poisons, and the utmost care should be exercised in their use. Neither should be used in the pure state, but must be diluted with water. One part of carbolic acid in from twenty to thirty parts of water makes a very good general disinfectant. One part of corrosive sublimate (bichloride of mercury) in from one thousand to six thousand parts of water makes an excellent disinfectant for use in scrubbing woodwork, furniture, floors, and walls, and it is often employed for soiled clothing and excretions from the body. Many other chemicals are used as disinfectants. After smallpox, diphtheria, scarlet fever, and other highly communicable diseases have been in a house, it should be thoroughly fumigated. For this purpose formaldeliyde is used almost entirely at present, for it seems to be more satisfactory than any other substance. The physician in charge, or the health department, should take charge of the fumigation and see that it is effectively done.

220. Personal Hygiene. - The health, happiness, and well-being of a person depend upon his sanitary surroundings and personal habits of living. Both require the careful attention of every individual. Public health and general sanitation are indispensable conditions to individual health, and, on the other hand, healthy indi- 
viduals must make up a healthy community. Every case of sickness diminishes the public health and endangers the entire community. Lack of general sanitation in any community threatens the health of every individual.

Under favorable sanitary surroundings the death rate is decreased and the span of human life lengthened, while in a community in which the persons are ignorant and careless as to their habits of living, the death rate is increased and the period of life shortened. In the United States the length of life (the average age at death) has increased about four years during the decade from I 890 to 1900 , as shown by the census rate of I900.

It is a hopeful sign that the death rate in our cities and the rural districts is watched carefully from year to year, and it should be a matter of public pride to see it decrease gradually. Public sanitation will not accomplish it alone, though it will contribute its share, but there must go with it more hygienic personal modes of living. The important thing is for each individual to form, early in life, good hygienic habits of living, and to become informed on all matters pertaining to public health and sanitation.

\section{SUMMARY OF THE MAIN POINTS}

I. There are many problems of public health and general sanitation that should receive the attention of the intelligent citizens in every community.

2. Many of the problems are assigned to officers, boards, 
and committees appointed for the purpose of looking after the public health.

3. All such organized efforts should receive the support and coöperation of every intelligent citizen. The health departments cannot do what they should without the aid of the public.

4. The federal government and each state and city appoint persons to inspect and examine foods, as meats, fish, milk, vegetables, and fruits. These inspectors condemn and destroy whatever they find that is stale, adulterated, or otherwise unwholesome.

5. The water is frequently polluted with disease germs, and then it must be boiled before it is safe to use for drinking purposes. Most of the outbreaks of typhoid fever can be traced to contaminated water or milk.

6. Pure, wholesome, odorless air is a matter of great importance to the health of any people. Much can be done in the cities to control the nuisances that vitiate the atmosphere.

7. The removal and disposal of the garbage, ashes, rubbish, and wastes of all kinds are of great importance to good sanitation.

8. The chief methods of disposing of the garbage in the large cities are dumping on low grounds and in the water, plowing under as a fertilizer, feeding to swine and other animals, selling to farmers, cremation, reducing to certain useful products, as fats and oils ; but cremation is the most satisfactory from a sanitary standpoint.

9. The air, water, foods, houses, cellars, yards, streets, alleys, parks, public buildings, public baths, persons, and clothing should all be kept just as clean as possible if we wish to maintain good sanitary conditions.

Io. Every communicable disease should be reported at once to the proper authorities by the attending physician, head of the family, or teacher in the school. 
I I. The premises should then be carefully inspected to ascertain the cause of the disease. Placards should be put up to warn the public of the danger within.

I2. The diseases that must be reported in most places are smallpox, cholera, scarlet fever, diphtheria, croup, yellow fever, typhus fever, typhoid fever, measles, whooping cough, consumption, meningitis, and leprosy. Some add chicken pox, erysipelas, mumps, relapsing fever, dysentery, trichinosis, plague, pneumonia, glanders, and malaria.

13. Fines imposed for failure to report communicable diseases range from $\$ 25$ to $\$$ I 000 in different states and cities.

14. All school children exposed to communicable diseases should be suspended from school at once. If the contagious disease is likely to gain a foothold in the community, school should be closed entirely until the danger is past.

r5. Personal health depends to a large extent upon the general sanitary surroundings, and public health in turn is conditioned on personal habits and modes of living. There is a close relation between public health and personal health.

r6. Every individual should form good hygienic habits of living, and become informed on all matters pertaining to public health and general sanitation. 


\section{CHAPTER XXI}

\section{FIRST AID IN ACCIDENTS AND EMERGENCIES}

221. Introduction. - When we are very sick or seri. ously injured, we want to be treated by a skilled physician because his careful study and long experience have given him a deep insight into all matters pertaining to the welfare of our bodies. There are, however, many slight indispositions and injuries whose treatment is so simple that there is no need of calling a physician. In severe illness and injuries it is usually very important for the saving of life, or at least for the relief of suffering, to do something at once, and not to wait until the physician arrives. Be certain, however, that you know what to do and how to set about it before you offer your services.

In this chapter we shall learn some very simple modes of treating a few of the more common illnesses and injuries that do not require the physician, or that demand attention in case no physician can be called immediately. These brief suggestions should be remembered by all.

222. Burns and Scalds. - If the burn is not severe, apply cold water at first. A tablespoonful of baking soda to a tumbler of water makes an excellent solution for burns of all kinds. Equal parts of linseed oil and 
limewater makes an excellent liniment for dressing burns. After the pain has disappeared vaseline should be freely used until the wound is healed. In severe cases call a skillful physician as soon as possible.

If the clothing catches fire, it is best to lie down on the ground or floor immediately, and roll back and forth until the flames are extinguished. Wrap up in a rug, carpet, blanket, shawl, overcoat, etc., as that will smother the flames at once. Do not run outdoors, for that serves to fan the flames.

223. Sunstroke. - When a person is overcome by the heat, he should lie down quietly in a cool, shady, airy place. Sponge the face, neck, and hands with cold water. Cloths dipped in ice water, or, still better, the ice bag, should be applied to the head, face, neck, and back. In severe cases the clothing may be removed and the patient packed in ice for an hour or more, as may be necessary. In heat exhaustion the body is cold and moist instead of hot and dry, and no cold should be applied. In such cases hot drinks should be given freely and heat applied to the entire body so as to restore the normal temperature as soon as possible.

224. Fainting. - Poor ventilation, disagreeable odors, or some sudden emotion may so disturb the circulation of the blood that the person loses consciousness. Fainting is not generally a very dangerous matter, and very little treatment is necessary. Lay the person flat on his back with the hips slightly elevated. If there is vomiting the person should be placed on his side. Loosen all tight clothing about the neck and waist at once. 
Place the person near an open window, or, still better, carry him out doors so that he may have plenty of fresh air. If necessary, sprinkle a little cold water on the face and apply ammonia (smelling salts) to the nose. If these simple remedies do not restore consciousness in a short time, send for a physician.

225. Suffocation. - Among the common causes of suffocation are foul gases, as from old wells or mines,
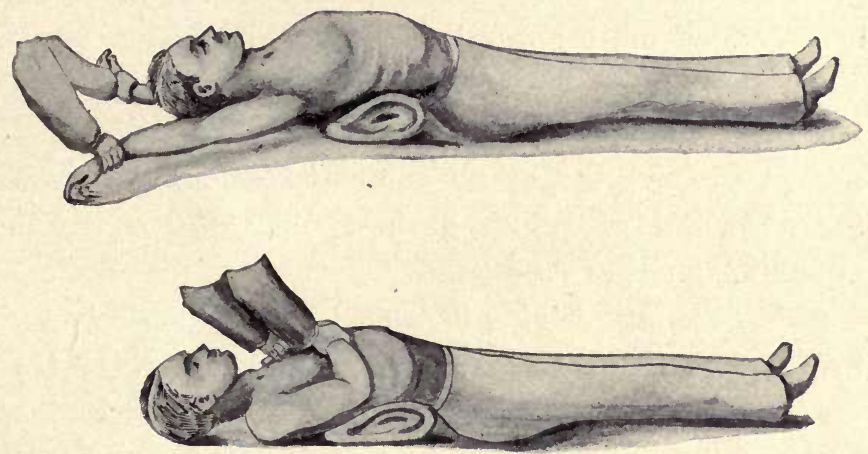

FIG. 162.-Artificial respiration (Zuppke). The upper, inspiration; the lower expiration.

coal gas from the furnace, stove, or range, illuminating gas from a jet that has not been properly turned off, and charcoal fumes. Carry the person to an open window where he may have plenty of fresh air. Loosen all tight clothing about the neck, chest, and waist. Dash a little cold water in the face. When he begins to breathe, hot water containing a little ammonia may be given. If these means are not sufficient, use artificial respiration. This may be done as follows: Place the 
person on his back with something under the shoulders to keep them slightly elevated. See that his tongue does not drop back into the pharynx. Take hold of his arms near the elbows and slowly raise them up, so as to bring them together over his head, and pull firmly for a moment. Then lower the arms slowly until they press against the ribs, pressing in firmly for a moment, so as to expel some air from the lungs. Repeat this movement about sixteen times a minute, for two hours or more, or until natural breathing has been begun. Keep the person warm all the time, using hot water bottles or warm bricks and blankets. As soon as the person can breathe, apply ammonia (smelling salts) to the nose and give him a little hot water containing aromatic spirits of ammonia.

226. Choking. - This is caused by some object like a fish bone, a toothpick, a marble, a peach stone, a coin, etc., lodging in the throat. A sharp slap on the back between the shoulders may be sufficient to dislodge the object. If the patient is a child, hold it up by the heels and slap it on the back. Sometimes the foreign body can be seen in the throat if the tongue is pressed down, and can be easily removed with the forefinger. Do not be afraid to reach well down the throat, for if the object cannot be removed in this way you may induce the person to vomit and thus dislodge it. Or you may have the person drink water, swallow jelly, scraped apple, mashed potatoes, or any such soft substance, so that the object may be forced down into the stomach. The object should be dislodged as soon as possible. 
227. Apparent Drowning. - After the person has been removed from the water, place him on a flat surface, face down, and raise the hips just a little so that the water may be removed from the air passages and the lungs. Loosen all clothing about the neck, chest, and waist. Then begin artificial respiration (described under suffocation), and continue it for two hours or more, unless natural breathing is restored sooner. At the same time rub the body vigorously with the hands, and keep it as warm as possible. When natural respiration begins, hold smelling salts to his nose and give him a little hot water containing aromatic spirits of ammonia. Keep the person quiet and warm for several hours, even after breathing has been restored. Remember you must (I) remove the water and mucus from the air passages, (2) restore natural respiration, and (3) keep him quiet and warm, and all must be done as quickly as possible.

228. Fits. - A fit seldom proves fatal. When a person has a fit, see to it that he does not injure himself. Fold up a handkerchief and place it between the teeth so as to prevent biting the tongue and lips. Loosen the clothing about the neck, chest, and waist, give plenty of fresh air, and, if necessary, sprinkle a little cold water in the face or on the chest. Let the person lie down and keep quiet for several hours, and, if possible, get some sleep.

Convulsions, due to an attack of indigestion, are not uncommon among children. In case of a convulsion give the child an emetic at once. Immerse the feet and legs or even the entire body in hot water, and bathe the head 
and face in cold water for a few minutes. Often the cold application to the head is sufficient.

229. Bruises. - A bruise should be carefully washed at once, and then have cold water or ice applied to it. Be careful, however, that the person does not become chilled. Keep the bruise clean and the injured part quiet until the swelling has gone down and the soreness has disappeared. Hot water may be used in place of cold.

230. Frost Bite. - The ears, nose, cheeks, and fingers are the parts of the body most exposed to the cold. The skin first grows bright red because the capillaries become congested; then it turns bluish because the circulation becomes arrested; and, finally, gets a deep white color because it is frozen. Rub the frozen parts vigorously with snow, or apply ice water freely, and remain away from the fire until the circulation has been well started. When the parts begin to sting and itch, bathe them in cold water or cold oil. The person should first be kept in a cold room, and the return to a higher temperature should be as gradual as possible. If the frozen parts are warmed too rapidly, gangrene may set in.

231. Poisonous Stings. - When a person has been stung by a bee, wasp, hornet, mosquito, nettles, etc., see that the sting is pulled out if it was left there. Bathe the wound in hot water and squeeze out the poisonous matter at once. Then bathe it with a strong solution of soda, common salt, or ammonia.

232. Poisons. - Send for the nearest physician at once. Unless the poison is an acid, give an emetic to empty the stomach as soon as possible. Stir a teaspoonful of 
ground mustard into a tumbler of warm water, and give this amount every ten minutes until vomiting is produced. Run the forefinger down the throat to hasten the act. A strong solution of alum or common salt may be used if mustard is not at hand. Wash the stomach thoroughly by forcing the person to drink freely warm water and then to throw it up; repeat this several times. When the physician arrives he will know what to do to neutralize the poison that may remain in the system, and to remedy the injury that may have been done.

233. Sprains. - Sprains are caused by a sudden stretching of the ligaments at a joint. No bone is injured at all. Soak some cloths in cold water and tie these on firmly, so that the injured part may be kept cool and have perfect rest. Apply cold water from time to time and keep the bandage on for several days if the sprain is severe.

234. Dislocations. - A bone may be out of its proper position at a joint, but still not injured in any way. There is generally a deformity noticeable and a stiffness or fixity so that the bone cannot be moved. Dislocations are usually very painful, but not dangerous. The person should be taken to a surgeon at once. Cold water may be applied to relieve pain and keep down the swelling until the surgeon takes charge of the case. It is a good thing to keep the limb elevated and to rub it freely, so as to aid the circulation of the blood and the lymph.

235. Broken Bones. - When a bone is broken it must be set properly by a skillful surgeon so that the 
two parts may again grow together as they were before. If carefully set, there will be no deformity whatever in

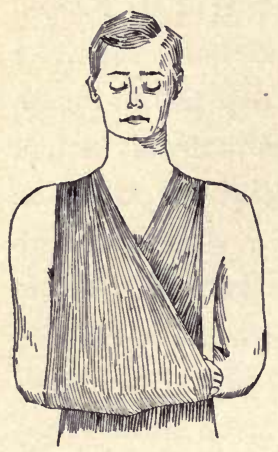

FIG. I63. - A temporary sling for a broken arm (Zuppke). most cases. If the person must be carried any distance, the broken bone should be kept as quiet as possible. Cold water may be applied if there is any swelling.

If any of the bones of the arms are broken, a sling may be made as shown in this figure. In this way the injured part may be carried with little pain. Splints may be made by tying thin pieces of wood to the injured part, so as to hold it firmly in position until the surgeon takes charge of the case.

236. Cuts in the Skin. - All cuts in the skin must first be carefully washed. Then, if the bleeding is not severe, bring the edges of the cut together if they are far apart and hold them in position by placing strips of plaster across the cut. It is best to apply some disinfecting lotion like carbolic acid (I part in IOO), or some simple ointment, and then bandage the wound as quickly as possible. If the bleeding is severe, measures must be taken to check it before bandaging the wound. Do not change the dressing of a cut very often, but when you do, see that the wound is thoroughly washed and disinfected.

237. External Bleeding. - This may belong to any one of three different kinds. (I) It may be from an 
artery, when the blood is bright red in color and the flow is in jets or spurts. (2) It may be from a vein, when the blood is slightly darker in color and the flow is steady and continuous. (3) It may be from ruptured capillaries, when the blood is red in color and the flow is very slow, the blood simply oozing from the wound. If the bleeding spot is not too large the most effective way to stop it temporarily is to press the thumb and fingers, or a piece of cotton wool, firmly into the wound.

If the bleeding is from an artery, tie a large hard knot in a handkerchief, and place the knot directly upon the artery at any convenient point $b e$ tween the heart and the bleeding cnd. Tie the handkerchief loosely and twist a stick as shown in the figure until the artery is completely compressed. If the bleeding is from a vein, it is sufficient to raise the part up and place a pad of cotton wool or a clean cloth on the wound and, after applying warm water, bandage it up tightly. If the bleeding is from capillaries, the

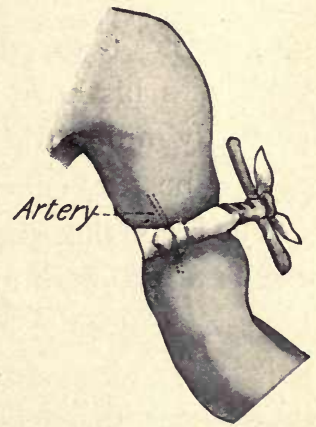

FIG. 164. - Checking the flow of blood from an artery (Zuppke). bandage just mentioned will usually be sufficient to check the flow immediately. If the loss of blood is likely to prove dangerous, send for a physician.

238. Nose Bleeding. - Nose bleeding is not uncommon among children, and, as a rule, it is not serious. If, however, it should continue too long or occur too frequently, it would be necessary to check it. A simple method is 
the following: Stand erect, hold the head up, and apply cold water or ice to the back of the neck and to the nose

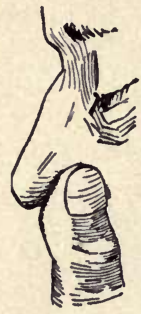

FiG. I65. - Checking nose bleeding (Zuppke). and forehead. If this does not stop the bleeding, inject cold water containing a little soda or common salt into the nostrils, or compress the bleeding nostril completely for ten minutes by pressing the thumb against the side.

239. Lung and Stomach Bleeding. Bleeding from the lungs is a very serious symptom. The blood that comes from the lungs has a very bright red color, and a frothy appearance. The person should lie on his back with his head and shoulders elevated, and remain perfectly quiet for several days. Small pieces of ice should be sucked and swallowed freely.

The blood that comes from the stomach has a dark red, almost black, color, and a sour taste, but it is never frothy. It may be in quite large pieces or lumps and have particles of food mixed with it. These cases are so serious that a good physician should be consulted.

240. Sore Throat. - This is a very common illness among both children and adults. It is due to many different causes. Some kinds of sore throat are very dangerous, and, unless simple home remedies afford relief very soon, it is always wise to consult a physician. Salt and water, or a solution of chlorate of potash, or of permanganate of potassium ( 1 part in 10,000), may be used as a throat wash or gargle. 


\section{GLOSSARY}

$\mathrm{Ab}-\mathrm{do}$ 'men (Latin abdere, to conceal), the large cavity of the body just below the diaphragm. It contains the stomach, the liver, the spleen, the kidneys, the pancreas, and the intestines, as its principal organs.

Ab-sorp'tion (Latin $a b$, from, and sorbeo, sorptus, I drink), the process of taking up fluids into the blood vessels or lymphatics.

Ad'e-noid (Greek aden, gland, and -oid, like), an abnormal growth of connective tissue in the upper part of the pharynx, often found in children.

Ad'i-pose (Latin adeps, fat), the form of animal tissue that contains fat.

Ad-re'nal (Latin ad, to, and renes, kidneys), a small gland at the upper end of each kidney.

Af'fer-ent (Latin $a d$, to, and ferens, bringing), conducting to an organ, as an afferent nerve or blood vessel.

Al-bu'min (Latin albus, white), a kind of proteid found in some foods, as eggs. It occurs in plant and animal tissues.

Al-i-men'ta-ry (Latin alimentarius, from alere, to nourish), a long tube that extends from the mouth to the end of the large intestine, in which the digestion of food takes place.

A-mœ'ba (Greek amoibe, change), one of the lowest forms of animal life, found in fresh water. It consists of a single cell and has the power to change its form and shape as it moves about.

A-næ'mi-a (Greek anaimia, want of blood), a condition in which the blood is deficient in the quantity or the quality of the red corpuscles.

A-nat'o-my (Greek anatome, dissection), the science of structure.

An'ti-tox'in (Greek anti, against, and toxicon, poison), a substance capable of producing immunity from certain diseases or of counteracting the poisonous effect of disease germs. 
A-or'ta (Greek aorte, the great artery), the great vessel which conducts blood from the left ventricle of the heart.

Ap-pend'i-ci'tis (Latin appendere, to hang), a disease of the vermiform appendix.

$\mathbf{A}^{\prime}$ 'que-ous hu'mor (Latin aqua, water, and humor, moisture), the liquid between the crystalline lens and the cornea of the eye. $\mathbf{A r}^{\prime}$ gon (Greek, inactive), an element contained in the atmosphere and remarkable for its chemical inertness.

Ar'ter-y (Latin arteria, windpipe), a vessel which carries blood away from the heart. The ancient anatomists supposed the arteries to contain air, hence the name.

Au'ri-cle (Latin auricula, diminutive of auris, ear), the upper one of the two chambers of the heart, so called from its resemblance to the ear.

Ba-cil'lus, pl. bacilli (Latin bacillum, diminutive of baculum, stick), a microscopic rod-shaped bacterium.

Bac-te'ri-um, pl. bacteria (Greek bakterion, staff or rod), a microscopic vegetable organism found in decaying organic matter.

Bi'ceps (Latin bis, two, and caput, head), a muscle of the upper arm which serves to bend the arm at the elbow.

Bi-cus'pids (Latin bis, two, and cuspis, point), the double pointed teeth between the canines and the molars.

Bile (Latin bilis), a fluid secreted by the liver and poured into the intestines.

Bron'chi (Greek bronchos, windpipe), the two large branches of the trachea.

Bron-chi'tis (Greek bronchos, windpipe), an inflammation of the mucous lining of the bronchial tubes.

Ca-nine' (Latin canis, dog), the sharp, pointed teeth between the incisors and the bicuspids; so named because they are prominent in the dog.

Cap'il-la-ry (Latin capillus, hair), the small, hairlike blood vessels that connect the arteries and veins.

Car'di-ac (Greek kardia, heart), pertaining to the heart.

Car'pal (Latin carpus, wrist), pertaining to the wrist.

Car'ti-lage (Latin cartilago, bristle), a smooth, solid, elastic connective tissue found between bones, and forming certain organs, as the trachea, larynx, etc.

Ca-tarrh', an inflammation of the mucous membrane of the nose. 
Cell (Latin cella, hiding place), a tiny bit of protoplasm containing a nucleus. The cell is the unit of structure.

Cer'e-bel'lum (Latin, little brain), the little brain situated at the back of and below the cerebrum.

Cer'e-brum (Latin, brain), the front brain, occupying most of the skull.

Ce-ru'men (Latin cera, wax), the wax secreted by the ear.

Chlo'ral, a powerful drug used to produce sleep.

Cho'roid (Greek chorion, skin, and -oid, like), the second or middle coat of the eyeball.

Chyle (Greek chylos, juice), the nutritious portion of the food that has been digested and is ready to be absorbed.

Cil'i-a (pl. of Latin cilium), little, hairlike projections found on the cells of the mucous membrane in some of the organs, as the nose and trachea.

Clav'i-cle (Latin clavicula, a little key or lock), the collar bone.

Coc'cus (Greek kokkos, grain, seed), a form of bacteria, spherelike in shape.

Coc'cyx (Greek, cuckoo), the last four vertebræ of the spinal column, consolidated into a single bone; so named from its fancied resemblance to the bill of the cuckoo.

Coch'le-a (Latin, snail shell), the coiled portion of the inner ear.

Con-ges'tion (Latin con-, together, and gerere, gestus, to bring), an unhealthy accumulation of blood in any part of the body.

Con-sump'tion (Latin con-, with, and sumere, sumptus, to consume), a disease of the lungs.

Con-va-les'cence (Latin con-, with, and valescere, to get strength), the renewal of health and strength after a disease.

Cor'pus-cle (Latin corpusculum, a small body), a small particle, as a blood disk.

Cra'ni-al (Latin cranium, skull), pertaining to the skull.

Cra'ni-um, skull.

Deg-lu-ti'tion (Latin de, down, and glutire, glutitus, to swallow), the act of swallowing.

Den'drites (Greek dendron, tree), the branches of a nerve cell that carry impressions to the cell body of which they are a part. Den'tine (Latin dens, dentis, tooth), the substance composing the greater part of teeth.

Der'mis (Greek derma, skin), the under layer of the skin. 
Di'a-phragm (Greek diaphragma, partition), a large, circular muscle separating the chest from the abdomen.

Dif-fu'sion (Latin dis, in different directions, and fundere, to spread), a spreading or flowing of a liquid or gas in all directions.

Di-ges'tion (Latin di-, in all directions, and gero, gestus, I bear), the conversion of food into a state suitable for absorption into the blood.

Diph-the'ri-a (Greek diphthera, membrane), a dangerous disease of the throat, and sometimes extending into the œsophagus, the larynx, and trachea.

Dis-in-fect'ants, agencies used to destroy germs of diseases.

Dor'sal (Latin dorsum, back), pertaining to the back.

Ef'fer-ent (Latin $e$, out, and ferens, bringing), conveying outward or away from an organ.

Ef-flu'vi-a (Latin $e$, out, and fluere, to flow), subtile or invisible particles given off by all substances that have an odor.

E-lim'i-na'tion (Latin eliminare, eliminatus, to put forth from the threshold), the process of discharging waste products or foreign substances through the various organs of excretion.

E-mul'si-fy (Latin $e$, out, and mulgere, mulsus, to milk), to reduce from an oily to a milky substance in which the fat particles are in a very finely divided state, giving it the appearance of solution.

En-am'el, the very hard tissue covering the crown of the teeth.

En'do-lymph (Greek endo, within, and lympha, water), the watery fluid contained in the membranous labyrinth of the internal ear.

En-dos'te-um (Greek endo, within, and osteon, bone), the membrane lining the hollow cavity of a bone.

Ep'i-der'mis (Greek epi, upon, and derma, skin), the outer layer of the skin, commonly called the scarf-skin.

Ep'i-glot'tis (Greek epi, upon, and glotta, tongue), the cartilage covering the opening into the larynx during the act of swallowing. Ep'i-the'li-al (Greek epi, upon, and thele, wart or nipple), the outer layer of cells in the skin and mucous membranes.

Eth'moid (Greek ethmos, sieve, and -oid, like), a sievelike bone forming the roof of the nose.

Eu-sta'chi-an tube (named from Eustachio, a noted Italian physician), a small tube leading from the pharynx to the middle ear. 
Fer'ment (Latin fermentum, yeast), a substance causing fermentation, as yeast.

Fi'ber (Latin fibra, a fiber), a fine, slender, threadlike substance in the tissues of the body.

Flex' or (Latin flectere, flexus, to bend), a muscle that bends the part of the body to which it belongs.

Fol'li-cle (Latin follis, a bag), a glandlike tube or a little cavity, as a hair follicle.

Fu-mi-ga'tion (Latin fumigare, fumigatus, to smoke), the cleansing of infected rooms or clothing by burning certain substances, as formaldehyde.

Fun'dus (Latin, bottom), the bottom of a hollow organ, as the fundus of the stomach.

Gan'gli-on, pl. ganglia (Greek, tumor or knot), a collection or knot of nerve cell bodies.

Gas'tric (Greek gaster, stomach), belonging to the stomach.

Germ (Latin germen, sprout, bud), a name applied to organisms which give rise to certain diseases.

Germ'i-cide (Latin germen, germ, and cadere, to slay), a substance

- that has power to destroy disease germs.

Gland (Latin glans, acorn), an organ that manufactures a fluid that may be used in the body or that may be eliminated from it.

Glot'tis (Greek, windpipe), the opening at the top of the windpipe.

Goi'tre (Latin guttur, the throat), a swelling of the glands of the neck. It is most common in mountainous regions, especially in Switzerland.

Gul'let (Latin gula, throat), the throat or œsophagus.

$\mathrm{Hab}^{\prime}$ it (Latin haberre, habitus, to keep), a fixed mode of action.

He-pat'ic (Greek hepar, liver), pertaining to the liver.

Hu'me-rus (Latin), the large bone between the shoulder and elbow.

Hy'gi-ene (Greek Hygeia, the goddess of health), that branch of

physiology which treats of the laws of health.

In-ci'sor (Latin incidere, incisus, to cut into), a fore tooth which is used in cutting or biting food.

In-oc-u-la'tion (Latin inoculare, inoculatus, to bud), the practice of communicating a disease to a person by putting contagious matter into his blood.

In-som'ni-a (Latin in-, not, and somnus, sleep), sleeplessness. 
In'ter-cost'al (Latin inter, between, and costa, rib), between the ribs. In-tes'tine (Latin intus, within), the lower portion of the alimentary canal; the bowels.

I'ris (Latin, the goddess of the rainbow), the colored curtain of the eye with the pupil at its center.

Jaun'dice (Old French jaunisse, yellow), a disease in which the skin, eyes, and the secretions have a yellowish color due to an excess of bile pigments in the blood.

Kre'a-tin (Greek kreas, flesh), a product derived from the oxidation - of proteids.

Lach'ry-mal glands (Latin lacrima, tear), the small organs that produce the tears.

Lac'te-als (Latin lac, lactis, milk), vessels of the small intestine that absorb chyle and carry it to the thoracic duct; so named from their milklike color.

Lar'ynx, the voice box, at the upper end of the windpipe.

Le-gu'mi-nous (Latin legumen, pulse), a large family of plants, including the pea, bean, clover, lupine, lentil, etc.

Lens (Latin, lentil), so named from the resemblance of a double convex lens to the seed of a lentil), the important refracting medium of the eye.

Lig'a-ment (Latin ligare, to bind), a band of connective tissue that holds bones in place, as at a joint.

Lum'bar (Latin lumbus, loin), pertaining to that part of the body between the hips and the floating ribs; the loins.

Lymph (Latin lympha, water), a fluid derived from the blood; it surrounds all living cells of the body.

Lym-phat'ics, the small vessels that carry lymph from the tissues to the blood vessels.

Ma'lar (Latin mala, cheek), the cheek bone'.

Mal'le-us (Latin, hammer), a small bone of the middle ear, resenbling a hammer in shape.

Mas'ti-ca'tion (Latin masticare, masticatus, to chew), chewing.

Me-dul'la (Latin medius, middle), the enlargement at the upper end of the spinal cord.

Mem'brane (Latin membrana, skin, covering), a thin tissue used to protect organs, either by lining or by covering the'n.

Met'a-car'pal (Greek meta, between, and karpos, wrist), the five bones in the palm of the hand. 
Me''a-tar'sal (Greek, meta, between, and tarsos, the flat of the foot). the five bones of the instep.

Mi'cro-scope (Greek mikros, small, and skopeo, I look at), an instrument for looking at very small objects.

Mi'tral valves (Latin mitra, head dress, especially for a bishop), the valves between the left auricle and ventricle; the bicuspid valves.

Mo'lar (Latin mola, mill, from molere, to grind in a mill), the last teeth on each side of the jaw; the grinding teeth.

Mo'tor areas (Latin movere, motus, to move), those areas of the brain that control the movements of the muscles.

My'o-sin (Greek mys, myos, muscle), a proteid substance found in muscle cells; one of the proteid foods obtained from lean meats.

Nar-cot'ic (Greek narkotikos, from narke, torpor, numbness), a drug that produces sleep, as opium.

Nic'o-tine (from Nicot, a Frenchman, who first introduced tobacco in France), the poisonous element in tobacco.

$\mathrm{Ni}^{\prime}$ tro-gen (Latin nitrum, niter, and -gen, producing), an element forming about four fifths of the air we breathe.

$\mathrm{Nu}^{\prime}$ cle-us (Latin, small nut, kernel), the central mass seen in nearly all cells.

Nu-tri'tious (Latin nutrire, nutritus, to feed, nourish), full of nourishment.

Oc-cip'i-tal (Latin occiput, back of the head), relating to the back of the head, as the occipital bone, the occipital lobe of the brain.

E-soph'a-gus (Greek oisophagos, from oiso, I shall bear, and phagein, to eat), the tube that carries food from the pharynx to the stomach; the gullet.

01-fac'to-ry (Latin olere, to smell, and facere, factus, to make), pertaining to the sense of smell.

O'pi-um (Greek opion, poppy juice), a drug made from the juice of the poppy.

Op'tic (Greek optikos), pertaining to the sense of sight.

Or'bit (Latin orbis, a circle), the eye socket.

Or'gan (Latin organum, implement), a collection of tissues arranged in some definite and compact way to perform some speciai function. 
Os-mo'sis (Greek osmos, a pushing), the diffusion of fluids through membranes.

0x'y-gen (Greek oxys, sharp, acid, and -gen, producing, as it was supposed to be present in all acids), an element forming about one fifth of the air we breathe.

Pal'ate (Latin palatum, roof of mouth), a bone forming part of the roof of the mouth and floor of the nose.

Pan'cre-as (Greek, pan, all, and kreas, flesh), an important digestive gland located just back of and below the stomach; the sweetbread.

Par'a-site (Greek para, beside, and sitos, food; parasitos, eating beside another at his table), an organism that lives on or within the body of another.

Pa-ri'e-tal bones (Latin paries, a wall), the large bones at the top and sides of the skull.

Pa-rot'id (Greek para, near, beside, and ous, otos, ear), the salivary gland just below and in front of the ear.

Pa-tel'la (Latin, small pan), the kneepan.

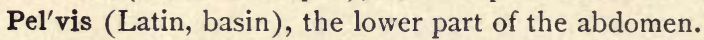

Pen'ni-form (Latin penna, feather, and -form), shaped like a feather.

Per'i-car'di-um (Greek peri, about, and kardia, heart), a saclike membrane covering the heart.

Per'i-lymph (Greek peri, around, and Latin lympha, water), the liquid found in the bony labyrinth of the inner ear.

Per'i-os'te-um (Greek peri, around, and osteon, bone), the thin membrane covering a bone.

Per'i-stal'sis (Greek peri, around, and stellein, to place, arrange), the wavelike contractions running along the alimentary canal, which push the contents onward.

Phar'ynx (Greek, throat), a funnel-shaped organ back of the nose and mouth. It serves as a food passage, as an air passage, and as an organ of voice.

Plas'ma (Greek plassein, to form), the liquid portion of the blood. It carries the corpuscles and the solid foods.

Pleu'ra (Greek, ribs), a saclike membrane covering the lungs and lining the thorax.

Pneu-mo'ni-a (Greek pneumon, lung), a disease of the lungs.

Pons (Latin, bridge), a band of nerve tissue connecting the bulb with the cerebrum and with the cerebellum. 
Pro'te-ids (Greek protos, first), the food stuffs that build tissues.

Pro'to-plasm (Greek protos, first, and plasma, form), the original cell substance, "the physical basis of life."

Py-lor'us (Greek pyloros, gate keeper), the opening between the stomach and the small intestine; also the muscle that closes the opening.

$\mathrm{Ra}^{\prime}$ di-us (Latin, staff, rod, spoke of a wheel), the bone of the forearm on the thumb side.

Res'pi-ra'tion (Latin re-, again, back, and spirare, spiratus, to blow), the process of taking oxygen into the blood and getting carbon dioxid out.

Ret'i-na (Latin rete, net), the innermost coat of the eyeball, in which the fibers of the optic nerve end.

$\mathrm{Sa}$ 'crum (Latin sacrum, sacred; os sacrum, the sacred bone, so called from its having been offered formerly in sacrifices), the bone at the lower end of the spine just above the coccyx.

Sa-li'va (Latin, spittle), the secretion of the salivary gland; it serves to moisten the mouth, to aid in swallowing, and to aid in digestion.

Sca-lene' (Greek skalenos, uneven), muscles of the neck that aid in breathing.

Scap'u-la (Latin), the shoulder blade.

Scle-rot'ic (Greek skleros, hard), the hard, tough, outer coat of the eyeball.

Se-ba'ceous glands (Latin sebum, grease), the oil glands of the skin.

Se-cre'tion (Latin se-, apart, and cernere, cretum, to sift), the process of forming certain liquids by the glands of the body, as bile, saliva, gastric juice.

Sem'i-lu'nar (Latin semi-, half, and luna, moon), shaped like a halfmoon.

Sen'so-ry areas (Latin sensus, feeling), the portions of the brain to which the incoming stimuli are carried.

Se'rum (Latin, whey), the yellowish, watery fluid that is squeezed out when blood clots. .

Sphe'noid (Greek sphen, wedge, and -oid, like), a large bone on the under surface of the skull.

Sphinc'ter (Greek sphinkter, anything that binds tight), a muscle that surrounds an opening or tube, as the pyloriç muscle. 
Spi-ril'lum (Latin spira, coil), a spiral or corkscrew-shaped bacterium.

Spi-rom'e-ter (Latin spirare, to breathe, and -meter), an instrument used to measure the capacity of the lungs.

Sta'pes (Latin, stirrup), the third bone of the ear, shaped like a stirrup.

Ster'num (Greek sternon, breast), the breast bone. The ribs are attached to it in front.

Stim'u-lus (Latin, a goad), any substance that can excite a nerve or a muscle to greater action.

Sub-lin'gual glands (Latin sub, under, and lingua, tongue), the salivary glands under the tongue.

Sub-max'il-la-ry glands (Latin sub, under, and maxilla, jawbone), the salivary glands under the lower jaw.

Su'ture (Latin suere, sutus, to sew), the way the bones of the skull are joined together; a kind of joint.

Syn-o'vi-al (Greek syn, with, and Latin ornm, egg), a fluid resembling the white of egg, secreted by the membrane in movable joints.

Ten'don (Latin tendere, to stretch), the fibrous tissue at the ends of muscles; a sinew.

Tho-rac'ic duct (Latin thorax, thoracis, breast), the large lymphatic trunk that passes through the thorax and empties into the left subclavian vein.

Tib'i-a (Latin), the shin bone.

Tis'sue (French tissu, from Latin texere, to weave), a collection of like cells for a common purpose.

Tra'che-a (Greek trachys, rough), the windpipe.

Tri'ceps (Latin tres, tria, three, and caput, head), one of the muscles of the upper arm. It straightens the arm at the elbow.

Tri-chi'na, pl. trichinæ (Greek trichinos, hairy), a parasite sometimes found in pork. It is the cause of the disease called trichinosis. Tri-cus'pid (Latin tres, tria, three, and cuspis, point), the valve between the right auricle and ventricle of the heart.

Tur'bi-nate bones (Latin turbinatus, from turbo, a whirl), two small bones in the nasal cavities.

Ty'phoid (Greek typhos, stupor arising from fever), a disease of the small intestine.

Ul'na (Latin, elbow), one of the bones of the forearm. 
Vac'ci-na'tion (Latin vaccinus, from vacca, cow), the process of introducing vaccine (cow-pox) through the skin.

Ven'ti-la'tion (Latin ventilare, ventilatus, to fan, from ventus, venti, wind), the process of exchanging foul air in a room for pure, wholesome air.

Ven'tri-cles (Latin ventriculus, diminutive of venter, stomach), the thick-walled chambers of the heart.

Ver'te-bra (Latin, from vertere, to turn), the name of each of the twenty-four bones of the spinal column.

Vil'lus, pl. villi (Latin, shaggy hair), the name of the tiny projections of the mucous membrane in the small intestine.

Vis'ce-ra (Latin), the organs of the abdomen.

Vit're-ous humor (Latin vitrens, glassy), the liquid filling the eyeball back of the lens.

$\mathrm{Vo}^{\prime}$ cal cords (Latin vox, vocis, voice), the bands of tissue in the larynx that produce sounds as the air is expelled from the lungs.

Vo'mer (Latin, plowshare), a small bone forming the lower part of the partition between the nostrils. 



\section{INDEX}

\section{AlL References are to PAGes.}

Abdomen, 45.

Absorption, 97.

from intestines, 97 .

from stomach, 97 .

of fats, 98 .

Accidents, First aid in, $315-324$.

Accommodation, 270-27I.

Adam's apple, 213.

Adenoid growths, 6I-62, 216.

Adjustable desk, I86.

Adrenals, I44.

Adulterated foods, 106, 302.

Air, 304-305.

Impure, Sources of, 62-63.

passages, 40-46.

Diseases of, 59 .

Purified, 63.

Alcohol, 34-37.

and digestion, II6-II7.

Appetite for, 37 .

as a food, 36 .

Effects of, on the blood, 137.

on the brain, 249-250.

on the kidneys, I64.

on the liver, II6, 249.

on the mind, 250.

on the morals, 249.

on the muscles, 204.

on the nerves of chest, 69.

on the skin, I64.

on the stomach, II6, 248.

alcoholic drinks, $35^{-36}$.

Alcoholic spirits, 36 .

Alimentary canal, 73-74, I16.

Amœeba, 4.

Anæmia, 15.

Anatomy, 2-3.
Antitoxin, 292.

Anvil, 260.

Aorta, I24, I32.

Appendicitis, II5-II6.

Appetite, I Io-III.

for alcohol, 37 .

Aqueous humor, 270.

Arm bone, 170.

Arteries, 123, 124, I32.

Ascending vena cava, IO2, I27, I3I

Aspirates, 215.

Association areas, 232, 233.

fibers, 234.

Asthma, 60 .

Astigmatism, 273.

Auditory canal, 259.

nerve, 262.

Axone, 222, 224.

Bacillus, 279.

Backbone, see Vertebræ.

Bacteria, 60-6I, 108-I I0, II4, 279.

Diseases due to, 279-297.

of cholera, 283, 289 .

of consumption, $6 \mathrm{I}, 283,287$.

of diphtheria, 283,291 .

of grippe, 283,296 .

of lockjaw, 283 .

of pneumonia, $60,283,288$.

of typhoid, II4, 283, 290.

Bathing, I56-I59.

Time of, 158 .

Value of, 156 .

Baths, Kinds of, $\mathrm{I}_{57}-\mathrm{I} 5^{8}$.

Bile, 90-9I.

Bile-duct, 90 .

Bleeding, 322-324. . . 


\section{INDEX}

Blind spot, 272.

Blood, 12-14, 21.

Changes in, $\mathrm{r}_{43^{-}} \mathrm{r} 45$.

Circulation of, I3I.

clotting, I4.

corpuscles, 12-I4.

Distribution of, I4.

How air gets in, 52 .

How to keep, pure, $\mathrm{r}_{5}$.

Quantity of, 14 .

Rate of, flow, I33-134.

Uses of, 12.

Bones, 167-177.

as levers, 207-2Io.

Broken, 32I-322.

Composition of, I74-175.

Structure of, I75-I77.

Table of, 172-I74.

Uses of, 167.

Brain, 219, 227-230, 239.

and education, $24 \mathrm{I}-242$.

compared to central railroad station, 219, 221 .

Exercise of, 240.

of ape, 229.

of bird, 229.

of dog, 229.

of fish, 229.

of man, 229.

of marsupial, 229.

of pigeon, 229.

of reptile, 229.

Breast bone, see Sternum.

Breathing and chest freedom, 67-69.

Proper, 69.

Rate of, 55-56.

Bright's disease, I64.

Bronchi, 43, 44.

Bronchial tubes, 43-44.

Bronchitis, 60.

Bruises, 320.

Bulb, see Medulla.

Burns and scalds, 315-316.

Callus, 150.

Capillaries, 126-127, 131-132.

Carbohydrates, see Foods.

Carbon dioxid, 34, 54, 142 .

Cardiac orifice of stomach, 84 .
Carpal bones, I7 1 .

Cartilage, I77-178. $^{-1}$

Catarrh, 60.

Cell, 4-6, I4I-I42, 221.

axone, 222.

body, 222.

Definition of, 6 .

dendrites, 222.

Figure of, 5 .

medium, II.

nucleus, 22I.

Per cent of water in, $2 \mathbf{r}$.

Cerebellum, 228, 23 I.

Cerebrum, 228, 23I-234.

Cerumen, 259.

Chest, 45 .

Deformed, 67.

Freedom of, 67-69.

Natural, 67 .

Chicken pox, 294.

Choking, 318.

Cholera, 289-29o.

Choroid coat, 266.

Chyle, 91 .

Chyme, 85.

Cigarettes, $3^{8}$.

Ciliated cells, 42 .

Circulation, Plan of, 125 .

Clavicle, I7o.

Cleanliness, 307-308.

Clothing, 159-16r.

Coccus, 279.

Coccyx, I7o.

Cochlea, 26I.

Coffee, 32-33.

Colds, 60.

Collar bone, see Clavicle.

Colon, 89.

Commissural fibers, 234.

Complemental air, 5 I.

Concha, 259.

Consumption, 6I, 287.

Contagious diseases, 284.

Convulsions, 3 I9.

Cooking, 107-I08.

Cornea, 266.

Corpuscles of blood, see Blood corpuscles.

Correct position at desk, I8I. 
Coughing, 50.

Course of blood, I3I.

Crystalline lens, 270.

Curved spine, $184-187$.

Cuticle, see Epidermis.

Cutis, see Dermis.

Cuts in the skin, 322 .

Defective vision, 272-274.

Deglutition, see Swallowing.

Dendrites, 222, 224.

Dermis, I50-I5I.

Descending vena cava, I27, I3I.

Diabetes, 164 .

Diaphragm, 45, 49 .

Digestion, 72-95.

Intestinal, 88-89.

Mouth, 80.

of certain foods, 87 .

Stomach, 84 .

'Time required for, 87 .

Diphtheria, 29I-292.

Diseases, 59, 308-310.

and bacteria, 279-297.

Disinfection after, 3IO-3II.

Schools and, 309.

Disinfectants, 3 Io-3rr.

Dislocations, 321 .

Dress and digestion, II2-II3.

Dropsy, 129 .

Drowning, 319.

Drumhead, 260.

Duct, see names of ducts.

Dysentery, 290-29I.

Dyspepsia, II4.

Ear, 259-265.

Care of, 264 .

Eardrum, 259.

Eating, Hygiene of, II I-II2.

Effluvia, 257.

Emergencies, see Accidents.

Emulsification, 98.

Endolymph, 262.

Endosteum, I76-177.

Epidermis, I50-15I.

Epiglottis, 43, 213.

Eustachian tube, 260.
Exercise, Amount of, 200-20I.

Brain, 240.

Massage as, 203-204.

Time for, 202.

Value of, I99-200.

Exhale, 48.

Exhaled air, 54 .

Expiration, 49.

Eye, Care of, 274-276.

Muscles of, 267-268.

Eyeball, 265-267, 270.

Eyebrows, 269.

Eyelashes, 268.

Eyelids, 268.

Fainting, 316-3I7.

Farsightedness, 273.

Fatigue of muscles, 202-203. of brain, 244-246.

Fats, Absorption of, 98. see also under Foods.

Femur bone, I7I.

Fermentation, 35 .

Fibrinogen, I4.

Fibula, 172.

Fits, 319-320.

Food, amount of, 27-28.

Food and air, 239-240.

Food stuffs, I8.

Foods, 17, 102, 301-302.

Adulterated, 106, 302.

Animal, 23-24.

Carbohydrates, 18, 19-20.

Cereals, 24.

Definition of, 17 .

Fats, 18, 20.

Kinds of, 17 .

Oxygen, 18, 22.

Proteids, 5, 18-19.

Pure, 105.

Salt, I8, 2 I.

Substances taken with, 22-23.

Value of cooking, 26-27.

Vegetable, 24-26.

Water, 18, 20-21.

Foot, 172.

of a Chinese woman, 183.

Foreign body in eye, 275.

Formaldehyde, $3 \mathbf{I I}$. 


\section{INDEX}

Freckles, I5I.

Frog's brain, 229.

Frog's nerve, 224.

Gall-bladder, 9 I.

Ganglia, 235 .

Garbage, 305-307.

Gastric glands, see Glands, Gastric. juice, 85 .

General senses, 254.

"Gin-drinker's" liver, II7.

Glands, 74-75.

Gastric, 74-76, 86.

Intestinal, 74-76.

Parotid, 81.

Salivary, 74-76.

Sebaceous, I5I.

Structure of, 75 .

Sublingual, 8I.

Submaxillary, 8I.

Sweat, 15 I.

Glottis, 43 .

Goitre, I44.

Grippe, 296.

Habit, 242-244.

Hair, I54-I55.

follicle, 154 .

Hearing, Sense of, 258-259.

Heart, 45, I2I-I24.

beat, 135 .

Sounds of, 136 .

Heat, Animal, I45.

Loss of, 146-147.

Helix, 259.

Hipbones, I70.

"Hob-nailed" liver, II7.

Human body, I-2.

compared to city, 6-7.

compared to locomotive, 2 .

Plan of, 72.

Humerus bone, I7o.

Hygiene, Definition of, 3-4.

of absorption, 105-118.

of digestion, $105^{-1} 18$.

of ear, 264-265.

of eating, III-II2.

of eye, $274-276$.
Hygiene of food, 26.

of nervous system, 239-251.

of respiration, 59-7I.

Personal, 3II-3I2.

Public, 299-312.

Hyoid bone, 170 .

Immunity, 285 .

Incubation, 286.

Incus, r7o.

Indigestion, Intestinal, II4.

Infection, 286.

Influenza, 60, 296.

Inhale, 48.

Inhaled air, 54 .

Insane, 236.

Insomnia, 248.

Inspiration, 49.

Intestinal digestion, see Digestion, Intestinal.

Intestinal glands, see Glands, Intestinal.

juices, 89 .

Intestines, 88-90.

Large, I03, I I7.

Iris, 266.

Joints, $178-180$.

Classes of, $\mathbf{I} 79$.

Juice, Gastric, see Gastric juice.

Pancreatic, see Pancreatic juice.

Kidneys, I6I-I64. Effect of alcohol on, 164.

Kneepan, see Patella.

Kreatin, I43.

Labyrinth, Bony, 26r. Membranous, 26r.

Lachrymal bone, I70. glands, 269.

Lacteal, $\mathbf{1 0 0 .}$

Laryngitis, 60.

Larynx, 42-43, 2I3-2I4.

Leaping, 2 I 2.

Leg, Bones of, I7I-I72.

Ligaments, I79.

Light, Course of, 271. 
Liver, 74, 90, IOI, II6-II7. trouble, II5.

Lobes of the Brain, 231. Frontal, 23I.

Occipital, 231.

Parietal, 231.

Temporal, 23 I.

Loudness of tone, 214 .

Lungs, 44.

Air in, 47-50.

Bleeding of, 324 .

Capacity of, 50-53.

Changes in air in, 54-55.

Covering of, 46 .

Lobes of, 45-46.

Lymph, II, I4, I28, I40-I4I. nodes, Ioo.

Lymphatic duct, 128 ,

Lyınphatics, 128-129.

Lymphatic vessels, Ioo.

Mad, see Insane.

Malarial fever, 295.

Malleus, 170, 260.

Marrow, 175 .

Massage, 203-204.

Measles, 292-293.

Meat, 24.

Inspection of, 299, 302.

Medulla, 230-23I.

Metacarpals, I7 I.

Metatarsals, $\mathbf{1 7 2 .}$

Milk, 33-34.

Mind and brain, 235-237.

Mitral valve, I24, I3I.

Mixed nerves, 225.

Motor areas, 232, 233.

fibers, 225.

nerves, see Nerves.

Mouth, 75-76.

Mucous membrane, 75 .

Mumps, 294.

Muscles, 189-218.

Classes of, $\mathbf{1 8 9 .}$

Food of, 198.

Intercostal, 47.

Large, I95-I97.

of expression, 213-213.

Special uses of, 207.
Muscles, Structure of, I92-I93.

Myosin, I93.

Nails, I53.

Nasal cavities, 257.

Nearsightedness, 272.

Nerve, 224-225.

cell, changes due to fatigue, 244-245. of rat, 222.

center, 226.

fibers, 224-225.

tissue, 22I.

Nerves, 223.

Afferent, 223.

Efferent, 223.

Mixed, 225.

Motor, 223.

Sciatic, 223.

Sensory, 223.

Nervous system, 219-237.

Nervous system of pigeon, 230.

Sympathetic, 234.

Nicotine, 37 .

Nose, 4I-42.

bleeding, 323 .

Nostrils, I7o.

Esophagus, 83.

Oil glands, see Glands, Sebaceous.

Optic Nerve, 267.

Order of topics, 7-9.

Organ, Definition of, 6.

Organism, Definition of, 6 .

Organs of excretion, 149.

Osmosis, 53, 97.

Overwork, 244-246.

Oxygen, 18, 22, 54 .

Palate bones, I70.

Palm bones, see Metacarpals.

Pancreas, 89-9I, I44.

Section of, 89.

Pancreatic juice, 90.

Papillæ, 15I, 254, 256.

Patella, I72.

Pelvic girdle, I7o.

Pepsin, 85.

Pericardium, 48, 12r.

Perilymph, 26r.

Periosteum, I76-177. 
Peristalsis, 92-93.

Personal hygiene, see Hygiene, Personal.

Perspiration, Insensible, $\mathbf{I}_{52}$.

Sensible, I52.

Phalanges, I7I, 172 .

Pharynx, 42-43.

Physical training in our schools, 20I202.

Physiology, Definition of, 3 .

Pigment, I5I, I54.

Pink eye, 296-297.

Pitch of tones, 2 I4.

Plasma, Definition of, 13.

Pleura, 46.

Pneumonia, 60, 288-289.

Poisonous stings, 320 .

Poisons, 320-32I.

Polypi, 216.

Pons, 228, 231.

Portal vein, Ioo-Ior.

Posture, $180-187$.

Projection fibers, 233.

Proteids, see Foods.

Protoplasm, 4.

Public health and personal hygiene, 299-3I4.

Pulmonary arteries, 123.

Pulse, r36-r37.

Pupil, 266.

Pyloric orifice, 84 .

Pylorus, 84.

Radius, I70.

Reflex acts, 226.

Reserve air, 5 r.

Residual air, 52.

Respiration, $40-5^{8}$.

Artificial, 3 I7.

Hygiene of, $59-72$.

Rest, 202-203.

and sleep, 246-248.

Retina, 267.

Ribs, 48, 170.

Round shoulders, I84-I87.

Running, 2II-212.

Sacrum, I70.

Saliva, $8 \mathrm{r}$.
Salivary̆ glands, see Glands.

Salts, see Foods.

Scalene muscles, 47.

Scapula, $\mathbf{1 7 0 .}$

Scarfskin, see Epidermis.

Scarlet fever, 292.

Sclerotic coat, 266.

Sebaceous glands, see Glands, Sebaceous.

Semilunar valve, I24.

Sensations, 253-254.

Sensory areas, 232.

fibers, 225 .

Sensory nerves, see Nerves.

Serum, I4.

Shoes, 159-160.

Shoulder blade, see Scapula.

Sight, Sense of, 265.

Singing, 2I6.

Sitting, 2 I I.

Skeleton, 167.

Skin, I50-166.

Appendages of, ${ }_{5} 53$.

Care of, $155^{-1} 5^{6 .}$

Glands of, I5I-I 53 .

Skull, I68.

of Flathead Indian, 183.

Sleep, 246-248.

Smallpox, 293-294.

Smell, Sense of, $257^{-25^{8}}$.

Solar plexus, 235 .

Sore throat, 324 .

Sound, Definition of, $25^{8}$. wave, 263 .

Speech, 215.

Spinal cord, 225-227. ganglion, 226.

Spirillum, 279.

Spirometer, 50.

Spleen, I44-I45.

Sprains, 321 .

Standing, 2IO-2II.

Stapes, I70, 26o.

Starches and sugars, see under Foods.

Sternum, I70.

Stomach, 84-86.

bleeding, 324 .

Sublingual glands, see Glands, Sublingual. 
Submaxillary glands, see Glands, Submaxillary.

Subvocals, 215.

Suffocation, 317-318.

Sunstroke, 3 I6.

Supplemental air, 5 I.

Swallowing, 82-84.

Sweat glands, see Glands.

Swimming, 212.

Symmetrical posture, 182.

Synovial fluid, I79.

System, Definition of, 6.

Tarsal bones, I72.

Taste buds, 256.

Sense of, $256-257$.

Tea, 32-33.

Teeth, 76-8o.

Care of, ro8-1 ro.

Structure of, 78-80.

Temperature, Regulation of, I47.

Tendon of Achilles, I92.

Tendons, I92.

Thigh bone, see Femur.

Thoracic duct, IoO, 128.

Thouglit centers, 233 .

'Thyroid bodies, 144 . starvation, I44.

Tibia, $\mathbf{1 7 2 .}$

Tidal air, 5 I.

Tight clothing, 67, I 12-II3, 159 .

Tissue, Definition of, 6 .

Tobacco, 37-38.

Effects of, on the brain, 250-25I. on the heart, 137 .

on the muscles, 204.

on the nervous system, 250.

Tones, 214.

Tongue, 256-257.

Tonsils, 76.

Enlarged, 216.

Touch bodies, 255 .

Sense of, $254^{-255}$.

Trachea, 43-44.
Tree of life, 23 I.

Trichinæ, 26.

Tricuspid valve, 124, 131.

True skin, see Cutis.

Turbinated bone, 170.

Typhoid fever, 3I, II4, 290.

Ulna, I70.

Urea, 162.

Venæ cavæ, see Ascending vena cava and Descending vena cava.

Ventilation, 64-66.

Method of, 66-67.

Ventricles, 122.

Vermiform appendix, II5.

Vertebræ, I70.

Villi, 98-100.

Vitreous humor, 270.

Vocal cords, $2 I_{4}$.

Voice, Care of, 2I6-2I7.

sounds, 214-215.

Vomer, I70.

Vowel sounds, 215.

Walking, 2I I-2I2.

Wastes, 143 .

Water, 18, 20-21.

contaminated by surface drainage, $3 \mathbf{I}$.

Filtered, 32.

Ice, 32 .

Impure, 3I, 303.

Pure, 30.

supply, 302-304.

Whooping cough, 294.

Windpipe, see Trachea.

Wrist bones, see Carpal bones.

X-ray photograph of hand, Frontispiece.

Yeast plants, 34-35.

Yellow fever, 295-296.

Yellow spot, 272. 



\title{
Tarr and McMurry's Geographies
}

A NEW SERIES OF GEOGRAPHIES IN TWO, THREE, OR FIVE VOLUMES

\author{
By RALPH S. TARR, B.S., F.G.S.A. \\ Cornell University
}

AND

FRANK M. McMURRY, Ph.D.

Teachers College, Columbia Univerity

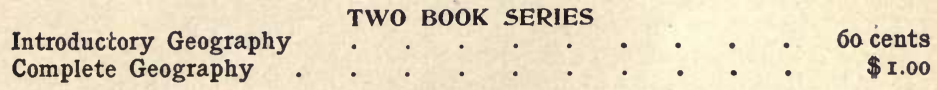

THE THREE BOOK SERIES

FIRST Book (4th and $5^{\text {th }}$ Years) Home Geography and the Earth

as a Whole

SECOND BOOK (6th Year) North America . . . . . 75 cents

THIRD BOOK (7th year) Europe and Other Continents . . . 75 cents

THE FIVE BOOK SERIES

FIRST PART (4th year) Home Geography . . . . . . 40 cents SECOND PART (5th year) The Earth as a Whole . . . . 40 cents THIRD PART (6th year) North America . . . . . 75 cents FOURTh PART (7th year) Europe, South America, Etc. . . . 50 cents FIFTH PART (8th year) Asia and Africa, with Review of North

America

To meet the requirements of some courses of study, the section from the Third Book, treating of South America, is bound up with the Second Book, thus bringing North America and South America together in one volume.

The following Supplementary Volumes have also been prepared, and may be had separately or bound together with the Third Book of the Three Book Series, or the Fifth Part of the Five Book Series:

\section{SUPPLEMENTARY VOLUMES}

New York State . . 30 cents

The New England States. 30 cents

Utah

California . . . 30 cents

Texas

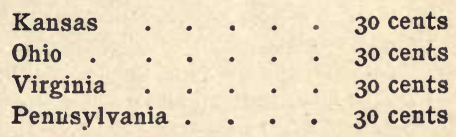

35 cents

When ordering, be careful to specify the Book or Part and the Series desired, and whether with or without the State Supplement.

PUBLISHED BY

\section{THE MACMILLAN COMPANY}

\section{FIFTH AVENUE, NEW YORK}

CHICAGO BOSTON SAN FRANCISCO ATLANTA




\title{
An Ancient History for Beginners
}

\author{
By GEORGE WILLIS BOTSFORD, Ph.D.
}

Lecturer in Ancient History, Columbia University

$12 \mathrm{mo}$

Half Leather

$\$ I .50$ net

"The decided merit of Professor Botsford's books seems to be vitality, thorough grasp of the subject, and charm of presentation." - A. F. BARNARD, Chicago Manual Training School, Chicago, Ill.

"My class have found it first of all interesting. Besides this, they have gained a real appreciation of the ancient civilization about which they have studied. The work is broad and scholarly in its treatment, but at the same time written in such a clear, simple manner that the pupils have studied it understandingly and with sympathy." - Miss MABEL CHESLEY, High School, Fulton, N.Y.

"In this book are preserved the excellent features which render the author's histories of Greece and Rome so superior to other school histories." - Miss M. EdNa WAKEFIELD, High School, Haverhill, Mass.

"Botsford's Ancient History for Beginners was put into our Normal School, Preparatory Course, as the basal text-book in ancient history just as soon as it was issued. We like the book." - MiSS BLANCHE E. HAZARD, Rhode Island Normal School, Providence, R.I.

"Botsford's Ancient History should have an extensive use. It is one of the few books not too difficult for secondary schools." - PROF. T. F. MORAN, Purdue University, Lafayette, Ind.

"A close acquaintance with Botsford's Ancient History confirms me in my first opinion of the book as the best elementary work on ancient history that has yet appeared. I have recommended it for use in all Missouri schools where free choice of text-books is allowed." - N. M. TRENHOLME, University of Missouri, Columbia, Mo.

"I have carefully examined your Botsford's Ancient History and have given it a thorough test in class work. It gives a clear, forcible, condensed narration of ancient history and includes accounts of many of the important discoveries of recent years which have a direct bearing on Roman and Grecian history. I heartily recommend it for use in any high school." - A. H. WINDER, Asst. Prin. of High School, Dayton, Ohio.

"After a careful examination of your Ancient History I pronounce-it one of the finest on the market. Botsford is certainly a historian in every sense. We shall put in the book as soon as opportunity offers. This is the best indorsement I can give it." - J. F. BERGEN, Superintendent of Schools, Mineral Point, Wis.

\section{THE MACMILLAN COMPANY}

\section{Fifth Avenue, New York}




\title{
A HISTORY OF GREECE
}

\section{For High Schools and Academies}

\author{
By GEORGE WILLIS BOTSFORD, Ph.D. \\ Instructor in the History of Greece and Rome in Harvard University
}

8vo. Half Leather. \$1.10 net

\begin{abstract}
"Dr. Botsford's 'History of Greece' has the conspicuous merits which only a text-book can possess which is written by a master of the original sources. Indeed, the use of the text of Homer, Herodotus, the dramatists, and the other contemporary writers is very effective, and very suggestive as to the right method of teaching and study. The style is delightful. For simple, unpretentious narrative and elegant English the book is a model. In my judgment, the work is far superior to any other text-book for high school or academic use which has yet appeared. Its value is enriched by the illustrations, as also by the reference lists and the suggestive studies. It will greatly aid in the new movement to encourage modern scientific method in the teaching of history in the secondary schools of the country. It will be adopted by Stanford as the basis of entrance requirements in Grecian history."

- Professor George Elliot Howard, Stanford University, Cal
\end{abstract}

\section{A HISTORY OF ROME}

\section{For High Schools and Academies}

\author{
By GEORGE WILLIS BOTSFORD, Ph.D. \\ Instructor in the History of Greece and Rome in Harvard University
}

8vo. Half Leather. \$1.10 net

\section{TEACHABLE QUALITIES}

x. Treatment of the external and internal history of the Republic in separate chapters; this conduces to simplicity, continuity of thought, and hence interest.

2. Each chapter corresponds with a period or epoch; this helps the pupil to gain a distinct conception of each period, and to a correct arrangement and subordination of events. In most books the chapters are arbitrary divisions.

3. Marginal headings - sufficiently bold to be used as topics, but they do not interrupt the thourght, or break the interest, as they would, were they extended across the page.

4. Frequent quotation of sources; makes the subject more vivid and real.

5. Concrete treatment of the constitution. This book represents the people, senators, and magistrates as living, thinking, acting, governing, etc. It does not treat Rome as an abstract legal or political system, but as a city made up of human beings.

6. Movement - in the entire book there is no isolated paragraph; the thought is continuous throughout and the verbs are in the active voice.

7. The outline of the Republican constitution, p. $353 \mathrm{ff}$, serves as an example of what should be done in the preparation of lessons, and at the same time is a complete, logical presentation of the only really difficult subject in Roman history.

8. The "Studies" require a thorongh digestion of the material, and one who works them out faithfully will be able to pass the examination for admission to any college.

\section{THE MACMILLAN COMPANY}

\section{FIFTH AVENUE, NEW YORK}

Boston Chicago Atlanta San Francisco




UNIVERSITY OF CALIFORNIA LIBRARY

$$
\text { mite - nor }
$$


.

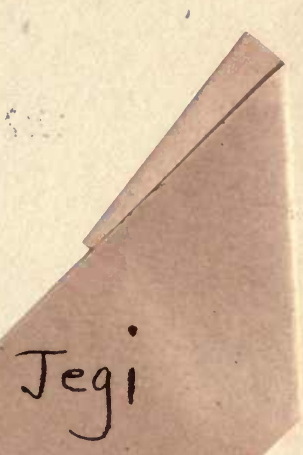

Riologi dú 
80080

8

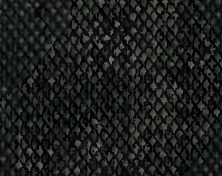

708:

28. $00 \%$ 